Final Technical Report

\title{
Modeling the Physical and Biochemical Influence of Ocean Thermal Energy Conversion Plant Discharges into their Adjacent Waters
}

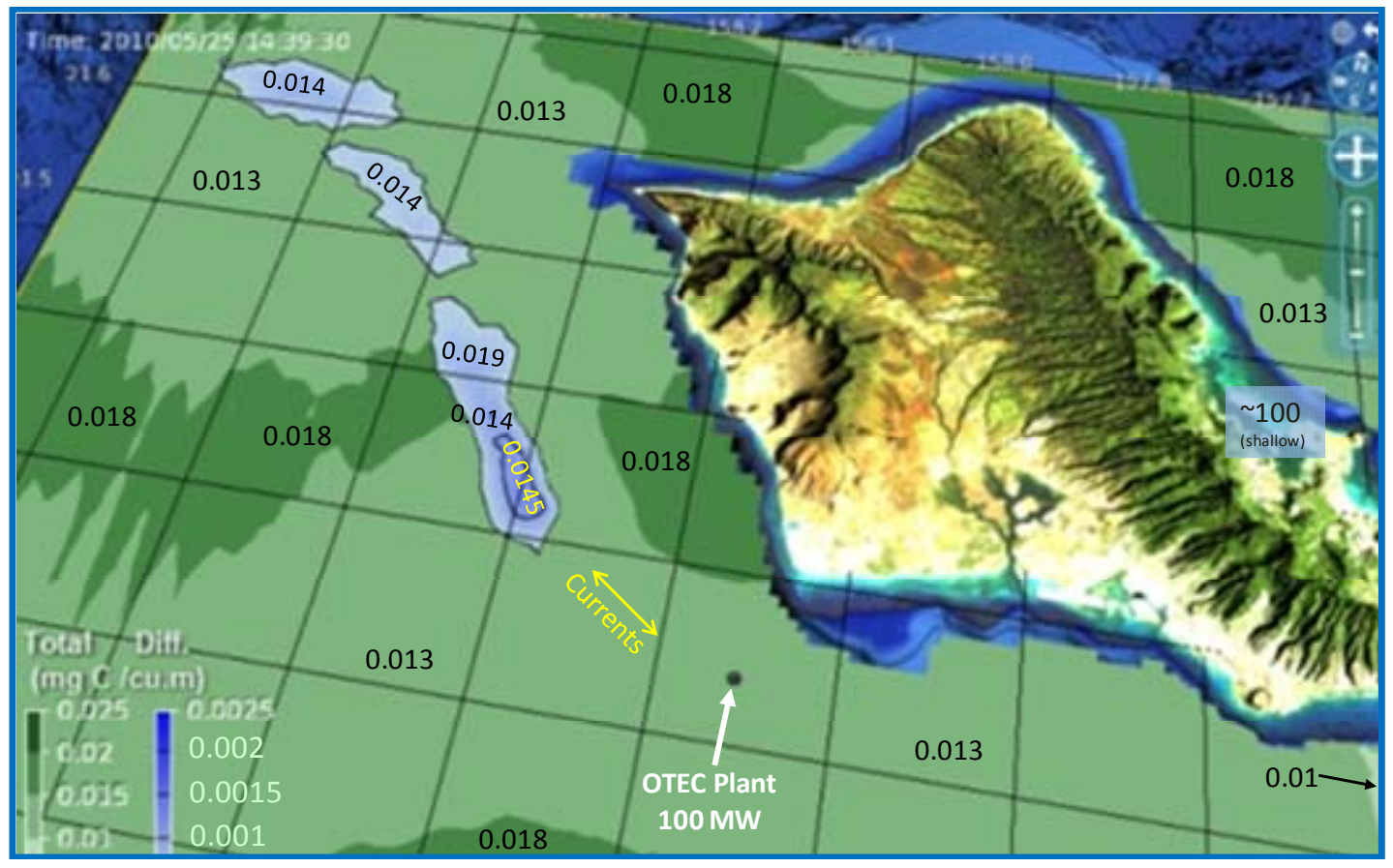

U.S. DEPARTMENT OF ENERGY AWARD No. DE-EE0003638

SEPTEMBER 2010 - AUguST 2012

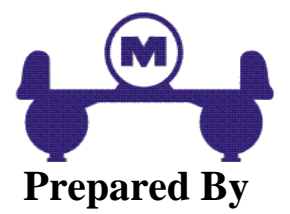

MaKai OCean Engineering, InC.， PO Box 1206 KAIlua, HaWAit 96734

Principal InVestigator: Pat Grandelli, P.E

Greg Rocheleau, John Hamrick, Ph.D, Matt Church, Ph.D, Brian PowellPh.D

29 September 2012 


\section{Final Technical Report}

\section{Modeling the Physical and Biochemical Influence of Ocean Thermal Energy Conversion Plant Discharges into their Adjacent Waters}

DoE AwARD No. DE-EE0003638

Prepared For

THE DEPARTMENT OF ENERGy (DoE):

MARINE AND HYDROKINETIC INITIATIVE

Prepared By

MAKAi OCEAN ENGINEERING, INC.

PO Box 1206

KAILUA, HAWAII 96734

Principal InVestigator: Pat Grandelli ${ }^{1} \quad$ Pat.Grandelli@Makai.com 808-259-8871

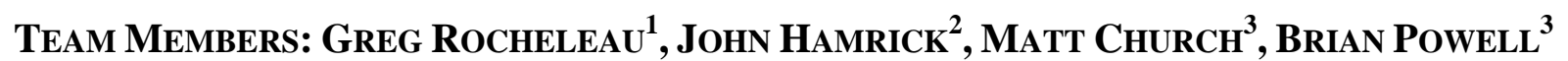

(1-MAKAi OCEAN ENGINEERING, INC., 2-TETRATECH, INC., 3-UNIVERSITY OF HAWAII, SOEST)

This report is based upon work supported by the U. S. Department of Energy under Award Number EE0003638. Any findings, opinions, and conclusions or recommendations are those of the author(s) and do not necessarily reflect the views of the Department of Energy or any other agency of the United States Government.

Neither the United States Government nor any agency thereof, nor any of their employees, makes any warranty, express or implied, or assumes any legal liability or responsibility for any information disclosed in this report.

Earlier work was performed under National Defense Center of Excellence for Research in the Ocean Sciences contract \# 58686.

29 September 2012 


\section{EXECUTIVE SUMMARY}

This paper describes the modeling work by Makai Ocean Engineering, Inc. to simulate the biochemical effects of of the nutrient-enhanced seawater plumes that are discharged by one or several 100 megawatt OTEC plants. The modeling is needed to properly design OTEC plants that can operate sustainably with acceptably low biological impact.

Ocean Thermal Energy Conversion (OTEC) uses large flows of warm tropical seawater and cold deep seawater to generate non-polluting electric power. The magnitude of the global OTEC resource dwarfs that of other other marine renewable energy technologies, and OTEC power is non-intermittent, making it suitable for utilities and manufacturing. Small demonstration OTEC plants using commercially-available equipment have generated 50 - 270 kilowatts of electricity. Recent advances in offshore design and cold water pipe technologies have renewed interest in developing large 100 megawatt plants that would be cost-competive with local island utilities. Such plants would have several seawater pumps, each equivalent to tugboat engines, that would guide 750 tonnes per second of seawater thorugh the OTEC system.

At most potential OTEC sites, the tropical ocean is thermally stratified into a well-mixed warm upper layer overlying cooler and denser seawater. This stratification hinders the supply of nutrients upwelled into the photic zone, which results in a nutrient-limited "oligotrophic" phytoplankton community having low biological productivity. Discharging deep seawater nutrients (primarily nitrates) into the upper waters from the OTEC plant could potentially enhance phytoplankton growth, shift community species composition, or cause algal blooms. It is desirable to discharge the seawater flows deep enough so that the discharged nutrients are diluted and remain below the photic zone. Thus, the size and depth of the large seawater ducts affect both the overall architecture of an OTEC plant as well as the extent of the perturbation to the ambient phytoplankton populations.

In order to quantify the effect of discharge configuration and phytoplankton response, Makai Ocean Engineering implemented a biological and physical model for the waters surrounding O`ahu, Hawai i, using the EPA-approved Environmental Fluid Dynamics Code (EFDC). Each EFDC grid cell was approximately 1 square kilometer by 20 meters deep, and used a time step of three hours. The biological model was set up to simulate the biochemical response for three classes of organisms: Picoplankton $(<2 u \mathrm{~m})$ such as prochlorococccus, nanoplankton $(2-20 u \mathrm{~m})$, and microplankton (> $20 \mathrm{um}$ ) e.g., diatoms. The dynamic biological phytoplankton model was calibrated using chemical and biological data collected for the Hawaii Ocean Time Series (HOTS) project. Peer review of the biological modeling was performed by Dr. John Hamrick, the author of EFDC, and by Dr. Matt Church of the University of Hawai'i, a leading marine microbiologist.

The physical oceanography model uses boundary conditions from a surrounding Hawai'i Regional Ocean Model, (ROM) operated by the University of Hawai'i and the National Atmospheric and Oceanic Administration. The ROM provided tides, basin scale circulation, mesoscale variability, and atmospheric forcing into the edges of the EFDC computational domain. This model is the most accurate and sophisticated Hawai'ian Regional Ocean Model presently available, assimilating realtime oceanographic observations, as well as model calibration based upon temperature, current and salinity data collected during 2010 near the simulated OTEC site. The ROM program manager, Dr. Brian Powell of the University of Hawai'i, peer-reviewed Makai's implementation of the ROM 
output into our EFDC model. The supporting oceanographic data was collected for a Naval Facilities Engineering Command / Makai project.

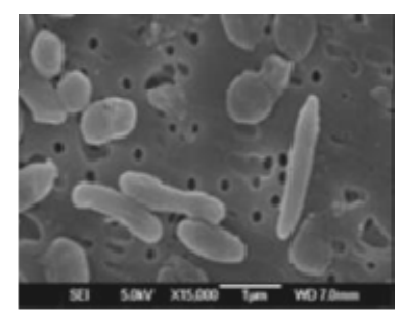

Prochlorococcus

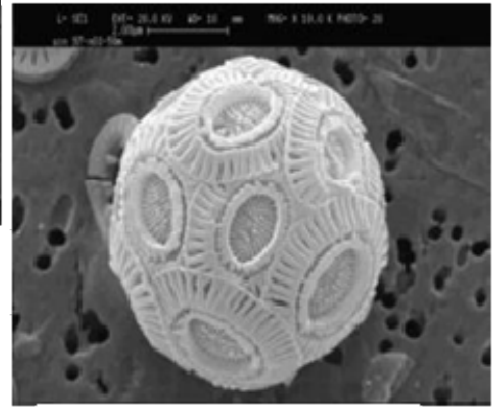

Emiliania

Images: http://cmore.soest.hawaii.edu/microscopy

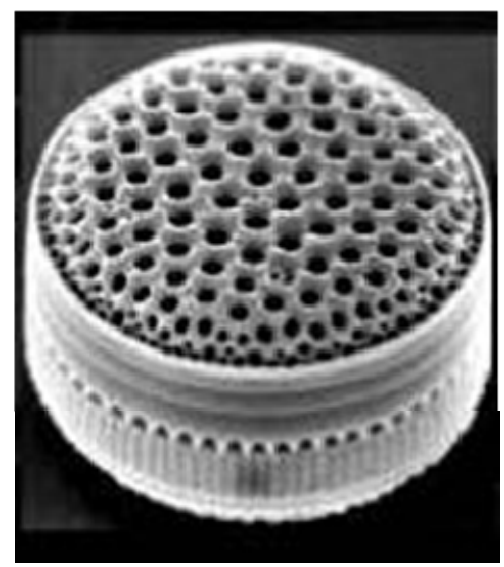

Diatoms

Figure 1. Phytoplankton examples modeled for each size class. ( $<2 \mathrm{um}, 2-20 u \mathrm{~m}$, and $>20 u \mathrm{~m})$

Using these models, the negatively-buoyant discharge flows were simulated by a dynamically coupled Lagrangian jet-plume entrainment model in the near-field, and by dynamic oceanic circulation and turbulence in the far-field. The result is a three-dimensional time-dependent model of the oceanic circulation, nutrient concentration due to natural variability and OTEC operation, with corresponding phytoplankton growth dynamics. This is the most sophisticated and realistic plume model yet developed for OTEC.

Results: The model was run for a 100 MW OTEC Plant consisting of four separate ducts, discharging a total combined flow rate of $420 \mathrm{~m}^{3} / \mathrm{s}$ of warm water and $320 \mathrm{~m}^{3} / \mathrm{s}$ of cold water in a mixed discharge at 70 meters deep. Each duct was assumed to have a discharge port diameter of $10.5 \mathrm{~m}$ producing a downward discharge velocity of about $2.18 \mathrm{~m} / \mathrm{s}$.

The natural system, as measured in the HOTS program, has an average concentration of 10-15 $\mathrm{mgC} / \mathrm{m}^{3}$. To calibrate the biological model, we first ran the model with no OTEC plant and varied biological parameters until the simulated data was a good match to the HOTS observations. This modeling showed that phytoplankton concentration were patchy and highly dynamic. The patchiness was a good match with the data variability observed within the HOTS data sets. We then ran the model with simulated OTEC intake and discharge flows and associated nutrients.

Directly under the OTEC plant, the near-field plume has an average terminal depth of 172 meters, with a volumetric dilution of $13: 1$. The average terminal plume temperature was $19.8^{\circ} \mathrm{C}$. Nitrate concentrations are 1 to $2 \mathrm{umol} / \mathrm{kg}$ above ambient. The advecting plume then further dilutes to less than $1 \mathrm{umol} / \mathrm{kg}$ above ambient within a few kilometers downstream, while remaining at depth. 
Because this terminal near-field plume is well below the $1 \%$ light limited depths $(\sim 120 \mathrm{~m})$, no immediate biological utilization of the nutrients occurs.

The figure below shows a typical model result at 1440 on May 25th, 2010. Phytoplankton concentration at 100 meters depth is shown by the green patches that denote natural variations of between 0.010 and 0.020 milligrams carbon per cubic meter. The light blue patches delineate the slightly elevated picoplankton levels caused by the 100 MW OTEC discharge plume, raising the concentration by 0.001 or 0.0015 milligrams carbon per cubic meter. Due to varying ocean circulation, this zone of perturbation at 100 meters depth will dynamically shift location, increase in concentration, or vanish. No perturbation occurs in the upper 40 meters of the ocean.

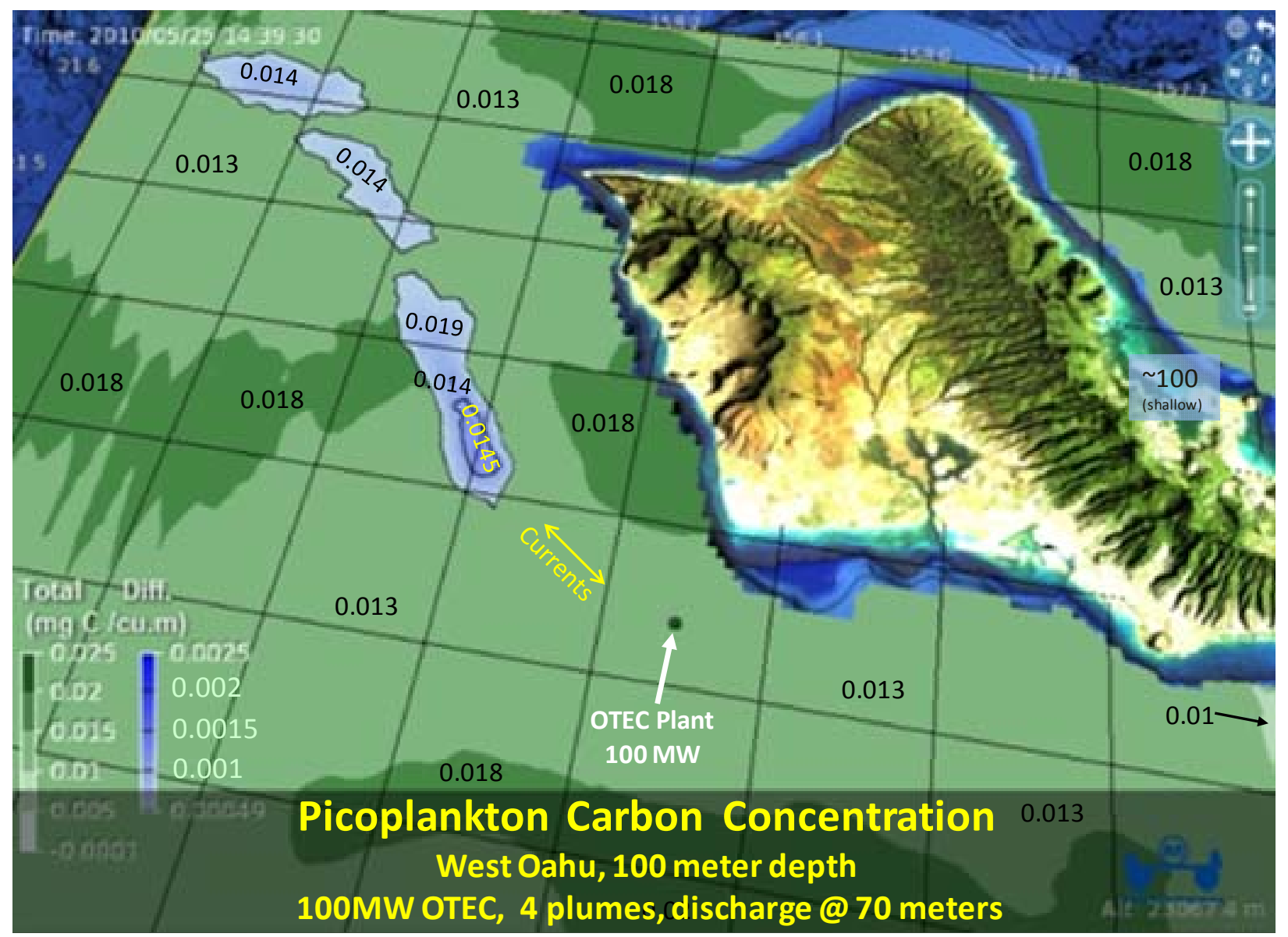

Figure 2. Post-processed OTEC Bioplume model output, for picoplankton carbon at $100 \mathrm{~m}$ depth.

As the nitrate is advected and dispersed downstream, a fraction of the deep ocean nutrients $(<0.5$ umol $/ \mathrm{kg}$ perturbation) mix upward where they are utilized by the ambient phytoplankton population. This occurs approximately twenty-five kilometers downstream from the plant at 110 70 meters depth. For pico-phytoplankton, modeling results indicate that this nutrient perturbation causes a phytoplankton perturbation of approximately $1 \mathrm{mgC} / \mathrm{m}^{3}(\sim 10 \%$ of average ambient concentrations) that covers an area $10 \times 5 \mathrm{~km}$ in size at the 70 to $90 \mathrm{~m}$ depth. Thus, the perturbations are well within the natural variability of the system, generally corresponding to a 10 to $15 \%$ 
increase above the average pico-phytoplankton biomass. This perturbation exhibits a meandering horizontal plume trajectory and spatial extent, but remains similar in magnitude (generally 1-2 $\left.\mathrm{mgC} / \mathrm{m}^{3}\right)$.

The diatom perturbations become more noticeable after three weeks of the simulation period, when the nearshore diatom population trends towards a greater concentration of 1 to $3 \mathrm{mgC} / \mathrm{m}^{3}$. Relative to the background concentrations, this increased response is a fraction of the ambient, with perturbations remaining within fluctuations of the existing system.

The perturbations were quantified by post-processing each time-step of model simulations without OTEC plants, with identical simulations that included OTEC plumes. Without this post processing, the $10-25 \%$ perturbations were obscured by the larger dynamic variations naturally caused by ocean circulation. Convenient summaries of the data can be viewed in Table 2 and Figure 100 of this report.

ACCOMPLISHMENTS COMPARED TO GOALS \& OBJECTIVES: This modeling effort has successfully attained its goals and objectives, as listed below.

1. Process data from an oceanographic array measuring continuous ocean current profiles, temperatures and conductivity at the Makai/Lockheed Martin initial OTEC site in West Oahu. Completed.

2. Use these data to improve the accuracy and calibrate the local output from a newly developed regional ocean model, HIROM, which is part of an integrated global program funded by NOAA and other government agencies. Completed.

3. Use the newly calibrated HIROM boundary conditions to force Makai's OTEC Hydrodynamic Model, developed with State of Hawaii funds (CEROS), under various OTEC design configurations and operating conditions. Completed.

4. Implement eutrophication modeling within the OHM to define the effect of the nutrient-rich and low oxygen deep seawater on increased productivity of phytoplankton. Completed. 
SUMMARY: This study has showed that the biochemical response of OTEC discharges can be modeled, quantified, and dynamically visualized for OTEC plants having different discharge configurations. We now have an extremely useful tool for use by OTEC regulators and designers. In all cases modeled (discharge at 70 meters depth or more), no perturbation occurs in the upper 40 meters of the ocean's surface. The picoplankton response in the $110-70$ meter depth layer is approximately a $10-25 \%$ increase, which is well within naturally occurring variability. The nanoplankton response is negligible. The enhanced productivity of diatoms (microplankton) is small, but this additional "standing stock" may potentially enhance growth if the plume water subsequently advects into nearshore water.

Another significant finding is that detecting the plume of an OTEC pilot plant, as envisioned for the "NAVFAC OTEC Pilot Plant", will require many more samples in time and space than was originally envisioned, because ocean variability is greater than anticipated.

Finally, the model does not attempt to calculate the higher order trophic levels where fauna consume the phytoplankton, but these results could be readily extended to this purpose. The subtle phytoplankton increase of our baseline design suggests that higher-order effects will be very small. 


\section{TABLE OF CONTENTS}

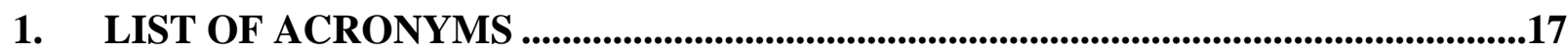

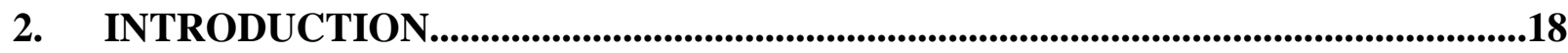

2.1 OTEC AND ENVIRONMENTAL PLUME MODELS ........................................

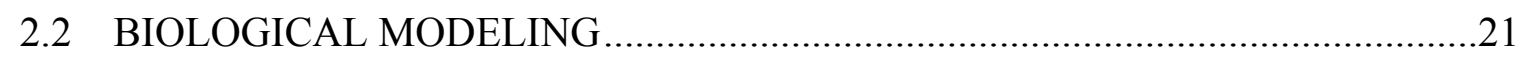

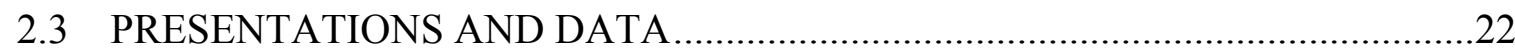

3. COMPUTER MODELING INFORMATION ...............................................................24

3.1 DESCRIPTION OF THE OCEAN CIRCULATION MODEL ................................24

3.2 HYDRODYNAMIC NEAR-FIELD PLUME MODEL ............................................27

3.3 DESCRIPTION OF THE BIOLOGICAL MODEL \& LOCAL

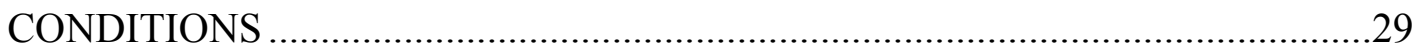

3.3.1. Overview of Assumptions and Modifications …………………...................30

3.3.2. Model Formulas and Parameters ……………….........................................31

3.4 BIOLOGICAL BOUNDARY CONDITIONS AND INITIALIZATION ……..........35

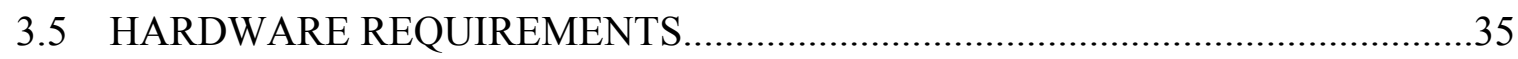

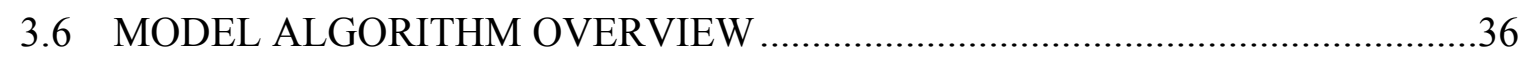

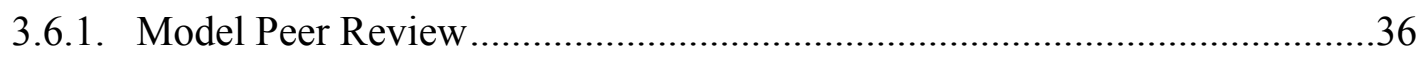

3.6.2. Model Strengths and Weaknesses.................................................................37

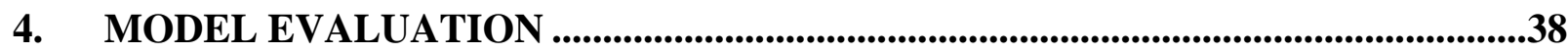

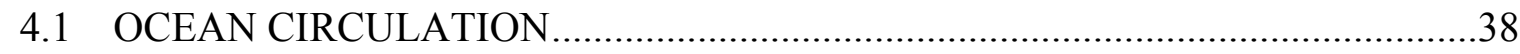

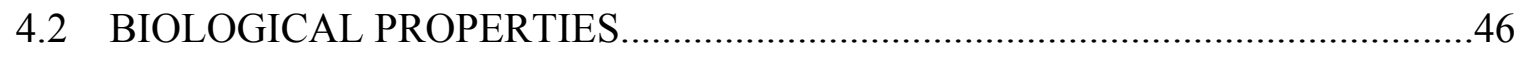

4.3 BIOLOGICAL SIMULATION WITH NO OTEC..................................................47

5. RESULTS: PHYTOPLANKTON RESPONSE TO OTEC

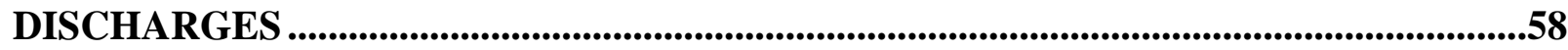

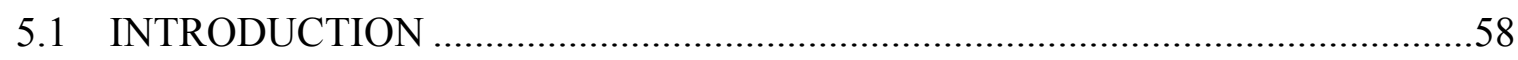

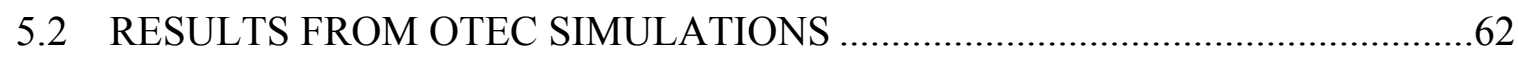

5.2.1. Single 100MW OTEC Plant: 70 meter discharge, 4 Discharge Ducts .........62

5.2.2. Three 100MW OTEC plants: 70 Meter Discharge, 4 Discharge plumes per

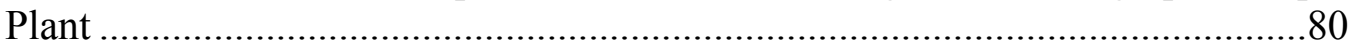

5.2.3. Three 100MW OTEC plants with 95 Meter Discharge, 4 Ducts each .........97

5.2.4. Single 100MW OTEC plant: 70 Meter Discharge, 8 Ducts ........................106

5.2.5. Single 100MW OTEC Plant: 95 Meter Discharge, 8 Ducts ........................115

5.2.6. Single 2.5MW OTEC Spar: 70m discharge, 1 Duct....................................124

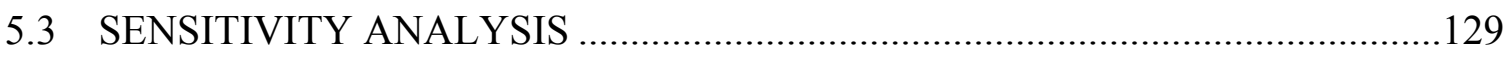

6. DISCUSSION \& COMPARISON .......................................................................131

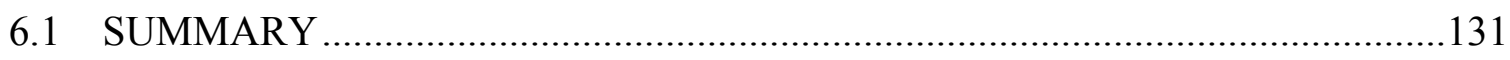




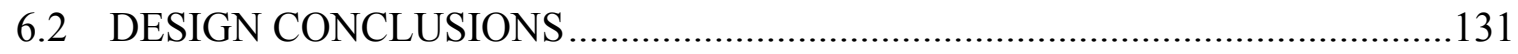

6.3 FUTURE WORK, IMPLICATIONS, MODEL LIMITATIONS..........................133

7. PRODUCTS DEVELOPED.....................................................................................134

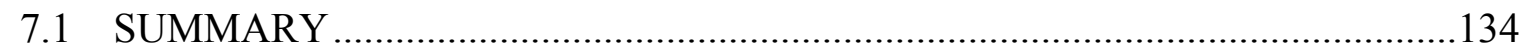

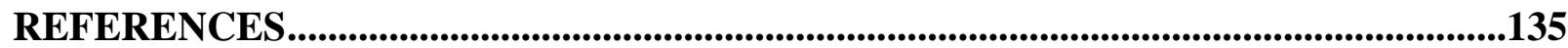




\section{LIST OF FIGURES}

Figure 1. Phytoplankton examples modeled for each size class ...................................................

Figure 2. Post-processed OTEC Bioplume model output..........................................................

Figure 3. Makai's first version of an OTEC plume model .......................................................19

Figure 4. (Left) Nitrate concentration and currents at $130 \mathrm{~m}$ depth, 1000, 19 Feb 2008 ..............20

Figure 5. The computational domain used by the EFDC-based OTEC Bioplume Model, ...........25

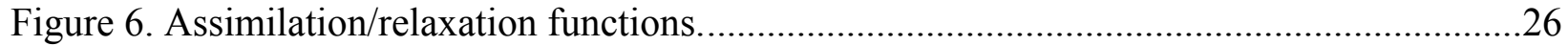

Figure 7. The bathymetry and grid extent of the Hawaii ROMS model......................................2

Figure 8. Image of $100 \mathrm{MW}$ OTEC plant with four $70 \mathrm{~m}, 1 \mathrm{~m} / \mathrm{s}$ mixed discharges, ....................28

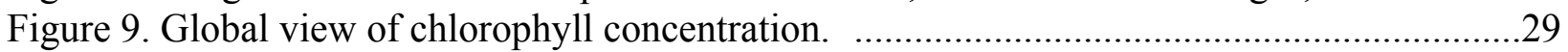

Figure 10. Comparison of chlorophyll A concentrations...........................................................

Figure 11. Logic flow diagram of the major biological components ............................................32

Figure 12. Comparison of light limitation formulae used by this model........................................34

Figure 13. Model domain of the Makai OTEC Biological Plume model. ....................................39

Figure 14. Northward (top row) and eastward currents............................................................

Figure 15. Standard deviation (in meters per second) of northward (top row) and eastward (bottom row) currents from the HIROM (left column) and plume model (right column) within the $\mathrm{O} 1$ and $\mathrm{K} 1$ diurnal tidal band ( $\sim 1$ cycle per day).

Figure 16. The standard deviation (in meters per second) of northward (top row) and eastward (bottom row) currents from the HIROM (left column) and plume model (right column $)$ within low frequency band $(\sim 0.7$ cycles per day).. .....................................42

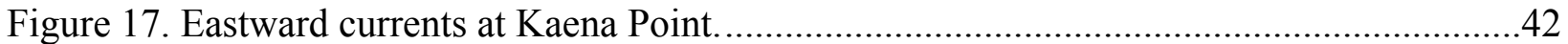

Figure 18. Northward currents at Kaena Point. ........................................................................4

Figure 19. Sea surface elevations at Kaena Point. Red is the EFDC nested solution, black is the HIROM parent grid.........................................................................................43

Figure 20. Eastward currents at Mokapu' 'u. Red is the EFDC nested solution, black is the HIROM parent grid.

Figure 21. Northward currents at Mokapu 'u. Red is the EFDC nested solution, black is the HIROM parent grid.

Figure 22. Sea surface elevations at Mokapu 'u. Red is the EFDC nested solution, black is the HIROM parent grid.

Figure 23. Eastward currents at NAVAFC mooring off Southwest O'ahu. Red is the EFDC nested solution, black is the HIROM parent grid.

Figure 24. Northward currents at NAVFAC mooring off southwest O'ahu. Red is the EFDC nested solution, black is the HIROM parent grid.

Figure 25. Sea surface elevations at NAVFAC mooring off Southwest O`ahu. Red is the EFDC nested solution, black is the HIROM parent grid. ....................................................45

Figure 26. Spectra ofcurrents from the ADCP and plume model..................................................45

Figure 27. Examples of phytoplankton modeled for each size class. ..........................................46

Figure 28. First simulation timestep of model, without an OTEC plant .....................................49

Figure 29. Model results after 8 simulation steps, (21 hours) starting to show variability due to ocean circulation and turbulence

Figure 30. Model results after one week, displaying significant local variations. This particular date exhibited the largest carbon variation observed at 70 meters depth. ...................51

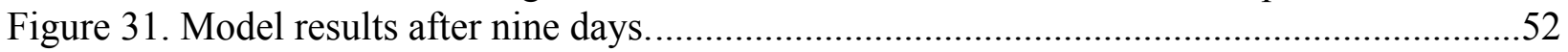


Figure 32. Model results for 10 June 2010 at 1639 . Carbon concentrations and variability on this date are generally representative of the forty day simulation ......................................53

Figure 33. Model results for 17 June 2010 at 2239, after 29 simulation days.............................54

Figure 34. Revision X: biological time series at NAVFAC mooring location...............................56

Figure 35. Revision ZA: biological time series at NAVFAC mooring location. Further analysis of the conditions durgin day 25 to day 30 , when biomass is noticeably low, is due to a change in the ambient circulation causing a convergent zone to develop in this location, inhibiting the upward mixing of nutrients at depth.

Figure 36. Image of modeling domain and the $5400 \mathrm{~km}^{2}$ zone (red polygon) used to compute an average phytoplankton concentration in the OTEC plumes.......................................58

Figure 37. Average picophytoplankton carbon concentrations in a large area $\left(5400 \mathrm{~km}^{2}\right)$ offshore of west and south $\mathrm{O}^{\prime}$ ahu from 40 to $140 \mathrm{~m}$ depth

Figure 38. Average diatom carbon concentrations in a large area $\left(5400 \mathrm{~km}^{2}\right)$ offshore of west and south O'ahu from 40 to $140 \mathrm{~m}$ depth.

Figure 39. Average large (eukaryotic) phytoplankton carbon concentrations............................61

Figure 40. Pico-phytoplankton biomass (prochlorococcus, synechococcus, etc.) in $\mathrm{mgC} / \mathrm{m}^{3}$ from the RevX 100MW OTEC simulation.

Figure 41. Pico-phytoplankton biomass (prochlorococcus, synechococcus, etc.) in $\mathrm{mgC} / \mathrm{m}^{3}$ from the RevX 100MW OTEC simulation. Figures show the plan view at 190, 170, 150, $130,110,90,70$, and 50 meter depths at June $17^{\text {th }}$ at 16:40 Hawaii Standard Time...65

Figure 42. Pico-phytoplankton biomass (prochlorococcus, synechococcus, etc.) in $\mathrm{mgC} / \mathrm{m}^{3}$ from the RevX 100MW OTEC simulation. Figures show the plan view at 190, 170, 150, $130,110,90,70$, and 50 meter depths at June $17^{\text {th }}$ at $16: 40$ Hawaii Standard Time...66

Figure 43. Pico-phytoplankton biomass (prochlorococcus, synechococcus, etc.) in $\mathrm{mgC} / \mathrm{m}^{3}$ from the RevX 100MW OTEC simulation. Figures show the plan view at 190, 170, 150, $130,110,90,70$, and 50 meter depths at June $24^{\text {th }}$ at 16:40 Hawaii Standard Time...67

Figure 44. Nitrate perturbation (umol $/ \mathrm{kg}$ ) due to the RevX 100MW OTEC plant, and contour lines of the resultant pico-phytoplankton perturbation (black lines) drawn at intervals of $0.5 \mathrm{mgC} / \mathrm{m}^{3}$ ( $<2 \mathrm{um}$ size class, predominantly prochlorococcus and synechococcus). June $3^{\text {rd }}, 2010$ at 16:40 Hawaii Standard Time.

Figure 45. Nitrate perturbation (umol/kg) due to the RevX 100MW OTEC plant, and contour lines of the resultant pico-phytoplankton perturbation June $7^{\text {th }}, 2010$ at 16:40 Hawaii Standard Time.

Figure 46. Nitrate perturbation (umol/kg) due to the RevX 100MW OTEC plant, and contour lines of the resultant pico-phytoplankton perturbation (black lines) drawn at intervals of $0.5 \mathrm{mgC} / \mathrm{m}^{3}$ ( $<2 \mathrm{um}$ size class, predominantly prochlorococcus and synechococcus). June $17^{\text {th }}, 2010$ at 16:40 Hawaii Standard Time. .70

Figure 47. Nitrate perturbation (umol/kg) due to the RevX 100MW OTEC plant, and contour lines of the resultant pico-phytoplankton perturbation (black lines) drawn at intervals of $0.5 \mathrm{mgC} / \mathrm{m}^{3}(<2 \mathrm{um}$ size class, predominantly prochlorococcus and synechococcus). June $24^{\text {th }}, 2010$ at 16:40 Hawaii Standard Time.

Figure 48. Diatom phytoplankton biomass in $\mathrm{mgC} / \mathrm{m}^{3}$ from the RevX 100MW OTEC simulation. Figures show the plan view at 190, 170, 150, 130, 110, 90, 70, and 50 meter depths at at June $3^{\text {rd }}$ at 16:40 Hawaii Standard Time. 
Figure 49. Diatom phytoplankton biomass in $\mathrm{mgC} / \mathrm{m}^{3}$ from the RevX 100MW OTEC simulation. Figures show the plan view at 190, 170, 150, 130, 110, 90, 70, and 50 meter depths at at June $7^{\text {th }}$ at 16:40 Hawaii Standard Time.

Figure 50. Diatom phytoplankton biomass in $\mathrm{mgC} / \mathrm{m}^{3}$ from the RevX 100MW OTEC simulation. Figures show the plan view at 190, 170, 150, 130, 110, 90, 70, and 50 meter depths at at June $17^{\text {th }}$ at 16:40 Hawaii Standard Time

Figure 51. Diatom phytoplankton biomass in $\mathrm{mgC} / \mathrm{m}^{3}$ from the RevX 100MW OTEC simulation. Figures show the plan view at 190, 170, 150, 130, 110, 90, 70, and 50 meter depths at June $24^{\text {th }}$ at 16:40 Hawaii Standard Time.

Figure 52. Nitrate perturbation (umol/kg) due to the RevX 100MW OTEC plant, and contour lines of the resultant diatom perturbation (black lines) drawn at intervals of 0.5 $\mathrm{mgC} / \mathrm{m}^{3}$. June $3^{\text {rd }}, 2010$ at 16:40 Hawaii Standard Time.

Figure 53. Nitrate perturbation (umol/kg) due to the RevX 100MW OTEC plant, and contour lines of the resultant diatom perturbation (black lines) drawn at intervals of 0.5 $\mathrm{mgC} / \mathrm{m}^{3}$. June $10^{\text {th }}, 2010$ at 16:40 Hawaii Standard Time.

Figure 54. Nitrate perturbation (umol/kg) due to the RevX 100MW OTEC plant, and contour lines of the resultant diatom perturbation (black lines) drawn at intervals of 0.5 $\mathrm{mgC} / \mathrm{m}^{3}$. June $17^{\text {th }}, 2010$ at 16:40 Hawaii Standard Time.

Figure 55. Nitrate perturbation (umol/kg) due to the RevX 100MW OTEC plant, and contour lines of the resultant diatom perturbation (black lines) drawn at intervals of 0.5 $\mathrm{mgC} / \mathrm{m}^{3}$. June $24^{\text {th }}, 2010$ at 16:40 Hawaii Standard Time.

Figure 56. Pico-phytoplankton biomass (prochlorococcus, synechococcus, etc.) in $\mathrm{mgC} / \mathrm{m}^{3}$ from the RevX 3x100MW OTEC simulation. Figures show the plan view at 190, 170, 150, $130,110,90,70$, and 50 meter depths at at June $3^{\text {rd }}$ at 16:40 Hawaii Standard Time. 81

Figure 57. Pico-phytoplankton biomass (prochlorococcus, synechococcus, etc.) in $\mathrm{mgC} / \mathrm{m}^{3}$ from the RevX 3x100MW OTEC simulation. Figures show the plan view at 190, 170, 150, $130,110,90,70$, and 50 meter depths at at June $10^{\text {th }}$ at 16:40 Hawaii Standard Time. 82

Figure 58. Pico-phytoplankton biomass (prochlorococcus, synechococcus, etc.) in $\mathrm{mgC} / \mathrm{m}^{3}$ from the RevX 3x100MW OTEC simulation. Figures show the plan view at 190, 170, 150, $130,110,90,70$, and 50 meter depths at at June $17^{\text {th }}$ at 16:40 Hawaii Standard Time. 83

Figure 59. Pico-phytoplankton biomass (prochlorococcus, synechococcus, etc.) in $\mathrm{mgC} / \mathrm{m}^{3}$ from the RevX 3x100MW OTEC simulation. Figures show the plan view at 190, 170, 150, $130,110,90,70$, and 50 meter depths at at June $24^{\text {th }}$ at 16:40 Hawaii Standard Time. 84

Figure 60. Nitrate perturbation (umol $/ \mathrm{kg}$ ) due to the RevX 3x100MW OTEC plant, and contour lines of the resultant pico-phytoplankton perturbation (black lines) drawn at intervals of $0.5 \mathrm{mgC} / \mathrm{m}^{3}$. June $3^{\text {rd }}, 2010$ at 16:40 Hawaii Standard Time...............................85

Figure 61. Nitrate perturbation (umol/kg) due to the RevX 3x100MW OTEC plant, and contour lines of the resultant pico-phytoplankton perturbation (black lines) drawn at intervals of $0.5 \mathrm{mgC} / \mathrm{m}^{3}$. June $10^{\text {th }}, 2010$ at 16:40 Hawaii Standard Time. .86

Figure 62. Nitrate perturbation (umol $/ \mathrm{kg}$ ) due to the RevX 3x100MW OTEC plant, and contour lines of the resultant pico-phytoplankton perturbation (black lines) drawn at intervals of $0.5 \mathrm{mgC} / \mathrm{m}^{3}$. June $17^{\text {th }}, 2010$ at 16:40 Hawaii Standard Time.

Figure 63. Nitrate perturbation (umol/kg) due to the RevX 3x100MW OTEC plant, and contour lines of the resultant pico-phytoplankton perturbation (black lines) drawn at intervals of $0.5 \mathrm{mgC} / \mathrm{m}^{3}$. June $24^{\text {th }}, 2010$ at $16: 40$ Hawaii Standard Time. .88 
Figure 64. Diatom phytoplankton biomass in $\mathrm{mgC} / \mathrm{m}^{3}$ from the RevX $3 \times 100 \mathrm{MW}$ OTEC simulation. Figures show the plan view at 190, 170, 150, 130, 110, 90, 70, and 50 meter depths at at June $3^{\text {rd }}$ at 16:40 Hawaii Standard Time.

Figure 65. Diatom phytoplankton biomass in $\mathrm{mgC} / \mathrm{m}^{3}$ from the RevX $3 \times 100 \mathrm{MW}$ OTEC simulation. Figures show the plan view at 190, 170, 150, 130, 110, 90, 70, and 50 meter depths at at June $10^{\text {th }}$ at 16:40 Hawaii Standard Time.

Figure 66. Diatom phytoplankton biomass in $\mathrm{mgC} / \mathrm{m}^{3}$ from the RevX $3 \times 100 \mathrm{MW}$ OTEC simulation. Figures show the plan view at 190, 170, 150, 130, 110, 90, 70, and 50 meter depths at at June $17^{\text {th }}$ at 16:40 Hawaii Standard Time.

Figure 67. Diatom phytoplankton biomass in $\mathrm{mgC} / \mathrm{m}^{3}$ from the RevX $3 \times 100 \mathrm{MW}$ OTEC simulation. Figures show the plan view at 190, 170, 150, 130, 110, 90, 70, and 50 meter depths at at June $24^{\text {th }}$ at 16:40 Hawaii Standard Time.

Figure 68. Nitrate perturbation (umol/kg) due to the RevX 3x100MW OTEC plant, and contour lines of the resultant diatom perturbation (black lines) drawn at intervals of 0.5 $\mathrm{mgC} / \mathrm{m}^{3}$. June $3^{\text {rd }}, 2010$ at 16:40 Hawaii Standard Time.

Figure 69. Nitrate perturbation (umol $/ \mathrm{kg}$ ) due to the RevX 3x100MW OTEC plant, and contour lines of the resultant diatom perturbation (black lines) drawn at intervals of 0.5 $\mathrm{mgC} / \mathrm{m}^{3}$. June $10^{\text {th }}, 2010$ at 16:40 Hawaiian Standard Time.

Figure 70. Nitrate perturbation (umol/kg) due to the RevX 3x100MW OTEC plant, and contour lines of the resultant diatom perturbation (black lines) drawn at intervals of 0.5 $\mathrm{mgC} / \mathrm{m}^{3}$. June $17^{\text {th }}, 2010$ at 16:40 Hawaiian Standard Time.

Figure 71. Nitrate perturbation (umol $/ \mathrm{kg}$ ) due to the RevX 3x100MW OTEC plant, and contour lines of the resultant diatom perturbation (black lines) drawn at intervals of 0.5 $\mathrm{mgC} / \mathrm{m}^{3}$. June $24^{\text {th }}, 2010$ at 16:40 Hawaiian Standard Time.

Figure 72. Nitrate perturbation (umol $/ \mathrm{kg}$ ) due to the RevX 100MW 95m OTEC plant, and contour lines of the resultant pico-phytoplankton perturbation (black lines) drawn at intervals of $0.5 \mathrm{mgC} / \mathrm{m}^{3}$. June $3^{\text {rd }}, 2010$ at 16:40 Hawaii Standard Time.

Figure 73. Nitrate perturbation (umol $/ \mathrm{kg}$ ) due to the RevX 100MW 95m OTEC plant, and contour lines of the resultant pico-phytoplankton perturbation (black lines) drawn at intervals of $0.5 \mathrm{mgC} / \mathrm{m}^{3}$. June $10^{\text {th }}, 2010$ at 16:40 Hawaii Standard Time.

Figure 74. Nitrate perturbation (umol $/ \mathrm{kg}$ ) due to the RevX 100MW 95m OTEC plant, and contour lines of the resultant pico-phytoplankton perturbation (black lines) drawn at intervals of $0.5 \mathrm{mgC} / \mathrm{m}^{3}$. June $17^{\text {th }}, 2010$ at $16: 40$ Hawaii Standard Time. 100

Figure 75 Nitrate perturbation (umol/kg) due to the RevX 100MW 95m OTEC plant, and contour lines of the resultant pico-phytoplankton perturbation (black lines) drawn at intervals of $0.5 \mathrm{mgC} / \mathrm{m}^{3}$. June $24^{\text {th }}, 2010$ at 16:40 Hawaii Standard Time.

Figure 76. Nitrate perturbation (umol $/ \mathrm{kg}$ ) due to the RevX 100MW 95m OTEC plant, and contour lines of the resultant diatom perturbation (black lines) drawn at intervals of $0.5 \mathrm{mgC} / \mathrm{m}^{3}$. June $3^{\text {rd }}, 2010$ at 16:40 Hawaiian Standard Time.

Figure 77. Nitrate perturbation (umol $/ \mathrm{kg}$ ) due to the RevX 100MW 95m OTEC plant, and contour lines of the resultant diatom perturbation (black lines) drawn at intervals of $0.5 \mathrm{mgC} / \mathrm{m}^{3}$. June $10^{\text {th }}, 2010$ at 16:40 Hawaiian Standard Time.

Figure 78. Nitrate perturbation (umol $/ \mathrm{kg}$ ) due to the RevX 100MW 95m OTEC plant, and contour lines of the resultant diatom perturbation (black lines) drawn at intervals of $0.5 \mathrm{mgC} / \mathrm{m}^{3}$. June $17^{\text {th }}, 2010$ at 16:40 Hawaiian Standard Time. 
Figure 79. Nitrate perturbation (umol $/ \mathrm{kg}$ ) due to the RevX 100MW 95m OTEC plant, and contour lines of the resultant diatom perturbation (black lines) drawn at intervals of $0.5 \mathrm{mgC} / \mathrm{m}^{3}$. June $24^{\text {th }}, 2010$ at $16: 40$ Hawaiian Standard Time.

Figure 80. Nitrate perturbation (umol/kg) due to the RevX 100MW 8x70m OTEC plant, and contour lines of the resultant pico-phytoplankton perturbation (black lines) drawn at intervals of $0.5 \mathrm{mgC} / \mathrm{m} 3$. June $3^{\text {rd }}, 2010$ at 16:40 Hawaii Standard Time.

Figure 81. Nitrate perturbation (umol $/ \mathrm{kg}$ ) due to the RevX 100MW 8x70m OTEC plant, and contour lines of the resultant pico-phytoplankton perturbation (black lines) drawn at intervals of $0.5 \mathrm{mgC} / \mathrm{m} 3$. June $10^{\text {th }}, 2010$ at 16:40 Hawaii Standard Time. 108

Figure 82. Nitrate perturbation (umol/kg) due to the RevX 100MW 8x70m OTEC plant, and contour lines of the resultant pico-phytoplankton perturbation (black lines) drawn at intervals of $0.5 \mathrm{mgC} / \mathrm{m} 3$. June $17^{\text {th }}, 2010$ at Hawaii Standard Time.

Figure 83. Nitrate perturbation (umol/kg) due to the RevX 100MW 8x70m OTEC plant, and contour lines of the resultant pico-phytoplankton perturbation (black lines) drawn at intervals of $0.5 \mathrm{mgC} / \mathrm{m} 3$. June $24^{\text {th }}, 2010$ at $16: 40$ Hawaii Standard Time.

Figure 84. Nitrate perturbation (umol $/ \mathrm{kg}$ ) due to the RevX 100MW 8x70m OTEC plant, and contour lines of the resultant diatom perturbation (black lines) drawn at intervals of $0.5 \mathrm{mgC} / \mathrm{m} 3$. June $3^{\text {rd }}, 2012$ at 16:40 Hawaii Standard Time......

Figure 85. Nitrate perturbation (umol/kg) due to the RevX 100MW 8x70m OTEC plant, and contour lines of the resultant diatom perturbation (black lines) drawn at intervals of $0.5 \mathrm{mgC} / \mathrm{m} 3$. June $10^{\text {th }}, 2012$ at 16:40 Hawaii Standard Time.

Figure 86. Nitrate perturbation (umol $/ \mathrm{kg}$ ) due to the RevX 100MW 8x70m OTEC plant, and contour lines of the resultant diatom perturbation (black lines) drawn at intervals of $0.5 \mathrm{mgC} / \mathrm{m} 3$. June $17^{\text {th }}, 2012$ at 16:40 Hawaii Standard Time.

Figure 87. Nitrate perturbation (umol/kg) due to the RevX 100MW 8x70m OTEC plant, and contour lines of the resultant diatom perturbation (black lines) drawn at intervals of $0.5 \mathrm{mgC} / \mathrm{m} 3$. June $24^{\text {th }}, 2012$ at 16:40 Hawaii Standard Time.

Figure 88. Nitrate perturbation (umol/kg) due to the RevX 100MW 8x95m OTEC plant, and contour lines of the resultant pico-phytoplankton perturbation (black lines) drawn at intervals of $0.5 \mathrm{mgC} / \mathrm{m}^{3}$. June $3^{\text {rd }}, 2010$ at 16:40 Hawaii Standard Time.

Figure 89. Nitrate perturbation (umol/kg) due to the RevX 100MW 8x95m OTEC plant, and contour lines of the resultant pico-phytoplankton perturbation (black lines) drawn at intervals of $0.5 \mathrm{mgC} / \mathrm{m}^{3}$. June $10^{\text {th }}, 2010$ at 16:40 Hawaii Standard Time.

Figure 90. Nitrate perturbation (umol $/ \mathrm{kg}$ ) due to the RevX 100MW 8x95m OTEC plant, and contour lines of the resultant pico-phytoplankton perturbation (black lines) drawn at intervals of $0.5 \mathrm{mgC} / \mathrm{m}^{3}$. June $17^{\text {th }}, 2010$ at 16:40 Hawaii Standard Time. .............118

Figure 91. Nitrate perturbation (umol/kg) due to the RevX 100MW 8x95m OTEC plant, and contour lines of the resultant pico-phytoplankton perturbation (black lines) drawn at intervals of $0.5 \mathrm{mgC} / \mathrm{m}^{3}$. June $24^{\text {th }}, 2010$ at 16:40 Hawaii Standard Time.

Figure 92. Nitrate perturbation (umol $/ \mathrm{kg}$ ) due to the RevX 100MW 8x95m OTEC plant, and contour lines of the resultant diatom perturbation (black lines) drawn at intervals of $0.5 \mathrm{mgC} / \mathrm{m}^{3}$. June $3^{\text {rd }}, 2010$ at 16:40 Hawaii Standard Time.

Figure 93. Nitrate perturbation (umol/kg) due to the RevX 100MW 8x95m OTEC plant, and contour lines of the resultant diatom perturbation (black lines) drawn at intervals of $0.5 \mathrm{mgC} / \mathrm{m}^{3}$. June $10^{\text {th }}, 2010$ at 16:40 Hawaii Standard Time. 
Figure 94. Nitrate perturbation (umol/kg) due to the RevX 100MW 8x95m OTEC plant, and contour lines of the resultant diatom perturbation (black lines) drawn at intervals of $0.5 \mathrm{mgC} / \mathrm{m}^{3}$. June $17^{\text {th }}, 2010$ at 16:40 Hawaii Standard Time.

Figure 95. Nitrate perturbation (umol/kg) due to the RevX 100MW 8x95m OTEC plant, and contour lines of the resultant diatom perturbation (black lines) drawn at intervals of $0.5 \mathrm{mgC} / \mathrm{m}^{3}$. June $24^{\text {th }}, 2010$ at 16:40 Hawaii Standard Time.

Figure 96. Nitrate perturbation (umol $/ \mathrm{kg}$ ) due to the $2.5 \mathrm{MW}$ MiniSpar at the time and date indicated.

Figure 97. Nitrate perturbation (umol/kg) due to the 2.5 MW MiniSpar at the time and date indicated

Figure 98. Nitrate perturbation (umol $/ \mathrm{kg}$ ) due to the 2.5 MW MiniSpar at the time and date indicated.

Figure 99. Nitrate perturbation (umol $/ \mathrm{kg}$ ) due to the $2.5 \mathrm{MW}$ MiniSpar at the time and date indicated

Figure 100. Left: Bar graph showing the average phytoplankton populations from each of the OTEC and non-OTEC simulations 


\section{LIST OF TABLES}

Table 1: Biological parameters used in RevX-RevZA. (Parameters that vary are bold font) ......55

Table 2: OTEC configurations for RevisionX simulation results, including near-field plume properties and perturbation between OTEC and non-OTEC cases. 


\section{LIST OF ACRONYMS}

ADCP Acoustic Doppler Current profiler

ALOHA A Long-term Oligotrophic Habitat Assessment

CEROS Center for Excellence in the Ocean Sciences

CFD Computational Fluid Dynamics

CTD Conductivity, Temperature, Depth

DESA Distributed Entrainment Sink Approach

DOC Dissolved Organic Carbon

DOE U.S. Department of Energy

DON Dissolved Organic Nitrogen

EFDC Environmental Fluid Dynamics Code

EPA U.S. Environmental Protection Agency

ERDC U.S. Army Corps of Engineers Research and Development Center

HIROM Hawai'i Regional Ocean Model

HOTS Hawai'i Ocean Time Series

NASA National Aeronautics and Space Administration

NAVFAC Naval Facilities Engineering Command

NCOM Navy Coastal Ocean Model

NELHA Natural Energy Laboratory of Hawaii Authority

NOAA National Oceanic and Atmospheric Administration

NPSG North Pacific Subtropical Gyre

OTEC Ocean Thermal Energy Conversion

POC Particulate Organic Carbon

PON Particulate Organic Nitrogen

ROM Regional Ocean Model

SOEST School of Ocean and Earth Science and Technology, University of Hawaii

SSH Sea Surface Height

SST Sea Surface Temperature 


\section{INTRODUCTION}

\subsection{OTEC AND ENVIRONMENTAL PLUME MODELS}

Ocean Thermal Energy Conversion (OTEC) is a process that uses large quantities of deep cold seawater and warm surface seawater to drive a Rankine power cycle to generate continuous, utility-grade electricity. Several small (non-commercial) OTEC systems have demonstrated OTEC's feasibility, most notably with Georges Claude in 1930, and then during $1978-1998$ at the Natural Energy Laboratory of Hawaii Authority (NELHA). Recent oil price increases and advances in offshore technology have led to serious interest in floating OTEC plants that are large enough to be commercially viable (Van Ryzin, 2007). Since 2005, further OTEC studies have been sponsored by the Office of Naval Research, Naval Facilities Engineering Command, the U.S. Department of Energy, Lockheed Martin Corporation, and other countries.

Makai Ocean Engineering has participated in numerous OTEC studies (http://www.makai.com/eotec.htm), and we currently operate a large OTEC Test Facility at NELHA. During 2009 through 2011, Makai provided systems engineering for the preliminary design of an offshore OTEC Pilot Plant, during which it was abundantly clear that a plume modeling capability was needed to inform several major engineering decisions for future OTEC plants. The engineers and regulators needed a model that could quantify the dilution and dispersion of the discharge flows, providing assurances of the long-term sustainability of a large-scale OTEC plant. More specifically, this modeling was needed to specify the required discharge velocity and depth, which affects the plant's net power, overall layout, and cost. Such results will also be essential to regulators during the permitting and licensing process, including the National Oceanic and Atmospheric Administration (NOAA). Pursuant to 42 U.S.C. $\$ 9111$ (The OTEC Act of 1980) NOAA is required to consider the effects of OTEC plumes prior to issuing an OTEC license.

During 2009-2010, the Center of Excellence in Research for the Ocean Sciences sponsored Makai to develop a hydrodynamic numerical model to simulate OTEC discharges and plumes. This model simulated the near-field and far-field dilution and circulation of the large volumes of seawater used by a commercial-size (100 megawatt) OTEC plants (Rocheleau and Grandelli, 2011). A single $100 \mathrm{MW}$ OTEC plant requires approximately $420 \mathrm{~m}^{3} / \mathrm{s}$ of warm $\left(\sim 26^{\circ} \mathrm{C}\right)$ shallow seawater and $320 \mathrm{~m}^{3} / \mathrm{s}$ of deep seawater $\left(\sim 4^{\circ} \mathrm{C}\right)$ from $1000 \mathrm{~m}$ depth, requiring the modeling effort to resolve the physics on multiple physical scales. To achieve this, we developed a dynamically coupled lagrangian near-field plume and three-dimensional far-field circulation model that was also one-way nested within a data assimilative Regional Ocean Model System (ROMS) of Hawai $i$, providing dynamic ocean conditions that included basin-scale circulation, mesoscale eddies, and tidally forced barotropic and baroclinic flows. 


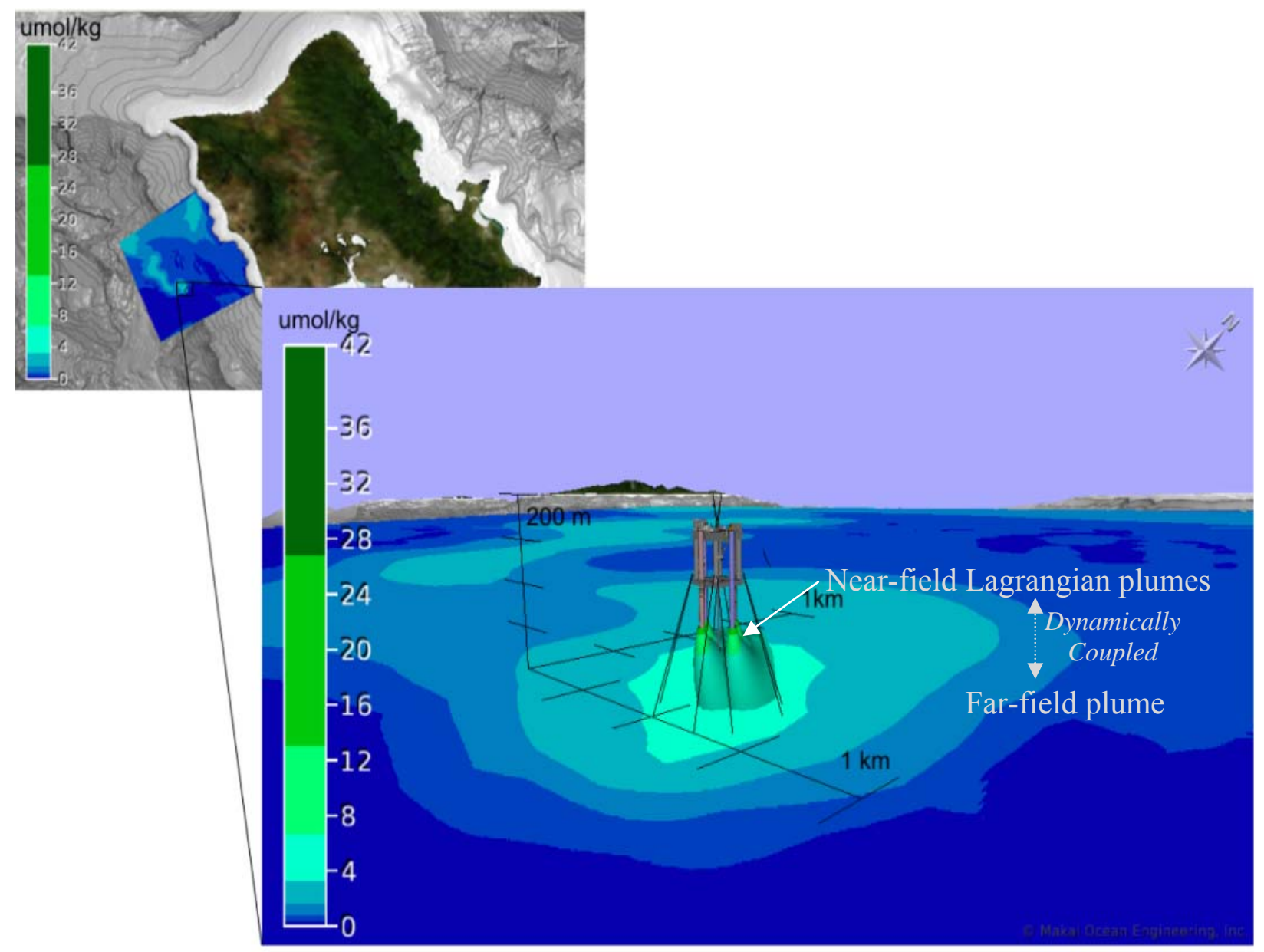

Slice taken at $150 \mathrm{~m}$. Day 7. 100MW-70m mixed discharge.

Figure 3. Makai's first version of an OTEC plume model had a smaller EFDC computational domain (in blue at upper left) with outer boundary conditions driven by the HIROM model. The near-field Lagrangian plumes shown exiting from the plant are dynamically coupled (two-way nested) to the far-field EFDC circulation model. Colors represent nitrate concentration.

The purpose of the CEROS-funded model, illustrated in Figure 3, was to realistically predict the dilution and path of nutrient-rich OTEC discharges, and provide design criteria to mitigate the potential environmental impacts. The open-ocean waters of Hawai'i are a stratified and oligotrophic (low biological productivity) system, with low nutrient concentrations in the mixed layer, and increasing nutrient concentrations below the photic zone. As a result, the nutrient-rich deep water will cause OTEC discharges to have elevated nutrient concentrations compared to the surrounding ambient ocean, which may cause a biological response and increased primary productivity of certain species. The Makai 2011 study simulated inert tracers, temperature, and nutrients in order to better understand the physical and chemical impacts to the surrounding environment. The cold dense plumes were shown to sink and remain below the upper photic zone, with the resultant nutrient perturbations typically diluting to near ambient conditions within one kilometer downstream of a 100MW OTEC plant. Figure 4, from the 2011 CEROS study, shows an example of the nitrate nutrient perturbations predicted by three $100 \mathrm{MW}$ OTEC plants and the complex plume geometries that are caused by the dynamic ocean circulation. 


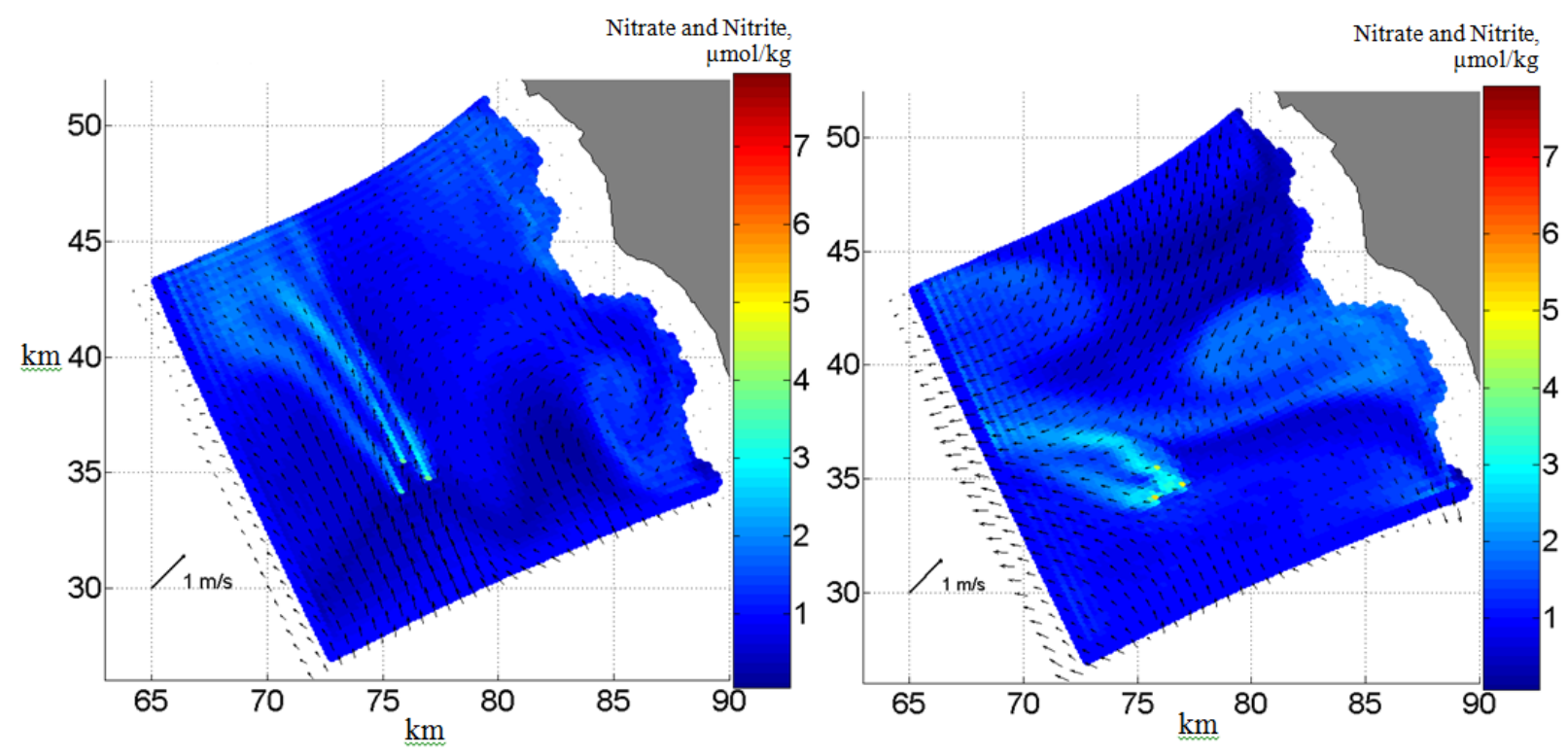

Figure 4. (Left) Nitrate concentration and currents at $130 \mathrm{~m}$ depth, 1000, 19 Feb 2008, showing the dynamic fate of the plumes when currents are strong and to the northwest. (Right) Nitrate concentration and currents at $130 \mathrm{~m}$ depth, 1600, 29 Feb 2008, when currents are relatively weak and directed to the west. Color scale represents nitrate and nitrite concentration in micromoles per kilogram of seawater. (Rocheleau and Grandelli, 2011)

However, the 2010-2011 study did not allow for simulation of the indigenous phytoplankton populations that would likely respond to nutrient perturbations. Several questions remained unanswered without a direct estimate of these biological responses:

- Does the nutrient perturbation remain deep enough to mitigate a significant biological response?

- How are the physical and biological processes coupled?

- Are there any combinations of conditions that could lead to a bloom event?

- What is the extent of the increased biological activity as a result of one 100MW OTEC plant? For three clustered 100MW OTEC plants?

- What is a practical limit on OTEC plant capacities or size based on the resulting biological impacts?

To answer these questions Makai obtained support from the US Department of Energy (DoE) Marine and Hydrokinetic Initiative. With DoE support, we have expanded the OTEC Plume Model and performed the following tasks: 
- Evaluated the physical accuracy of plume model with recently collected ADCP and CTD data from a NAVFAC-funded oceanographic mooring

- Analyzed the temperature, nutrient, $\mathrm{O}_{2}$, and $\mathrm{CO}_{2}$ concentrations of the OTEC model discharge plumes

- Implemented a phytoplankton model for in-situ Hawaiian waters within the existing plume model

- Evaluated the biological impacts from the OTEC plume, including analysis of the spatial extent and depths of the plume, and the potential for phytoplankton blooms

\subsection{BIOLOGICAL MODELING}

Numerical biological models have been widely described in literature, and have been used for a wide variety of applications, from simplified analytical solutions to complex numerical simulations of global ecosystems. The biological models, at their most basic level, are a set of differential equations to describe the rate of change in population biomass via biological and physical sources and sinks. For example, the rate of change of a phytoplankton population at any location and time is the sum effect of growth, physical transport (advection, mixing, sinking, etc.), and mortality (predation and death). The rate in change of nutrient concentration at any location and time is the result of biochemical production, consumption, and physical transport. These differential equations are often interdependent (e.g. growth is a function of nutrient concentration), creating a set of coupled differential equations. The fundamental difference between various biological models is in the formulations used to define the source and sink terms within these equations.

In the work of Bathen (1975), a plankton population model was developed for the phytoplankton response to OTEC induced phosphorous perturbations off Keahole Point, Hawaii. The model was based on the Michaelis-Menten growth kinetics and a series of simplifying assumptions that reduced the differential equations for population dynamics to a set of analytical algebraic equations. The solution provided an elegant method for estimating the biological response to an OTEC plume, but was inherently limited by the lack of data pertaining to the local phytoplankton populations as well as the computational resources that were available at that time.

In the past two decades, computational resources and more detailed observations have allowed more complex biological models to be developed, with directly coupled physical and biological numerical integrations. The work of Fasham, et al. (1990) incorporated additional components in the biological model to simulate the mixed layer dynamics of not only phytoplankton, zooplankton, and nitrate but also bacteria, ammonium, dissolved organic nitrogen, and detritus. This attempt at a basin scale, physically coupled, numerical phytoplankton model enabled flow between compartments, such as the mixed layer and deep ocean, which was critical for accurately simulating biochemical cycles in the ocean's mixed layer.

In more recent years, several models following upon the footsteps of Fasham that involved dynamic coupling to three-dimensional circulation models. Even in these biological models, one of the largest challenges still remaining is accurately determining the level of complexity required to adequately simulate the marine ecosystem of interest, while balancing the computational capabilities available. Gruber et al. (2006) note that their choice for model parameters inherently limited the success of their model to simultaneously simulate both a coastal upwelling and offshore 
oligotrophic zone. Yet, despite these challenges and limitations, several physical-biological coupled models have recently been introduced with biological parameters and formulations that reasonably reproduce the measured chlorophyll observations on regional to oceanic scales in their intended regions of interest (Lima and Doney, 2004; Wang et al. 2006, 2008, 2009, 2012; Calil, 2008; Gruber et al. 2006).

Unlike very large global and basin scale simulations, a limited-domain model can be improved and simplified by using local data. For example, the deep ocean surrounding Hawai $i$ is in the North Pacific Subtropical Gyre (NPSG) and has low surface chlorophyll and low nutrient concentrations. The major indigenous phytoplankton groups within this limited domain are local prochlorococcus, synecococcus, eukaryotes, and diatoms. The multi-institutional Hawaii Ocean Time Series (HOTS) program provides a multi-decade once-per-month dataset of physical, chemical, and biological data collected at Kahe Point, Oahu and Station ALOHA (A Long-term Oligotrophic Habitat Assessment, located at $22^{\circ} 45^{\prime} \mathrm{N}, 158^{\circ} 00^{\prime} \mathrm{W}$ ), north of Oahu. Observational data from HOTS has helped formulate a better understanding of the oligotrophic biology surrounding Hawai' $i$, and provided an immense amount of field data to calibrate and validate our simulation for the local plankton populations. In addition, there exists several ship-based experiments during large mesoscale eddy events (Brown et al. 2008; Landry et al. 2008; Rii et al. 2008) and incubation experiments that present in-situ data on the response of phytoplankton to contributions of nutrient rich deep-water specifically surrounding Hawai'i (McAndrew et al. 2007). These local observations and studies provide data to adequately parameterize the biological plume model for oligotrophic Hawai'i an waters.

In this report, we present Makai's work in expanding the existing plume model to include a dynamically coupled biochemical and biological phytoplankton model for the oligotrophic waters surrounding Oahu, Hawai'i. This report will include a description of the modeling methods and assumptions used, calibration of biological parameters using observational datasets, a sensitivity analysis of the chosen biological parameters, and an evaluation of the modeling results and potential biological impact from various OTEC discharge configurations.

Numerical biological models have been widely described in literature, and have been used for a wide variety of applications, from simplified analytical solutions to complex numerical simulations of global ecosystems. The biological models, at their most basic level, are a set of differential equations to describe the rate of change in population biomass via biological and physical sources and sinks. For example, the rate of change of a phytoplankton population at any location and time is the sum effect of growth, physical transport (advection, mixing, sinking, etc.), and mortality (predation and death). The rate in change of nutrient concentration at any location and time is the result of biochemical production, consumption, and physical transport. These differential equations are often interdependent (e.g. growth is a function of nutrient concentration), creating a set of coupled differential equations. The fundamental difference between various biological models is in the formulations used to define the source and sink terms within these equations.

\subsection{PRESENTATIONS AND DATA}

As part of this work, Makai made several presentations and a formal research paper, provided an oceanographic observation data set to NOAA, and placed a model animation onto the World Wide Web. This information has previously been submitted to the department of Energy, and is summarized below: 
All oceanographic data (ADCP and CTD) was submitted to NOAA liaison at the University of Hawaii, Mr. Patrick Caldwell during the second quarter of this project

Pat Grandelli and Greg Rocheleau gave extensive briefings on May 12 and 13, 2011 to Naval Facilities Engineering Command managers and NOAA, DoE, NMFS, EPA and Lockheed personnel at Lockheed in Manassas and NOAA offices in Silver Spring MD.

Presentation of conference paper by Greg Rocheleau entitled "Physical and Biological Modeling of a 100 Megawatt Ocean Thermal Energy Conversion Discharge Plume" at the Marine Technology Society's annual Oceans'11 Conference.

Pat Grandelli gave briefings on 23 September 2011 to NOAA, EPA and Lockheed NavFac OTEC team members via teleconference, in support of tasks 2.2 and 6.1 .

Upon NOAA request, Pat Grandelli gave briefing on 22 December, 2011 to NOAA and Korean government officials.

Makai has hosted one of our plume videos accessible to the general public at http://www.makai.com/e-otec.htm. Other videos showing more detail can be viewed by special arrangement.

Ms. Whitney Blanchard of DOE has requested presentation material for a briefing scheduled for Novemebr 2012 with Korean government officials. 


\section{COMPUTER MODELING INFORMATION}

\subsection{DESCRIPTION OF THE OCEAN CIRCULATION MODEL}

The plume model is based on the source code for the Environmental Fluid Dynamics Code (EFDC). Makai used the official EFDC source code, released in 2010, and maintained by TetraTech Inc. for the U.S. Environmental protection Agency. The author of EFDC, Dr. John Hamrick of TetraTech, served as a consultant to Makai for this work.

EFDC solves the three-dimensional, vertically hydrostatic, free surface, turbulent averaged equation of motion for a variable density fluid. The model utilizes the Mellor-Yamada 2.5 closure scheme for sub-grid scale vertical turbulence. Studies by Carter et al. (2008) have shown that the Mellor-Yamada 2.5 produces reasonable agreement to microstructure diffusivity measurements in the region. Boundary conditions were supplied from the regional ROMS ocean models operated by the University of Hawaii, referred hereafter in this report as HIROM (Powell, 2012).

The model domain extends from $158.9522^{\circ} \mathrm{W}, 20.4677^{\circ} \mathrm{N}$ to $157.3406^{\circ} \mathrm{W}, 21.9661^{\circ} \mathrm{N}$, encompassing the island of Oahu, Hawai'i and the surrounding ocean as shown in Figure 5. The horizontal grid is a rectangular, variable resolution 125 cell x 125 cell horizontal mesh with grid spacing of $1.5 \mathrm{~km}$ at the grid corners and $750 \mathrm{~m}$ at the grid interior. The vertical grid contains 50 layers, specified as a Z-grid orientation with $20 \mathrm{~m}$ resolution in the upper $200 \mathrm{~m}$ of the ocean. Below $200 \mathrm{~m}$ the vertical grid spacing increases each grid level by approximately $10 \%$ until reaching a maximum thickness of $308 \mathrm{~m}$. This orientation was chosen to maintain high vertical resolution in the mixed layer photic zone and the terminal plume depths, and use coarse grid spacing at depth to ease the computational requirements. Model bathymetry at the domain interior was obtained from the Main Hawaiian Islands Multibeam Bathymetry (www.soest.hawaii.edu/hmrg/ multibeam, 2012). The bathymetric data was interpolated near the open boundaries to match the HIROM grid in order to facilitate a numerically accurate and stable nesting scheme.

The model is forced by radiation boundary conditions, computed using the tidal surface elevations and depth averaged flows from the HIROM model output. Spatially varying wind stress is applied, obtained from the University of Hawaii WRF model, using the same spatial and temporal wind data as used in the HIROM parent grid. Time varying values for temperature and salinity are also prescribed at the open boundaries using the HIROM output. To reduce modeling instabilities, and better match the incoming boundary conditions, the model uses a data assimilative layer, commonly referred to as a "sponge" layer (Carter and Merrifield, 2007; Lavelle and Thacker 2008; Jensen 1998; Marchesiello et al. 2001). The assimilation replaces the computed solution with the exterior solution according to:

$$
\phi=\alpha \phi^{e x t}+(1-\alpha) \phi^{*}
$$

where $\alpha$ is the assimilative factor (user defined) and $\phi$ is the variable being assimilated. We have defined the layer as 10 grid cells thick, approximately $10 \%$ of the modeling domain on each boundary. The sponge layers uses stronger assimilation at the open boundaries and weaker assimilation at the interior. In this model, we have also implemented a stronger assimilation scheme in the top vertical layers, and applied lower assimilation at depth, using a second order decay below the top $100 \mathrm{~m}$ of the water column. Normal and tangential flows and temperature and 
salinity are all assimilated, although tangential flows are assimilated less strongly. The zone between the outer boundary and the dotted lines in Figure 5 is the location of these sponge layers for flow, temperature, and salinity assimilation. The left graph of Figure 6 shows a plot of the data assimilation factor based upon horizontal distance from the domain boundaries. The figure's right half shows decay of vertical data assimilation factor as a function of depth. These assimilation factors are reported in units of assimilation strength relative to the maximum assimilation used at the outer boundary. The maximum assimilation at the outer boundary was 0.15 for the flows and 0.025 for the temperature and salinity, far from $100 \%$ assimilation, but still strong enough to significantly improve model agreement and stability.

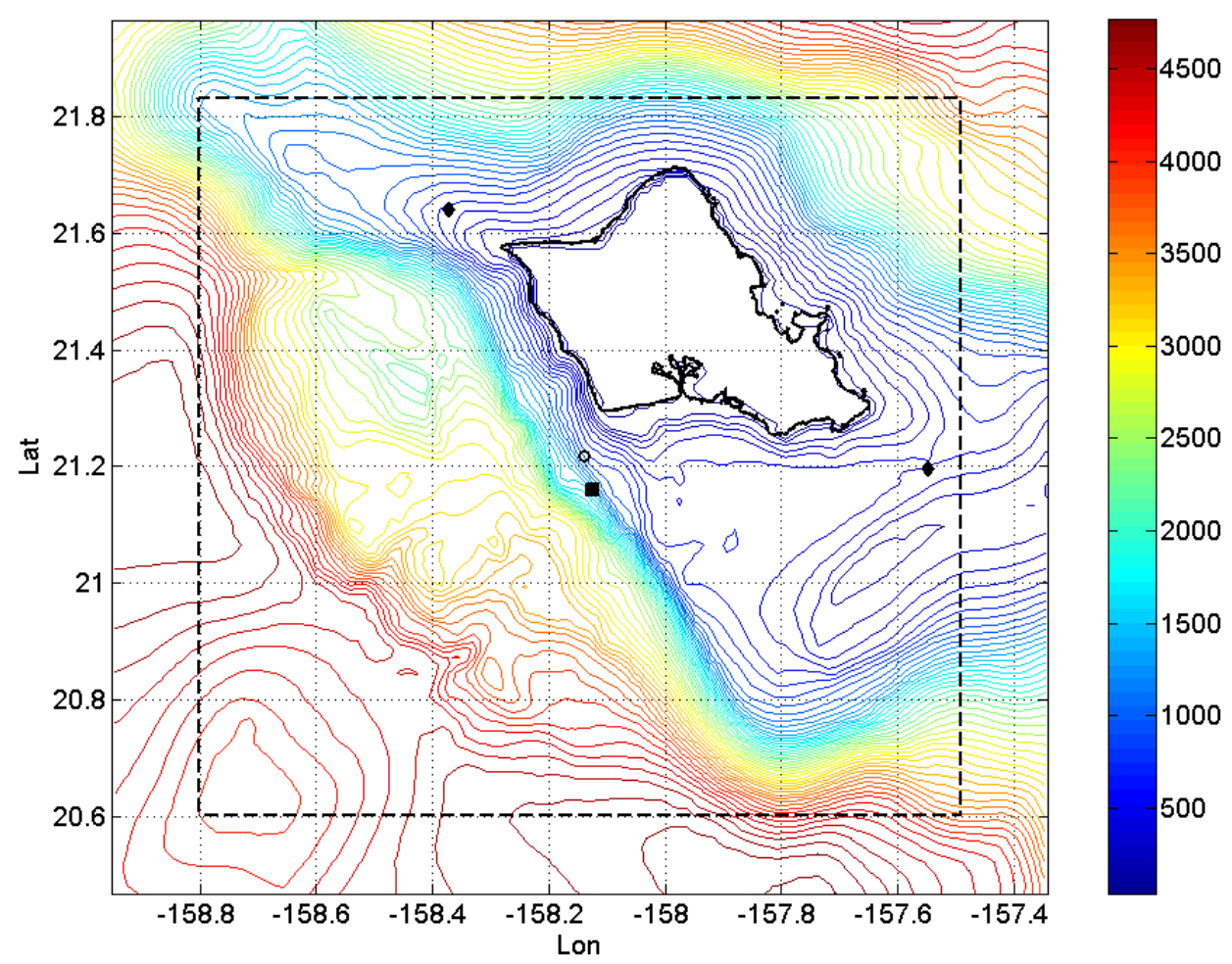

Figure 5. The computational domain used by the EFDC-based OTEC Bioplume Model, showing colored depth contours at 100 meter spacing. The validating current sensor data was collected at the location of the black square, and the simulated OTEC plant is located at the circle. 

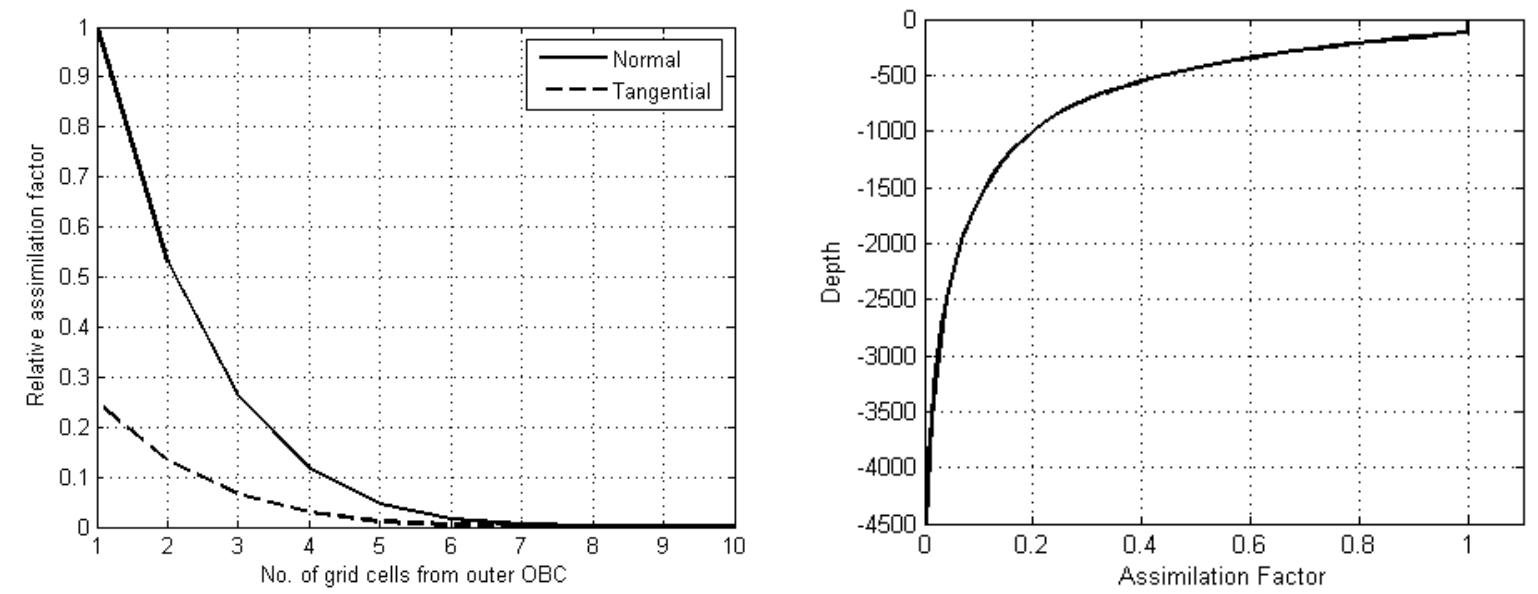

Figure 6. Assimilation/relaxation functions vary between 0 and 1 across the relaxation zone. The horizontal varying functions (left) were modified from the high order polynomials and hyperbolic functions proposed by Jensen (1998) and Carter et al. (2007), respectively. The depth varying functions (right) were found to improve model performance.

The plume model nesting scheme is shown in Figure 7, below. The parent grid is the HIROM (Hawaii Regional Ocean Model) model, a data-assimilative ROMS model with $4 \mathrm{~km}$ horizontal resolution. The boundary of the regional $4 \mathrm{~km}$ resolution ROMS domain is forced with the nontidal NCOM (Navy Coastal Ocean Model) solution and TPXO tides (volkov.oce.orst.edu/tides/). Wind stresses are supplied from a locally operated WRF model run at $9 \mathrm{~km}$ and $1.5 \mathrm{~km}$ resolution. The model also uses a 4D-Var assimilation on 4-day cycles, assimilating all available data: These data include along track Satellite Sea Surface Temperature (SST), Sea Surface Height (SSH), Argo drifting buoys, Conductivity/Temp/Depth sensors (CTD), Gliders, Acoustic Doppler Current Profilers (ADCP), and HF radar radials off the south shore of Oahu. More details on the HIROMS model can be found on the website http://oos.soest.hawaii.edu/pacioos/focus/modeling/roms.php. 


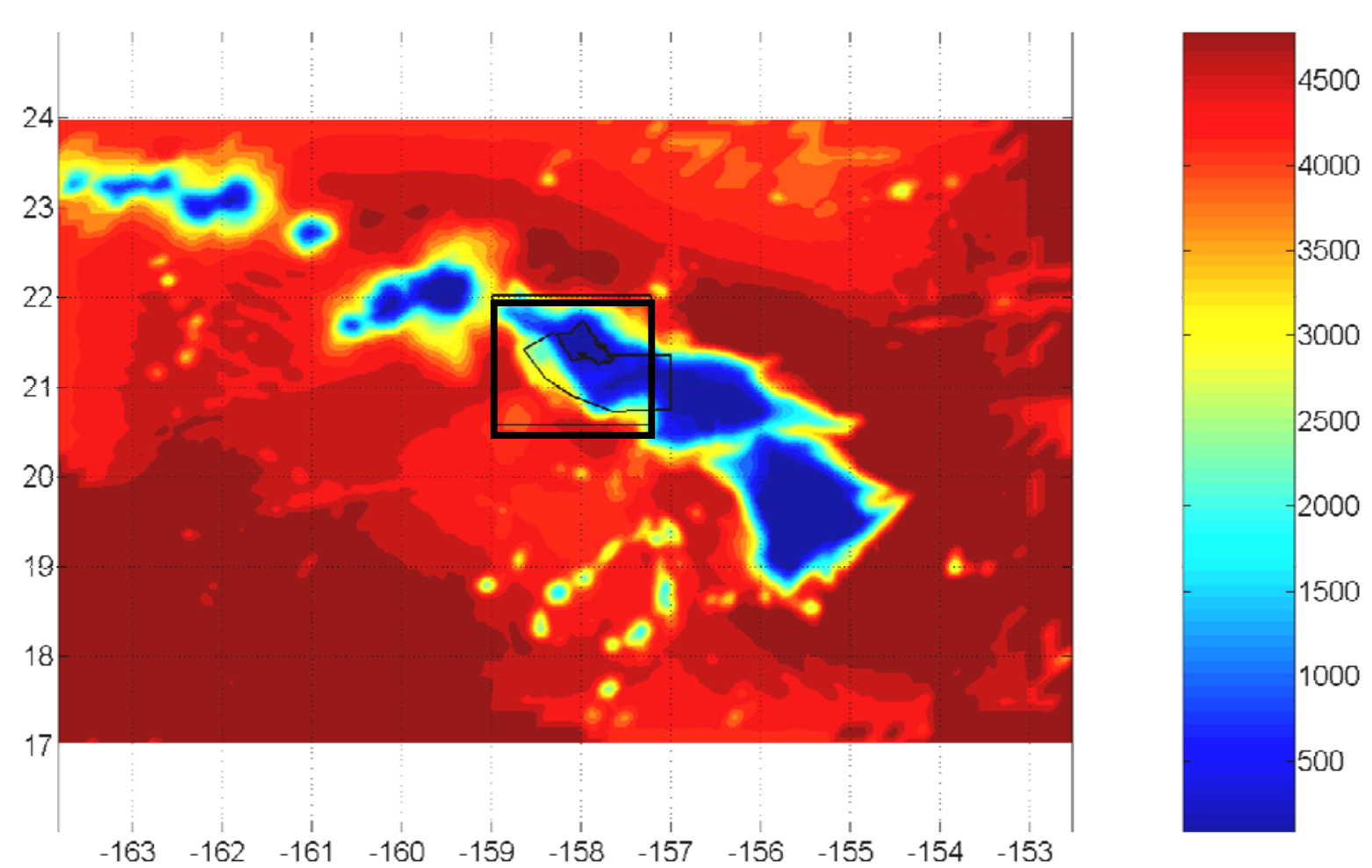

Figure 7. The bathymetry and grid extent of the $4 \mathrm{~km}$ resolution Univ. of Hawaii ROMS model (colormap), with the nested Makai Plume model (black rectangular grid), and the nested 1 km HIROMS domain (curvilinear black grid). Depths are in meters.

\subsection{HYDRODYNAMIC NEAR-FIELD PLUME MODEL}

The near-field dilution and trajectory of the OTEC discharges are simulated with a coupled Lagrangian jet-plume model. The three-dimensional circulation model is dynamically coupled to this jet-plume model using a Distributed Entrainment Sink Approach (DESA) (Choi and Lee, 2007; Choi et al, 2007). The DESA method provides accurate computations of the trajectory and average plume properties in highly turbulent and non-hydrostatic discharges without the need for ad-hoc mixing parameters and computationally inhibitive CFD analysis. 
The behavior of turbulent thermal discharges, such as near-field OTEC plumes, have been well documented in both laboratory and numerical studies (List 1982; Baines 2002; Turner 1969; MacDonald 1990; Lee et al. 1974; Lavelle 1994). The jet-plumes sink or rise depending on their momentum and buoyancy, and entrain the surrounding water via means of shear and vortex entrainment mechanisms. These processes are parameterized in the Lagrangian plume model using the formulations of Lee and Cheung (1990) and Lee and Chu (2003). At some point, the near-field plume has the same density as the ambient layer it is located, and has lost its initial discharge momentum. The near-field lagrangian plume model then "stops". The entrainment of ambient water along the plume's trajectory is modeled as a series of sink terms at the grid cell level of the circulation model, and the terminal plume is modeled as a source term at the terminal plume depth. For more detailed discussion of this method, the reader is strongly encouraged to reference the work of Choi and Lee (2007). Figure 8 shows these the near-field( and far-field model components for the 100MW OTEC plume.

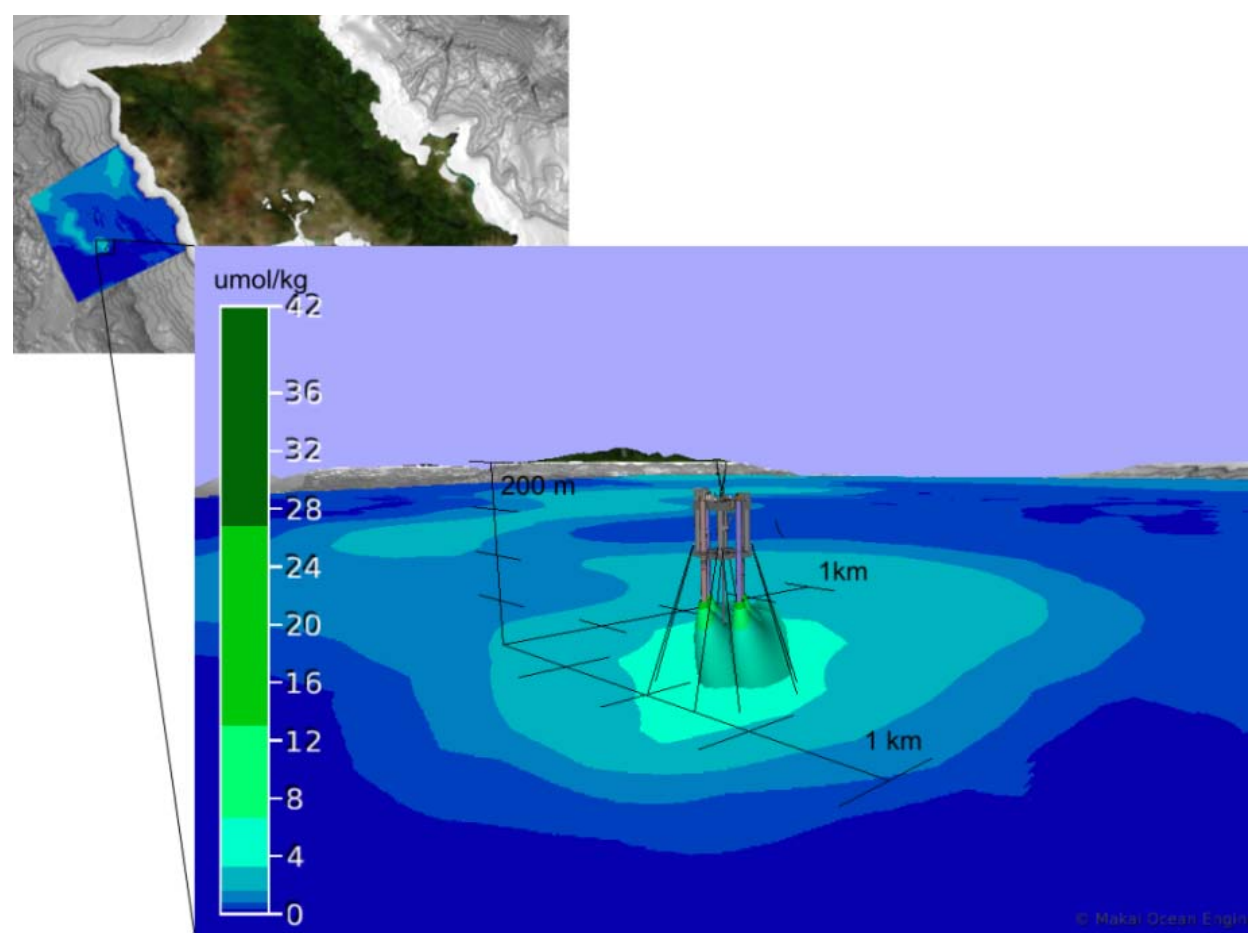

Figure 8. Image of 100 MW OTEC plant with four $70 \mathrm{~m}, 1 \mathrm{~m} / \mathrm{s}$ mixed discharges, depicting the resultant plumes and nitrate (nutrient) concentration. The near-field plumes are the jets discharged from the OTEC plant, with farfield illustrated at $130 \mathrm{~m}$ depth on the horizontal. The image was created with Makai Voyager. 


\subsection{DESCRIPTION OF THE BIOLOGICAL MODEL \& LOCAL CONDITIONS}

The biological-biochemical model employed in this study was the Environmental Fluid Dynamics Code (EFDC) Water Quality Model, which is a subset of the EFDC hydrodynamic model. EFDC has been in development since 1988, and has been applied to over 100 water bodies including reservoirs, estuaries, and coastal ocean regions. The EFDC water quality module was developed in collaboration with the U.S. Army Corps of Engineers Research and Development Center (ERDC) based on the CE-QUAL-ICM eutrophication kinetics models (Cerco and Cole 1995), and is an EPA-approved code. The biological model is dynamically coupled to the 3D physical model, with transport of all biological components simulated identically via mass-balance equations.

The ocean surrounding Hawaii's coastal waters is an oligotrophic environment. The term oligotrophic is from the Greek oligo, meaning "few, little", and trophic, meaning "nutrients". Its opposite is the more familiar term eutrophic, meaning "good nutrition". Global distribution of oligotrophic regions are shown in Figure 9 as dark to medium blue. They are the oceanic equivalent of terrestrial deserts.

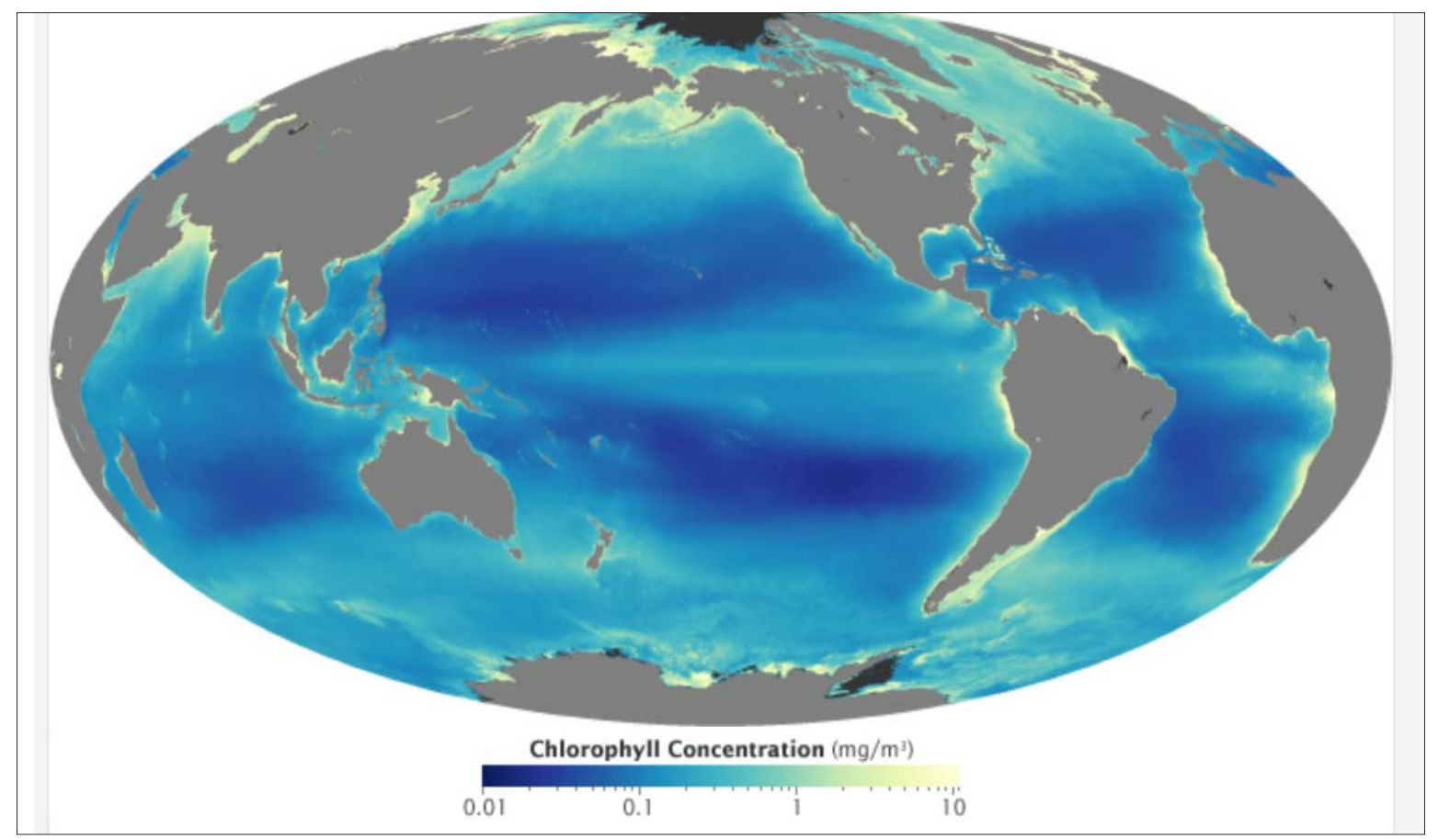

Figure 9. Global view of chlorophyll concentration. The yellow regions are $200-800$ times more productive than the blue (oligotrophic) regions that comprise $30 \%$ of the ocean's surface. From http://earthobservatory.nasa.gov/Features/Phytoplankton/page4.php (May 2002 - July 2010). 
Although the waters surrounding Hawaii are oligotrophic, near-shore waters receive nutrients from surface runoff or groundwater intrusion. Once in deeper water a few miles from these terrestrial sources, the offshore ocean near Hawaii receives much less nutrients and thus exhibits dramatically less photosynthetic productivity, as shown by Figure 10. Compared to shallow and constrained Kaneohe Bay and Honokohau harbor, the OTEC site is located in open ocean deep water, with correspondingly low productivity.

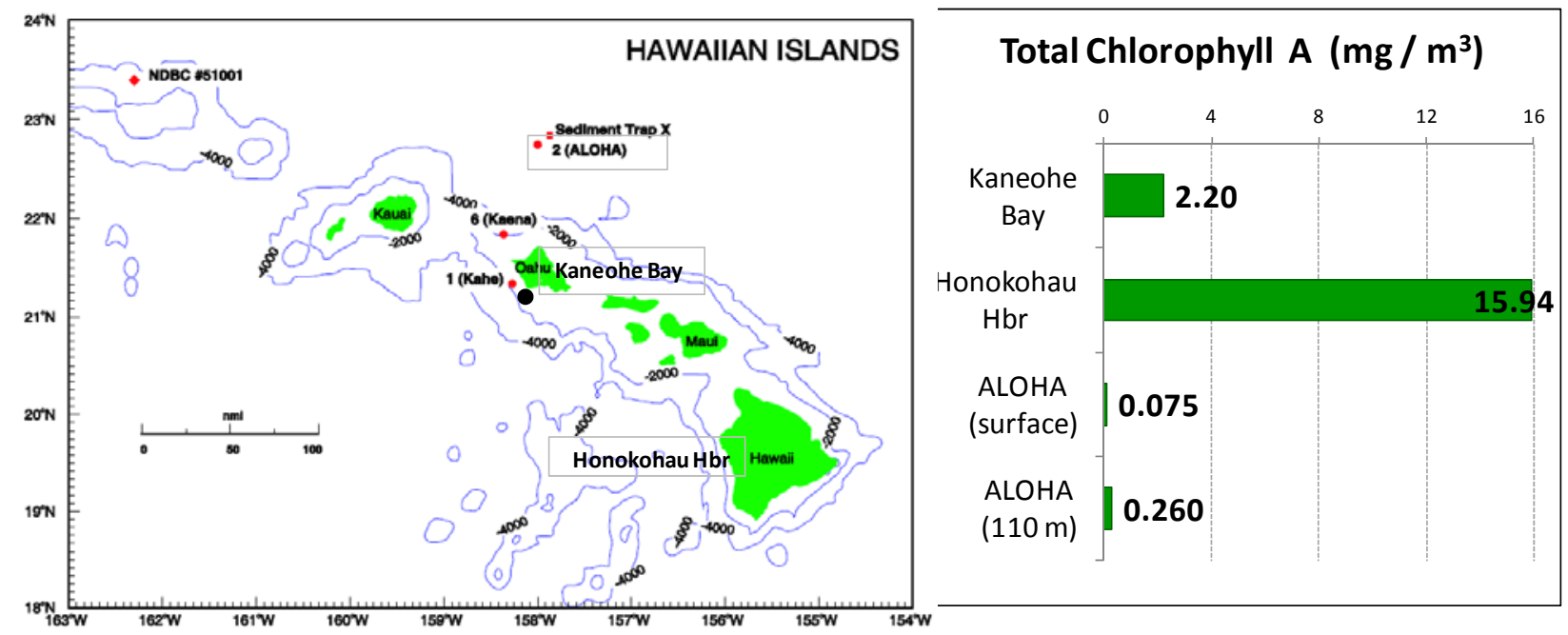

Figure 10. Comparison of chlorophyll A concentrations in Hawaii embayments and oligotrophic station ALOHA. The OTEC plant was simulated at the black dot southwest of Oahu. From Bienfang (1984) and Fujieki (2011).

\subsubsection{Overview of Assumptions and Modifications}

Several modifications were necessary to formulate the model for Hawaii's open ocean oligotrophic system and to incorporate the local observational datasets. The details will be discussed later, but the following discussion outlines the major underlying assumptions and reasoning for the model formulations.

The most significant assumption was that the model would simulate biochemical response for three classes of phytoplankton: Picoplankton $(<2 u \mathrm{~m})$ such as prochlorococcus, nanoplankton $(2-10$ $u \mathrm{~m}$ ), and microplankton ( $>20 \mathrm{um}$ ) e.g., diatoms. These particular size delineations were used upon Dr. Church's recommendation because they best matched size delineations available in the literature for model calibration.

The model assumes nitrate and nitrite as the main limiting nutrients. The measured Redfield ratios of existing populations and the ambient ratio of nitrate to phosphate in the surface layer generally supports the hypothesis of nitrate as a limiting nutrient. The N:P ratio in phytoplankton cells is typically 16:1, while the average ratio of dissolved inorganic $\mathrm{N}: \mathrm{P}$ in the nutrient replete surface layers is measured to be $0.26: 1$, indicating an excess of phosphate (HOT-DOGS, 2012). Recent observations by Johnson et al. (2010) strongly indicate that episodic and periodic mesoscale upwelling of nitrate provides the nutrient loads required to support the longer-term growth within the euphotic zone. In addition, Silicate was included in the model as a limiting nutrient for the diatoms. Discharged waters (sourced from the deep cold water intake) will have higher ratios of 
bio-available silicate compared to naturally occurring S:N:P ratios at the discharge depths, due to the naturally higher S:N:P ratios found in the deep ocean. Recent studies have shown that diatoms can initially outcompete the smaller phytoplankton species for nutrients, such as prochlorococcus, but the diatoms may become stressed by silica limitations over time (Brown et al. 2008; Landry et al. 2008; Rii et al. 2008).

The availability of nutrients for phytoplankton in the upper ocean is closely related to the remineralization of detrital organic matter. The EFDC model allows for three detrital groups: refractory and labile particulates and dissolved particulates. However, the plume model was simplified to only include particulate (i.e. large) detritus and the dissolved (i.e. small) detritus. These two detrital components are adequate to accurately simulate the slow and fast sinking organic fluxes produced by primary production in the surface layers (Wang et al. 2008; Gruber et al. 2006). This choice is admittedly inherent to the fact that detrital measurements and datasets are typically classified by size rather than type, due to the relatively poor characterization of the detrital pools (Karl et al. 2008). However, this classification has been shown to provide adequate functionality for numerical models.

Remineralization of particulate organic nitrogen (small slowly sinking detrital nitrogen) into ammonium, and the subsequent nitrification of ammonium into usable nitrate, provides a critical recycle of nutrients into the ecosystem. The standard nitrification formulas within EFDC were formulated for temperature and oxygen limitations, but no dependence on light. These formulations, intended for mid-latitude estuaries, were modified to use a nitrification rate inhibited only by light (Wang et al. 2008; Calil et al. 2008; Gruber et al. 2006), a more reasonable assumption for temperate oligotrophic waters. Finally, since the model is carbon based we used a constant light attenuation constant with depth without using variable carbon to chlorophyll ratios. After these modifications were completed, model data comparisons were performed, and the model was shown to reasonably reproduce the existing biomass observations (see section 4.3).

Recently, much interest has been invested in nitrifying bacteria found in the surface layer, which are believed to provide a non-negligible flux of biologically available nitrogen to the surface layers by reduction of $\mathrm{N}_{2}$. The plume model does not include nitrifiers and nitrogen fixation, which admittedly may lead the model to simulate a lower nitrate availability and biomass in the surface layer than in the real ocean. However, the OTEC plumes sink to depths of 100 to $160 \mathrm{~m}$, at or well below the base of the photic zone. The phytoplankton at these depths are dominated by the bottom up supply of nitrate and the top-down limitation of sunlight (Letelier et al. 2004), which are processes captured in the model's assumptions and formulations.

\subsection{2. $\quad$ Model Formulas and Parameters}

The biological model is carbon based with eleven differential equations describing the dynamics of the biological components, including: three phytoplankton groups (Small and Large Phytoplankton and Diatoms), three nutrient components (nitrate, ammonium, and silicate), and several biochemical components (Particulate Organic Carbon (POC), Dissolved Organic Carbon (DOC), Particulate Organic Nitrogen (PON), Dissolved Organic Nitrogen (DON), Particulate Silica, and Dissolved Oxygen [DO]). Figure 11 shows a flow diagram of the model's components. 


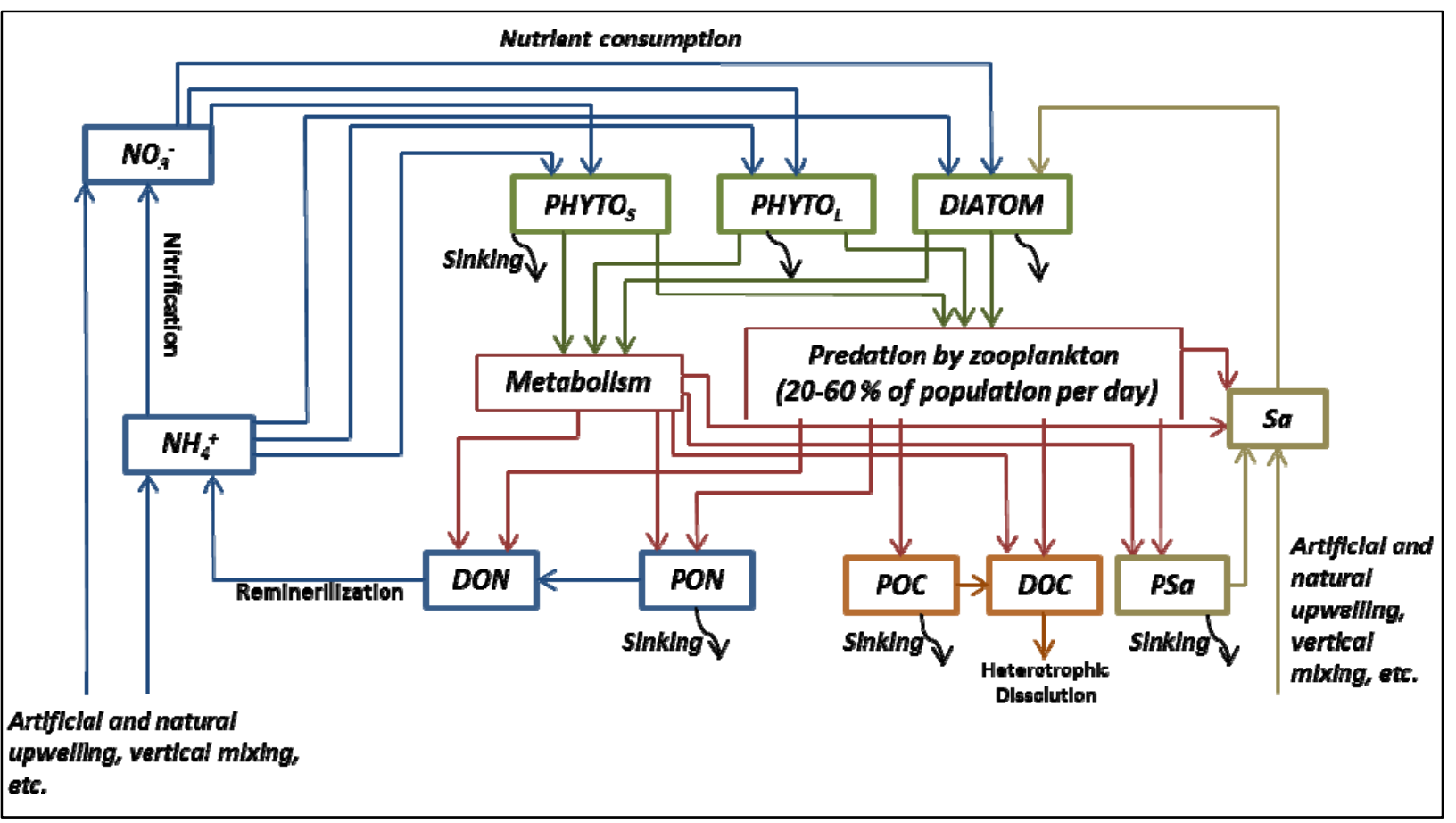

Figure 11. Logic flow diagram of the major biological components in the Makai OTEC Plume model. Blue lines denote nitrogen fluxes (nitrate, ammonium, dissolved and particulate organic nitrogen), red lines denote detrital fluxes as a results of mortality and metabolism, and green lines denote fluxes of phytoplankton biomass.

The biological source and sink terms are computed by equations 1 through 17 shown below:

Phytoplankton equations:

(1) $\quad \frac{d}{d t} C_{i}=\left(\mu_{i}-M_{i}-P_{i}\right)+\frac{d}{d z}\left(W S_{i} C_{i}\right) ; i=(\mathrm{S})$ small, (L) large, (D) diatom phytoplanktons

Growth Rate equations:

$$
\begin{aligned}
& \mu_{S, L}=\mu_{S m} e^{k_{T} T} f(I) f(N) \\
& \mu_{D}=\mu_{L m} e^{k_{T} T} f(I) f(N, S i)
\end{aligned}
$$

\section{Nutrient and Light Limitation equations:}

(4) $\quad f(\mathrm{~N})=\frac{\left[\mathrm{NH}_{4}\right]+\left[\mathrm{NO}_{3}\right]}{\mathrm{K}_{\mathrm{N}}+\left[\mathrm{NH}_{4}\right]+\left[\mathrm{NO}_{3}\right]}$

(5) $\quad f(N, S i)=\min \left(\frac{\left[\mathrm{NH}_{4}\right]+\left[\mathrm{NO}_{3}\right]}{\mathrm{K}_{N}+\left[\mathrm{NH}_{4}\right]+\left[\mathrm{NO}_{3}\right]}, \frac{\left[S i_{d}\right]}{K_{S}+\left[S i_{d}\right]}\right)$

(6) $\quad f(I)=\frac{I}{\sqrt{K_{I}^{2}+I^{2}}}$

Light Attenuation: 


$$
I(Z)=(\operatorname{par})\left(I_{0} e^{-k_{A} Z}\right) ; \operatorname{par}=0.43, \mathrm{k}_{\mathrm{A}}=0.038
$$

Nitrogen equations:

$$
\text { (8) } \frac{d}{d t} D_{P O N}=
$$

$\left[\left(\gamma_{S}\right) P_{S}+\left(\epsilon_{S}\right) M_{S}\right] C_{S} R_{N: C}+\left[\left(\gamma_{L}\right) P_{L}+\left(\epsilon_{L}\right) M_{L}\right] C_{L} R_{N: C}+\left[\left(\gamma_{D}\right) P_{D}+\left(\epsilon_{D}\right) M_{D}\right] C_{D} R_{N: C}-k_{P O N} D_{P O N}+$ $\frac{d}{d z}\left(W S_{P O N} * D_{P O N}\right)$

(9) $\quad \frac{d}{d t} D_{D O N}=\left[\left(1-\gamma_{S}\right) P_{S}+\left(1-\epsilon_{S}\right) M_{S}\right] C_{S} R_{N: C}+\left[\left(1-\gamma_{L}\right) P_{L}+\left(1-\epsilon_{L}\right) M_{L}\right] C_{L} R_{N: C}+$

$\left[\left(1-\gamma_{D}\right) P_{D}+\left(1-\epsilon_{D}\right) M_{D}\right] C_{D} R_{N: C}+k_{P O N} D_{P O N}-k_{D O N} D_{D O N}$

$$
\begin{aligned}
& \left.\frac{d}{d t} N O_{3}=-\left(1-\alpha_{S}\right) P_{S}\left(C_{S} R_{N: C}\right)-\left(1-\alpha_{L}\right) P_{L}\left(C_{L} R_{N: C}\right)\right)-\left(1-\alpha_{D}\right) P_{D}\left(C_{D} R_{N: C}\right)+k_{n i t} N H_{4} \\
& \frac{d}{d t} N H_{4}=-\left(\alpha_{S}\right) P_{S}\left(C_{S} R_{N: C}\right)-\left(\alpha_{L}\right) P_{L}\left(C_{L} R_{N: C}\right)-\left(\alpha_{D}\right) P_{D}\left(C_{D} R_{N: C}\right)+k_{D O N} D_{D O N}-k_{n i t} N H_{4} \\
& \alpha=N H_{4}\left(\frac{N O_{3}}{\left(K_{N}+N H_{4}\right)+\left(K_{N}+N O_{3}\right)}\right)+N H_{4}\left(\frac{K_{N}}{\left(N H_{4}+N O_{3}\right)+\left(K_{N}+N O_{3}\right)}\right)
\end{aligned}
$$

Carbon equations:

$$
\frac{d}{d t} D_{P O C}=\left[\left(\gamma_{S}\right) P_{S}\right] C_{S}+\left[\left(\gamma_{L}\right) P_{L}\right] C_{L}+\left[\left(\gamma_{D}\right) P_{D}\right] C_{D}-k_{P O C} D_{P O C}+\frac{d}{d z}\left(W S_{P O N} * D_{P O C}\right)
$$

$$
\frac{d}{d t} D_{D O C}=\left[\left(1-\gamma_{S}\right) P_{S}+\left(\delta_{S}\right) M_{S}\right] C_{S}+\left[\left(1-\gamma_{L}\right) P_{L}+\left(\delta_{L}\right) M_{L}\right] C_{L}+\left[\left(1-\gamma_{D}\right) P_{D}+\right.
$$

(SD)MDJCD+kPOCDPOC-KHRDDOC

$$
\delta=\zeta+(1-\zeta)\left(\frac{K_{R}}{K_{R}+D O}\right) \quad \text { Note: If } \zeta \text { and } K_{R}=0 \text { then there are no DOC sources from }
$$

metabolism. Otherwise, this formulation dictates how much respiration/metabolism creates $\mathrm{CO} 2$ vs. DOC depending on the dissolved oxygen content.

\section{Silica equations:}

$$
\begin{aligned}
& \frac{d}{d t} P S i=\left[\left(\gamma_{D}\right) P_{D}+\left(\epsilon_{D}\right) M_{D}\right] C_{D} R_{S i: C}-k_{S U A} P S i \\
& \frac{d}{d t} S i=\left[\left(1-\gamma_{D}\right) P_{D}+\left(1-\epsilon_{D}\right) M_{D}\right] C_{D} R_{S i: C}+k_{S U A} P S i
\end{aligned}
$$

Changes in the phytoplankton biomass (measured in C, for carbon) is controlled by the source and sink terms including growth $(\mu)$, natural mortality $(\mathrm{M})$, predation $(\mathrm{P})$, and vertical settling (WS).

The instantaneous growth rates are limited by the availability of photosynthetically available light (I $\mathrm{PAR})$, nutrients $\left(\mathrm{NO}_{3}{ }^{-}, \mathrm{NH}_{4}{ }^{+}, \mathrm{Si}\right)$, and temperature $(\mathrm{T})$. The growth limitation due to light is modeled with a modified Monod equation (eqn. 6) with a half-saturation constant, $\mathrm{K}_{\mathrm{I}}$, that provides functionally similar light dependencies as Wang et al (2008). Figure 12 shows a comparison of the light limitation formulations of Wang et al (2008) and those used in this model. The photosynthetically available light is assumed to be attenuated by seawater with a constant 
attenuation coefficient, $\mathrm{k}_{\mathrm{A}}$, with the assumption that chlorophyll levels contribute no significant additional attenuation. This simplification of the light attenuation was selected based on the availability of observational data (Letelier et al. 2004). An alternative formulation is to include terms for the light attenuation as a function of the chlorophyll and particulate matter concentrations throughout the water column (Wang et al. 2008; Lima and Doney. 2004). However, those methods require an accurate formulation for the variable chlorophyll to carbon ratio of phytoplankton groups and are more likely to be important in areas where there are dense surface blooms over large spatial regions, such as the upwelling regions of the Equatorial Pacific or California Coasts. Due to the relatively low level of biomass in the Hawaiian oligotrophic region and well measured light attenuation parameters, these increasingly complex formulations would likely only add to our modeling uncertainty. In addition, this simpler light attenuation coefficient will provide regulators with a conservative over-estimation of light availability under a bloom if it were to occur (i.e. phytoplankton growth), since the model would allow more light to pass through.

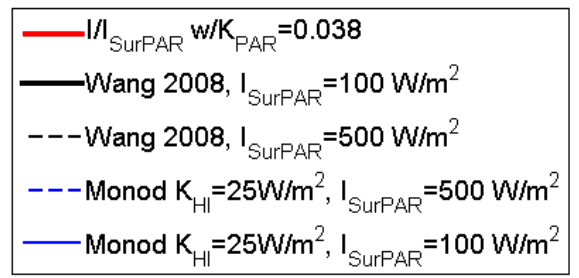

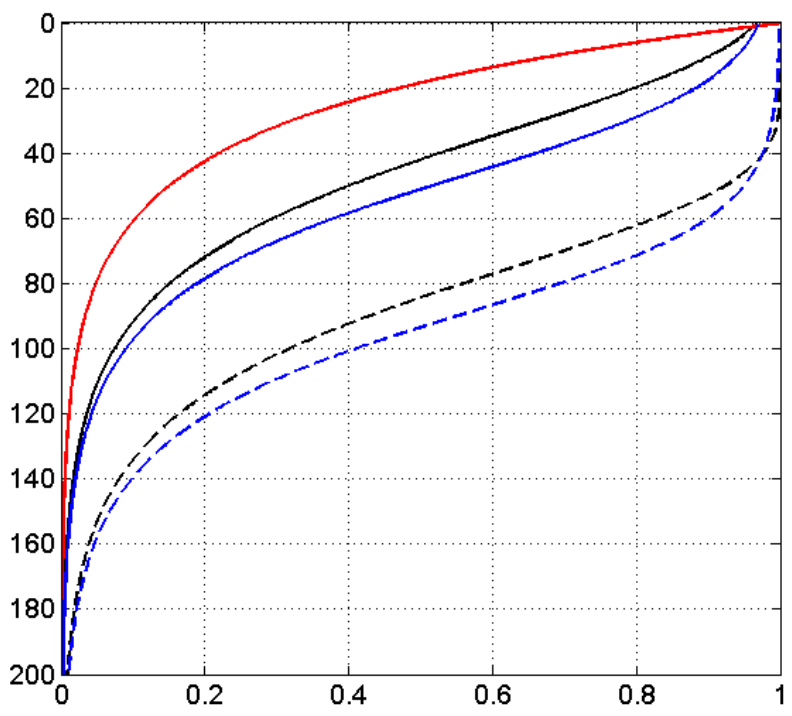

Figure 12. Comparison of light limitation formulae used by this model (Monod) with Wang's model. The ordinate is photosynthetically available light, and the abscissa is depth in meters.

Nutrient limitations are modeled with a Michaelis-Menten equation, using combined nitrate and ammonium concentrations. Half-saturation constants for the nutrients were defined using the range of observed values in previous studies (Wang et al. 2008; Eppley et al. 1969; Falkowski 1975; Lichtman et al. 2007; Harrison et al. 1996) and calibrated to reproduce the observations of local populations reasonably well. The nitrogen Michaelis-Menten kinetics includes both nitrate and ammonium nitrogen, but in oligotrophic open ocean systems the ammonium nitrogen is orders of magnitude lower in concentration. Preference for assimilation of ammonium versus nitrate is 
modeled with parameter, $\alpha$, defined in equation 12 above. This term appears in the source and sink terms for the nitrate and ammonium concentrations (eqns 10,11).

Several additional biological components are included in the model, in order to track the changes in water quality and to include accurate regeneration of ammonium and nitrate from detrital and dissolved organic nitrogen fluxes. As seen in the flow diagram in Figure 11, zooplankton predation and phytoplankton metabolism produce detrital and dissolved organic matter: DON, PON, DOC, and POC. The large refractory organic matter sinks relatively rapidly, while the dissolved labile matter sinks much slower. The DON's increased residence time in the water column, and it's labile properties, enables it to be remineralized into biologically available ammonium. This DON to ammonium remineralization is modeled implicitly using a constant remineralization rate. Similarly to Calil (2008) and Wang et al. (2008), we have assumed the subsequent nitrification of ammonium to nitrate occurs at a rate of $0.04 \mathrm{~d}^{-1}$, when below a dim light threshold. Sensitivity studies indicated that standing stocks of phytoplankton were mildly sensitive to the kinetics used to define this nitrogen cycle. For example, use of rapid sinking rates and low remineralization rates resulted in a deficit of available nutrients in the upper mixed layer, and an unrealistically low abundance of ambient phytoplankton biomass. The parameters currently used in this study have been selected from within the range of values found in literature, and are shown to reasonably reproduce the natural biomass and nutrient levels. The parameters of Revision $X$ represent the "typical" growth parameters discussed in Subtask 4.1, while Revision Za represents the "worst case".

\subsection{BIOLOGICAL BOUNDARY CONDITIONS AND INITIALIZATION}

The concentration of the biological state variables and components were initialized and forced using depth varying, but horizontally and temporally uniform, climatological mean values from the HOTS database. The HOTS dataset contains monthly samples taken at a fixed location off Kahe Point O'ahu and in the NPSG at Station ALOHA since 1988. The HOTS data includes in-situ and bottle measurements of nitrate, dissolved oxygen, silicate, particulate (organic) carbon, particulate (organic) nitrogen, dissolved organic carbon, and dissolved organic nitrogen. However, some of the critical biological modeling components are not as well defined in the HOTS program. The modeled ammonium concentrations were assumed to be a small fraction of the nitrate concentrations (Karl et al. 2008; Wang et al. 2008). Phytoplankton concentrations were computed using cell count samples taken with flow cytometry at Station ALOHA, converted to $\mathrm{mg} / \mathrm{ml}$ of carbon using conversions of $61 \mathrm{fgC} /$ cell for prochlorococcus, $92 \mathrm{fgC} /$ cell for synecoccocus (Bertilsson et al. 2003), and $488 \mathrm{fgC} /$ cell for eukaryotic phytoplankton greater than $2 \mathrm{um}$ in size (Worden et al. 2003). Cell counts for "other" phytoplankton from 2-10um were obtained from Eppley et al. 1970). Independent estimates for eukaryotic and prokaryotic phytoplankton were obtained from recent observations from incubation experiments within and around a mesoscale eddy event in Hawai i (Brown et al. 2008; Landry et al. 2008). These were in good agreement with the HOTS and Eppley datasets, but also provided an estimate of the local diatom populations.

\subsection{HARDWARE REQUIREMENTS}

As implemented, the model runs on a modern Quad Core Personal Computer having eight gigabytes of RAM and running a 64-bit LINUX operating system. This system was furnished 
by Lockheed Martin. We began the project using the Windows operating system on the same hardware, but the two gigabyte memory limitation of Windows forced us to shift operating systems to access more memory to simulate an adequately large computational domain. The domain used encompasses all of Oahu, while retaining grid cell resolution of approximately 1 square kilometer x 20 meter depth. Using this system, a 40-day simulation using three-hour time steps required approximately five days for processing.

\subsection{MODEL ALGORITHM OVERVIEW}

\subsection{1. $\quad$ Model Peer Review}

The U.S. EPA's website http://www.epa.gov/athens/wwqtsc/html/efdc.html states that: "The Environmental Fluid Dynamics Code (EFDC Hydro) is a state-of-the-art hydrodynamic model that can be used to simulate aquatic systems in one, two, and three dimensions. It has evolved over the past two decades to become one of the most widely used and technically defensible hydrodynamic models in the world. EFDC uses stretched or sigma vertical coordinates and Cartesian or curvilinear, orthogonal horizontal coordinates to represent the physical characteristics of a water body. It solves three-dimensional, vertically hydrostatic, free surface, turbulent averaged equations of motion for a variable-density fluid. Dynamically-coupled transport equations for turbulent kinetic energy, turbulent length scale, salinity and temperature are also solved. The EFDC model allows for drying and wetting in shallow areas by a mass conservation scheme. The physics of the EFDC model and many aspects of the computational scheme are equivalent to the widely used Blumberg-Mellor model and U. S. Army Corps of Engineers' Chesapeake Bay model."

As Makai implemented Hawaii-specific aspects of the local ocean circulation and phytoplankton modeling, we regularly obtained comments and peer reviews with our consultants, who are the relevant experts in their fields. Dr. Brian Powell is the Program Director for the NOAA-funded Hawaii Regional Ocean Model project. Dr. Matt Church is one of the leading microbiologists for biochemical oceanography at the University of Hawaii. Dr. John Hamrick is the author of EFDC and has performed numerous EFDC models of circulation and biochemical modeling. We also coordinated our efforts with the NOAA office of Ocean and Coastal Resource Management, which is developing revised OTEC regulations. During those meetings, other NOAA specialists attended in person or via teleconference.

As implemented, the model runs on a modern quad-core Personal Computer having eight gigabytes of RAM and running a 64-bit LINUX operating system. This hardware system was furnished by Lockheed Martin. When starting the project, we used the same hardware but were using the Windows operating system. However, the two gigabyte memory limitation of Windows forced us to shift operating systems to access more memory. This was because we desired to simulate a large computational domain encompassing all of Oahu, while retaining grid cell resolution of approximately 1 square kilometer x 20 meter depth. Using this system, a 40 day simulation using three-hour time steps required approximately five days for processing. 


\subsection{2. $\quad$ Model Strengths and Weaknesses}

Strengths and weaknesses of the model include:

- Strength. Incoming dynamic boundary conditions were based upon Dr. Powell's dataassimilative model.

- Strength. These boundary conditions were passed into the computational domain through a "sponge" layer. This technique resulted in a stable, non-reflective means of inputting the complex dynamic boundary conditions.

- Strength. The availability of the Hawaiian Ocean Time Series monthly oceanographic observations encompassing twenty-three years of physical, chemical and biological data enabled us to match the biological model to existing conditions

- Weakness. Since EFDC is an older, well-established model, it uses static memory allocation. As a result, it runs more slowly than a corresponding model capable of using dynamic memory allocation. 


\section{MOdel EVALUATiON}

\subsection{OCEAN CIRCULATION}

To examine the ability of the nested plume model to reproduce the dynamics of the HIROM model, we have performed extensive model-model comparisons. The model domains were analyzed for sea surface elevations, current dynamics throughout the water column, and density fluctuations. The comparison indicates that there is a very good agreement between the external HIROM forcing and the plume model solution. Figure 14 through Figure 16 show the standard deviation of the intertidal currents from the HIROM and EFDC simulations at water depths of 100 and $160 \mathrm{~m}$. It shows that the plume model reproduces the strengths and spatial locations of the tidal and intertidal currents around O'ahu very well. A time series comparison at Kaena Point and Mokapu 'u (Figure 17-Figure 25) also indicates that the circulation is accurately reproduced at these locations. The sea surface height is in excellent agreement between the HIROM and plume model, indicating that the barotropic tides are being accurately prescribed at the open boundaries.

In general, the southwest corner of O' ahu is known to be a tidal convergence zone (Bathen, 1978). As seen in Figure 14 and Figure 15, the tidal currents southwest of $\mathrm{O}^{\prime}$ ahu are modeled to be weaker than off Kaena Point and Mokapu 'u. This feature is resolved in both the nested plume model and parent HIROM model. These tidal flow features are tightly coupled to the local bathymetry, and are complex with weakly divergent and convergent fronts developing intermittently. Models will inherently differ in the prediction of exact location and spatial pattern of this feature if their bathymetries and resolution differ. Although Makai's EFDC model used higher resolution than the HIROM mode, the two models both exhibit similar resolution for these tidal features.

To further validate the plume model, the current dynamics were compared with actual ADCP current and CTD measurements. An oceanographic mooring funded by Naval Facilities Engineering Command (NAVFAC) and Makai was installed in 1600 meters of water off Southwest O'ahu, shown in Figure 13, from May to December of 2010. The simulations were run for forty days, from May $18^{\text {th }}$ to June $29^{\text {th }}, 2010$, and had continuous overlap with a subset of the nearby ADCP mooring data.

Figure 14 through Figure 22 shows that the flows at Mokapu 'u and Kaena are quite coherent, due to the bulk of Oahu and the restricted flow area near both of these points. In contrast, the NAVFAC mooring was located in deeper water where tidal currents from around $\mathrm{O}$ 'ahu converge, causing overall weaker tidal flows with more subtle variability. The complexity of the flows in this region precluded a simple comparison of time series between the HIROM model and the measured data.

A spectral comparison between the ADCP measurements and the modeled circulation of the same 40 day data set shows that the model is reproducing the tidal and low frequency processes at the NAVFAC location. Figure 23 through Figure 26 shows the time series and spectra of the eastward and northward current from the NAVFAC location for the model and the data. The model shows good agreement, with similar spectral energy at the M2 semidiurnal and O1 and K1 diurnal tidal frequencies. The plume model has a lesser spectral peak at the semidiurnal tide for eastward flows, but a slightly larger spectral peak for northward flows. (Note: the area under the spectral peaks indicate the magnitude of current fluctuations, not the height of the peaks). The HIROM and plume model also shows some significant lower frequency energy, not seen in the ADCP record, near 0.6 
cycles per day. This lower frequency signal originates in the HIROM forcing conditions, and can be seen in the time series records from June 1 to June 11,2010 as well as the spectra. The nested plume model does reproduce the general low frequency features, albeit at lower strengths. The EFDC model output is in adequate agreement with the in-situ ADCP measurements.
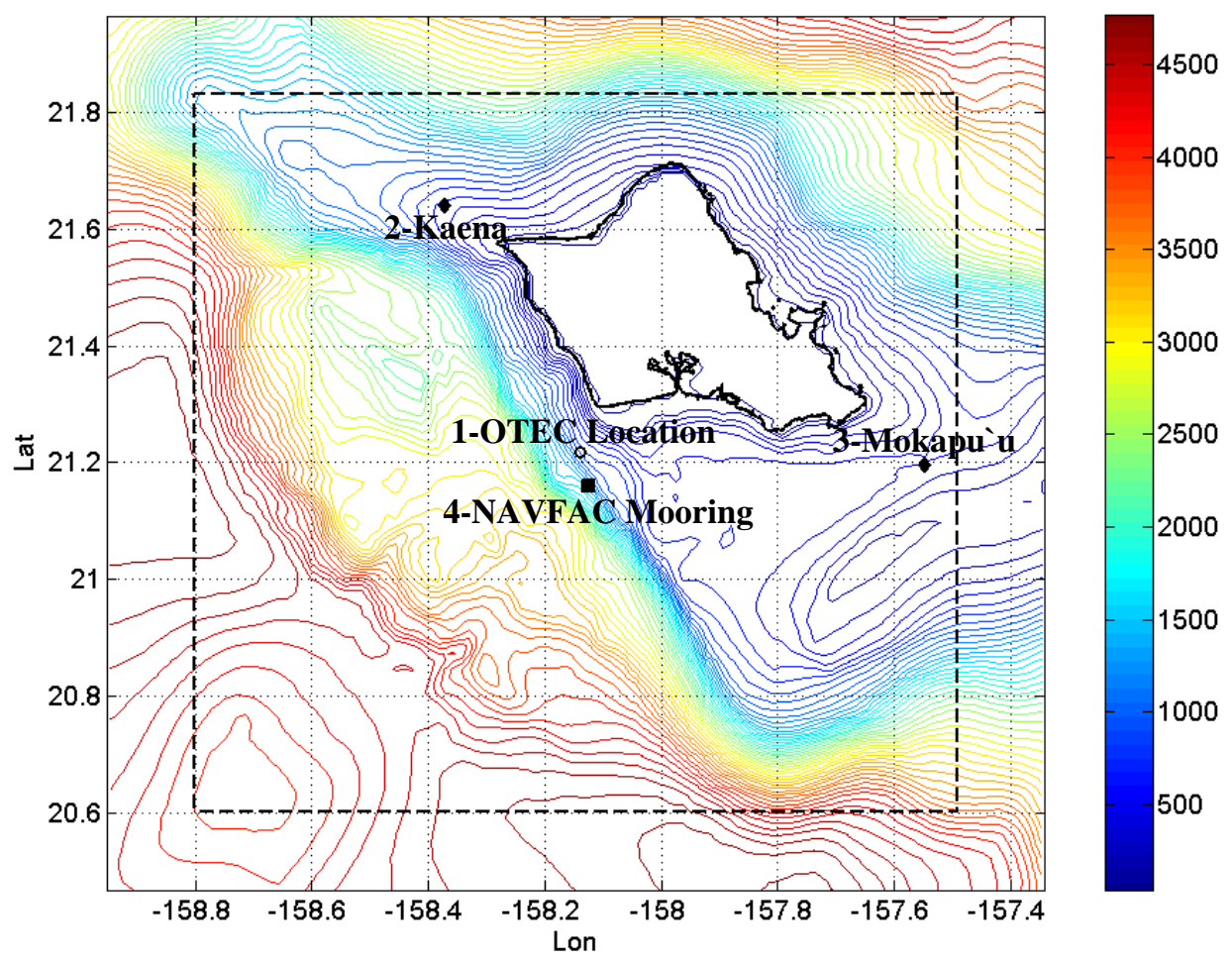

Figure 13. Model domain of the Makai OTEC Biological Plume model. The domain's "sponge layers" (described in Section 2.1) lie between the dashed line and the outer boundary. Black diamonds and squares show where time series comparisons are provided between HIROM and the Makai model. The NAVFAC mooring was at the black square. Simulated OTEC discharges occur at the labeled circle. Bathymetric contour spacing is $100 \mathrm{~m}$. 

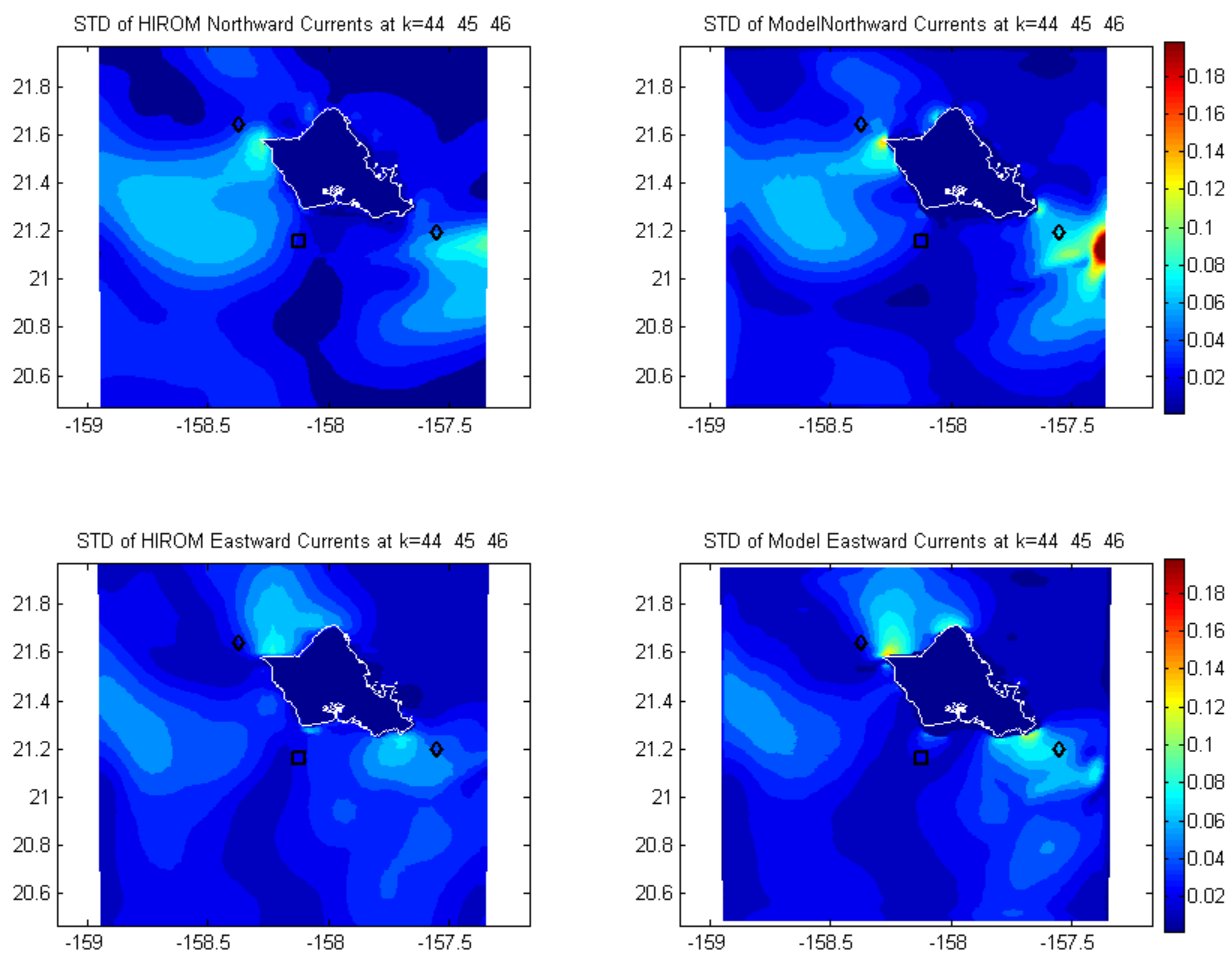

Figure 14. The standard deviation (in meters per second) of northward (top row) and eastward (bottom row) currents from the HIROM (left column) and plume model (right column) within the M2 semidiurnal tidal band ( 2 cycles per day). Standard deviations were computed from the flow averaged in the depth bins from 80 to $140 \mathrm{~m}$. 

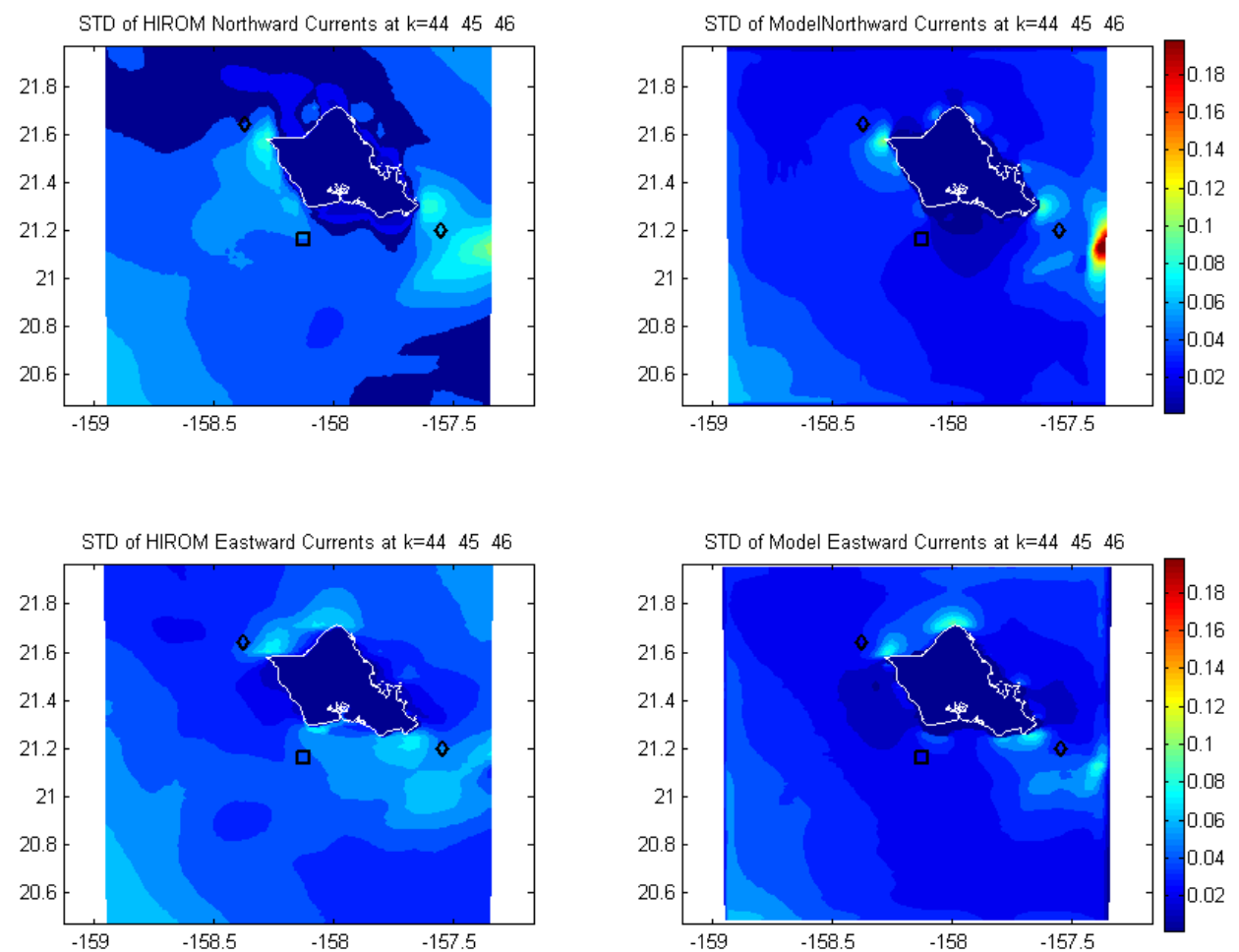

Figure 15. The standard deviation (in meters per second) of northward (top row) and eastward (bottom row) currents from the HIROM (left column) and plume model (right column) within the O1 and K1 diurnal tidal band ( 1 cycle per day). Standard deviations were computed from the flow averaged in the depth bins from 80 to $140 \mathrm{~m}$. 

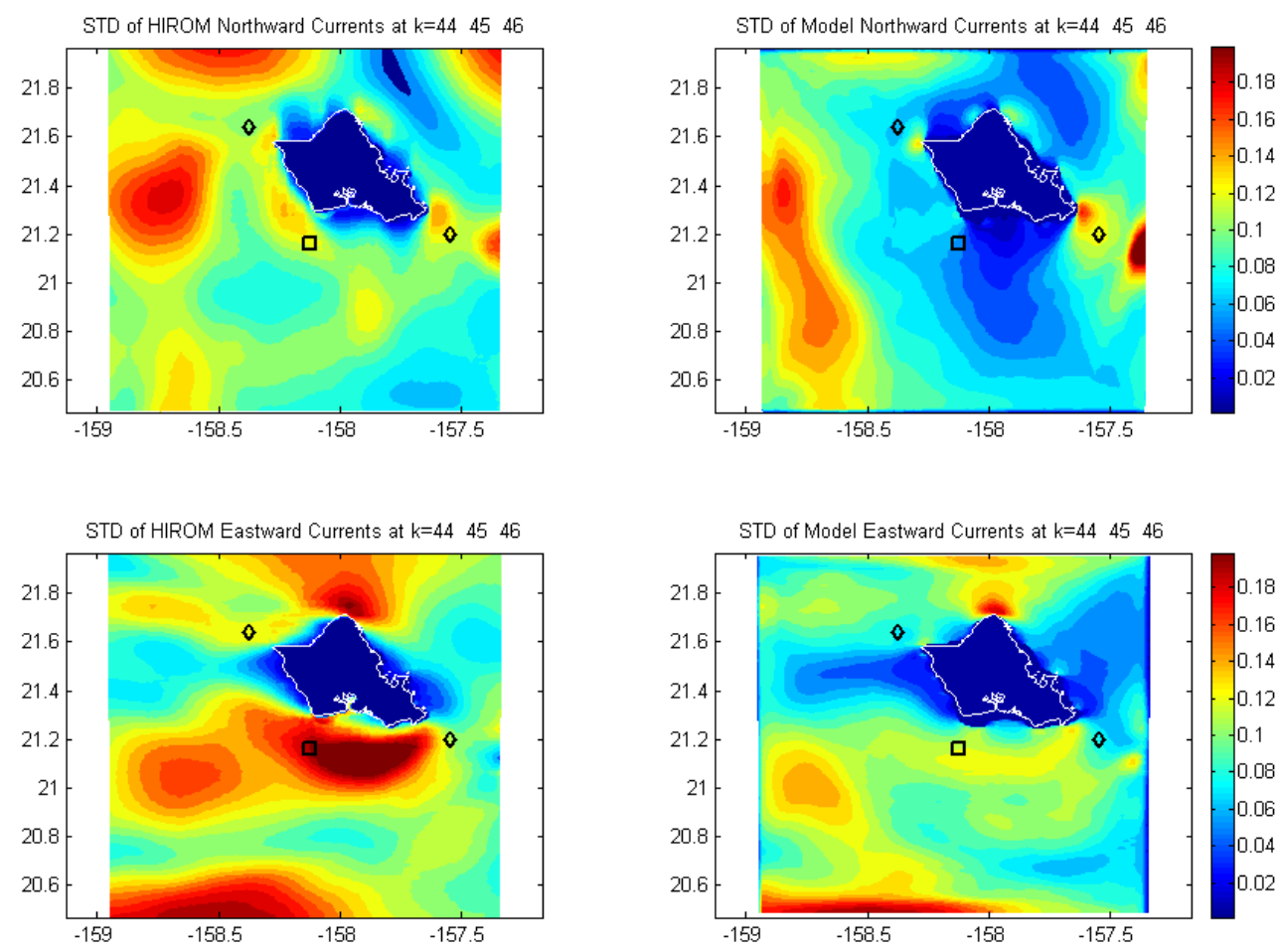

Figure 16. The standard deviation (in meters per second) of northward (top row) and eastward (bottom row) currents from the HIROM (left column) and plume model (right column) within low frequency band ( $\sim 0.7$ cycles per day). Standard deviations were computed from the flow averaged in the depth bins from 80 to $140 \mathrm{~m}$.
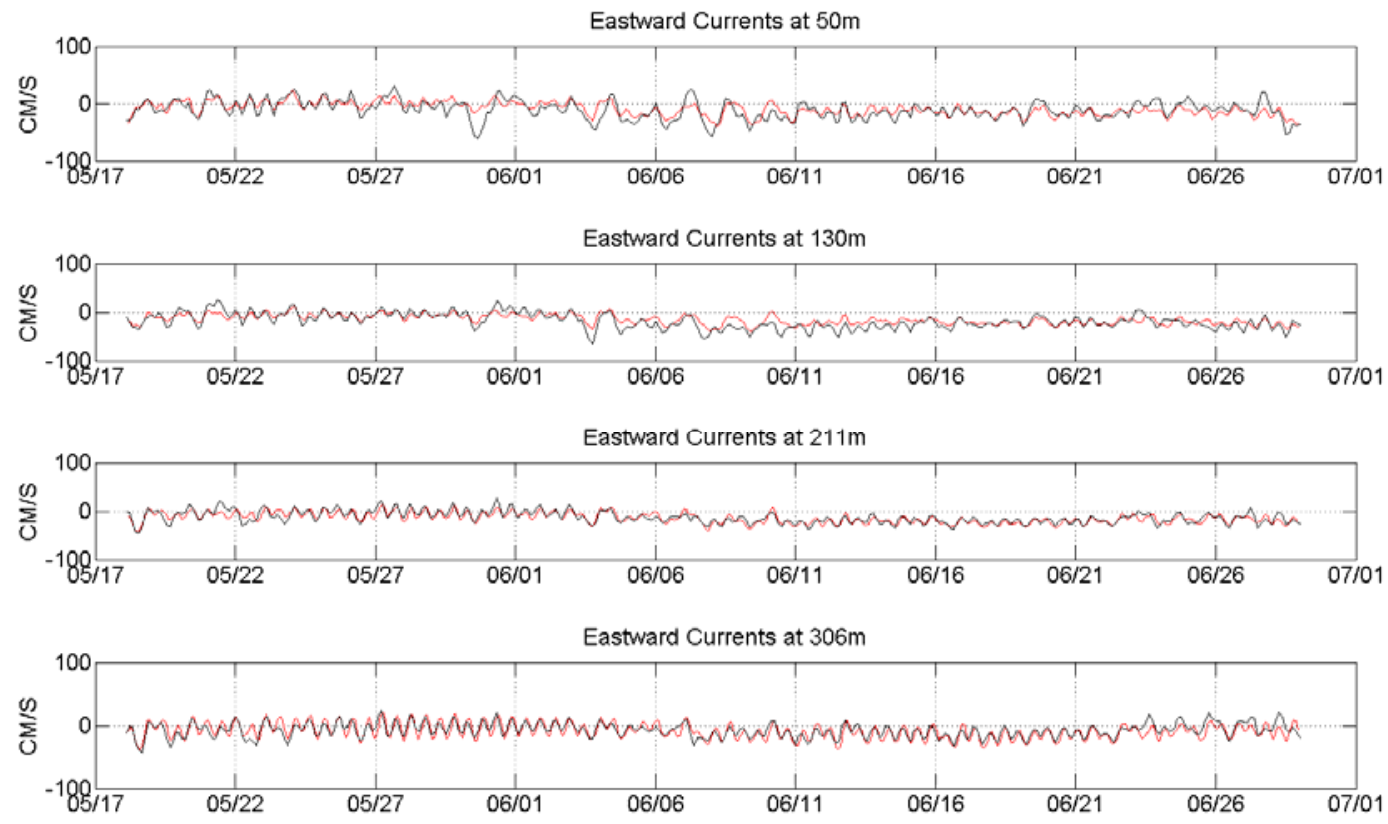

Figure 17. Eastward currents at Kaena Point. Red is the EFDC nested solution, black is the HIROM parent grid. 

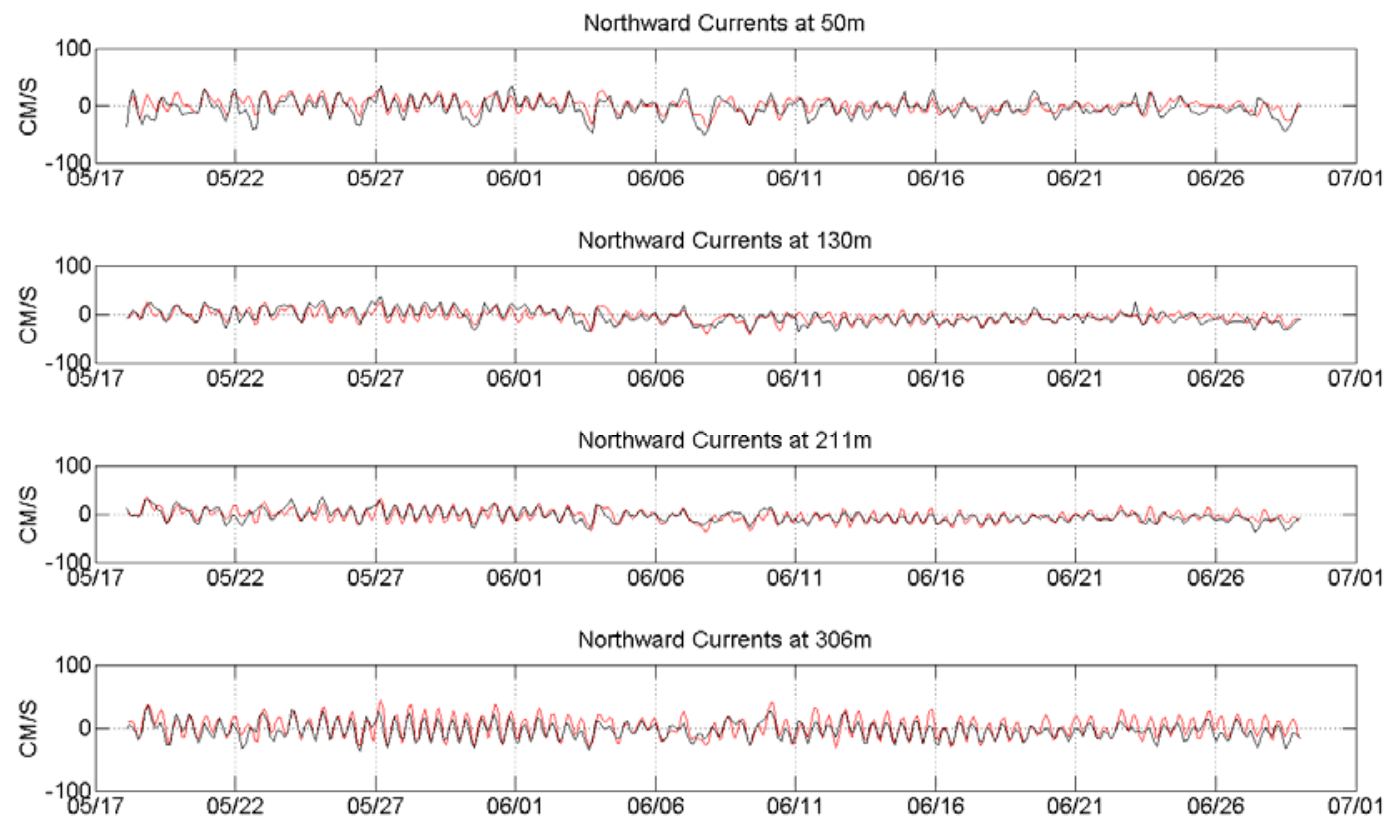

Figure 18. Northward currents at Kaena Point. Red is the EFDC nested solution, black is the HIROM parent grid.

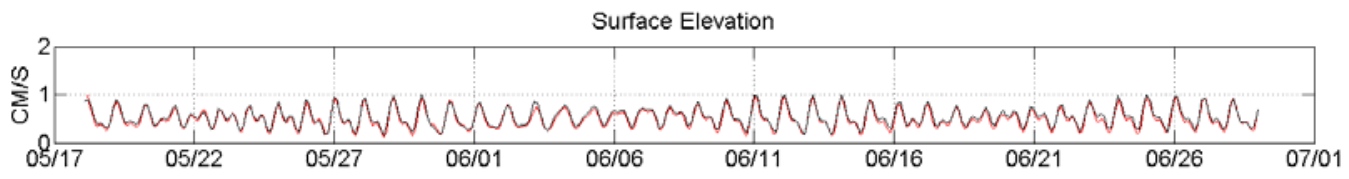

Figure 19. Sea surface elevations at Kaena Point. Red is the EFDC nested solution, black is the HIROM parent grid.
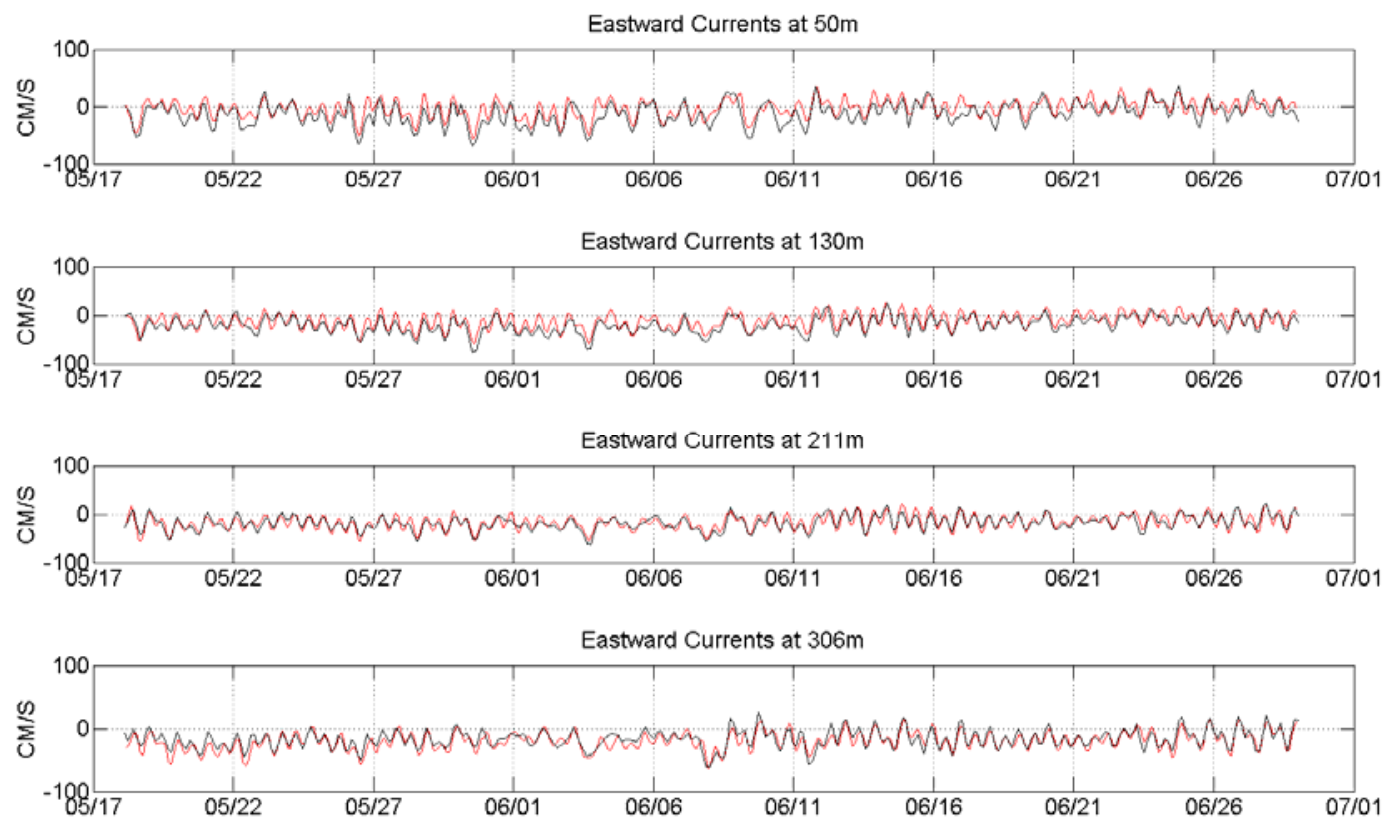

Figure 20. Eastward currents at Mokapu u. Red is the EFDC nested solution, black is the HIROM parent grid. 

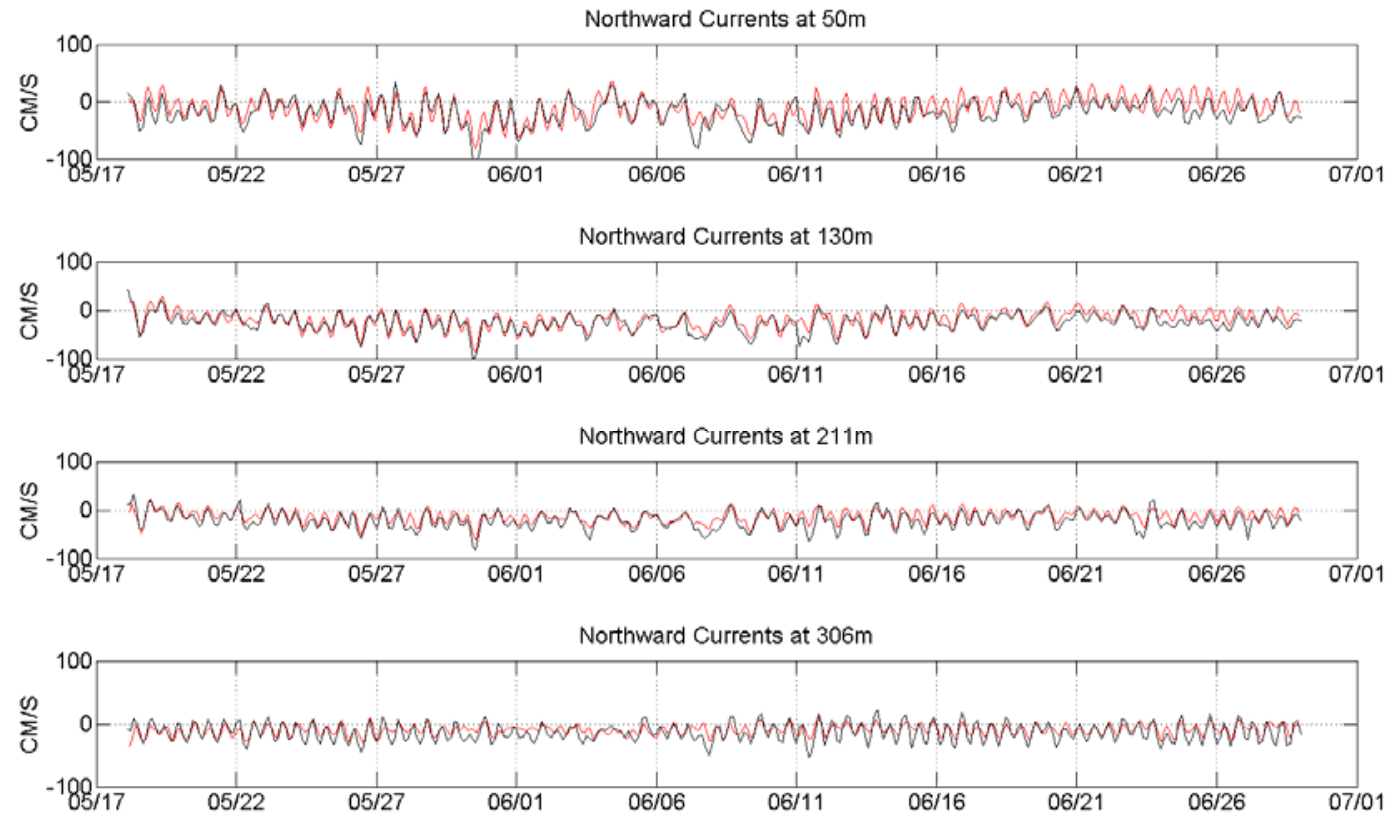

Figure 21. Northward currents at Mokapu 'u. Red is the EFDC nested solution, black is the HIROM parent grid.

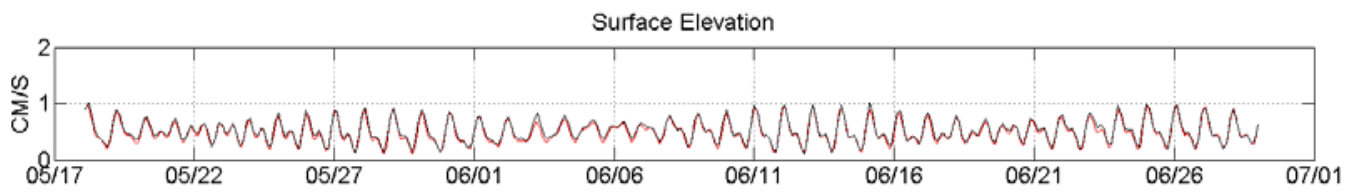

Figure 22. Sea surface elevations at Mokapu 'u. Red is the EFDC nested solution, black is the HIROM parent grid.
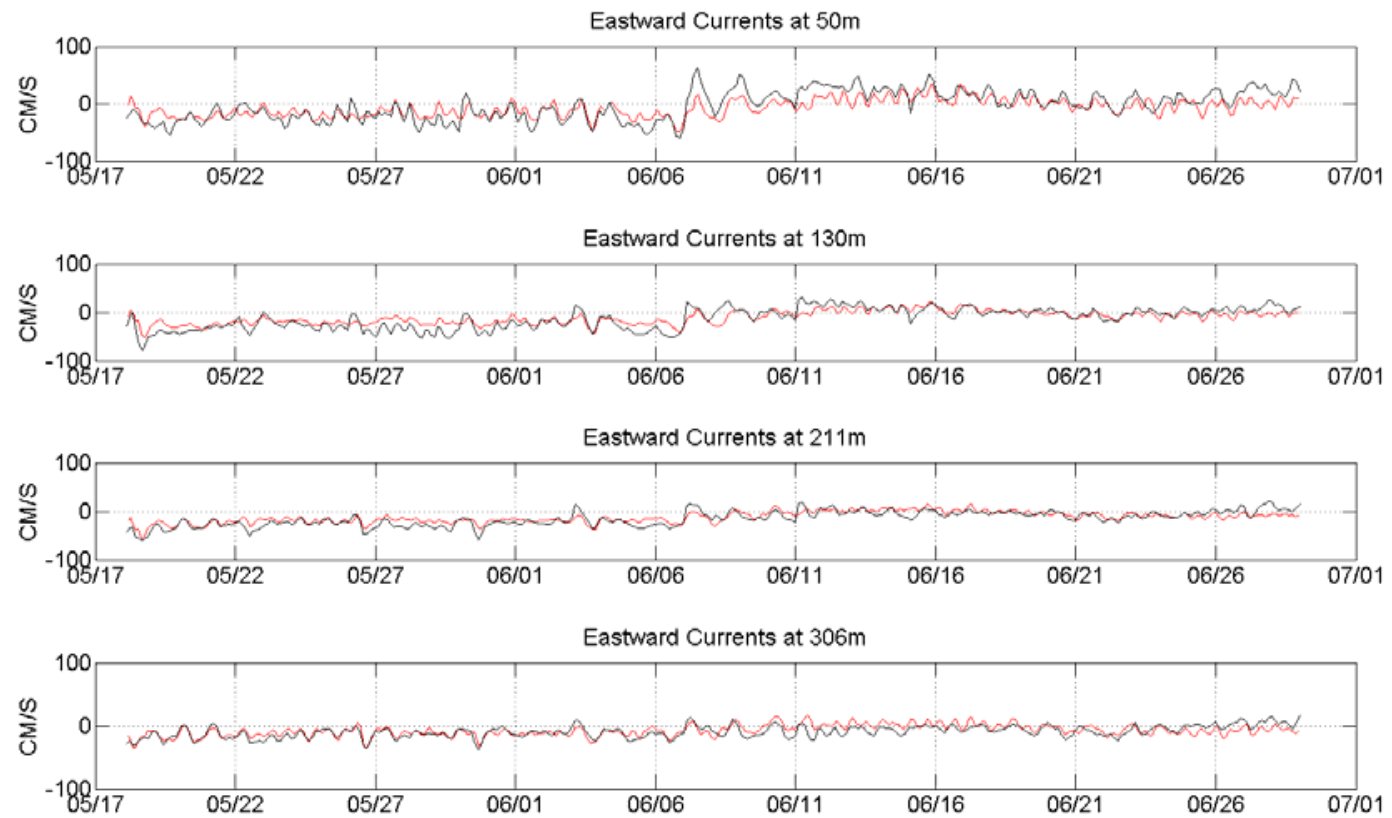

Figure 23. Eastward currents at NAVAFC mooring off Southwest O'ahu. Red is the EFDC nested solution, black is the HIROM parent grid. 

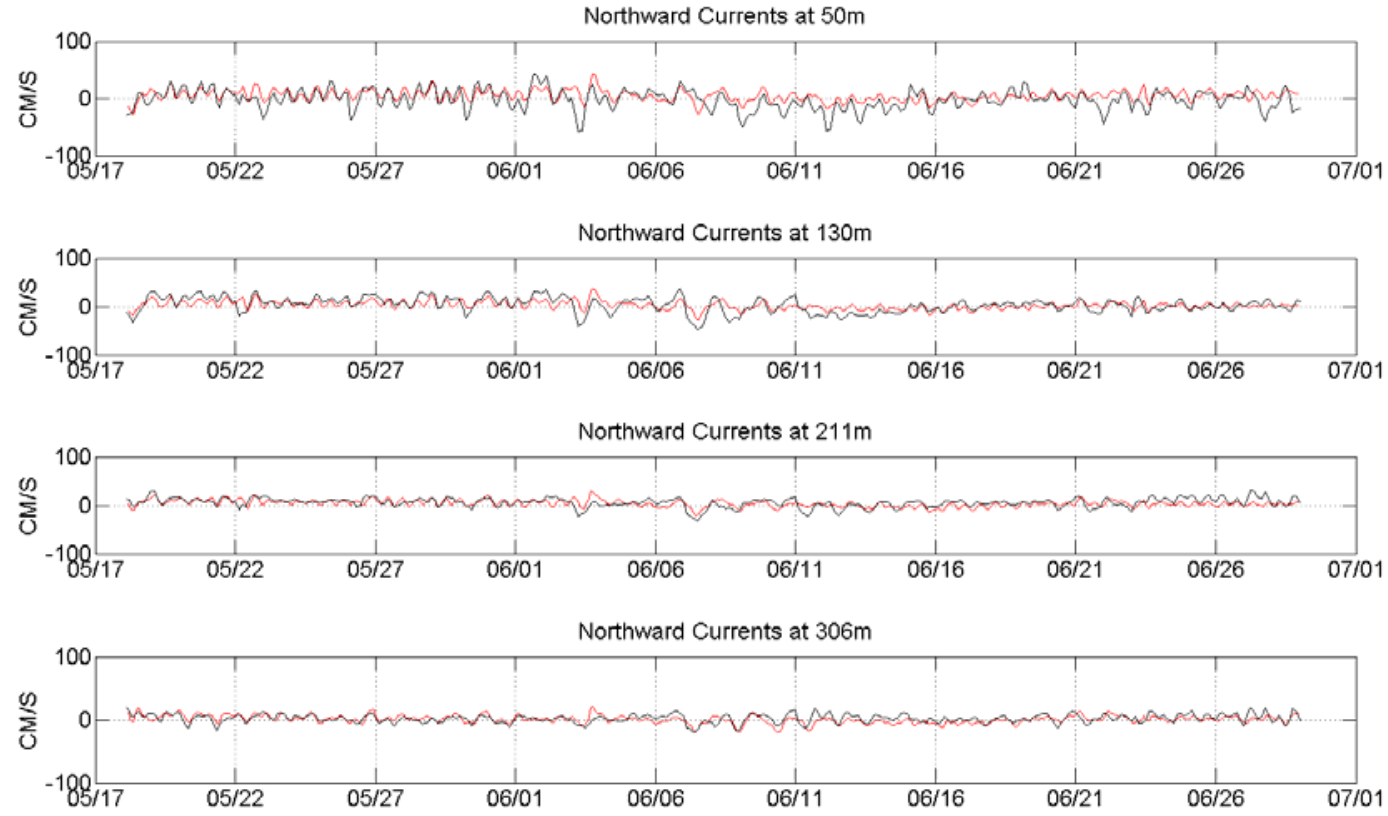

Figure 24. Northward currents at NAVFAC mooring off southwest O`ahu. Red is the EFDC nested solution, black is the HIROM parent grid.

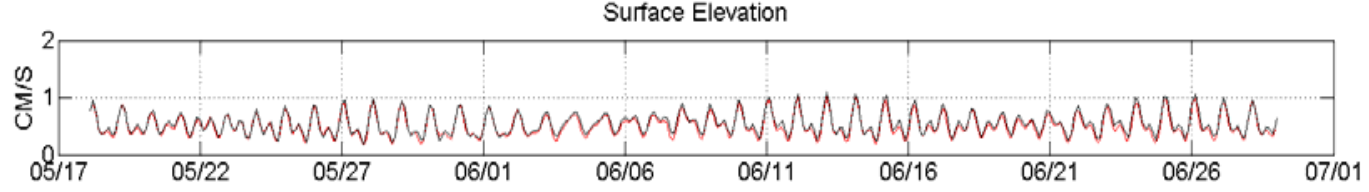

Figure 25. Sea surface elevations at NAVFAC mooring off Southwest O`ahu. Red is the EFDC nested solution, black is the HIROM parent grid.
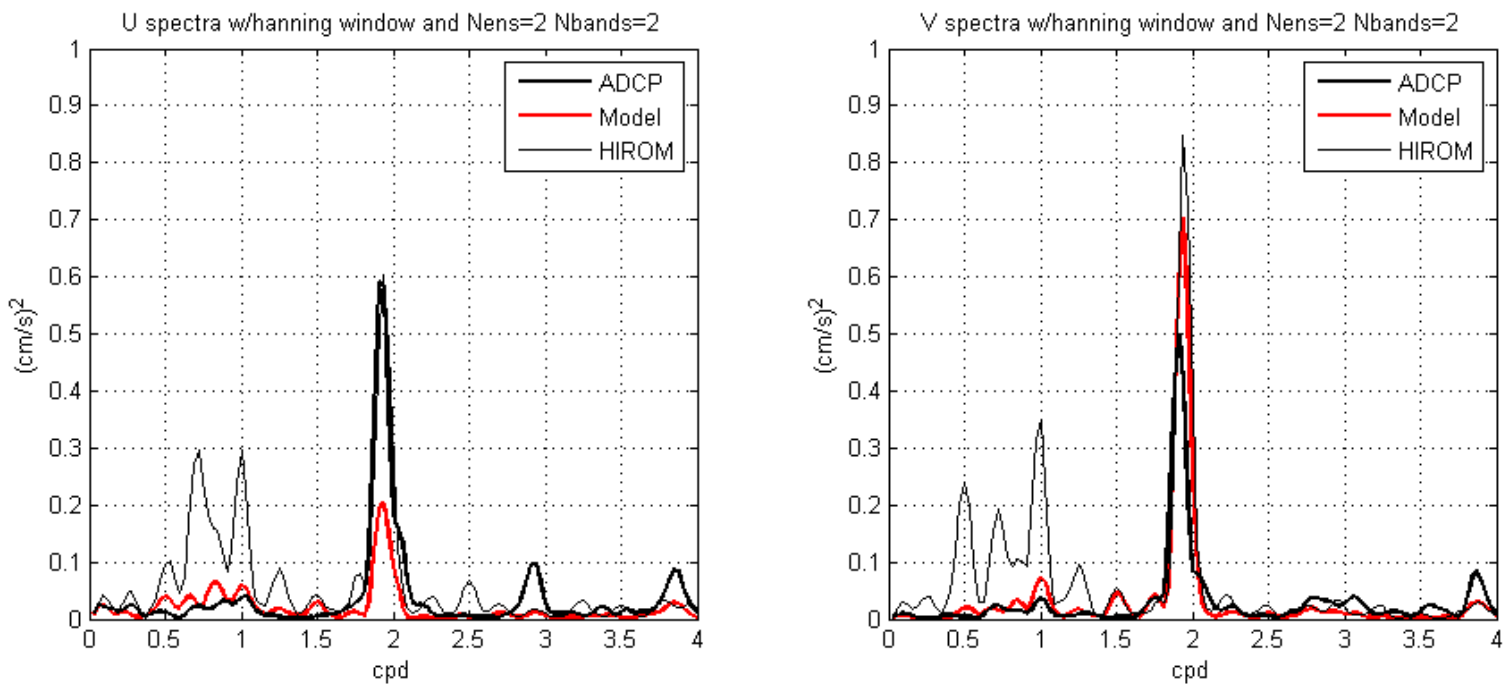

Figure 26. Variance preserving spectra of the eastward (left) and northward (right) currents from the ADCP (black lines) and plume model (red lines) averaged over the depth range of 100-160m at the NAVFAC mooring. ADCP data was bandpass filtered to remove high frequency current $(>4.5 \mathrm{cpd})$ fluctuations, and subsampled at the same output interval and period as the model data to preserve any aliasing between datasets. 


\subsection{BIOLOGICAL PROPERTIES}

The biological parameters were calibrated to reproduce the measured phytoplankton, nutrient, and organic matter concentrations, while keeping all parameters within the measured and acceptable ranges. To enable calibration of the biological parameters and independence from the prescribed boundary conditions, the model domain was enarged so that residence times could be significantly longer than the time scales of phytoplankton growth. The preliminary calibration process was necessarily fluid, with many of the changes in parameter values made in conjunction with the modifications described in Section 2. A "baseline" set of biological parameters were chosen after several preliminary simulations and adjustments (preliminary results not shown), named "Revision X". The naming convention was started with Revision A and proceeded through Revision $\mathrm{W}$ until all modifications and calibrations were deemed complete and satisfactory. Table 1 shows the list of parameters for RevX that were used in equations 1-17 (Section 2), which reasonably reproduce the naturally occurring biomass and water quality measurements. An additional set of conditions are discussed in this report, Revision ZA, which has lower predation rates and higher remineralization rates to promote greater phytoplankton growth and provide a sensitivity analysis on the growth kinetics. This paper focuses on these two sets of parameters, revX and revZA, to model the three phytoplankton classes (shown below in Figure 27).

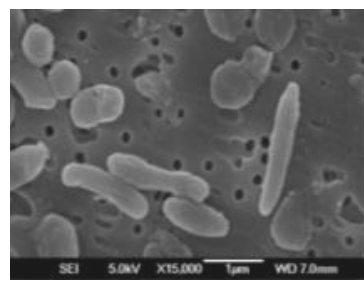

Prochlorococcus

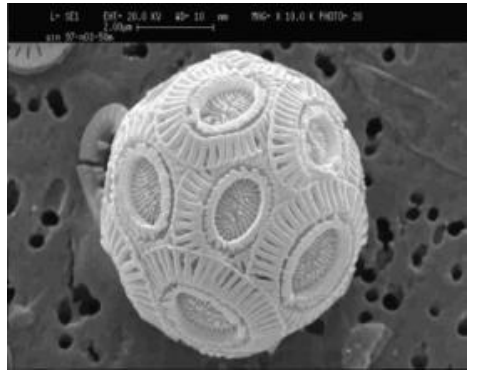

Emiliania

Images: http://cmore.soest.hawaii.edu/microscopy

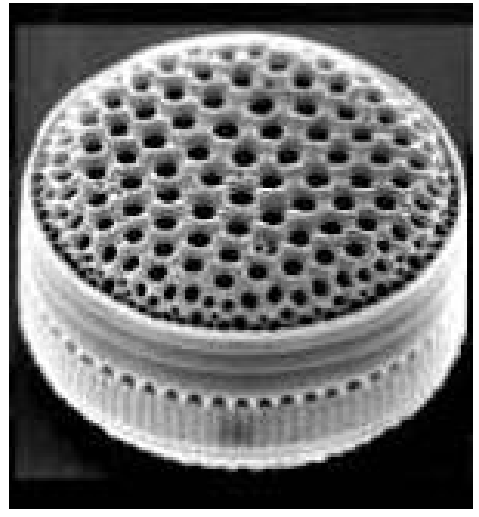

Diatoms

Figure 27. Examples of phytoplankton modeled for each size class. ( $<2 \mathrm{um}, 2-10 \mathrm{um}$, and $>20 \mathrm{um})$ 


\subsection{BIOLOGICAL SIMULATION WITH NO OTEC}

The model was run numerous times with no OTEC plant discharges in order to calibrate the biological parameters and obtain a satisfactory agreement between the modeled biological carbon and nutrient concentrations and the values reported in the HOTS and literature data.

Figure 28 illustrates the first modeled timestep, which shows the picophytoplankton concentrations used to initialize the model as discussed above in Section 2.4. The figure shows eight horizontal "slices" from 190 meters to 500 meters deep, with carbon concentration indicated by the color legend from 0-25 milligrams carbon per cubic meter. Figure 29 shows the model already becoming more variable after eight simulation steps ( 21 hours), and by the end of one week, Figure 30, the system exhibits the temporal and spatial variability observed during the remaining 33 simulation days. Typically, the highest levels of carbon and of variability are observed in the 90 and $70 \mathrm{~m}$ deep layers, near the base of the photic zone where there is a supply of nutrients from depth and light from above. Above this depth a lack of nutrients limits growth, while below it is the low light levels that limit growth. The deeper layers support less phytoplankton, and less obvious variability, since there is insufficeint light. Similarly, the shallow regions near Oahu often have increased carbon levels, due to the combination of nutrient supply from increased vertical mixing and high light conditions

An example of temporal variability is shown by comparing the southwestern corner of 10 June vs. 17 June at 90 meters depth in Figure 32 and Figure 33. Here, the picophytoplankton carbon concentration doubles during a period of one week, from $\sim 10$ to 20 milligrams carbon per cubic meter,. An example of the spatial variation can be observed at 70 meters depth on Figure 33 , where the carbon concentration varies from 5 to 22 milligrams carbon per cubic meter over a distance of less than fifty kilometers. This mesoscale patchiness is caused by the inherent response time of phytoplankton to the physical availability of nutrients (Mahadevan and Campbell et al. 2001; Abraham, 1998). Figure XX shows in-site chlorophyll measurements from a glider deployed off Southwest O'ahu in early April of 2009. The chlorophyll time series reveals similar variability, on the order of days, and several tens of kilometers (hahana.soest.hawaii.edu). The biological model appears to be simulating the inherent patchy characteristic of phytoplankton reasonably well.

In general, the picophytoplankton distribution can be typified as shown in Figure 32.

Due to the consistent vertical mixing along the shallow and steep coast of Oahu, there is also a consistent supply of nutrients relative to the open ocean waters. As a result, the diatom populations showed a general trend of increasing concentrations nearshore, as shown in the sections below. This nearshore trend can impact the diatom response of the OTEC plumes acting as a "seed" population, in contrast to the very low concentrations of diatoms that are typically measured in open ocean systems. (Note: This model is of the oligotrophic open ocean. It did not attempt to simulate the hundred-fold higher levels of carbon and nutrients within nearshore embayments.)

As we show in the following sections of this report, the phytoplankton perturbation induced by OTEC are seen only as a small "signal" that is easily overshadowed by the larger "noise" of this temporal and spatial variability. Visual inspection of carbon concentration with an OTEC plant would closely resemble the same timestep for the No OTEC simulation shown in Figure 28 
through Figure 33. To report more accurately on the OTEC induced changes in phytoplankton, Makai used this "No OTEC" simulation dataset extensively for post-processing to find the the "difference" or "perturbation" between OTEC simulation and the corresponding No OTEC simulation. This technique was critical for much of the analysis and data reporting described in the following sections of this report.

A time series of the No OTEC simulations are shown below in Figure 34 and Figure 35, taken at the NAVFAC mooring location and modeled OTEC site. The left column shows a profile of the simulated concentrations at each time step (black dots), and the average HOTS observational data plus and minus two standard deviations for reference (gray areas). The right column shows the color scaled contours of the phytoplankton and nutrient concentrations as a function of depth and time at the site. The model reproduces reproduces the biomass and nutrient levels of the HOTS data quite well, specifically the location of the biomass maximum around $100 \mathrm{~m}$ depth, with rapid decreases in biomass below.

The data from were depth averaged for the depth bins 0 to $60 \mathrm{~m}, 60$ to $120 \mathrm{~m}$, and $120 \mathrm{~m}$ to $180 \mathrm{~m}$, corresponding to the upper photic zone, the biomass maximum of the photic zone, and the base of the photic zone below the typical 1\% light level (Fujieki 2011).

The plume model revX produced concentrations of $4.3 \mathrm{mgC} / \mathrm{m}^{3}, 8.9 \mathrm{mgC} / \mathrm{m}^{3}$, and $2.1 \mathrm{mgC} / \mathrm{m}^{3}$ respectively, comparing well with HOTS cell count data, which shows an average phytoplankton concentration of $13.0 \mathrm{mgC} / \mathrm{m}^{3}, 8.9 \mathrm{mgC} / \mathrm{m}^{3}$, and $0.7 \mathrm{mgC} / \mathrm{m}^{3}$. The surface concentrations of the model are lower, possibly due to the lack of inclusion of atmospheric nutrient fluxes and the inclusion of nitrifying bacteria. The standard deviations of modeled and observed phytoplankton concentrations also agree reasonably well. This higher ambient biomass in the surface layers observed in HOTS also leads to some off the variability in the modeling results discussed above, since the boundaries are forced with this HOTS climatological average.

For RevZA the particulate organic nitrogen (PON) remineralization and nitrification rates were increased and the phytoplankton predation rates were decreased, in order to provide an upper bound on growth conditions. The average concentrations increased to $7 \mathrm{mgC} / \mathrm{m}^{3}, 16 \mathrm{mgC} / \mathrm{m}^{3}$, and $5 \mathrm{mgC} / \mathrm{m}^{3}$, respectively. Figure 35 shows the simulated biological components at the NAVFAC mooring location (and modeled OTEC site) during the non-otec simulation. As before in Figure 34, the left column shows a profile of the simulated concentrations at each time step (black dots), and the average HOTS observational data plus and minus two standard deviations for reference (gray areas). The right column shows the color scaled contours of the phytoplankton and nutrient concentrations as a function of depth and time at the site. This set of biological paramaters slightly overstimulates growth of biomass below $60 \mathrm{~m}$, but this provides a modeling numerical basis for an upper bound on the typical, unperturbed, phytoplankton growth to use in a sensitivity analysis of the OTEC induced perturbations. 
19-May-2010 19:39:50 HST
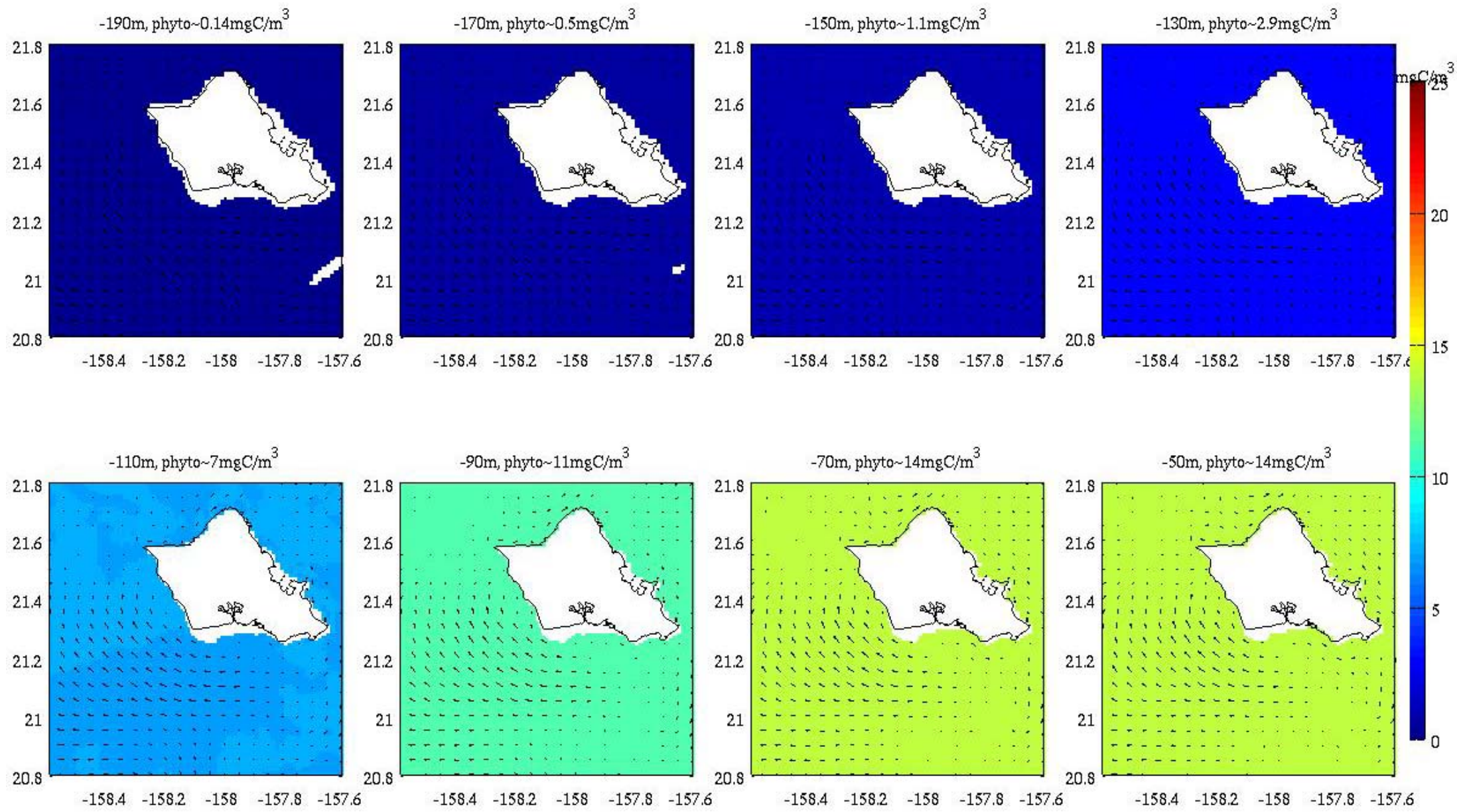

Figure 28. First simulation timestep of model, without an OTEC plant Note initial uniform distribution of carbon at indicated depths, based upon HOTS Station ALOHA profile data 
20-May-2010 16:39:50 HST
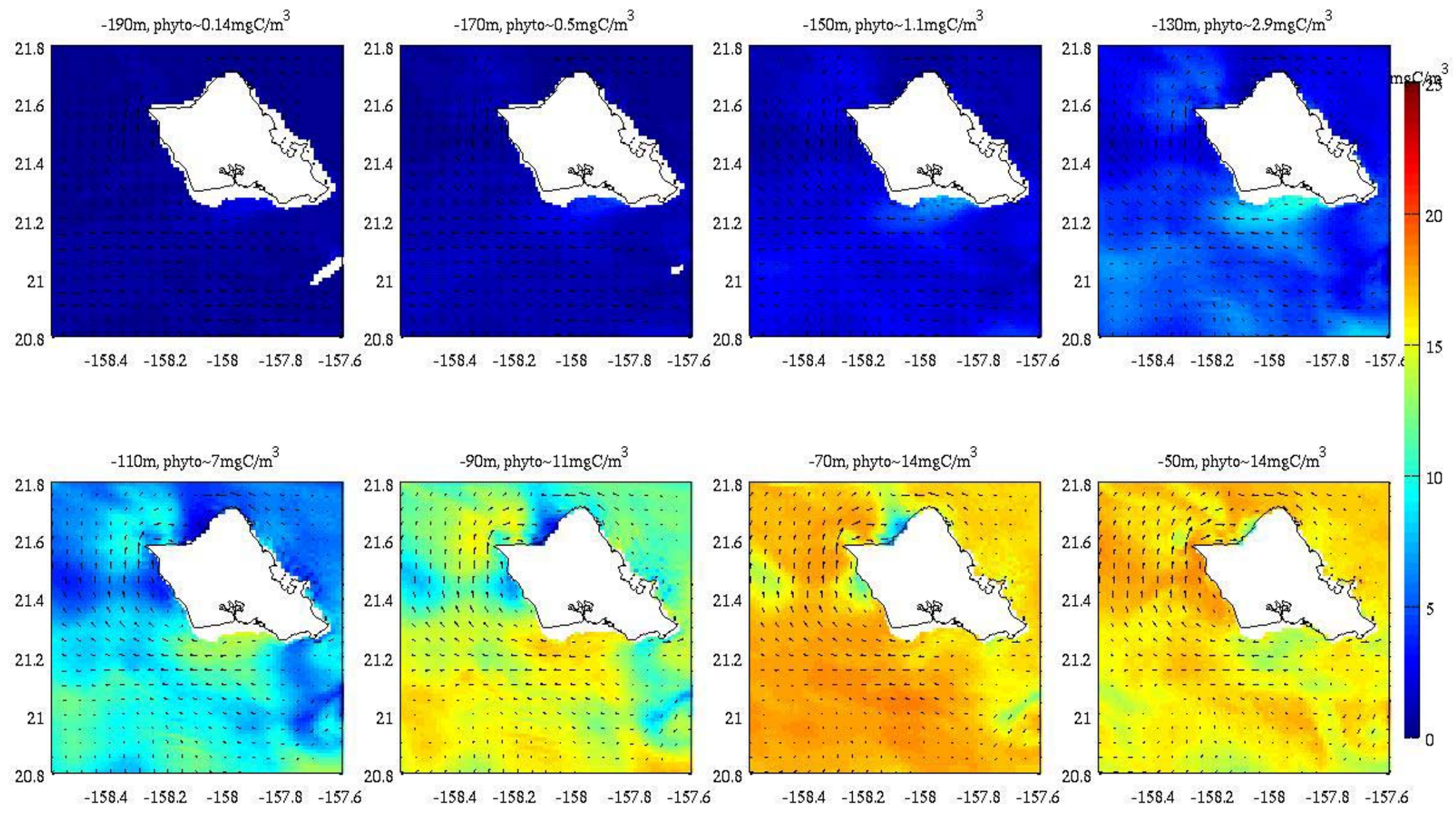

Figure 29. Model results after 8 simulation steps, (21 hours) starting to show variability due to ocean circulation and turbulence 
27-May-2010 22:39:50 HST
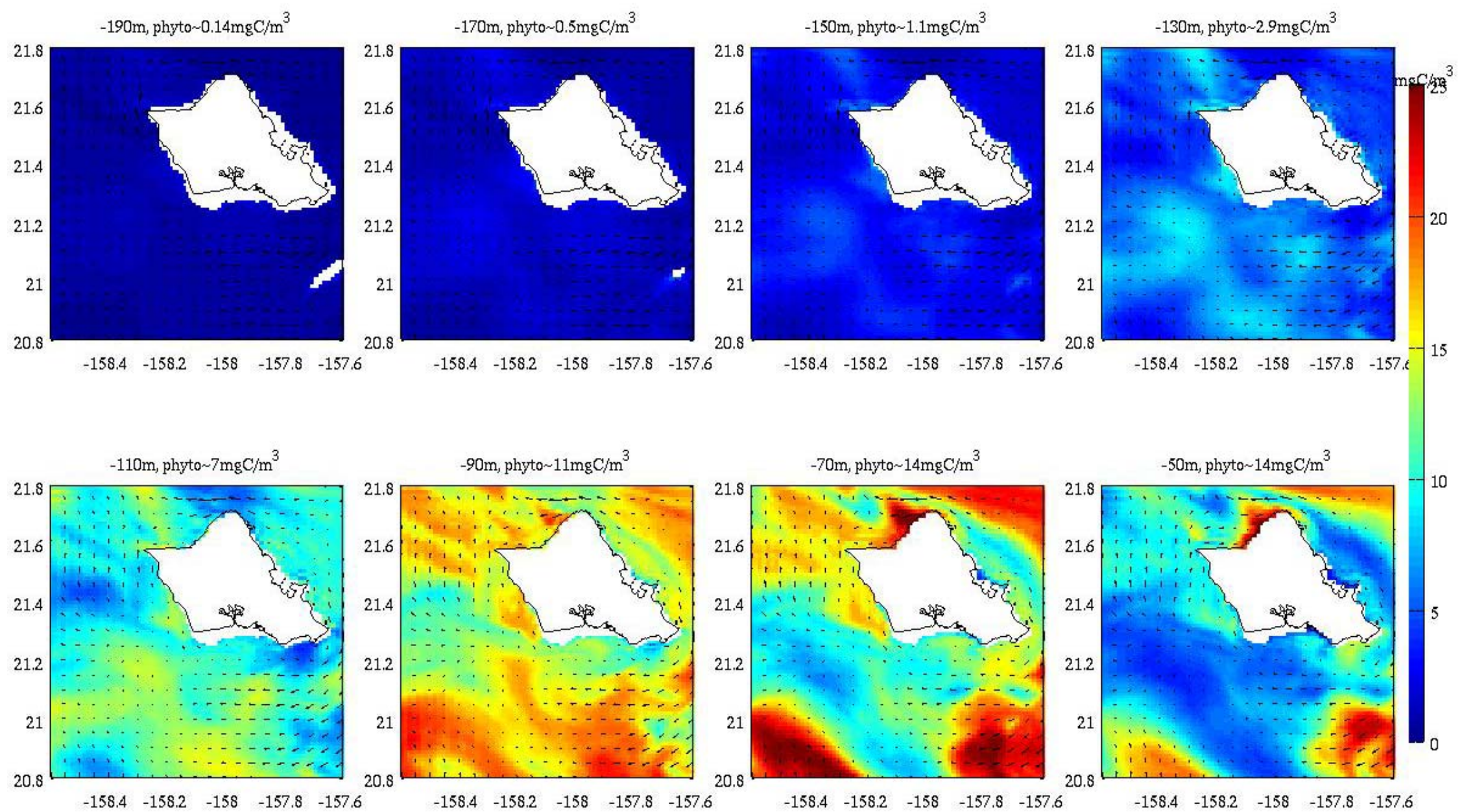

Figure 30. Model results after one week, displaying significant local variations. This particular date exhibited the largest carbon variation observed at 70 meters depth. 
29-May-2010 22:39:50 HST
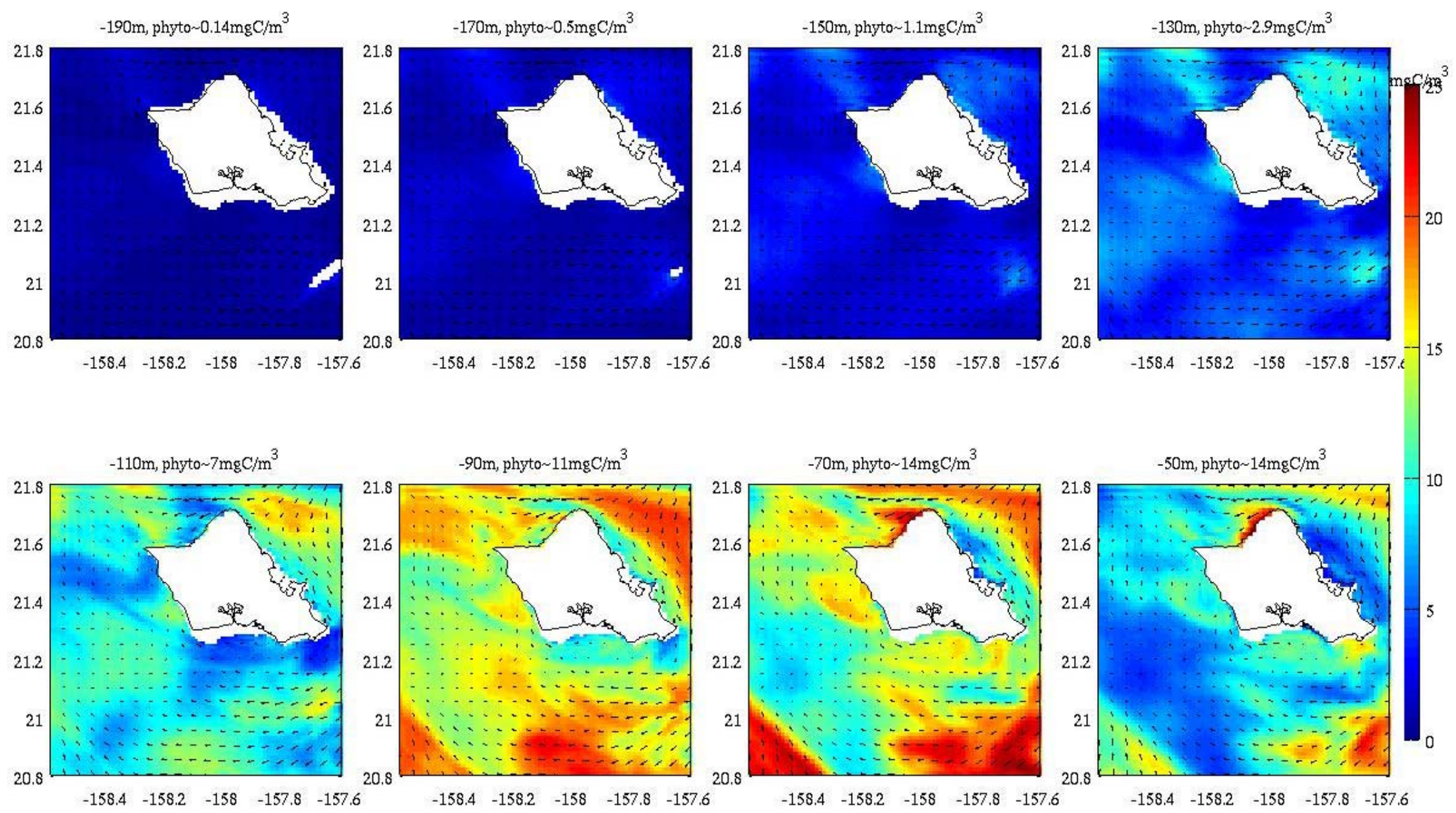

Figure 31. Model results after nine days. Some general observations are that depths deeper than $150 \mathrm{~m}$ display little carbon variability (due to insufficient light), and there is less carbon at 50 meters than at 70 meters (due to insufficient nutrients). 
10-Jun-2010 16:39:50 HST
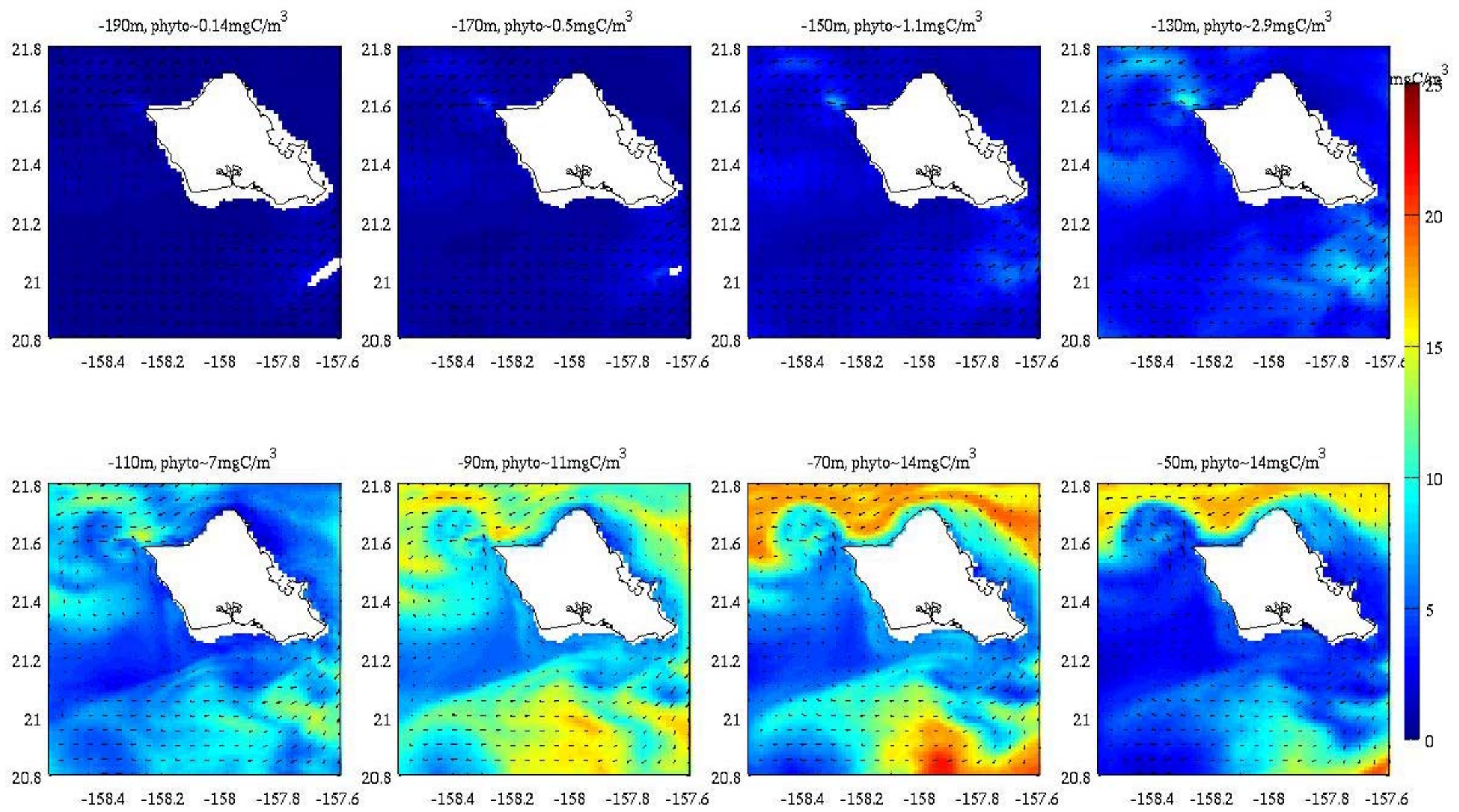

Figure 32. Model results for 10 June 2010 at 1639 . Carbon concentrations and variability on this date are generally representative of the forty day simulation 
17-Jun-2010 22:39:50 HST
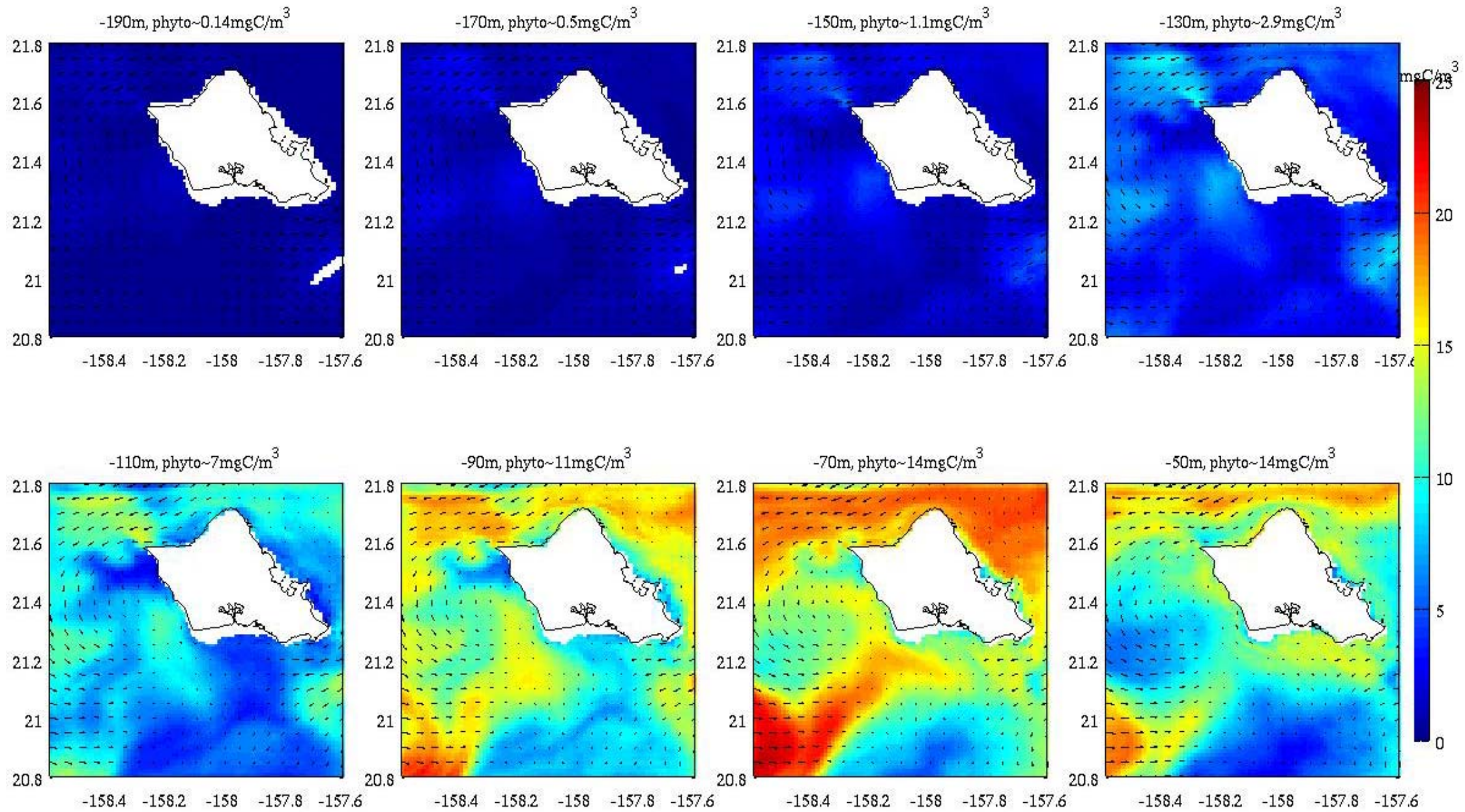

Figure 33. Model results for 17 June 2010 at 2239, after 29 simulation days. Note the sharp change in concentrations nearby at 90 and 70 meter depths. 
Table 1: Biological parameters used in RevX-RevZA. (Parameters that vary are bold font)

\begin{tabular}{|c|c|c|c|}
\hline Variable Description & RevX & RevZA & Units \\
\hline $\mathbf{u}_{\mathbf{1}}$ Max Growth & 2.6 & 2.6 & $d a y^{-1}$ \\
\hline $\mathbf{u}_{2}$ Max Growth & 5.2 & 5.2 & $d a y^{-1}$ \\
\hline $\mathbf{u}_{3}$ Max Growth & 3 & 3 & $d a y^{-1}$ \\
\hline $\mathbf{M}_{1}$ metabolism rate & 0.04 & 0.04 & $d a y^{-1}$ \\
\hline $\mathbf{M}_{\mathbf{2}}$ metabolism rate & 0.04 & 0.04 & $d a y^{-1}$ \\
\hline $\mathbf{M}_{\mathbf{3}}$ metabolism rate & 0.04 & 0.04 & $d a y^{-1}$ \\
\hline $\mathbf{P}_{1}$ predation rate & 0.5 & 0.375 & $d a y^{-1}$ \\
\hline $\mathbf{P}_{\mathbf{2}}$ predation rate & 0.31 & 0.2325 & $d a y^{-1}$ \\
\hline $\mathbf{P}_{\mathbf{3}}$ predation rate & 0.5 & 0.375 & $d a y^{-1}$ \\
\hline $\mathbf{W S}_{\mathbf{1}}$ settling velocity of algae 1 & 0.1 & 0.1 & $\mathrm{~m} / \mathrm{day}$ \\
\hline $\mathbf{W S}_{2}$ settling velocity of algae 2 & 0.5 & 0.5 & $\mathrm{~m} / \mathrm{day}$ \\
\hline $\mathbf{W S}_{3}$ settling velocity of algae 3 & 0.25 & 0.25 & $\mathrm{~m} /$ day \\
\hline $\mathbf{k}_{\text {T }}$ growth temp dependence (referenced to $25 \operatorname{deg} \mathrm{C}$ ) & -0.06 & -0.06 & $\operatorname{deg} C^{-1}$ \\
\hline $\mathbf{K}_{\mathbf{N}_{-} 1}$ half-sat nitrogen & 0.0015 & 0.0015 & $m g / L$ \\
\hline $\mathbf{K}_{\mathbf{N} \_2}$ half-sat nitrogen & 0.0075 & 0.0075 & $m g / L$ \\
\hline $\mathrm{K}_{\mathrm{N} \_} 3$ half-sat nitrogen & 0.003 & 0.003 & $m g / L$ \\
\hline $\mathbf{K}_{\text {si_z }}$ half-sat silica & 0.12 & 0.12 & $m g / L$ \\
\hline $\mathbf{K}_{\mathbf{I}}$ half-sat light & 25 & 25 & Ly/Day \\
\hline $\mathbf{k}_{\mathbf{A}}$ light extinction coeff. & 0.038 & 0.038 & meters $^{-1}$ \\
\hline \%PAR percent of surface radiation that is PAR & 0.43 & 0.43 & \\
\hline $\mathrm{y}_{1}$ Fraction predated to POM (pico-phytoplankton) & 0.9 & 0.9 & \\
\hline 1-y 1 Fraction predated to DOM (pico-phytoplankton) & 0.1 & 0.1 & \\
\hline$\varepsilon_{1}$ Fraction metabolized to POM (pico-phytoplankton) & 0.1 & 0.1 & \\
\hline $1-\varepsilon_{1}$ Fraction metabolized to DOM (pico-phytoplankton) & 0.9 & 0.9 & \\
\hline $\mathbf{y}_{2}$ Fraction predated to POM (large phytoplankton) & 0.9 & 0.9 & \\
\hline $1-y_{2}$ Fraction predated to DOM (large phytoplankton) & 0.1 & 0.1 & \\
\hline$\varepsilon_{2}$ Fraction metabolized to POM (large phytoplankton) & 0.1 & 0.1 & \\
\hline $1-\varepsilon_{2}$ Fraction metabolized to DOM (large phytoplankton) & 0.9 & 0.9 & \\
\hline $\mathbf{y}_{3}$ Fraction predated to POM (diatoms) & 0.9 & 0.9 & \\
\hline 1-y $\mathbf{y}_{3}$ Fraction predated to DOM (diatoms) & 0.1 & 0.1 & \\
\hline$\varepsilon_{3}$ Fraction metabolized to POM (diatoms) & 0.1 & 0.1 & \\
\hline 1- $\varepsilon_{3}$ Fraction metabolized to DOM (diatoms) & 0.9 & 0.9 & \\
\hline $\mathbf{R}_{\mathbf{N}: \mathbf{c}}$ nitrogen to carbon ratio in algae & 0.151 & 0.151 & $\mathrm{gN}: \mathrm{gC}$ \\
\hline WS PON settling velocity of POM & 2 & 1.5 & $\mathrm{~m} / \mathrm{day}$ \\
\hline KPON hydrolysis of PON to DON & 0.0025 & 0.0025 & $d a y^{-1}$ \\
\hline $\mathbf{k}_{\text {DON }}$ hydrolysis of DON to $\mathrm{NH} 4$ & 0.0015 & 0.0025 & $d a y^{-1}$ \\
\hline $\mathbf{k}_{\text {nit }}$ nitrification when PAR<1 Ly/Day (1 Ly/day=2.3 umolE $\left./ \mathrm{m}^{2} \mathrm{~s}\right)$ & 0.04 & 0.04 & $d a y^{-1}$ \\
\hline KPoc dissolution of POC to DOC & 0.02 & 0.02 & $d a y^{-1}$ \\
\hline $\mathbf{k}_{\mathrm{hr}}$ dissolution of POC to DOC & 0.001 & 0.001 & $d a y^{-1}$ \\
\hline gSi:gC silica to carbon ratio for algae diatoms & 0.22 & 0.22 & $g S i: g C$ \\
\hline ksuA dissolution rate of Biogenic Si to available Si & 0.2 & 0.2 & $d a y^{-1}$ \\
\hline
\end{tabular}



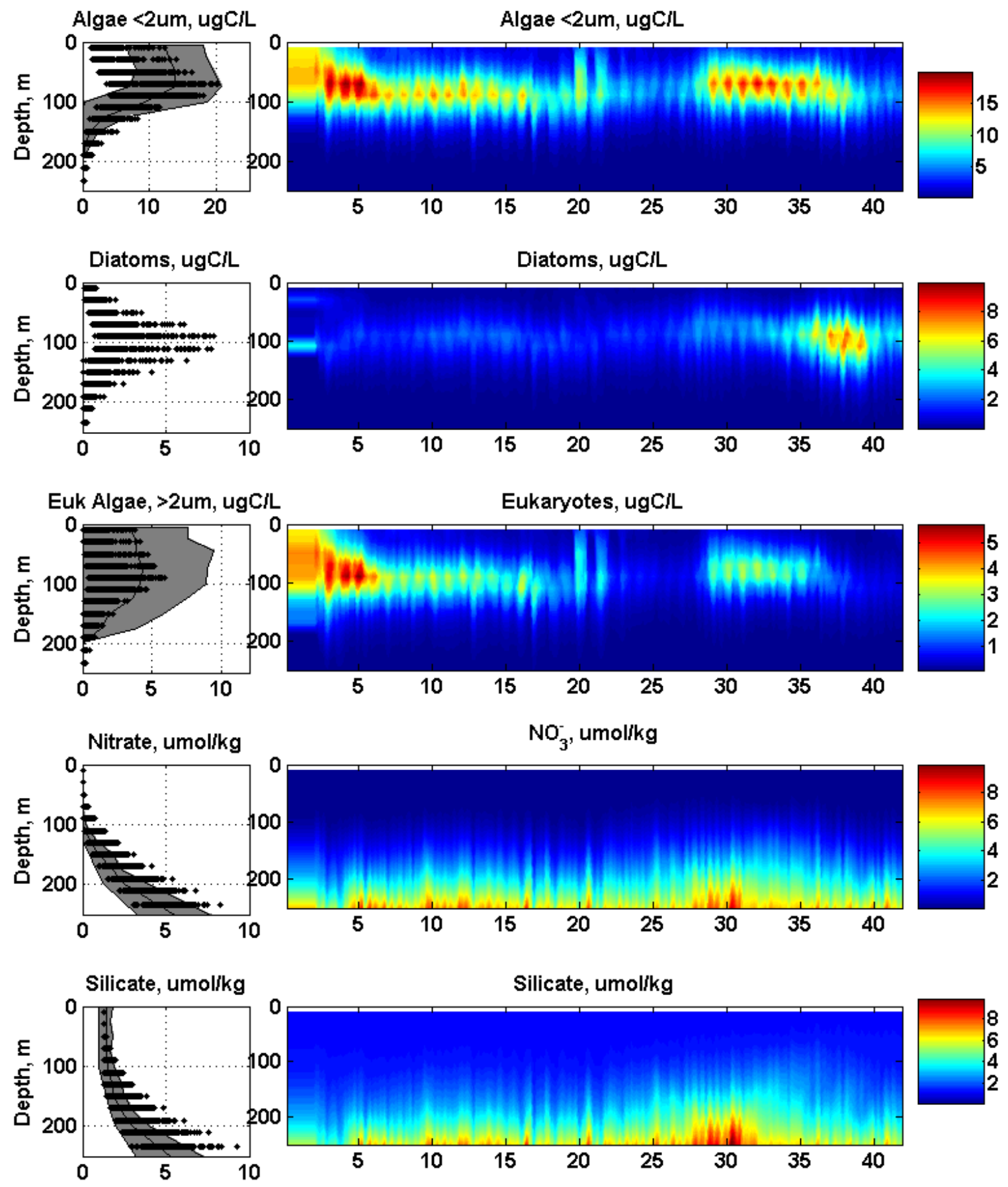

Figure 34. Revision X: biological time series at NAVFAC mooring location. Further analysis of the conditions during day 25 to day 30 , when biomass is noticeably low, is due to a change in the ambient circulation causing a convergent zone to develop in this location, inhibiting the upward mixing of nutrients at depth. 

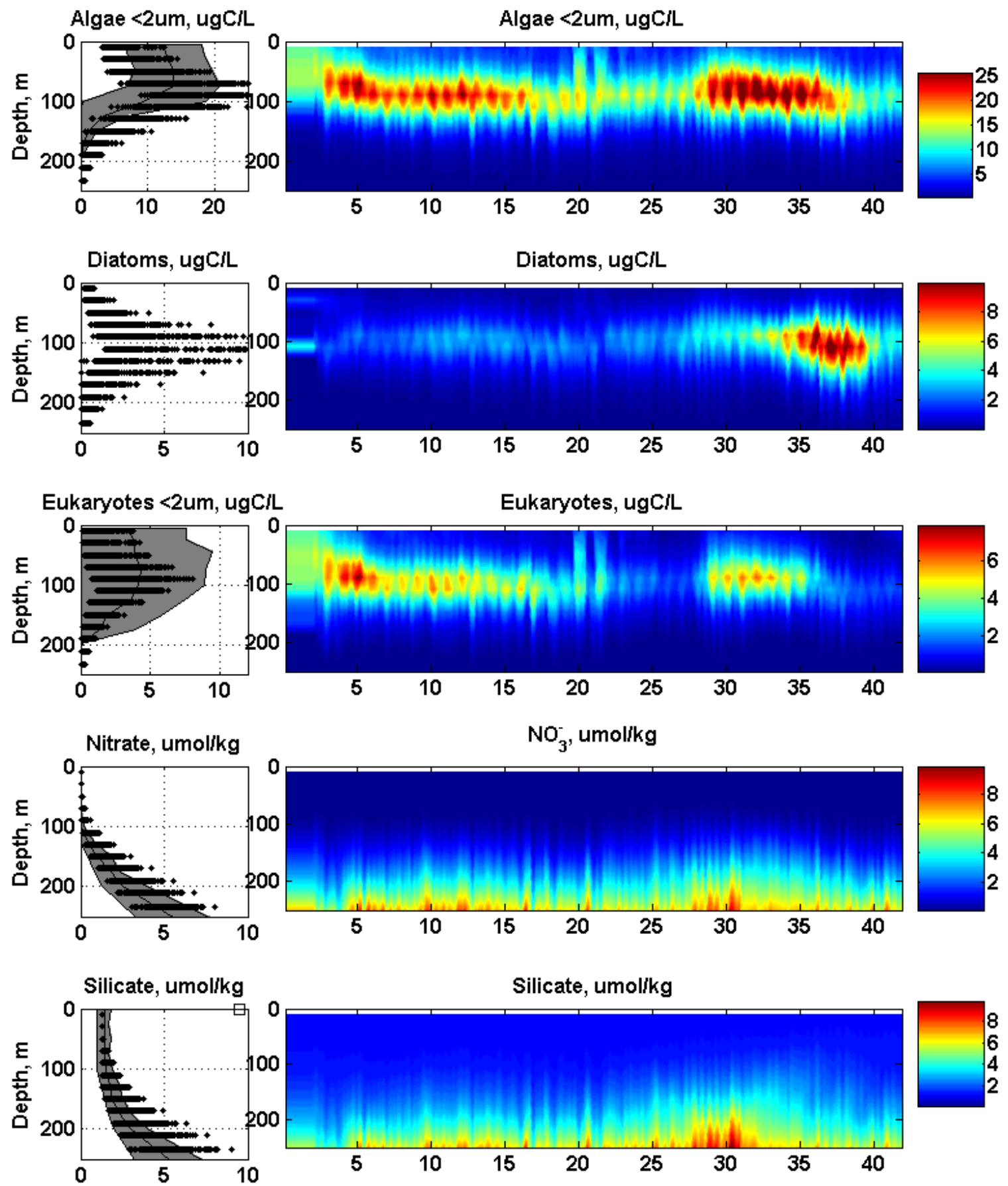

Figure 35. Revision ZA: biological time series at NAVFAC mooring location. Further analysis of the conditions durgin day 25 to day 30 , when biomass is noticeably low, is due to a change in the ambient circulation causing a convergent zone to develop in this location, inhibiting the upward mixing of nutrients at depth. 


\section{ReSUlTS: PHYTOPLANKTON RESPONSE TO OTEC DischaRgES}

\subsection{INTRODUCTION}

This chapter presents the model predictions for the phytoplankton response to different OTEC discharge configurations; including different discharge depths, number of discharge ports, and number of OTEC plants. As discussed in Section 3, the ambient biomass simulated in the nonOTEC scenario shows significant temporal and spatial variability. After running the OTEC simulations it became clear that the increase in biomass downstream of the OTEC plant is often indistinguishable from the "noise" of the ambient simulations and natural variability of the plankton populations. While this indicates that the perturbations or difference between the OTEC and non-OTEC are within the deviation of the natural systems, we still needed to provide a quantitative metric to measure the difference between an OTEC and non-OTEC phytoplankton community. To do so we computed the perturbation of the OTEC simulations, taken as the difference above the concentrations in the non-OTEC simulations.

summarizes the results of these perturbation calculations. The table includes the discharge configurations (first four columns), the terminal near-field plume properties (fifth column), the difference in phytoplankton between the OTEC and non-OTEC simulation concentrations within a limited area at the core of the plumes (sixth column), and the difference in phytoplankton concentrations between the OTEC and non-OTEC simulation averaged over a large $5400 \mathrm{~km}^{2}$ area offshore of west and south O'ahu and in the depth range of 40 to $140 \mathrm{~m}$ depth.

The "differences" tabulated for the core of the plumes in column 6 were estimated from the data contours of thte biological perturbations drawn in Figure 40 through Figure 95, which are discussed in detail in the following sections for each OTEC simulation. The differences in average phytoplankton concentration tabulated in column 6 were computed over the area shown below in Figure 36. This area encompasses locations that show measurable perturbation above the background biomass.

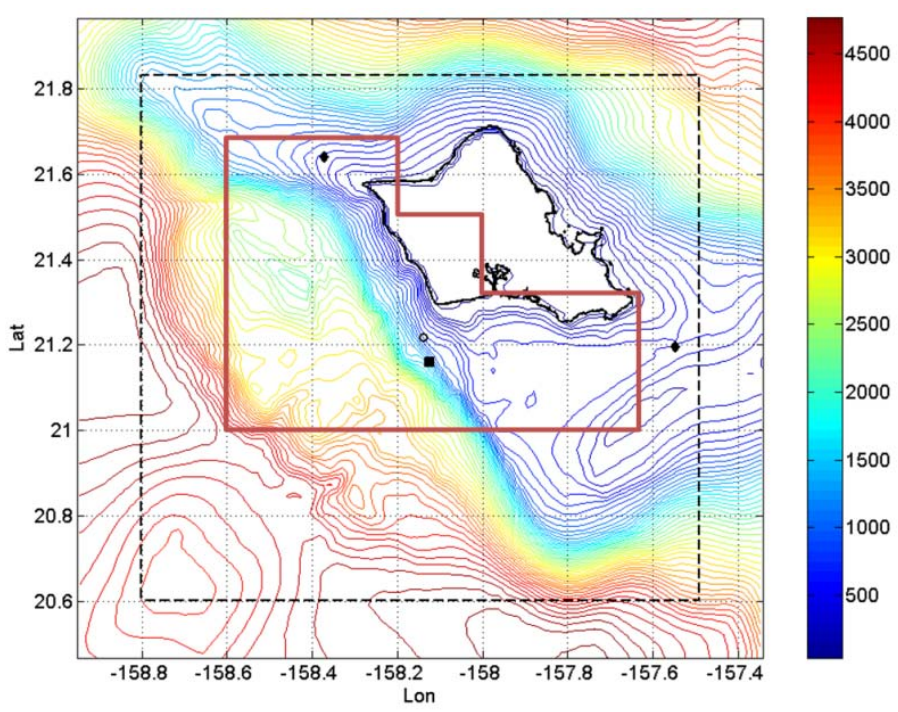

Figure 36. Image of modeling domain and the $5400 \mathrm{~km}^{2}$ zone (red polygon) used to compute an average phytoplankton concentration in the OTEC plumes. 
Table 2: OTEC configurations for RevisionX simulation results, including near-field plume properties and perturbation between OTEC and non-OTEC cases.

\begin{tabular}{|c|c|c|c|c|c|}
\hline $\begin{array}{c}\text { Number } \\
\text { of OTEC } \\
\text { plants }\end{array}$ & $\begin{array}{l}\text { Size } \\
(M W)\end{array}$ & $\begin{array}{c}\text { Discharge } \\
\text { depth } x \\
\text { number of } \\
\text { ducts. }\end{array}$ & $\begin{array}{l}\text { Terminal Plume } \\
\text { Properties, Notes }\end{array}$ & $\begin{array}{l}\text { Phytoplankton } \\
\text { perturbation in } \\
100 \mathrm{~km}^{2} \text { core area } \\
\text { of plume (Figs. } \\
36-95 \text { ) }\end{array}$ & $\begin{array}{l}\text { Phytoplankton } \\
\text { perturbation } \\
\text { averaged over } \\
5400 \mathrm{~km}^{2} \text { area } \\
\text { along West and } \\
\text { South O'ahu. }\end{array}$ \\
\hline None & 0 & N/A & $\begin{array}{l}\text { Model of "No OTEC" } \\
\text { condition to quantify } \\
\text { natural variablity due to } \\
\text { ocean circulation. }\end{array}$ & $\begin{array}{l}\text { Picophyto at } \\
100 \mathrm{~m} \text { depth } \\
\sim 10-15 \mathrm{mgC} / \mathrm{m}^{3} \\
\text { Diatoms at } 100 \mathrm{~m} \\
\text { depth 2-10 } \\
\mathrm{mgC} / \mathrm{m}^{3} *\end{array}$ & $\begin{array}{l}\text { No perturbations } \\
\text { Base Case. }\end{array}$ \\
\hline One & 100 & $70 \mathrm{~m} \times 4$ & $\begin{array}{l}\text { Depth }=172 \mathrm{~m} \\
\text { Vol. Dil. } 13: 1 \\
\text { Temp }=19.8^{\circ} \mathrm{C} .\end{array}$ & $\begin{array}{l}\Delta \text { Picophyto } \sim 1 \\
\mathrm{mgC} / \mathrm{m}^{3} \\
\Delta \text { Diatoms } \sim 1-3 \\
\mathrm{mgC} / \mathrm{m}^{3}\end{array}$ & 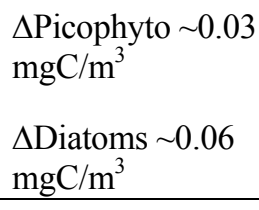 \\
\hline Three & 100 & $70 \mathrm{~m} \times 4$ & $\begin{array}{l}\text { Depth }=172 \mathrm{~m} \\
\text { Vol. Dil. } 13: 1 \\
\text { Temp=19. } 8^{\circ} \mathrm{C}\end{array}$ & $\begin{array}{l}\Delta \text { Picophyto } \sim 4-6 \\
\mathrm{mgC} / \mathrm{m}^{3} \\
\Delta \text { Diatoms } \sim 4-6 \\
\mathrm{mgC} / \mathrm{m}^{3}\end{array}$ & $\begin{array}{l}\Delta \text { Picophyto } \sim 0.05 \\
\mathrm{mgC} / \mathrm{m}^{3} \\
\Delta \text { Diatoms } \sim 0.2 \\
\mathrm{mgC} / \mathrm{m}^{3}\end{array}$ \\
\hline Three & 100 & $95 \mathrm{~m} \times 4$ & $\begin{array}{l}\text { Depth }=192 \mathrm{~m} \\
\text { Vol. Dil. } 12: 1 \\
\text { Temp }=18.8^{\circ} \mathrm{C} .\end{array}$ & $\begin{array}{l}\Delta \text { Picophyto } \sim 2-3 \\
\mathrm{mgC} / \mathrm{m}^{3} \\
\Delta \text { Diatoms } \sim 2-3 \\
\mathrm{mgC} / \mathrm{m}^{3}\end{array}$ & 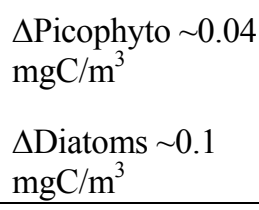 \\
\hline One & 100 & $70 \mathrm{~m} \times 8$ & $\begin{array}{l}\text { Depth }=154 \mathrm{~m} \\
\text { Vol. Dil. } 16.5: 1 \\
\text { Temp }=20.4^{\circ} \mathrm{C}\end{array}$ & $\begin{array}{l}\Delta \text { Picophyto } \sim 2-3 \\
\mathrm{mgC} / \mathrm{m}^{3} \\
\Delta \text { Diatoms } \sim 2-3 \\
\mathrm{mgC} / \mathrm{m}^{3}\end{array}$ & $\begin{array}{l}\Delta \text { Picophyto } \sim 0.03 \\
\mathrm{mgC} / \mathrm{m}^{3} \\
\Delta \text { Diatoms } \sim 0.09 \\
\mathrm{mgC} / \mathrm{m}^{3}\end{array}$ \\
\hline One & 100 & $95 \mathrm{~m} \times 8$ & $\begin{array}{l}\text { Depth }=175 \mathrm{~m} \\
\text { Vol. Dil. } 15.6: 1 \\
\text { Temp }=19.4^{\circ} \mathrm{C} .\end{array}$ & $\begin{array}{l}\Delta \text { Picophyto } \sim 1-2 \\
\mathrm{mgC} / \mathrm{m}^{3} \\
\Delta \text { Diatoms } \sim 0.5- \\
1.5 \mathrm{mgC} / \mathrm{m}^{3}\end{array}$ & 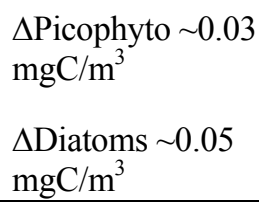 \\
\hline One & 2.5 & $70 \mathrm{~m} \times 1$ & & $\begin{array}{l}\Delta \text { Picophyto } \sim \\
<0.5 \mathrm{mgC} / \mathrm{m}^{3} \\
\Delta \text { Diatoms } \sim<0.5 \\
\mathrm{mgC} / \mathrm{m}^{3}\end{array}$ & $\begin{array}{l}\Delta \text { Picophyto } \sim 0.0 \\
\mathrm{mgC} / \mathrm{m}^{3} \\
\Delta \text { Diatoms } \sim 0.0 \\
\mathrm{mgC} / \mathrm{m}^{3}\end{array}$ \\
\hline
\end{tabular}

*Ambient diatom populations vary between nearshore and offshore regions. 


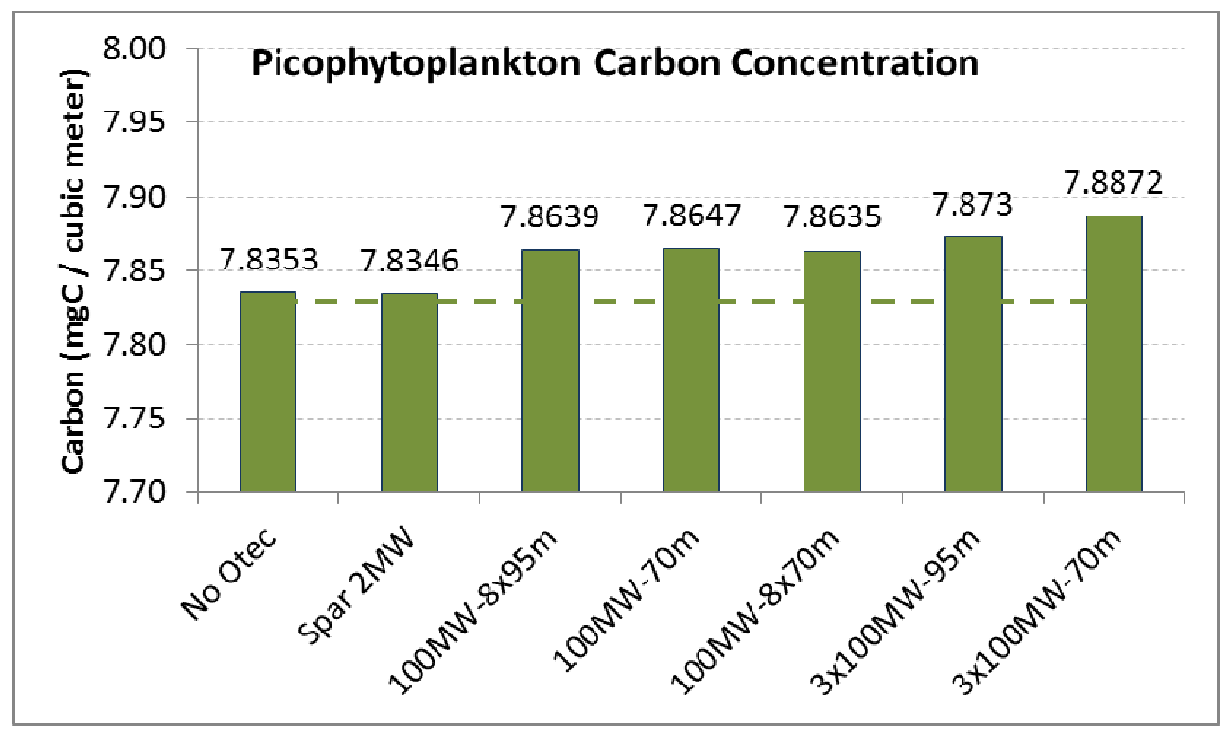

Figure 37. Average picophytoplankton carbon concentrations in a large area $\left(5400 \mathrm{~km}^{2}\right)$ offshore of west and south O'ahu during the entire simulation period from 40 to $140 \mathrm{~m}$ depth. Results are based on the revX biological parameters. The perturbation for each case is shown by the height above the No-OTEC dashed line. The largest perturbation shown is $0.66 \%$

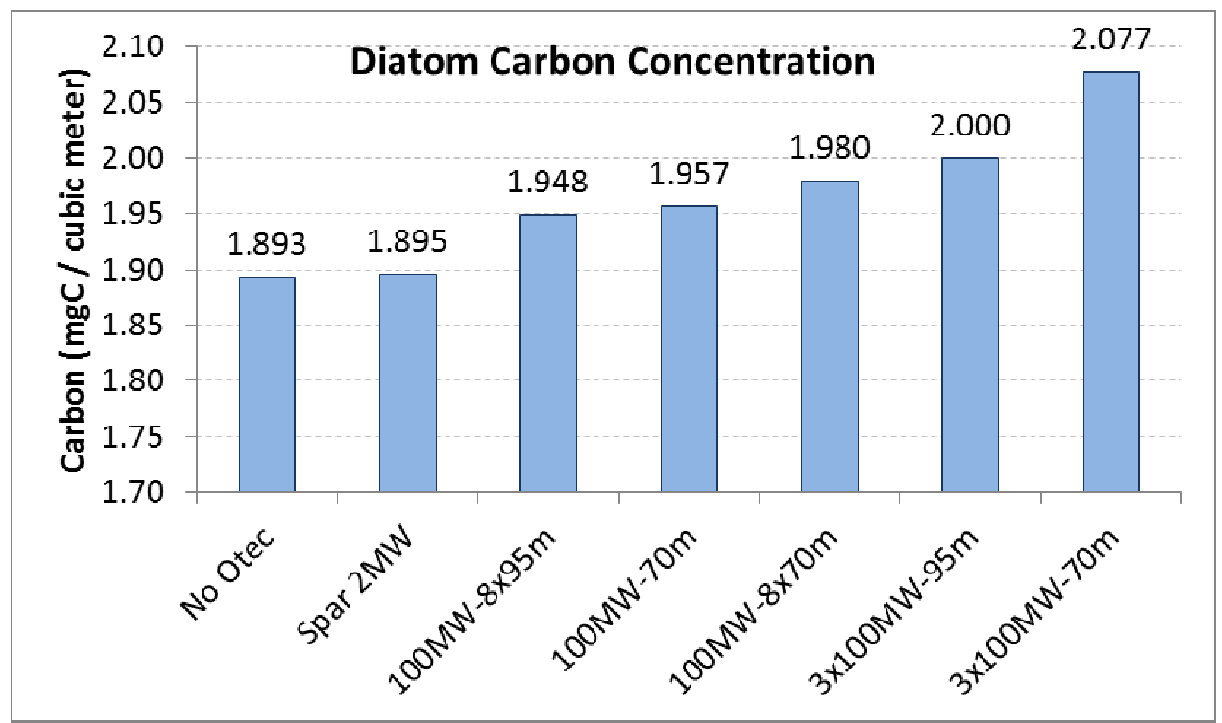

Figure 38. Average diatom carbon concentrations in a large area $\left(5400 \mathrm{~km}^{2}\right)$ offshore of west and south $\mathrm{O}^{\prime}$ ahu during the entire simulation period from 40 to $140 \mathrm{~m}$ depth. Results are based on the revX biological parameters. 


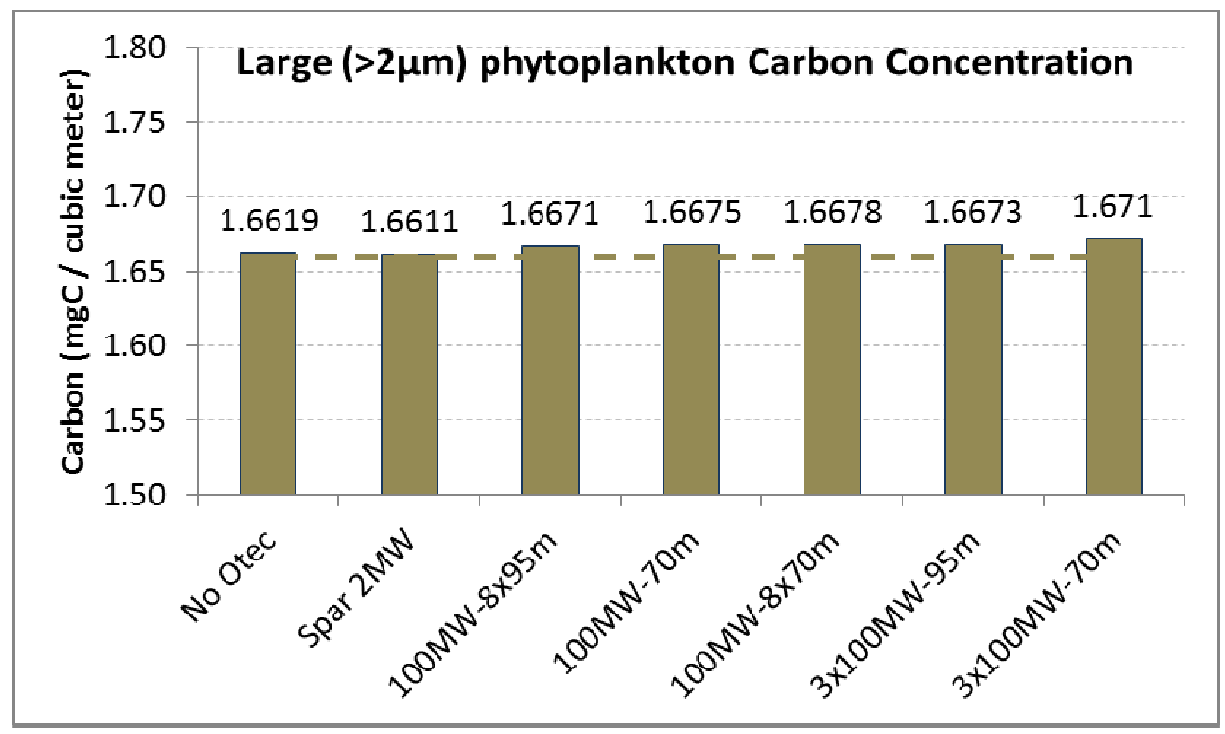

Figure 39. Average large (eukaryotic) phytoplankton carbon concentrations in a large area $\left(5400 \mathrm{~km}^{2}\right)$ offshore of

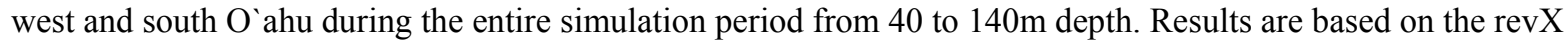
biological parameters. 


\subsection{RESULTS FROM OTEC SIMULATIONS}

\subsection{1. $\quad$ Single 100MW OTEC Plant: 70 meter discharge, 4 Discharge Ducts}

The model was run with an OTEC plant consisting of four separate ducts, discharging a total combined flow rate of $420 \mathrm{~m}^{3} / \mathrm{s}$ of warm water and $320 \mathrm{~m}^{3} / \mathrm{s}$ of cold water in a mixed discharge. Each duct was assumed to have a discharge port diameter of $10.5 \mathrm{~m}$ producing a downward discharge velocity of about $2.18 \mathrm{~m} / \mathrm{s}$. The near field plume had an average terminal depth of $172 \mathrm{~m}$ meters, with a volumetric dilution of 13:1. The average terminal plume temperature was $19.8^{\circ} \mathrm{C}$. The results show a measurable, but relatively limited, response of the ambient phytoplankton populations to the OTEC enhanced nutrient distributions downstream of the OTEC discharge. The nutrient perturbations are greatest directly below the plant (where the near-field plume terminates) and there is relatively rapid dilution as the plume gets advected, similar to the phenomena observed in Makai's first OTEC plume study (Rocheleau and Grandelli, 2011). There is a mild biological response downstream of the OTEC plant, where trace levels of nutrients have mixed into the upper water column.

The picophytoplankton biomass due to both the ambient natural dynamics and the plumes of the OTEC plant are shown in Figure 40 through Figure 43. The overall effect appears nearly identical to the No OTEC condition described in the previous section (Figure 28 through Figure 33). The "perturbation" or difference of the nitrate and picophytoplankton carbon concentrations of this OTEC simulation and the non-OTEC simulation are shown in Figure 44 through Figure 47. In the same manner, diatom biomass simulation data is displayed in Figure 48 through Figure 51, with corresponding diatom perturbation data presented in Figure 52 through Figure 55.

These figures show the background and diatom populations and the nitrate and biomass perturbations at different simulation time steps taken one week apart.

Under the OTEC plant, nitrate concentrations at the plume's terminal depth ( 170 meters $)$ are 1 to $2 \mathrm{umol} / \mathrm{kg}$ above ambient. The advecting plume then further dilutes to less than $1 \mathrm{umol} / \mathrm{kg}$ above ambient within a few kilometers downstream, while remaining at depth. Because this terminal near-field plume is below the $1 \%$ light limited depths $(\sim 120 \mathrm{~m})$ no immediate biological utilization of the nutrients occurs.

Also immediately under the OTEC discharge, there is a measurable biological perturbation of about $1 \mathrm{mgC} / \mathrm{m}^{3}$ of pico-plankton. This perturbation is the result from transport of entrained phytoplankton from the shallow warm water intake (we have assumed $100 \%$ of the entrained organisms survive and are transported with the plume.)

As the nitrate is advected and dispersed downstream, some of the nutrients become mixed into shallower water having better illumination, where the nutrients can be utilized by the ambient phytoplankton populations. Approximately twenty-five kilometers downstream from the plant there is an observable biological response. The nutrients have been advected and dispersed, with trace $(<0.5 \mathrm{umol} / \mathrm{kg})$ perturbations evident in the upper water column (the 70 to $90 \mathrm{~m} \mathrm{depth}$ ). Modeling results indicate that this nutrient perturbation causes a phytoplankton perturbation of approximately $1 \mathrm{mgC} / \mathrm{m}^{3}$ in pico-phytoplankton ( $\sim 10 \%$ of average ambient concentrations) that covers an area $10 \times 5 \mathrm{~km}$ in size. The natural system, as measured in the HOTS program and simulated for the No OTEC scenario, has an average concentration of $10-15 \mathrm{mgC} / \mathrm{m}^{3}$. Thus, the 
perturbations, although non-trivial, are well within the natural variability of the system and generally corresponding to a 10 to $15 \%$ increase above the average pico-phytoplankton biomass at the core of the phytoplankton perturbation.

The system is dynamic, and produces different plume characteristics as the background circulation and phytoplankton distributions vary over time. For pico-phytoplankton, the perturbation exhibits a widely varying horizontal plume trajectory and spatial extent, but remains similar in magnitude (generally $1-2 \mathrm{mgC} / \mathrm{m}^{3}$ ). For example, Figure 44 shows a phytoplankton perturbation 0.5 to 1.0 $\mathrm{mgC} / \mathrm{m}^{3}$ above ambient in a relatively symmetrical $20 \times 10 \mathrm{~km}$ patch to the northwest of the OTEC site. One week later, in Figure 45, we see a narrow $0.5 \mathrm{mgC} / \mathrm{m}^{3}$ perturbation that extends for several tens of kilometers, but has a width of less than $5 \mathrm{~km}$. Then, another week later, in Figure 46, we see a more symmetrical patch again, but to the southeast of the OTEC site. Again, another week later in Figure 47 we observe a larger perturbation to the northwest at Kaena Point that, at its core, is $2 \mathrm{mgC} / \mathrm{m}^{3}$ above ambient. During this time step we also observe a narrow and weak perturbation of $0.5 \mathrm{mgC} / \mathrm{m}^{3}$ extending from Kaena to Barbers Point.

The diatom perturbations exhibit an even more complex temporal pattern, and become noticeably more significant after three weeks of the simulation period, when the nearshore diatom population trends towards a greater concentration. This increase in ambient diatoms effectively "seeds" the nutrient perturbed waters, leading to a greater response, in this case on the order of 1 to $3 \mathrm{mgC} / \mathrm{m}^{3}$ over a relatively broad area. However, relative to the background concentrations, this increased response is still a fraction of the ambient. For example, in Figure 48 through Figure 51, the later images show greater background diatom population near the OTEC site, and Figure 52 through Figure 55 shows a corresponding increase in the diatom perturbations. Overall, however, both diatom and pico-phytoplankton populations show a limited response, with perturbations remaining within the natural fluctuations of the system. For example, near the end of the simulation in Figure 51 we observe an ambient coastal diatom concentration of 5 to $10 \mathrm{mgC} / \mathrm{m}^{3}$ and a perturbation of 1 to $2 \mathrm{mgC} / \mathrm{m}^{3}$ in Figure 55. The implications of these results will be discussed in Section 5, after describing the additional OTEC simulation results. 
03-Jun-2010 16:39:50 HST
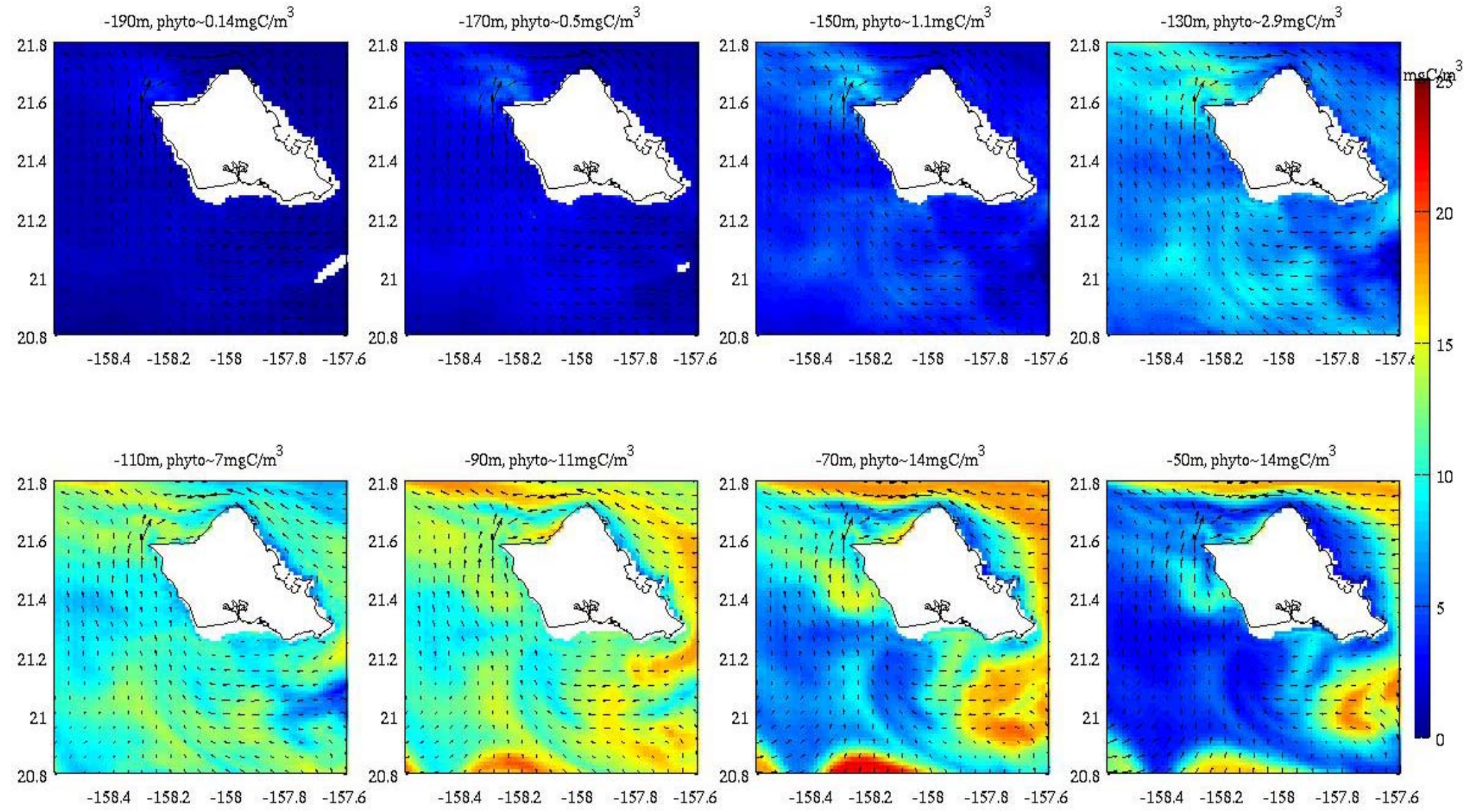

Figure 40. Pico-phytoplankton biomass (prochlorococcus, synechococcus, etc.) in $\mathrm{mgC} / \mathrm{m}^{3}$ from the RevX 100MW OTEC simulation. Figures show the plan view at 190, 170,150,130,110,90, 70, and 50 meter depths at June $3^{\text {rd }}, 2010$ at 16:40 Hawaii Standard Time. 

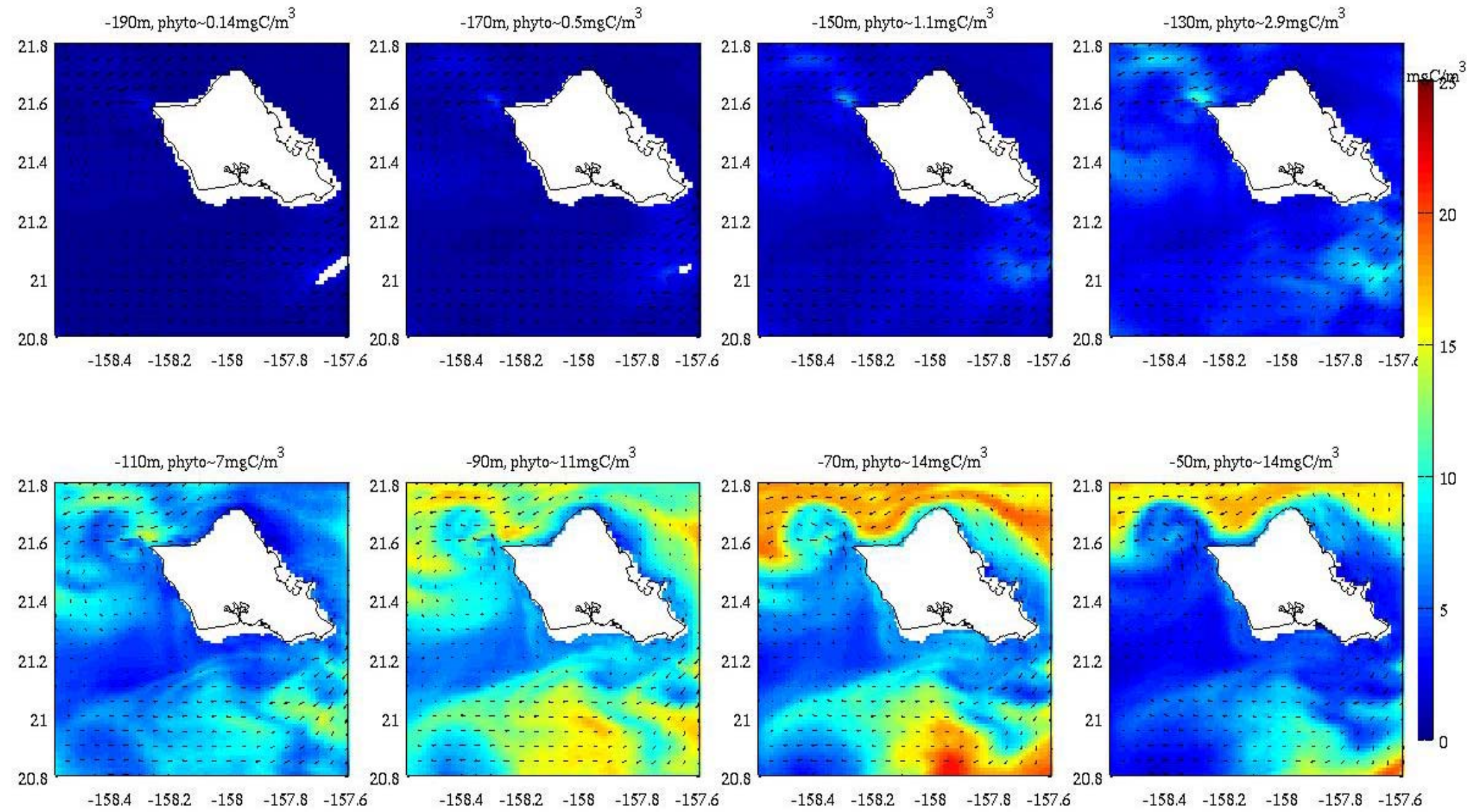

Figure 41. Pico-phytoplankton biomass (prochlorococcus, synechococcus, etc.) in $\mathrm{mgC} / \mathrm{m}^{3}$ from the RevX 100MW OTEC simulation. Figures show the plan view at $190,170,150,130,110,90,70$, and 50 meter depths at June $17^{\text {th }}$ at 16:40 Hawaii Standard Time. 
17-Jun-2010 16:39:50 HST
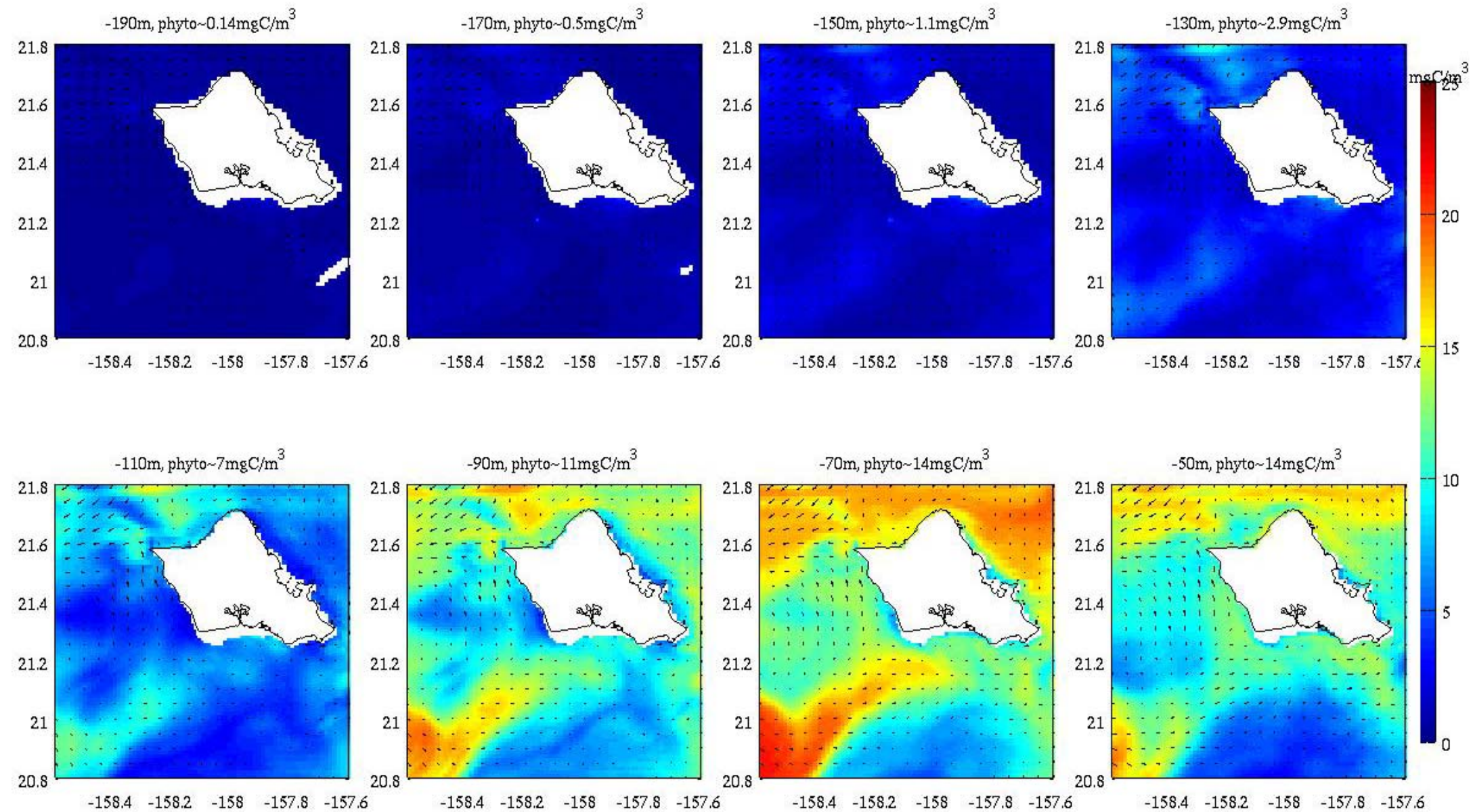

Figure 42. Pico-phytoplankton biomass (prochlorococcus, synechococcus, etc.) in $\mathrm{mgC} / \mathrm{m}^{3}$ from the RevX 100MW OTEC simulation. Figures show the plan view at $190,170,150,130,110,90,70$, and 50 meter depths at June $17^{\text {th }}$ at 16:40 Hawaii Standard Time. 
24-Jun-2010 16:39:50 HST
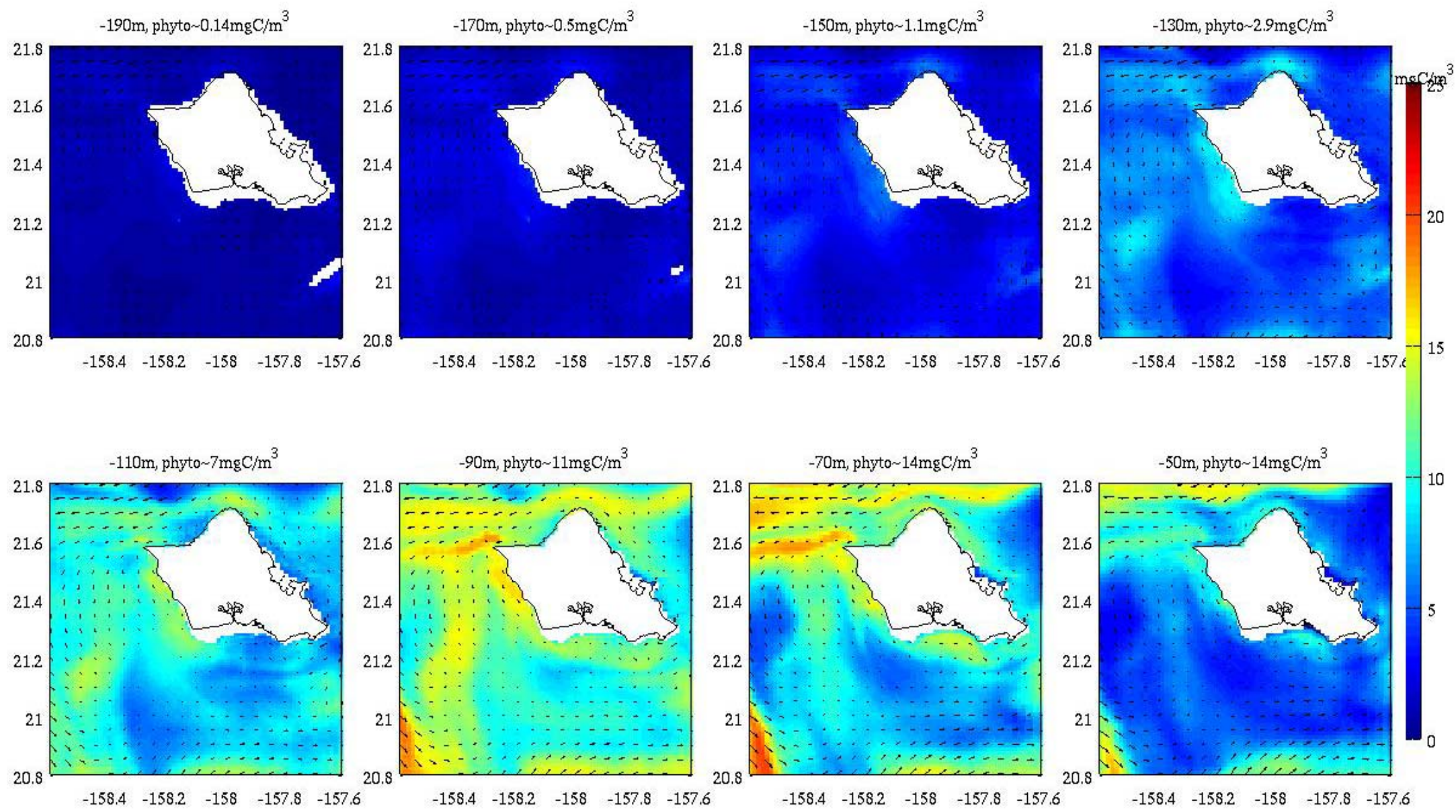

Figure 43. Pico-phytoplankton biomass (prochlorococcus, synechococcus, etc.) in $\mathrm{mgC} / \mathrm{m}^{3}$ from the RevX 100MW OTEC simulation. Figures show the plan view at $190,170,150,130,110,90,70$, and 50 meter depths at June $24^{\text {th }}$ at 16:40 Hawaii Standard Time. 
03-Jun-2010 16:39:50 HST

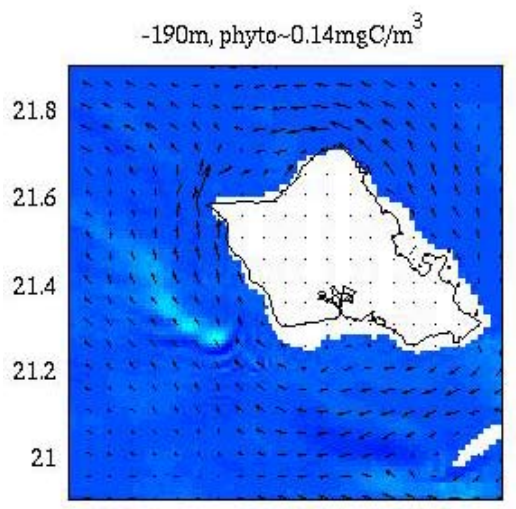

$\begin{array}{lllll}-158.4 & -158.2 & -158 & -157.8 & -157.6\end{array}$

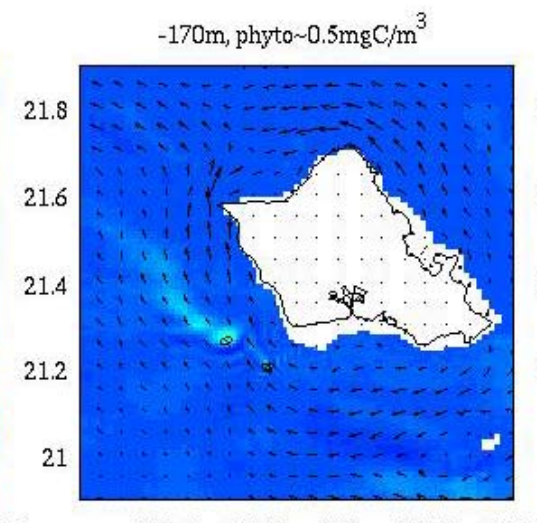

$\begin{array}{lllll}-158.4 & -158.2 & -158 & -157.8 & -157.6\end{array}$

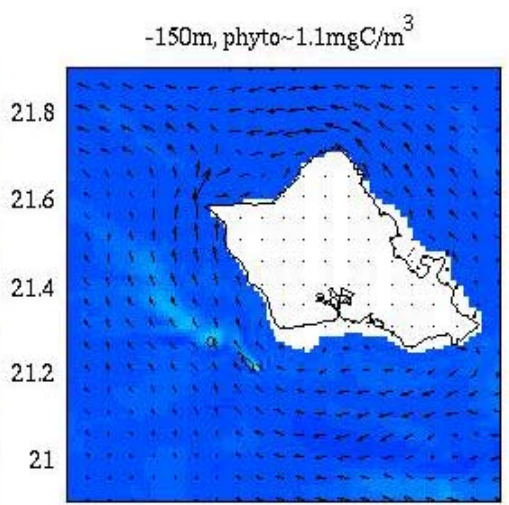

$\begin{array}{lllll}-158.4 & -158.2 & -158 & -157.8 & -157.6\end{array}$
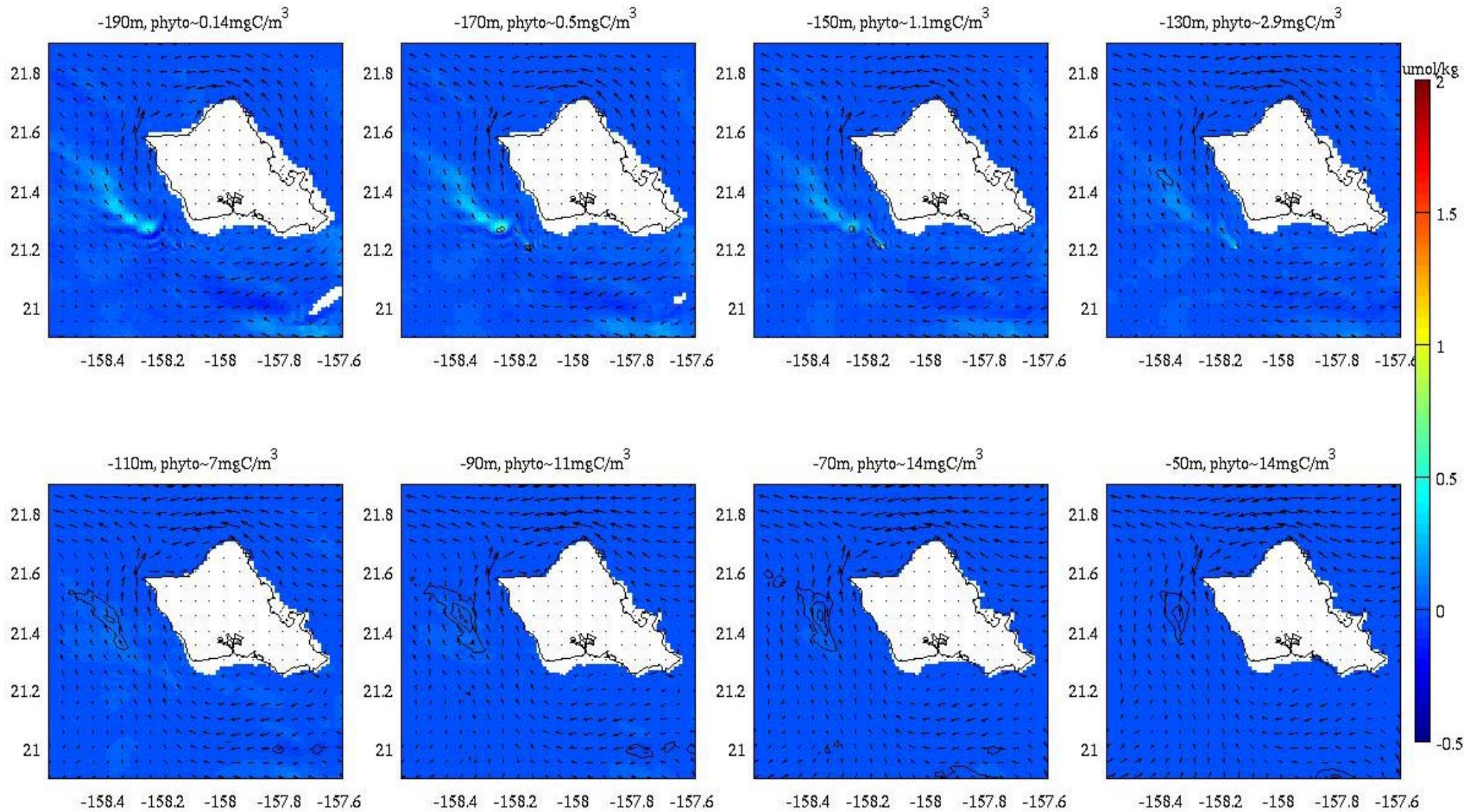

Figure 44. Nitrate perturbation (umol/kg) due to the RevX 100MW OTEC plant, and contour lines of the resultant pico-phytoplankton perturbation (black lines) drawn at intervals of $0.5 \mathrm{mgC} / \mathrm{m}^{3}\left(<2 \mathrm{um}\right.$ size class, predominantly prochlorococcus and synechococcus). June $3^{\text {rd }}$, 2010 at 16:40 Hawaii Standard Time. 
10-Jun-2010 16:39:50 HST
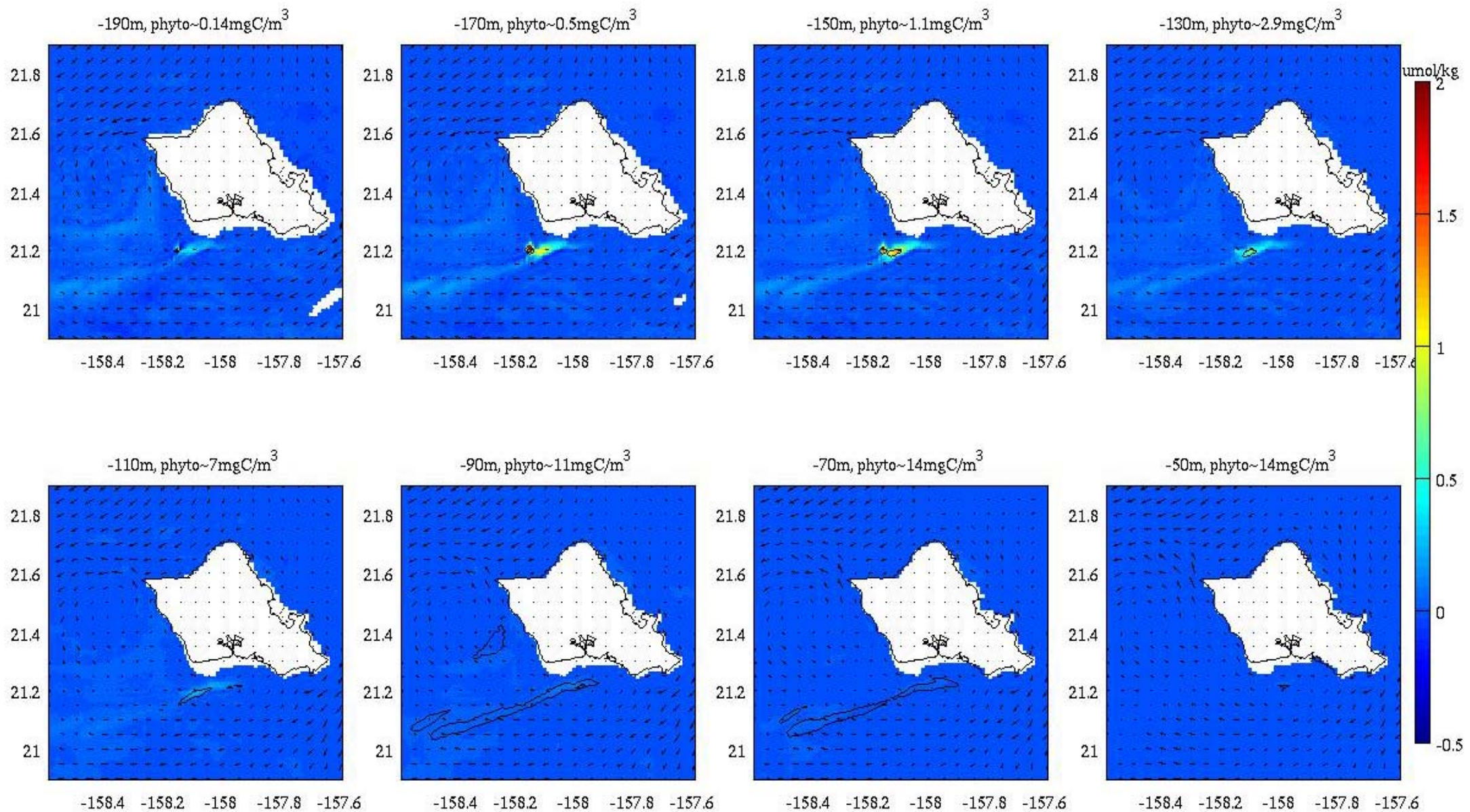

Figure 45. Nitrate perturbation (umol/kg) due to the RevX 100MW OTEC plant, and contour lines of the resultant pico-phytoplankton perturbation (black lines) drawn at intervals of $0.5 \mathrm{mgC} / \mathrm{m}^{3}$ ( $<2 \mathrm{um}$ size class, predominantly prochlorococcus and synechococcus). June $7^{\text {th }}, 2010$ at 16:40 Hawaii Standard Time. 


\section{7-Jun-2010 16:39:50 HST}

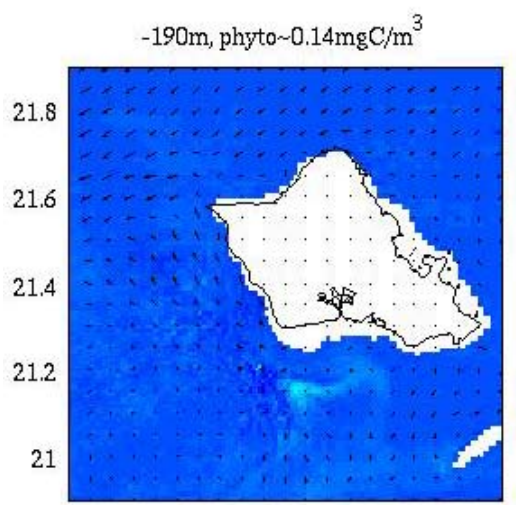

$-158.4 \quad-158.2 \quad-158 \quad-157.8 \quad-157.6$

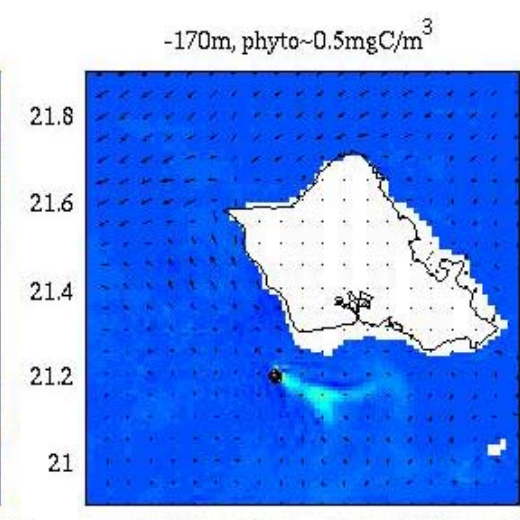

$\begin{array}{lllll}-158.4 & -158.2 & -158 & -157.8 & -157.6\end{array}$

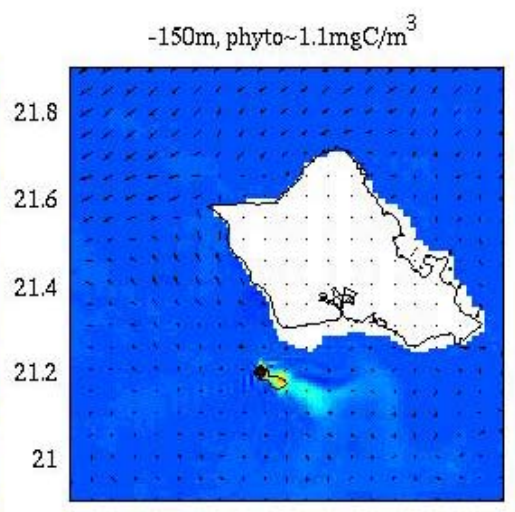

$-158.4 \quad-158.2 \quad-158 \quad-157.8 \quad-157.6$
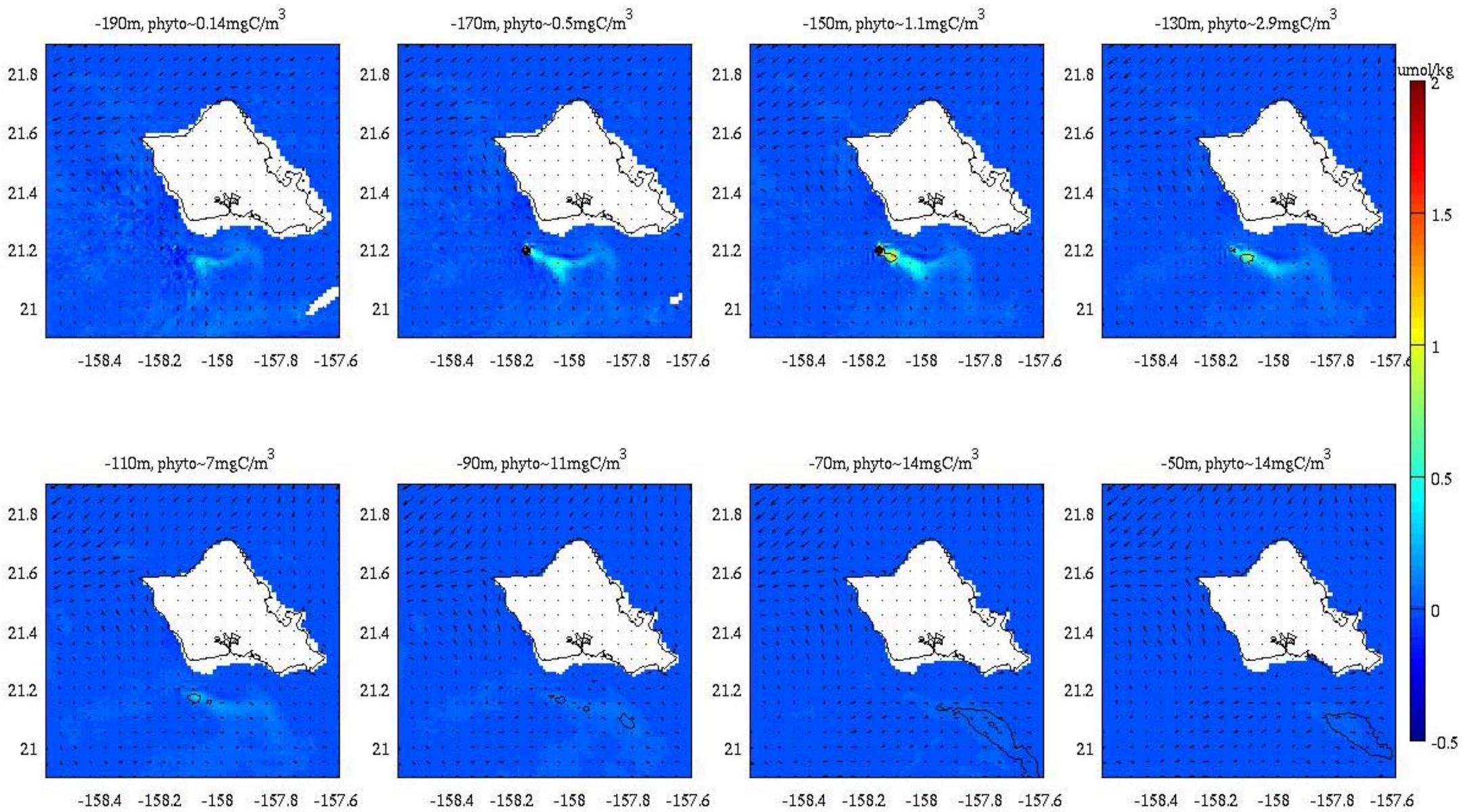

Figure 46. Nitrate perturbation (umol/kg) due to the RevX 100MW OTEC plant, and contour lines of the resultant pico-phytoplankton perturbation (black lines) drawn at intervals of $0.5 \mathrm{mgC} / \mathrm{m}^{3}\left(<2 \mathrm{um}\right.$ size class, predominantly prochlorococcus and synechococcus). June $17^{\text {th }}$, 2010 at $16: 40$ Hawaii Standard Time. 


\section{4-Jun-2010 16:39:50 HST}
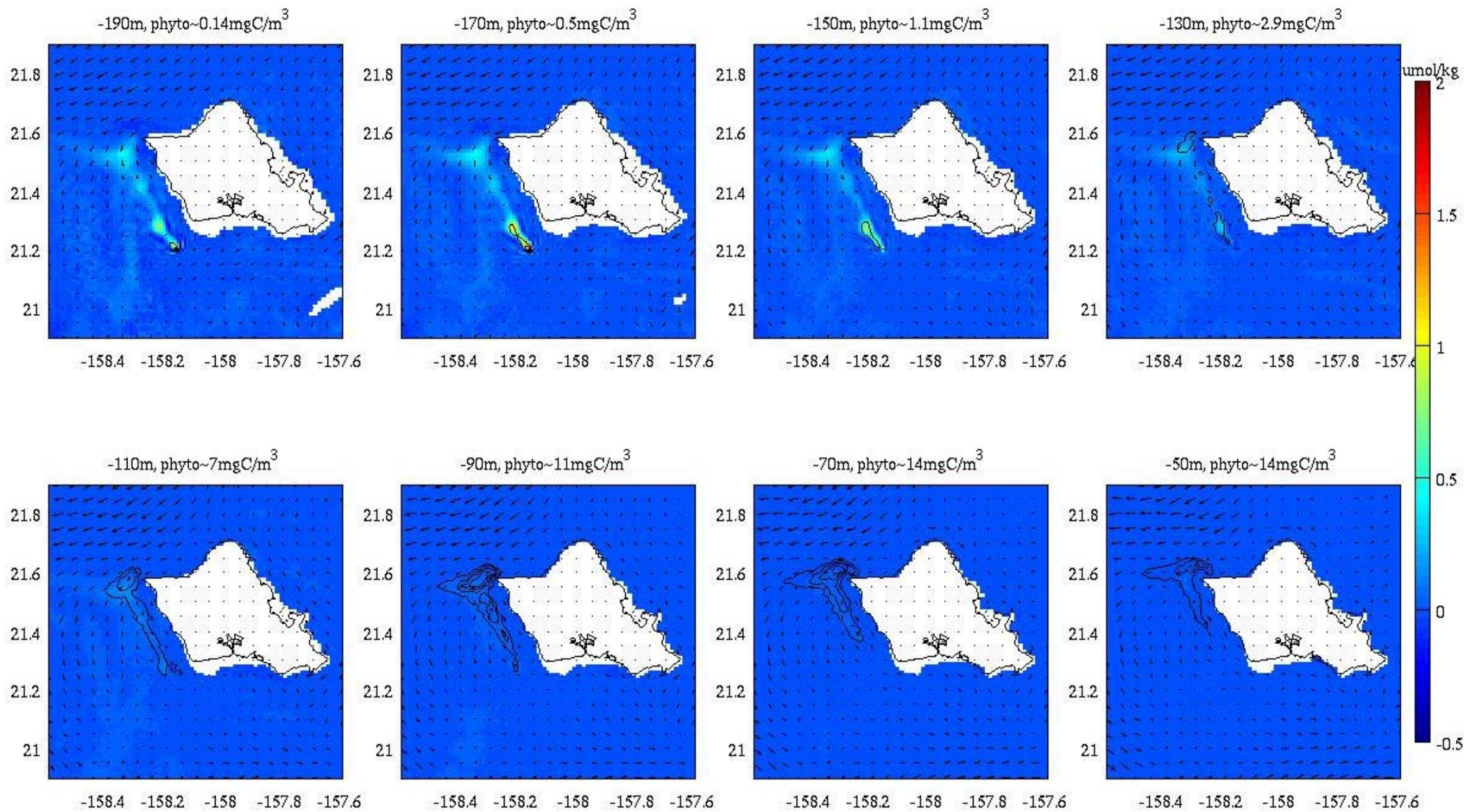

Figure 47. Nitrate perturbation (umol/kg) due to the RevX 100MW OTEC plant, and contour lines of the resultant pico-phytoplankton perturbation (black lines) drawn at intervals of $0.5 \mathrm{mgC} / \mathrm{m}^{3}$ (<2um size class, predominantly prochlorococcus and synechococcus). June $24^{\text {th }}$, 2010 at 16:40 Hawaii Standard Time. 
03-Jun-2010 16:39:50 HST
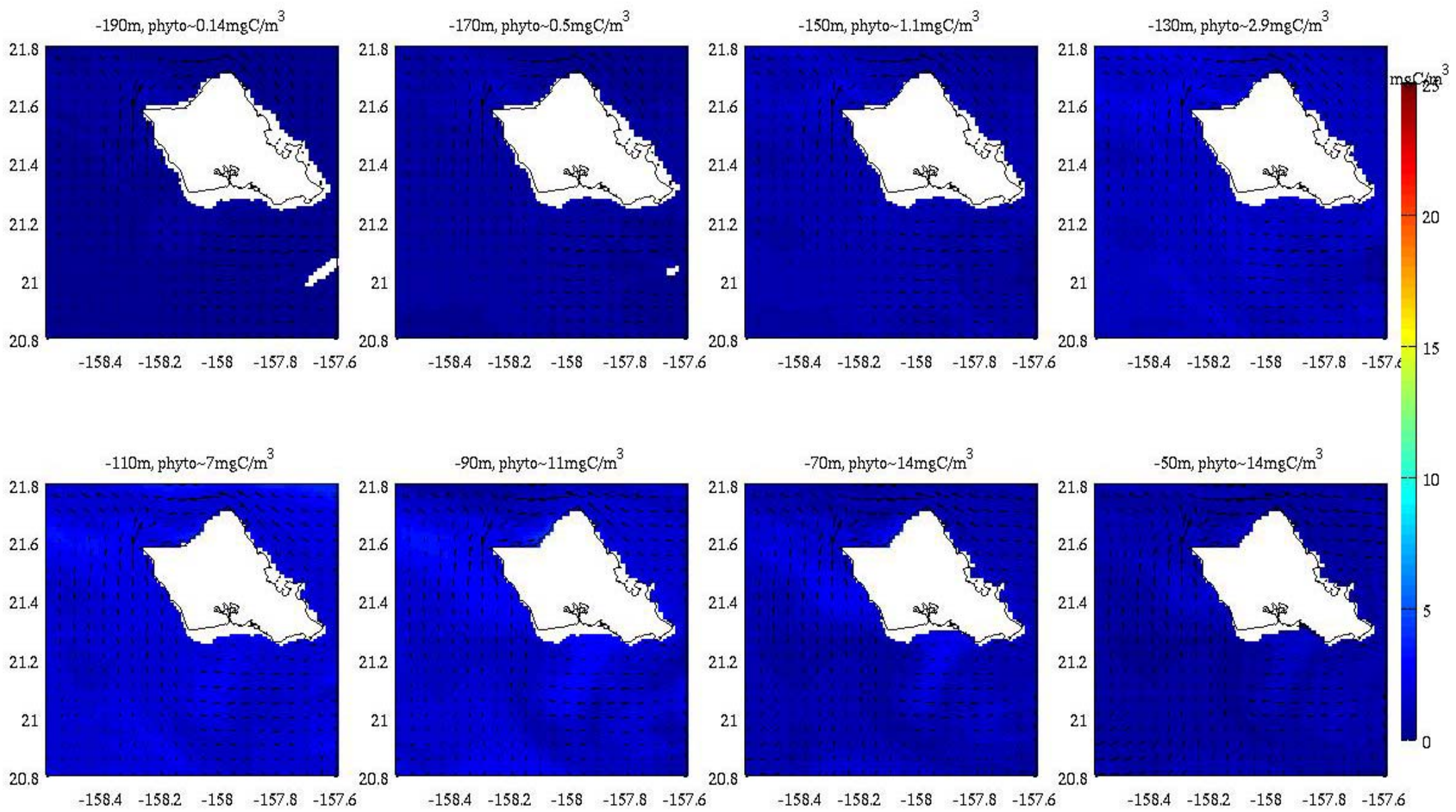

Figure 48. Diatom phytoplankton biomass in $\mathrm{mgC} / \mathrm{m}^{3}$ from the RevX 100MW OTEC simulation. Figures show the plan view at 190, 170, 150, 130, 110, 90, 70, and 50 meter depths at at June $3^{\text {rd }}$ at 16:40 Hawaii Standard Time. 
10-Jun-2010 16:39:50 HST
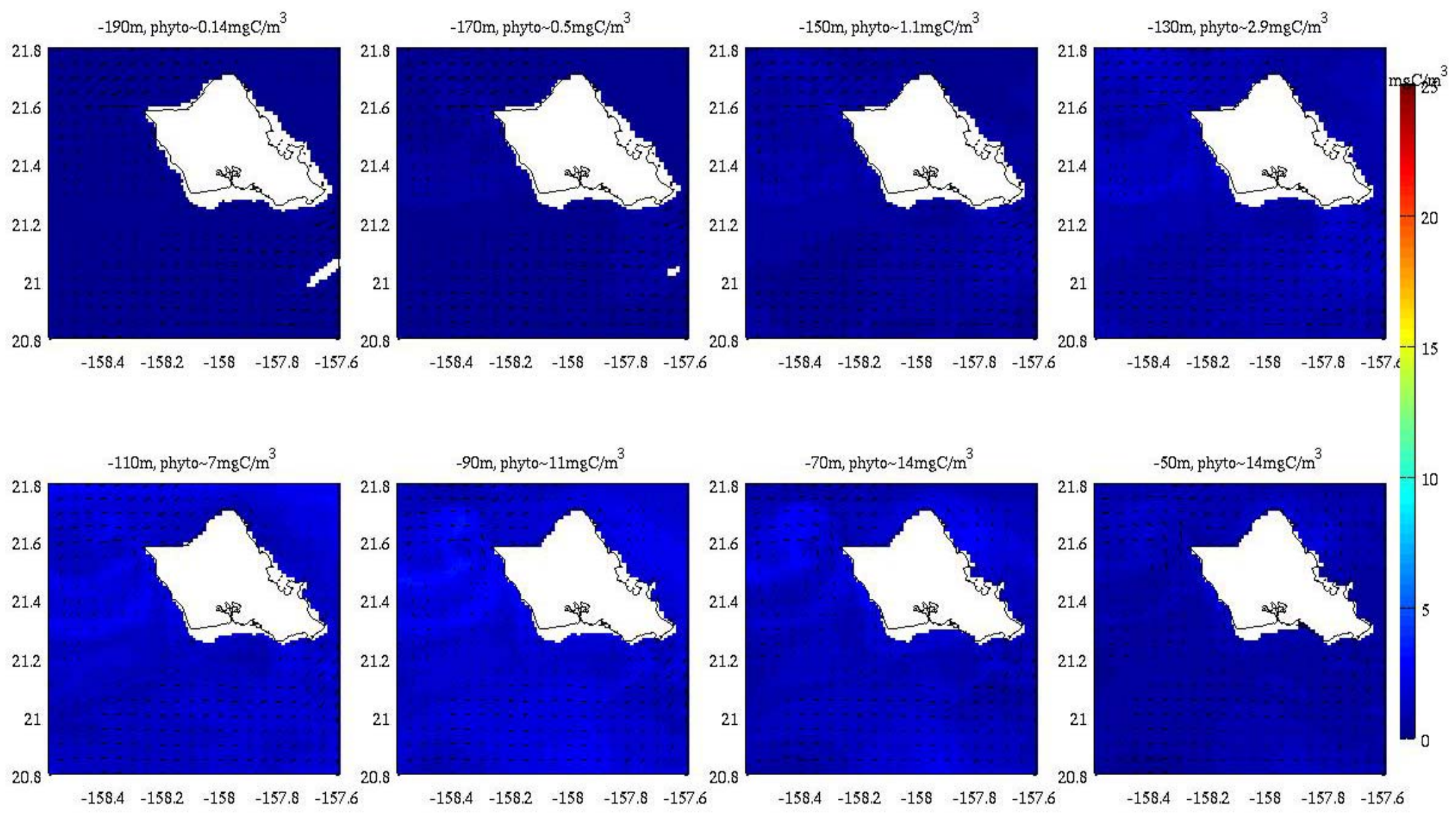

Figure 49. Diatom phytoplankton biomass in $\mathrm{mgC} / \mathrm{m}^{3}$ from the RevX 100MW OTEC simulation. Figures show the plan view at 190, 170, 150, 130, 110, 90, 70, and 50 meter depths at at June $7^{\text {th }}$ at 16:40 Hawaii Standard Time. 
17-Jun-2010 16:39:50 HST
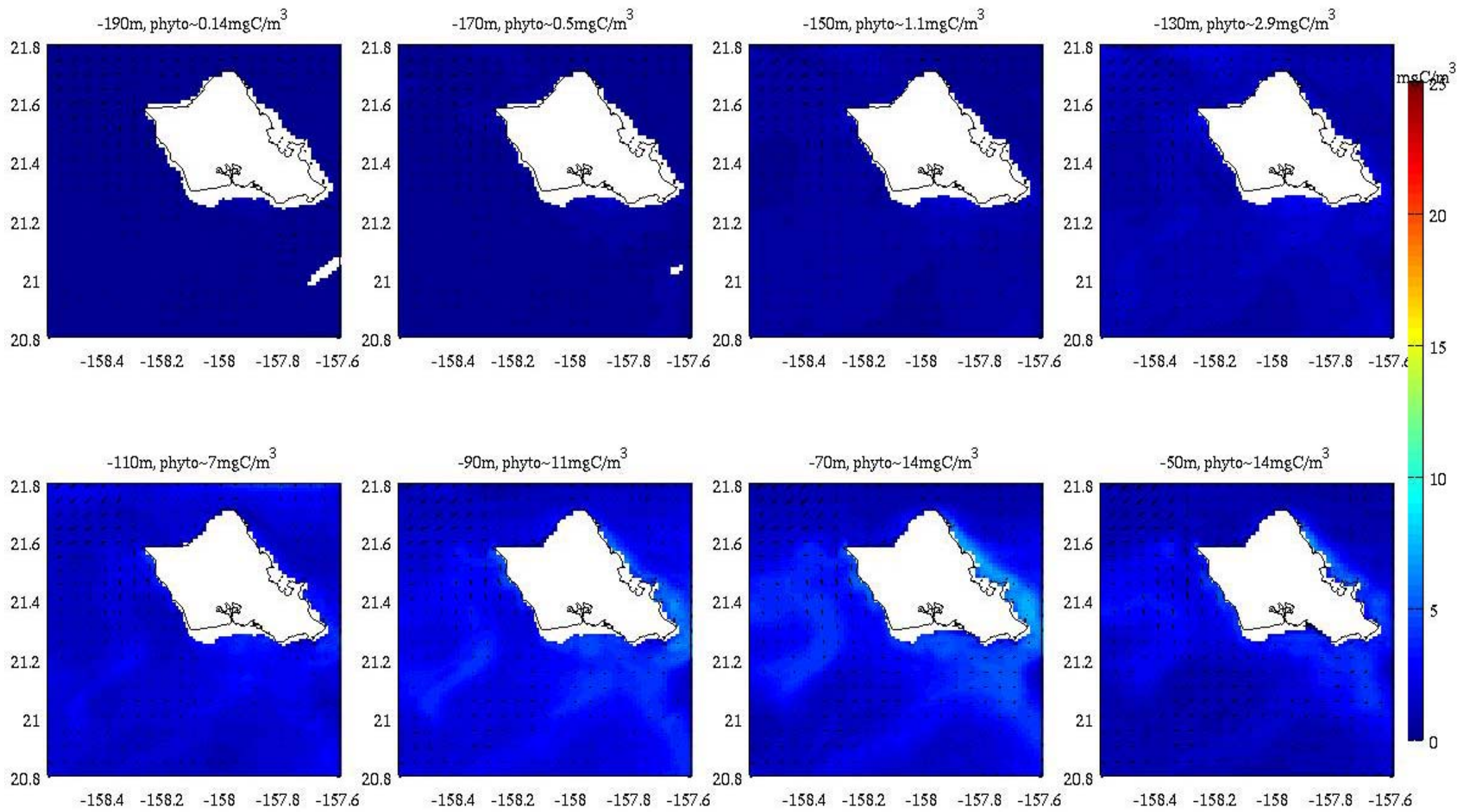

Figure 50. Diatom phytoplankton biomass in $\mathrm{mgC} / \mathrm{m}^{3}$ from the RevX 100MW OTEC simulation. Figures show the plan view at 190, 170, 150, 130, 110, 90, 70, and 50 meter depths at at June $17^{\text {th }}$ at $16: 40$ Hawaii Standard Time. 
24-Jun-2010 16:39:50 HST
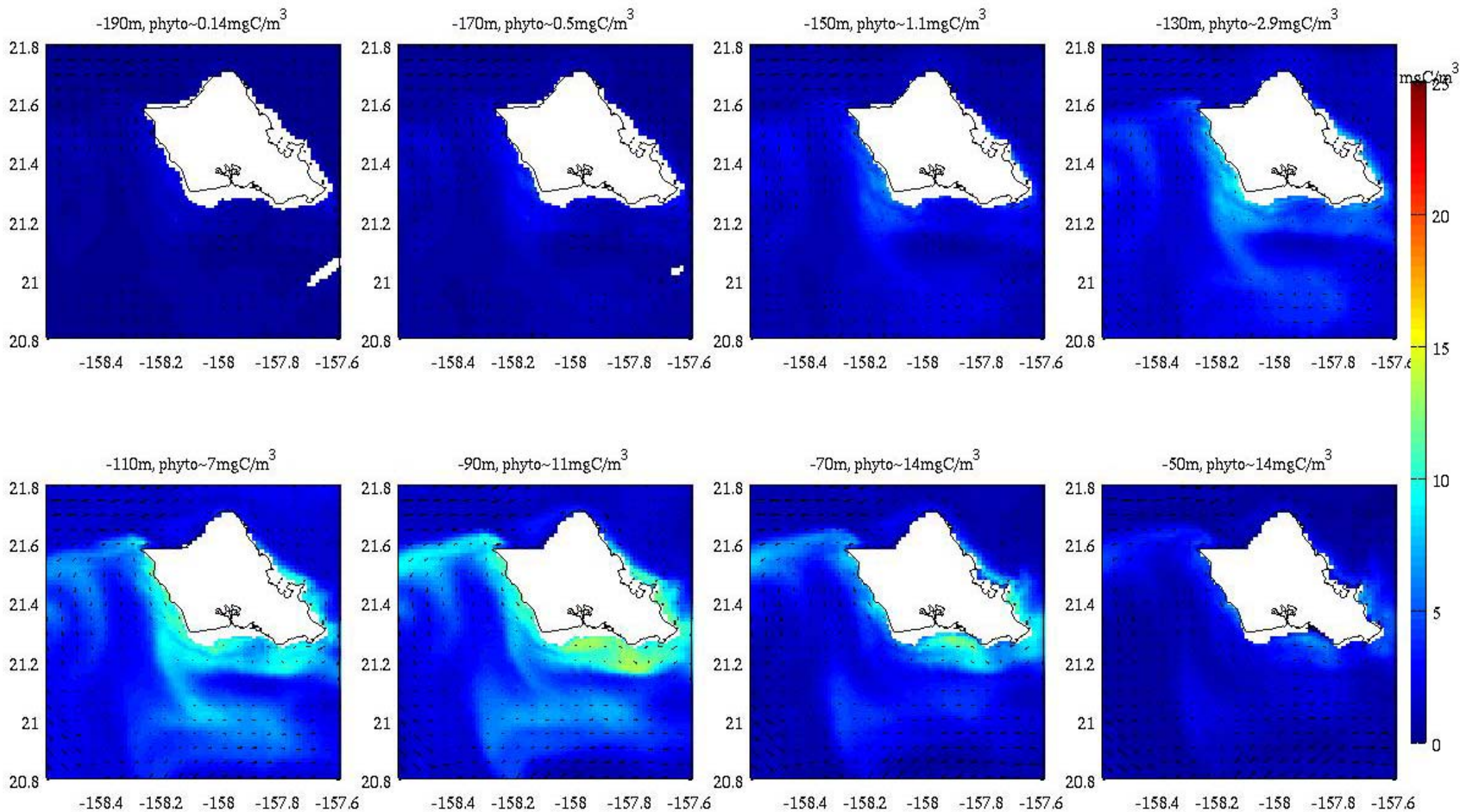

Figure 51. Diatom phytoplankton biomass in $\mathrm{mgC} / \mathrm{m}^{3}$ from the RevX 100MW OTEC simulation. Figures show the plan view at 190, 170, 150, 130, 110, 90, 70, and 50 meter depths at June $24^{\text {th }}$ at 16:40 Hawaii Standard Time. 
03-Jun-2010 16:39:50 HST
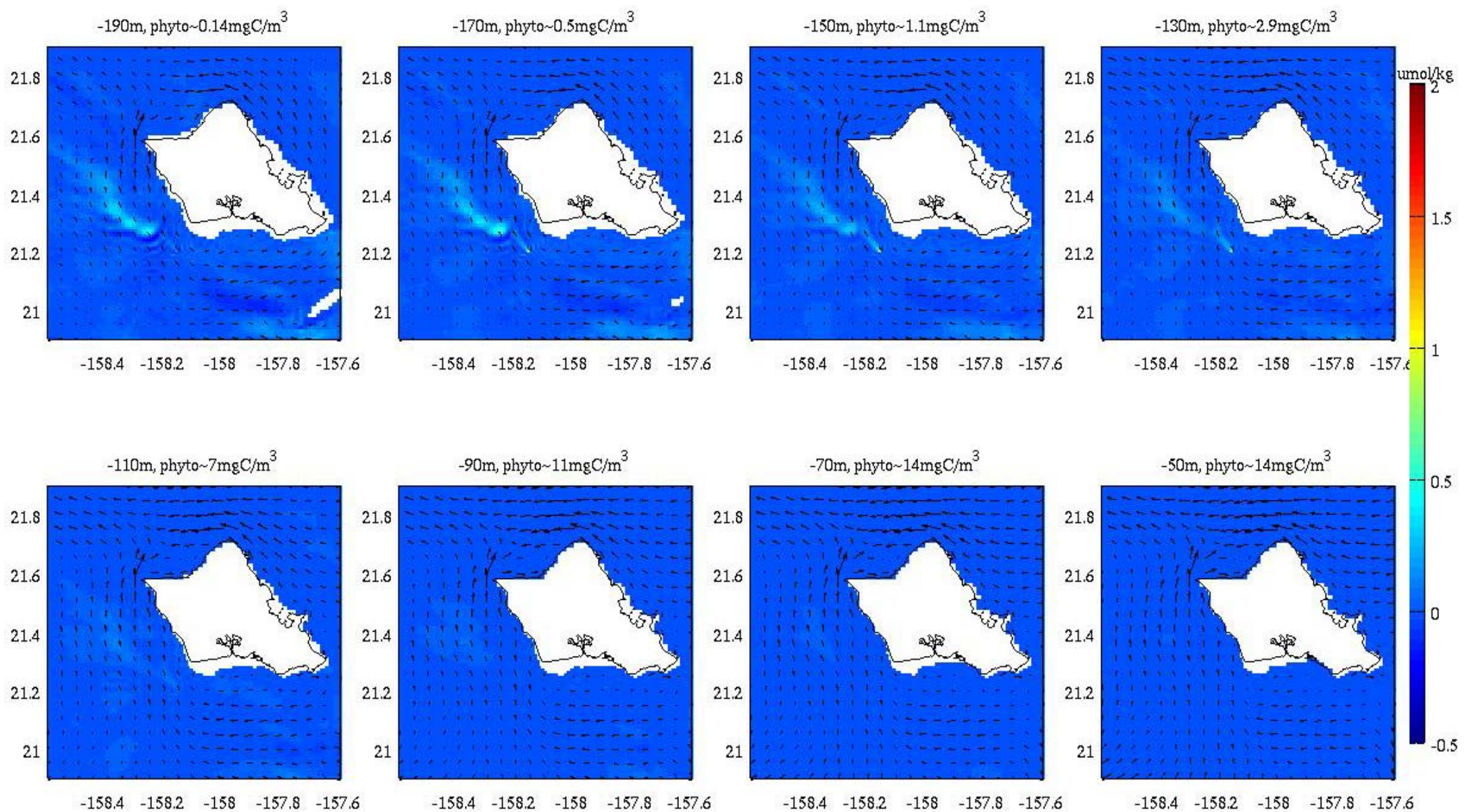

Figure 52. Nitrate perturbation (umol/kg) due to the RevX 100MW OTEC plant, and contour lines of the resultant diatom perturbation (black lines) drawn at intervals of $0.5 \mathrm{mgC} / \mathrm{m}^{3}$. June $3^{\text {rd }}, 2010$ at $16: 40$ Hawaii Standard Time. 
10-Jun-2010 16:39:50 HST
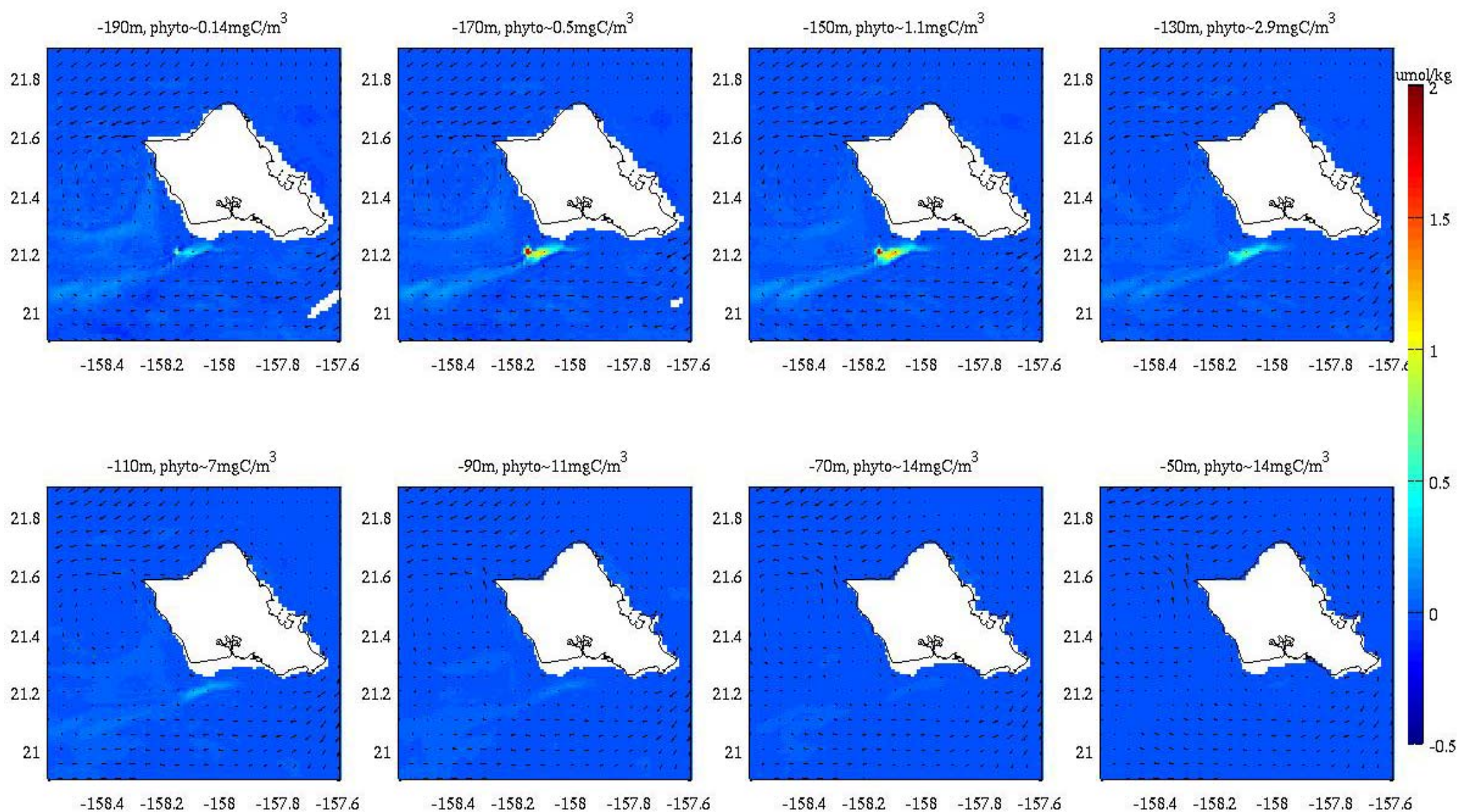

Figure 53. Nitrate perturbation (umol/kg) due to the RevX 100MW OTEC plant, and contour lines of the resultant diatom perturbation (black lines) drawn at intervals of $0.5 \mathrm{mgC} / \mathrm{m}^{3}$. June $10^{\text {th }}, 2010$ at $16: 40$ Hawaii Standard Time. 
17-Jun-2010 16:39:50 HST
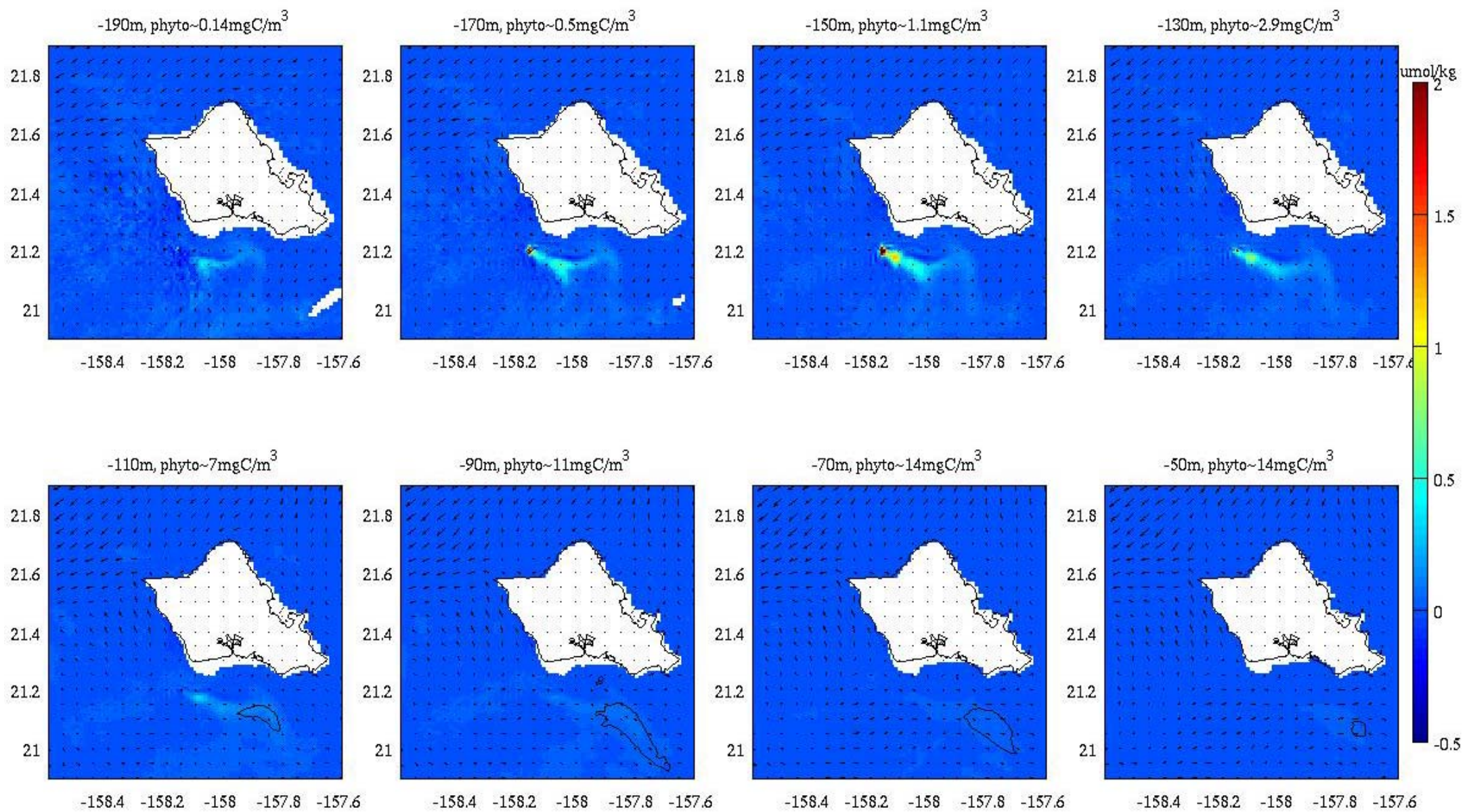

Figure 54. Nitrate perturbation (umol/kg) due to the RevX 100MW OTEC plant, and contour lines of the resultant diatom perturbation (black lines) drawn at intervals of $0.5 \mathrm{mgC} / \mathrm{m}^{3}$. June $17^{\text {th }}, 2010$ at $16: 40$ Hawaii Standard Time. 
24-Jun-2010 16:39:50 HST
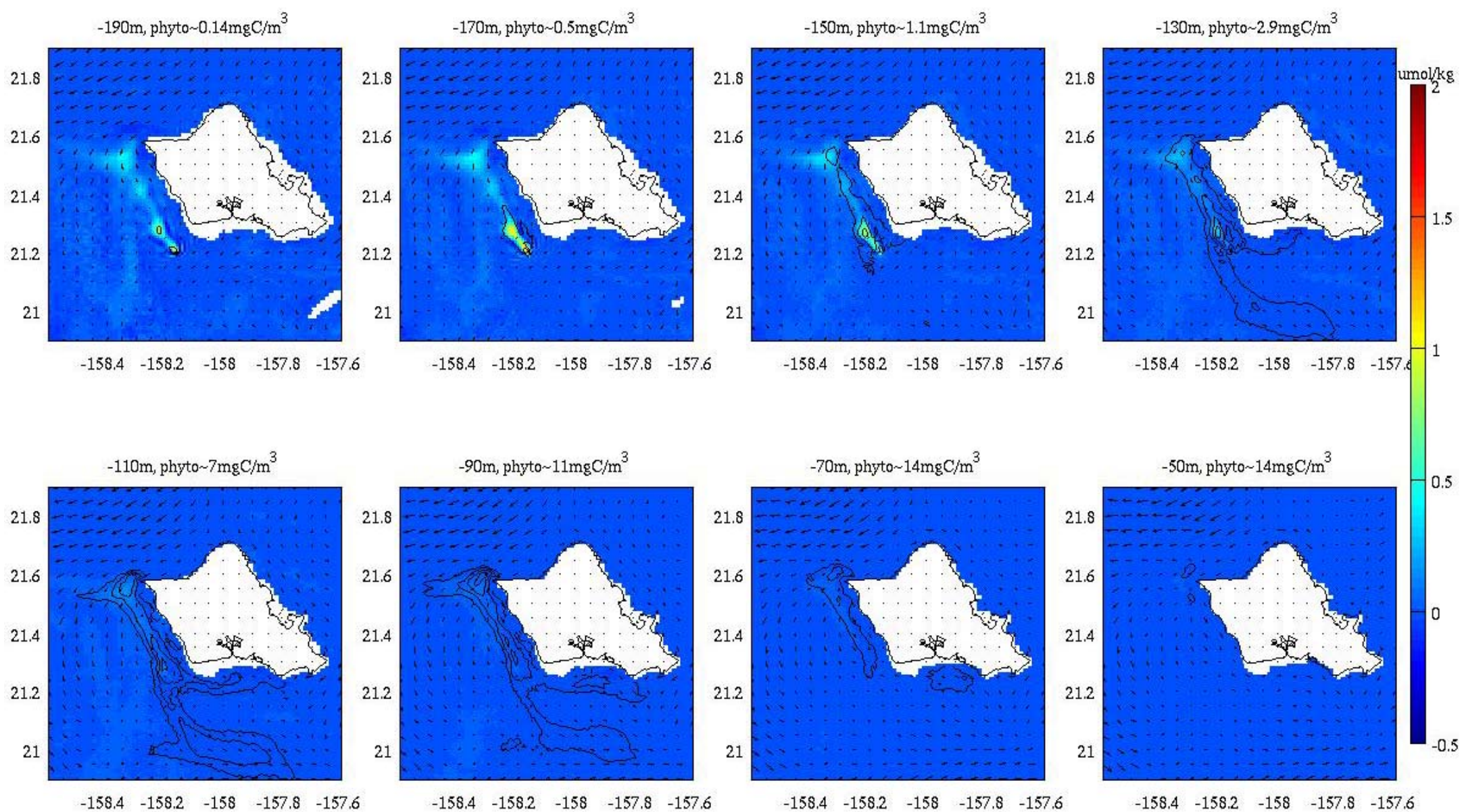

Figure 55. Nitrate perturbation (umol/kg) due to the RevX 100MW OTEC plant, and contour lines of the resultant diatom perturbation (black lines) drawn at intervals of $0.5 \mathrm{mgC} / \mathrm{m}^{3}$. June $24^{\text {th }}, 2010$ at $16: 40$ Hawaii Standard Time. 


\subsubsection{Three 100MW OTEC plants: 70 Meter Discharge, 4 Discharge plumes per Plant}

The model was run with three OTEC plants, each consisting of four separate flow structures discharging a total combined flow rate of $420 \mathrm{~m}^{3} / \mathrm{s}$ of warm water and $320 \mathrm{~m}^{3} / \mathrm{s}$ of cold water in a mixed discharge at 70 meter depth. Each discharge duct/port was assumed to have a diameter of $10.5 \mathrm{~m}$ producing a downward discharge velocity of about $2.18 \mathrm{~m} / \mathrm{s}$. The OTEC plants were spaced $1.1 \mathrm{~km}$ apart, a distance of two grid cells.

The results show an obvious increase in the biological response of picoplankton and diatoms compared to the single 100MW OTEC plant with the same discharge configurations. Images are represented as follows:

Figure 56 through Figure 59 shows the absolute pico-phytoplankton concentrations. Figure 60 through Figure 63 shows the nitrate and pico-phytoplankton perturbations compared to the the nonOTEC scenario. As seen in Figure 63, the $1 \mathrm{mgC} / \mathrm{m}^{3}$ contour of the pico-phytoplankton perturbation covers an area of $20-40 \mathrm{~km}$ by $10 \mathrm{~km}$ in size. There is significantly greater perturbation at the core of this area, reaching $4-6 \mathrm{mgC} / \mathrm{m}^{3}$, approximately three times the perturbation from a single 100MW OTEC plant of similar discharge configurations. This perturbation is approaching $25-50 \%$ of the ambient background concentrations for picophytoplankton, which are on the order of 10 to $15 \mathrm{mgC} / \mathrm{m}^{3}$.

The diatom perturbations shown in Figure 64 through Figure 67shows a similar increase relative to the single 100MW OTEC plant. The perturbation shown in Figure 68 through Figure 71 covers a broad area offshore of west and south Oahu, reaching concentrations of 4 to $6 \mathrm{mgC} / \mathrm{m}^{3}$ above the background levels (which are simulated to be $\sim 5-10 \mathrm{mgC} / \mathrm{m}^{3}$ nearshore of Oahu and less offshore). Whether such a perturbation to this ecosystem is acceptable is unclear until these estimates can be extended to an assessment of the higher trophic level organisms. These perturbations are not trivial, although they are small relative to natural diatom blooms observed in some of the periodic mesoscale eddies, nearshore embayments, and other non-oligotrophic ecosystems.

If lower phytoplankton concentrations were desired, an OTEC utility could install multiple systems with greater spacing between each plant. 
03-Jun-2010 16:39:50 HST
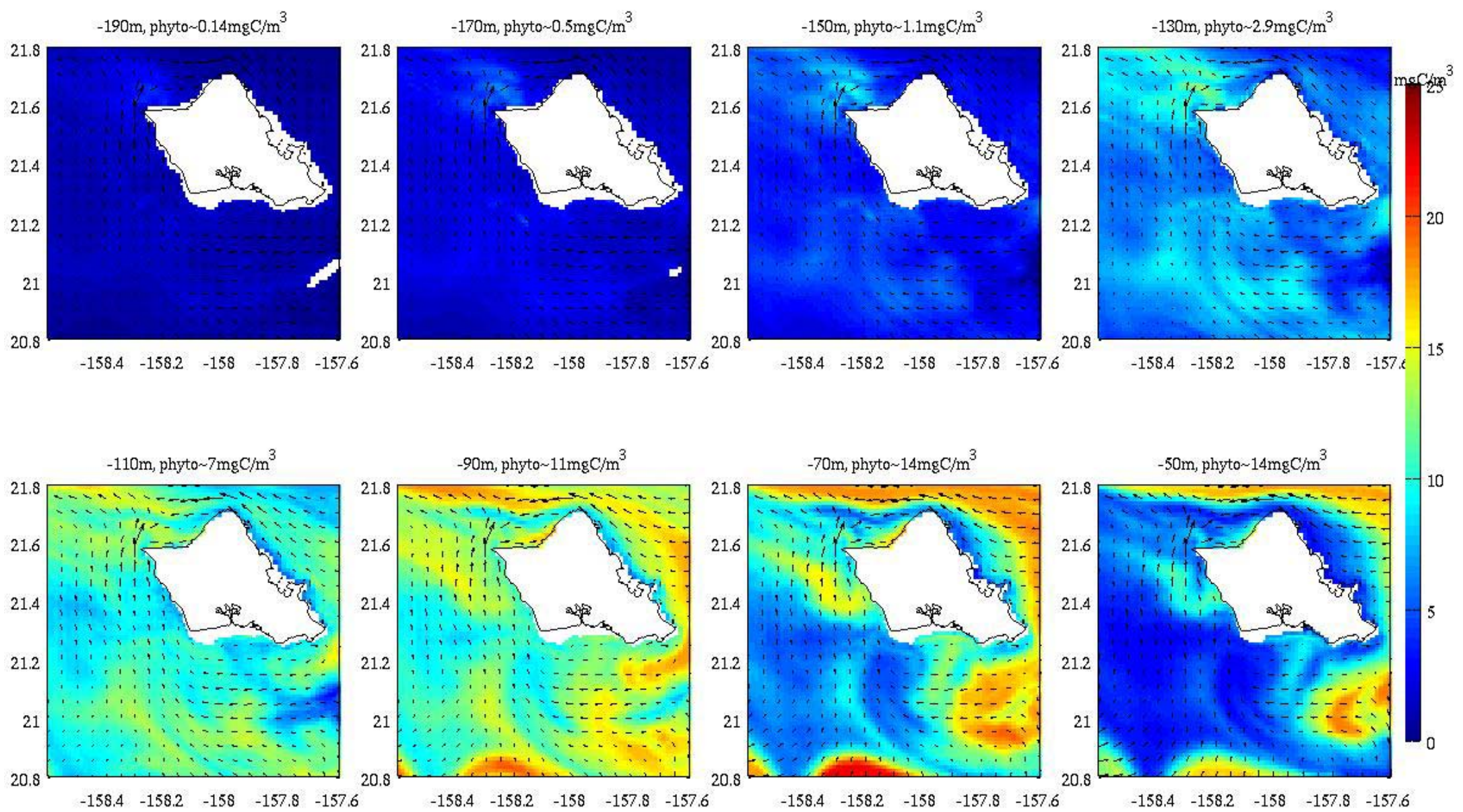

Figure 56. Pico-phytoplankton biomass (prochlorococcus, synechococcus, etc.) in $\mathrm{mgC} / \mathrm{m}^{3}$ from the RevX 3x100MW OTEC simulation. Figures show the plan view at $190,170,150,130,110,90,70$, and 50 meter depths at at June $3^{\text {rd }}$ at 16:40 Hawaii Standard Time. 
10-Jun-2010 16:39:50 HST
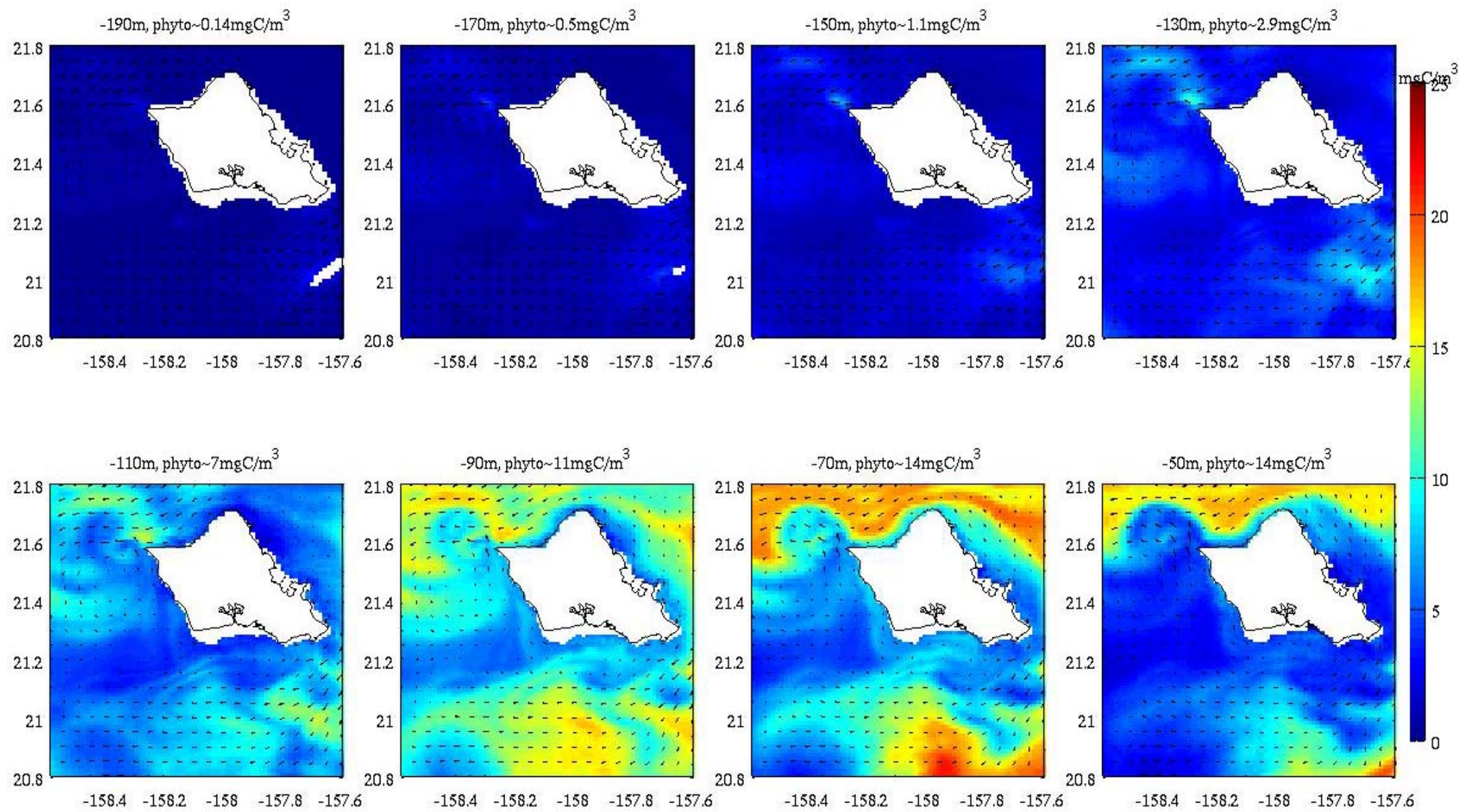

Figure 57. Pico-phytoplankton biomass (prochlorococcus, synechococcus, etc.) in $\mathrm{mgC} / \mathrm{m}^{3}$ from the RevX 3x100MW OTEC simulation. Figures show the plan view at $190,170,150,130,110,90,70$, and 50 meter depths at at June $10^{\text {th }}$ at 16:40 Hawaii Standard Time. 
17-Jun-2010 16:39:50 HST
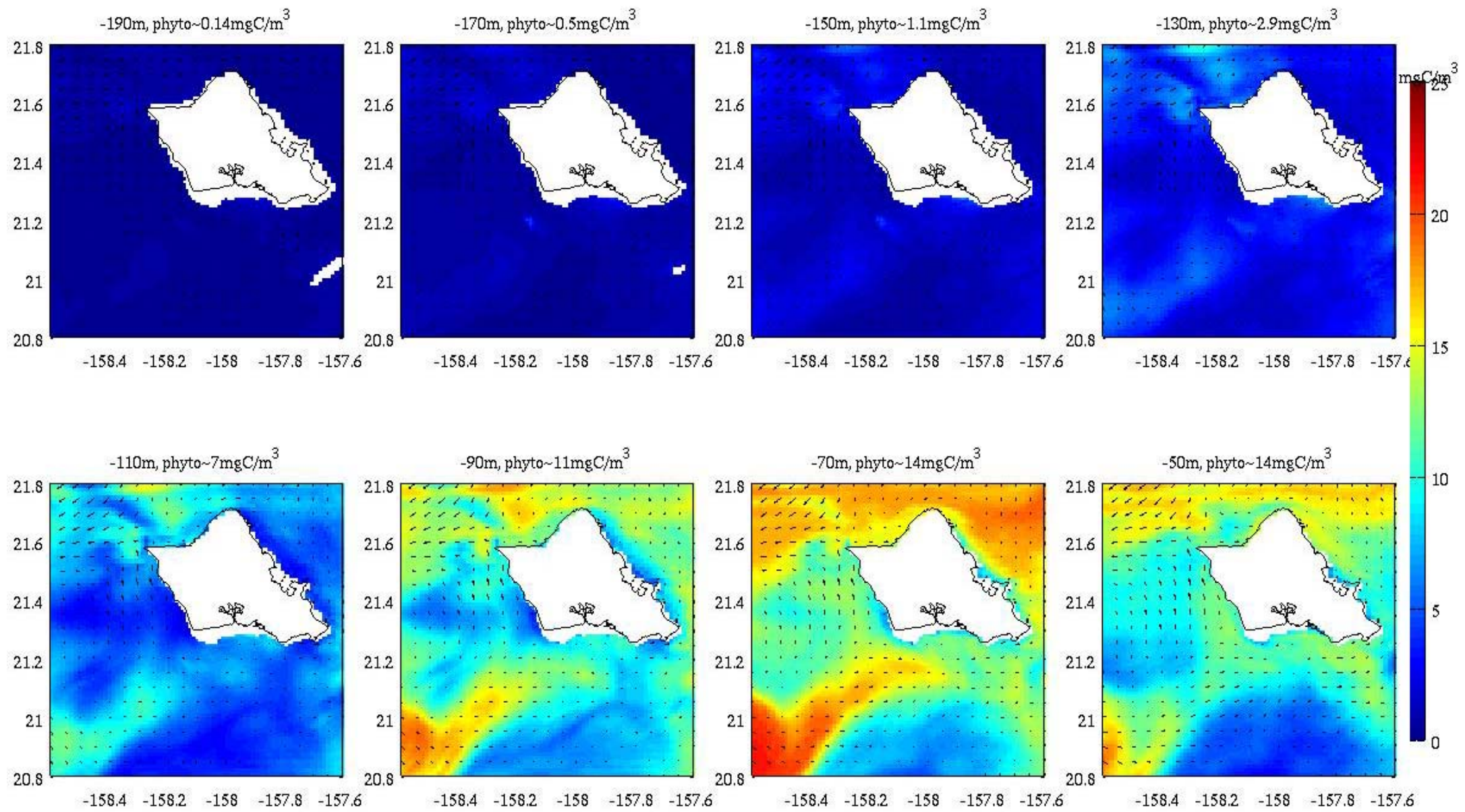

Figure 58. Pico-phytoplankton biomass (prochlorococcus, synechococcus, etc.) in $\mathrm{mgC} / \mathrm{m}^{3}$ from the RevX 3x100MW OTEC simulation. Figures show the plan view at $190,170,150,130,110,90,70$, and 50 meter depths at at June $17^{\text {th }}$ at $16: 40$ Hawaii Standard Time. 
24-Jun-2010 16:39:50 HST
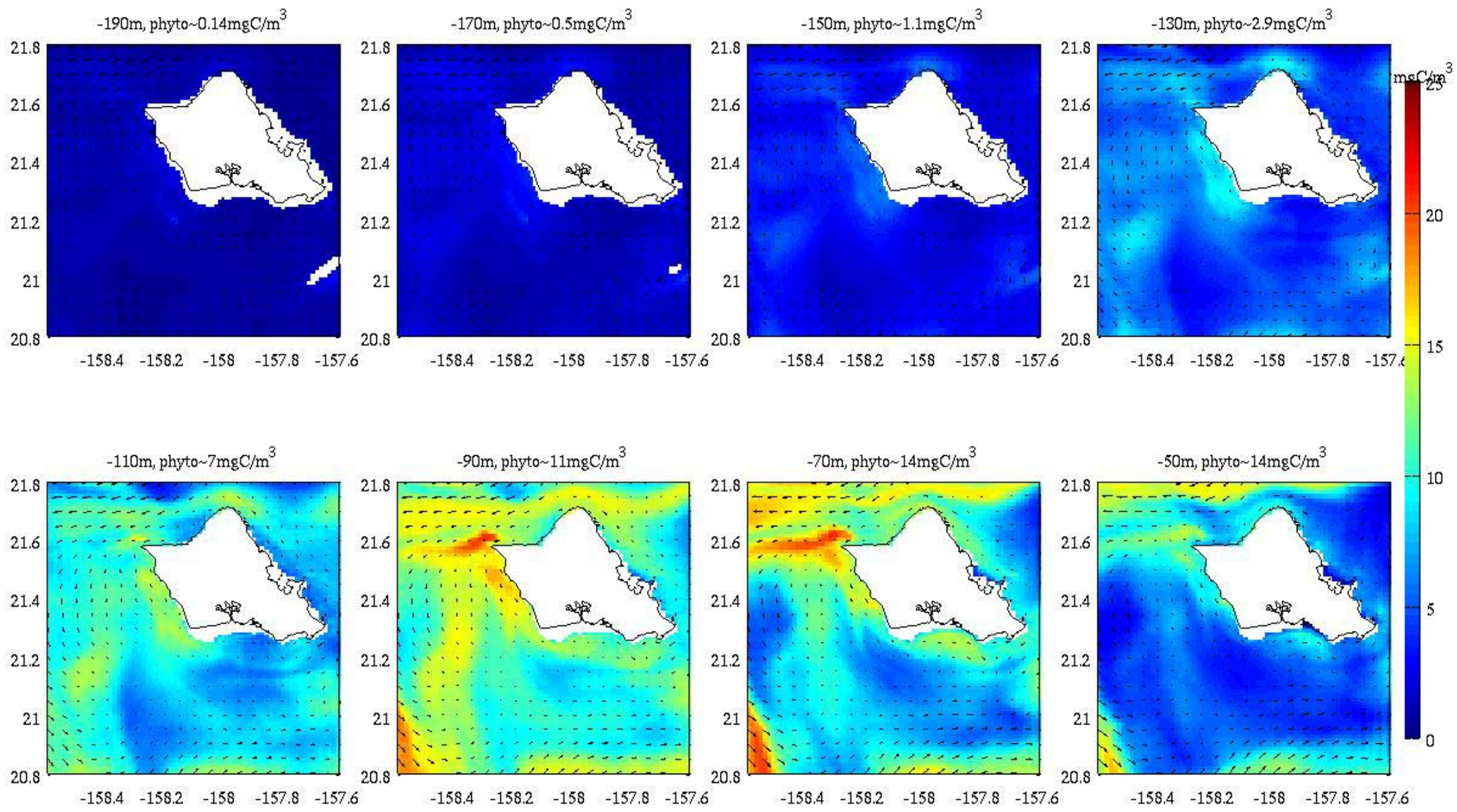

Figure 59. Pico-phytoplankton biomass (prochlorococcus, synechococcus, etc.) in $\mathrm{mgC} / \mathrm{m}^{3}$ from the RevX 3x100MW OTEC simulation. Figures show the plan view at $190,170,150,130,110,90,70$, and 50 meter depths at at June $24^{\text {th }}$ at $16: 40$ Hawaii Standard Time. 
03-Jun-2010 16:39:50 HST
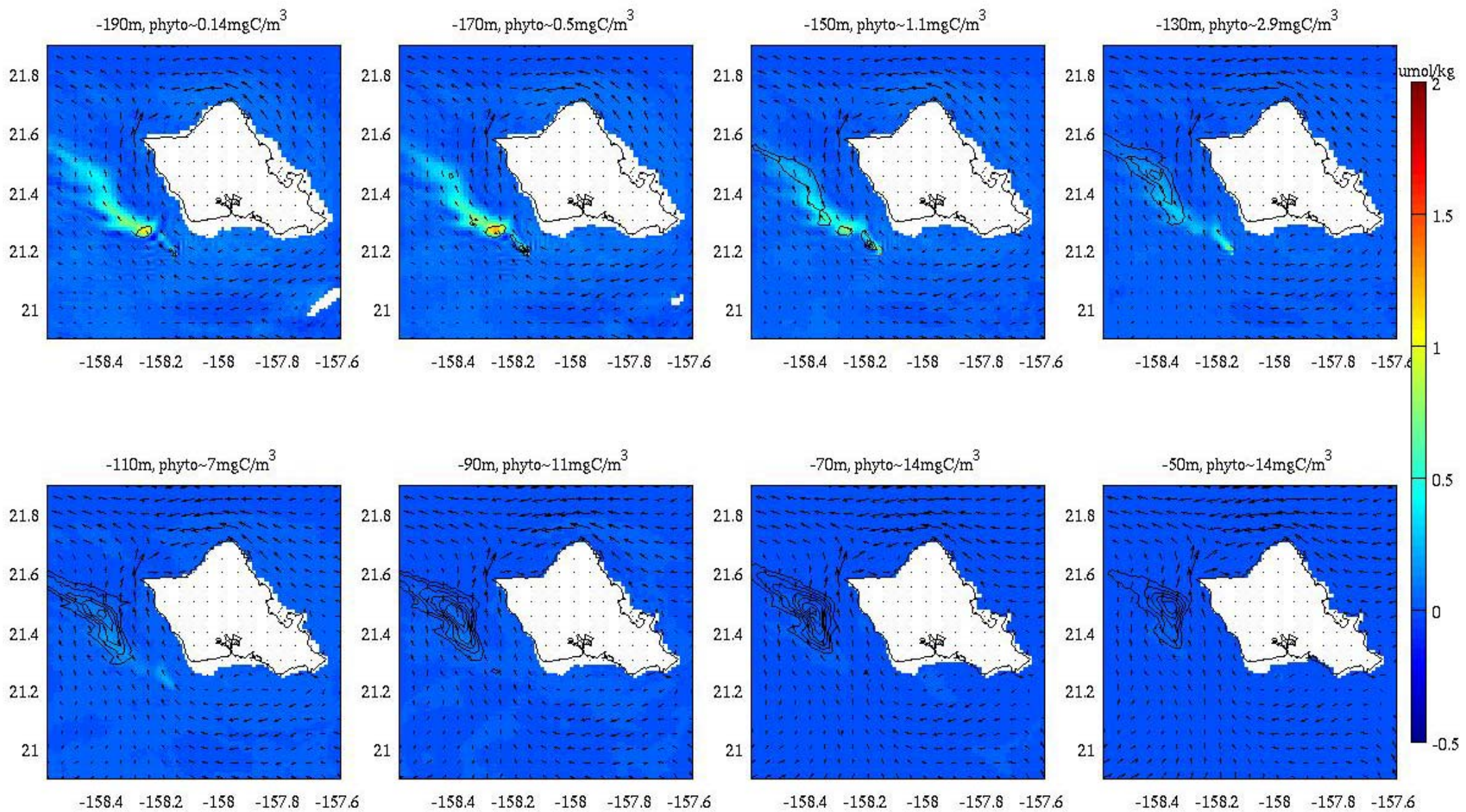

Figure 60. Nitrate perturbation (umol/kg) due to the RevX 3x100MW OTEC plant, and contour lines of the resultant pico-phytoplankton perturbation (black lines) drawn at intervals of $0.5 \mathrm{mgC} / \mathrm{m}^{3}$. June $3^{\text {rd }}, 2010$ at $16: 40$ Hawaii Standard Time. 
10-Jun-2010 16:39:50 HST
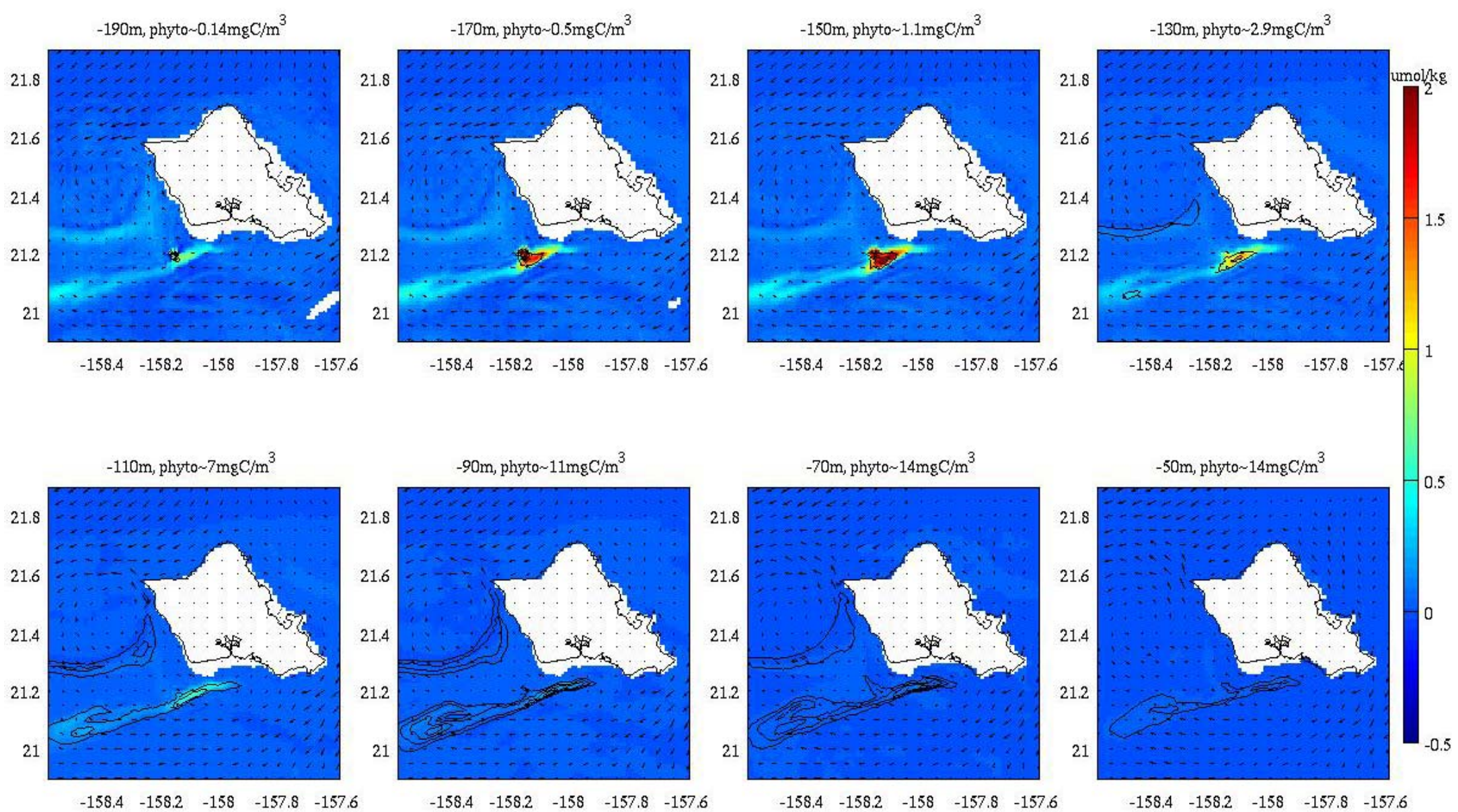

Figure 61. Nitrate perturbation (umol/kg) due to the RevX 3x100MW OTEC plant, and contour lines of the resultant pico-phytoplankton perturbation (black lines) drawn at intervals of $0.5 \mathrm{mgC} / \mathrm{m}^{3}$. June $10^{\text {th }}, 2010$ at 16:40 Hawaii Standard Time. 


\section{7-Jun-2010 16:39:50 HST}
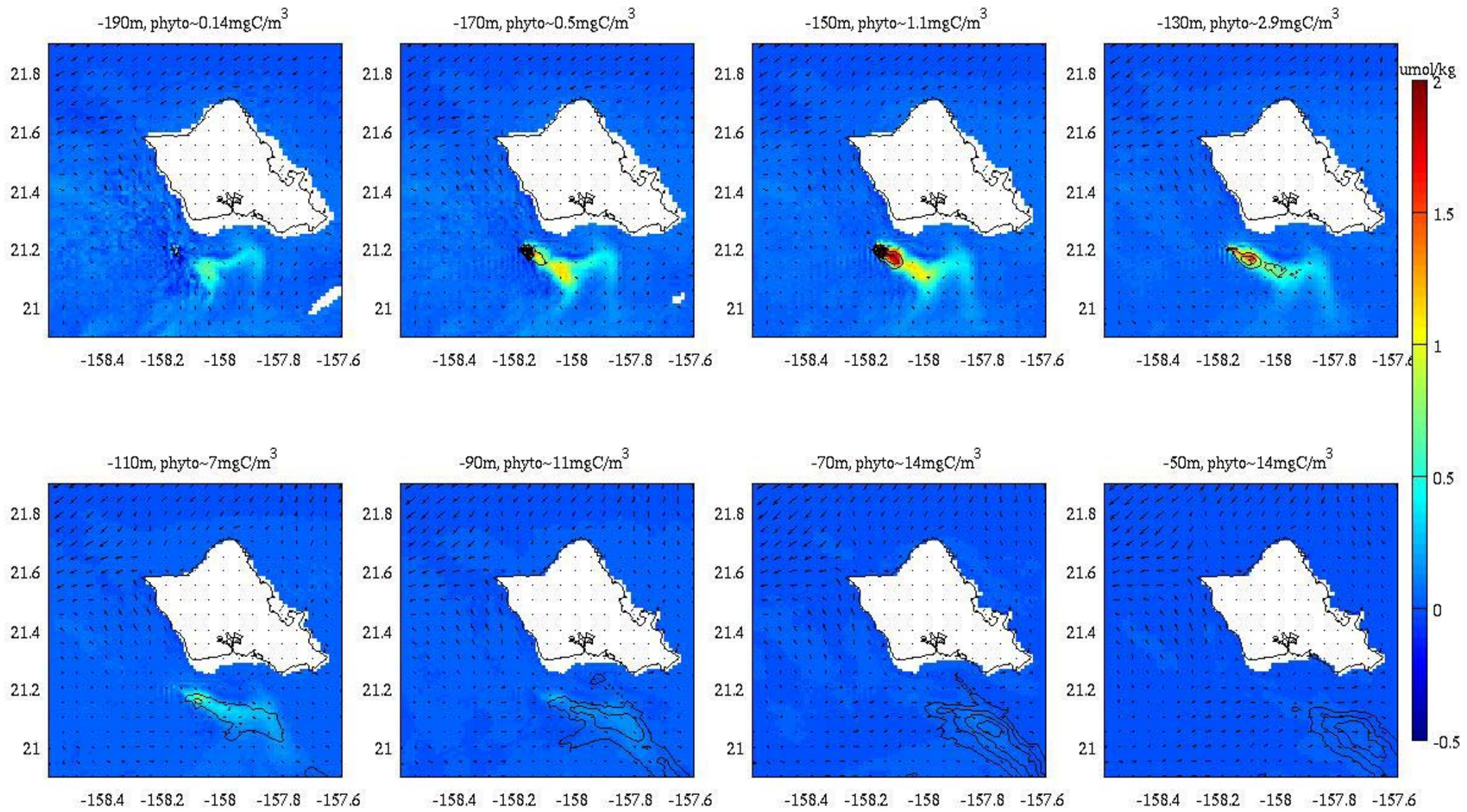

Figure 62. Nitrate perturbation (umol/kg) due to the RevX 3x100MW OTEC plant, and contour lines of the resultant pico-phytoplankton perturbation (black lines) drawn at intervals of $0.5 \mathrm{mgC} / \mathrm{m}^{3}$. June $17^{\text {th }}, 2010$ at $16: 40$ Hawaii Standard Time. 
24-Jun-2010 16:39:50 HST

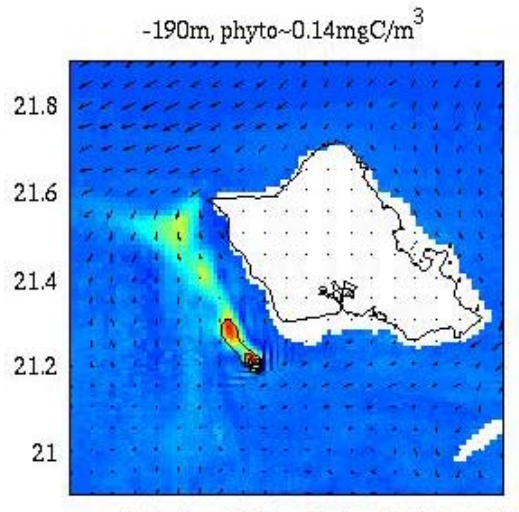

$-158.4 \quad-158.2-158 \quad-157.8-157.6$

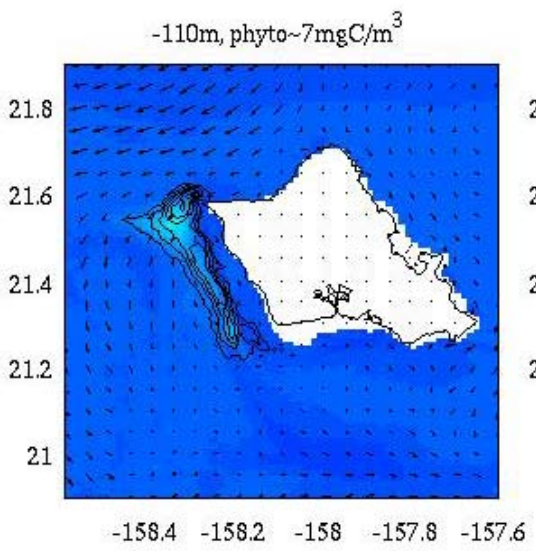

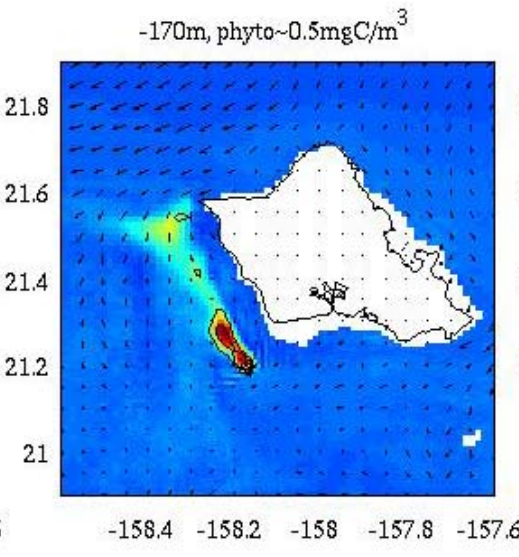

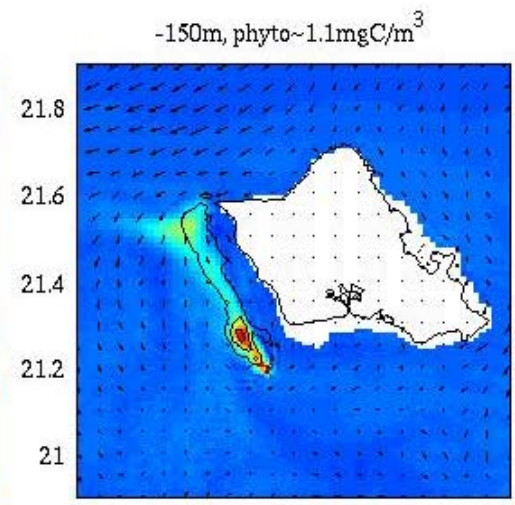

$-158.4-158.2-158 \quad-157.8-157.6$
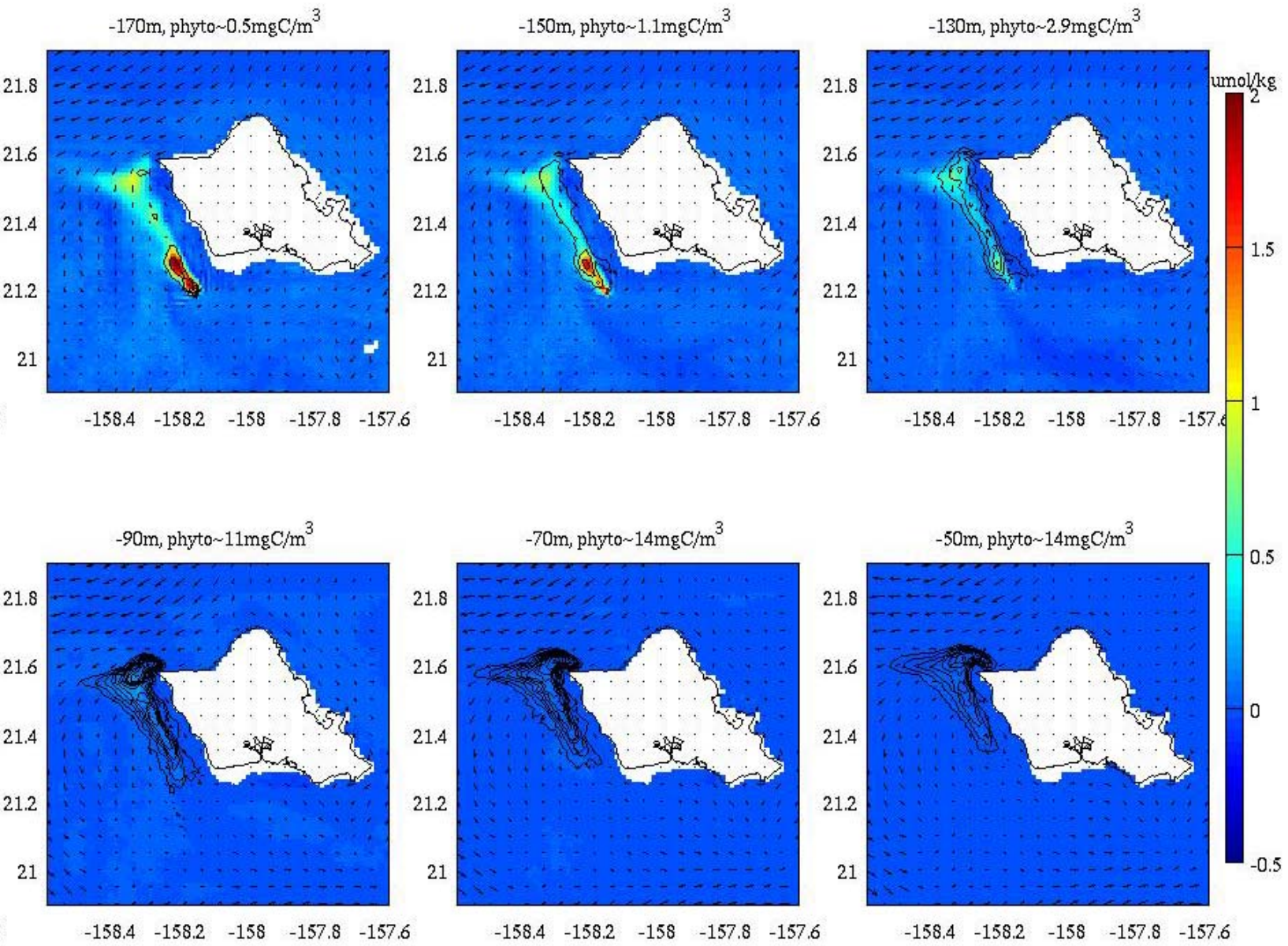

Figure 63. Nitrate perturbation (umol/kg) due to the RevX 3x100MW OTEC plant, and contour lines of the resultant pico-phytoplankton perturbation (black lines) drawn at intervals of $0.5 \mathrm{mgC} / \mathrm{m}^{3}$. June $24^{\text {th }}, 2010$ at 16:40 Hawaii Standard Time. 
03-Jun-2010 16:39:50 HST
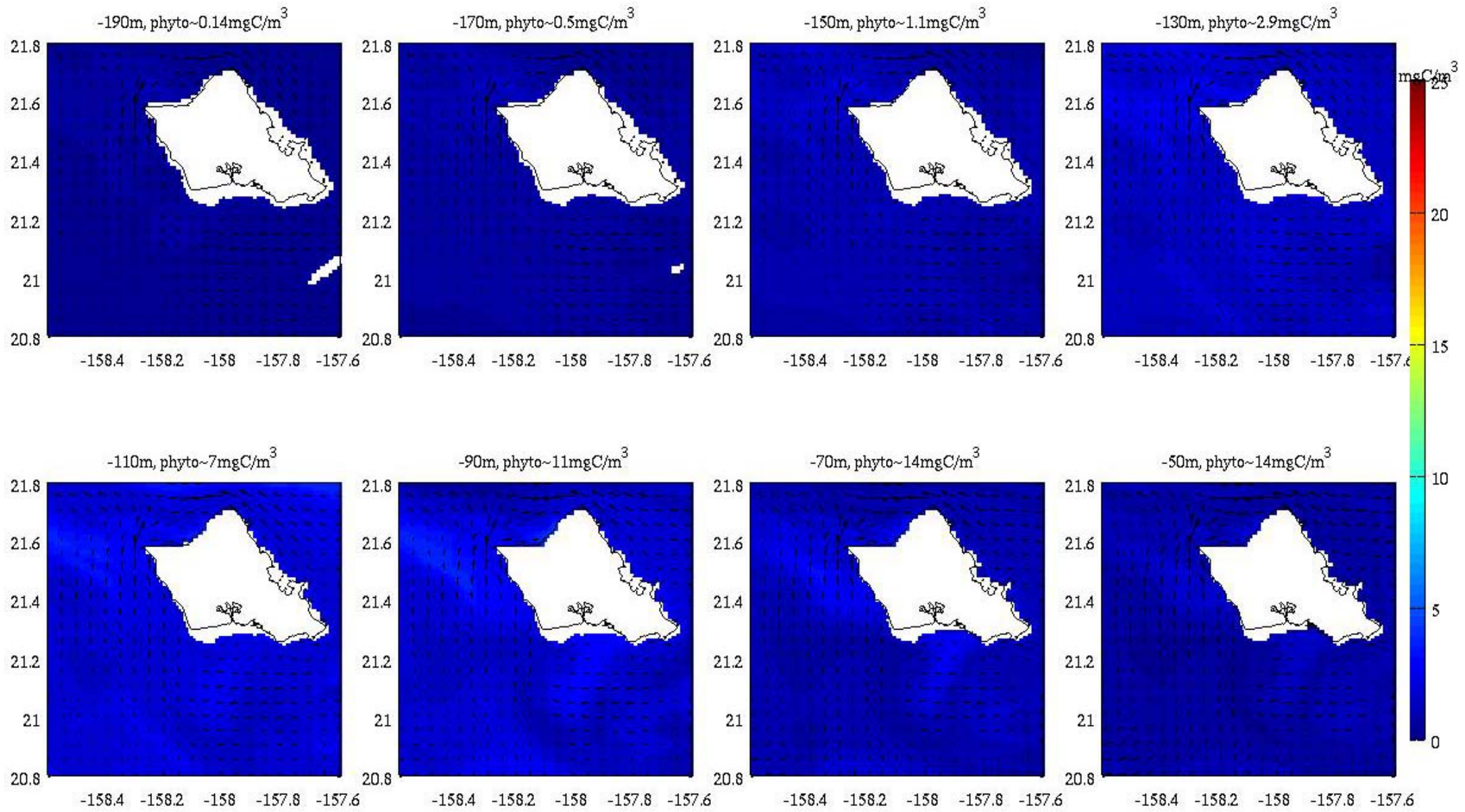

Figure 64. Diatom phytoplankton biomass in $\mathrm{mgC} / \mathrm{m}^{3}$ from the RevX 3x100MW OTEC simulation. Figures show the plan view at 190, 170, 150, 130, 110, 90, 70 , and 50 meter depths at at June $3^{\text {rd }}$ at 16:40 Hawaii Standard Time. 
10-Jun-2010 16:39:50 HST
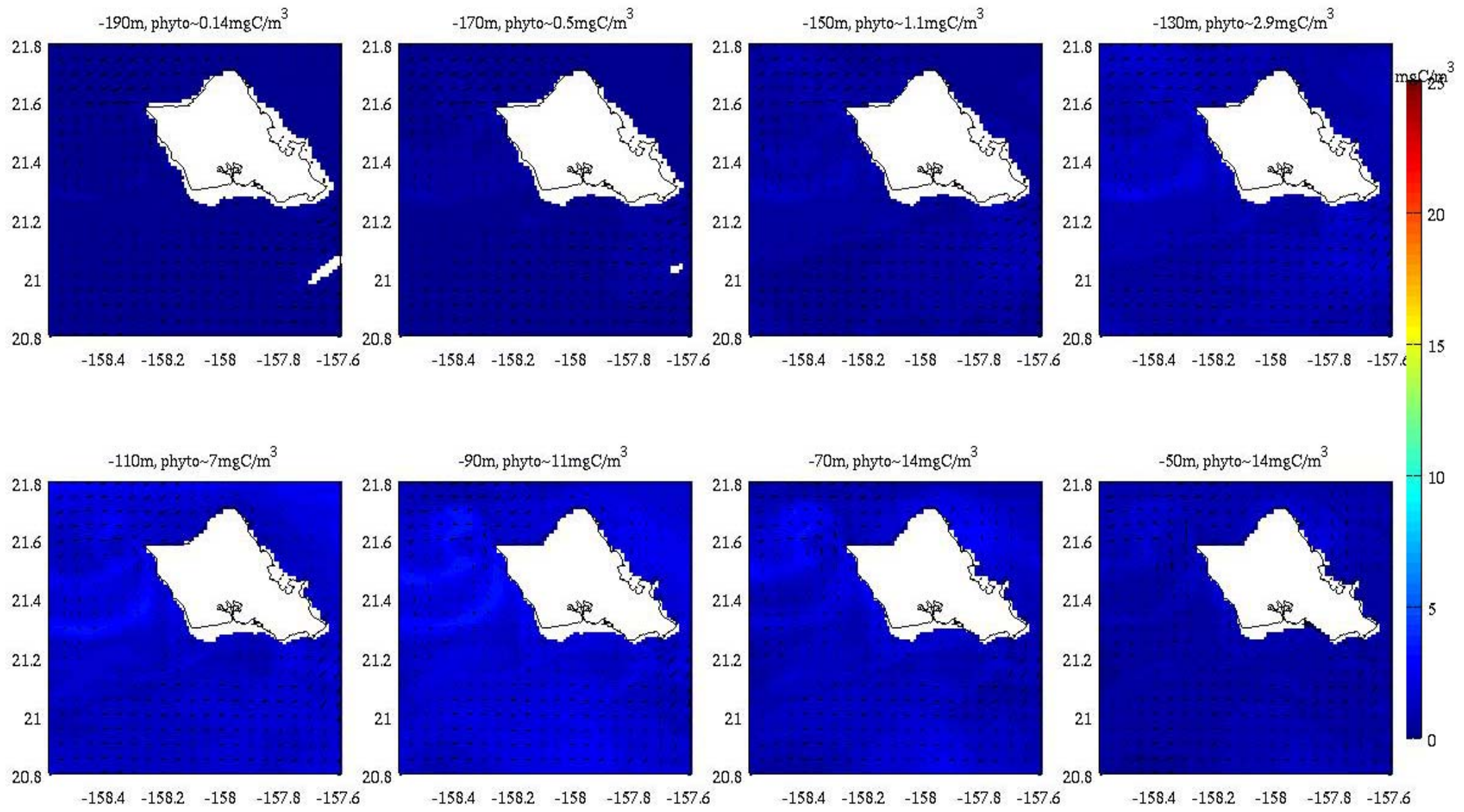

Figure 65. Diatom phytoplankton biomass in $\mathrm{mgC} / \mathrm{m}^{3}$ from the RevX 3x100MW OTEC simulation. Figures show the plan view at 190, 170, 150, 130, 110, 90, 70 , and 50 meter depths at at June $10^{\text {th }}$ at 16:40 Hawaii Standard Time. 


\section{7-Jun-2010 16:39:50 HST}
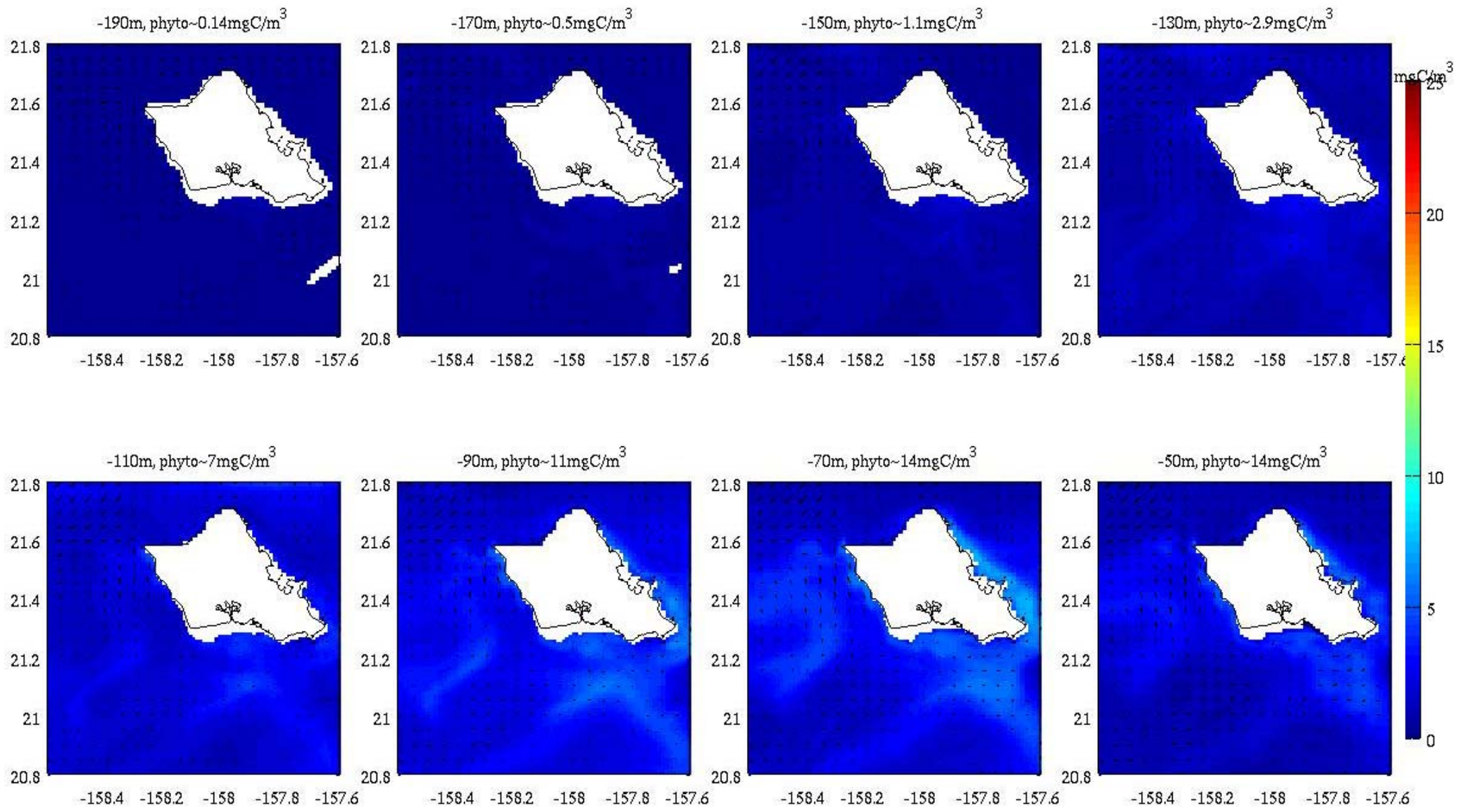

Figure 66. Diatom phytoplankton biomass in $\mathrm{mgC} / \mathrm{m}^{3}$ from the $\operatorname{RevX} 3 \times 100 \mathrm{MW}$ OTEC simulation. Figures show the plan view at 190, 170, 150, 130, 110, 90, 70 , and 50 meter depths at at June $17^{\text {th }}$ at 16:40 Hawaii Standard Time. 
24-Jun-2010 16:39:50 HST
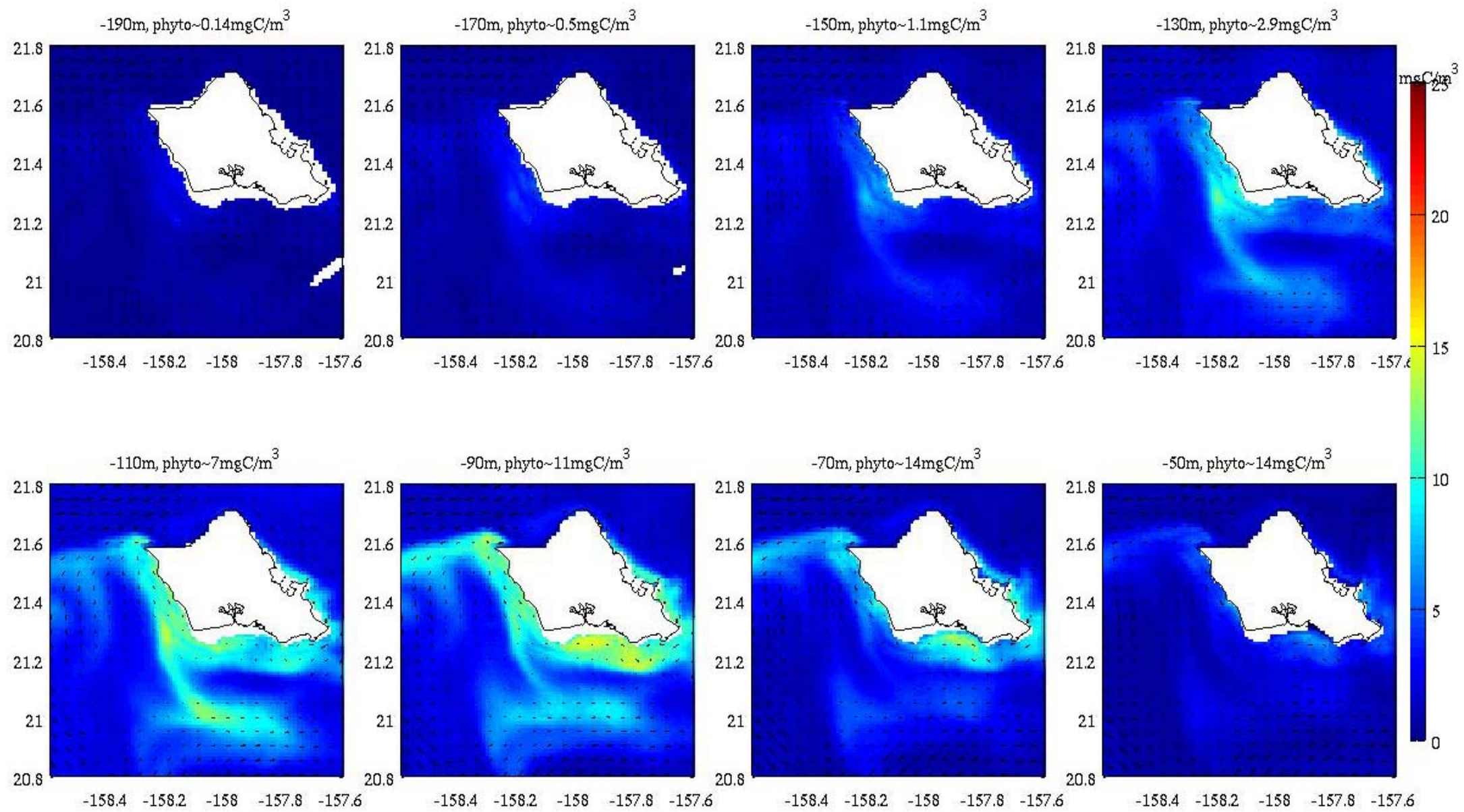

Figure 67. Diatom phytoplankton biomass in $\mathrm{mgC} / \mathrm{m}^{3}$ from the RevX 3x100MW OTEC simulation. Figures show the plan view at 190, 170, 150, 130, 110, 90, 70 , and 50 meter depths at at June $24^{\text {th }}$ at 16:40 Hawaii Standard Time. 
03-Jun-2010 16:39:50 HST

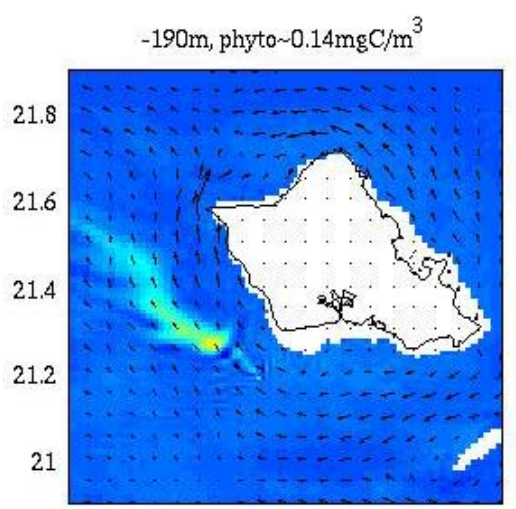

$\begin{array}{lllll}-158.4 & -158.2 & -158 & -157.8 & -157.6\end{array}$

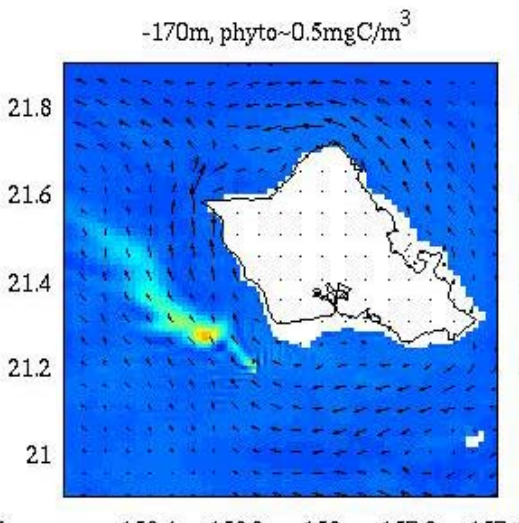

$\begin{array}{lllll}-158.4 & -158.2 & -158 & -157.8 & -157.6\end{array}$

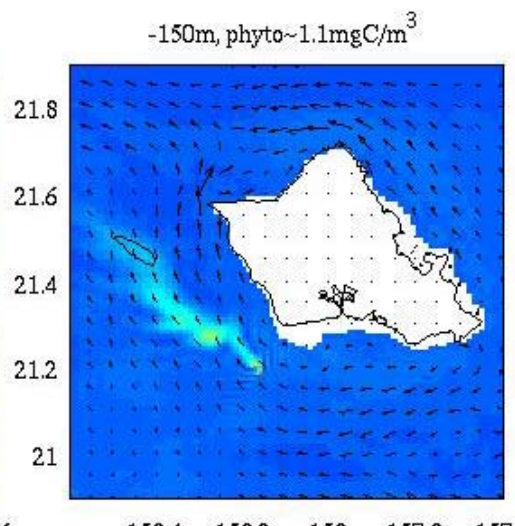

$\begin{array}{lllll}-158.4 & -158.2 & -158 & -157.8 & -157.6\end{array}$
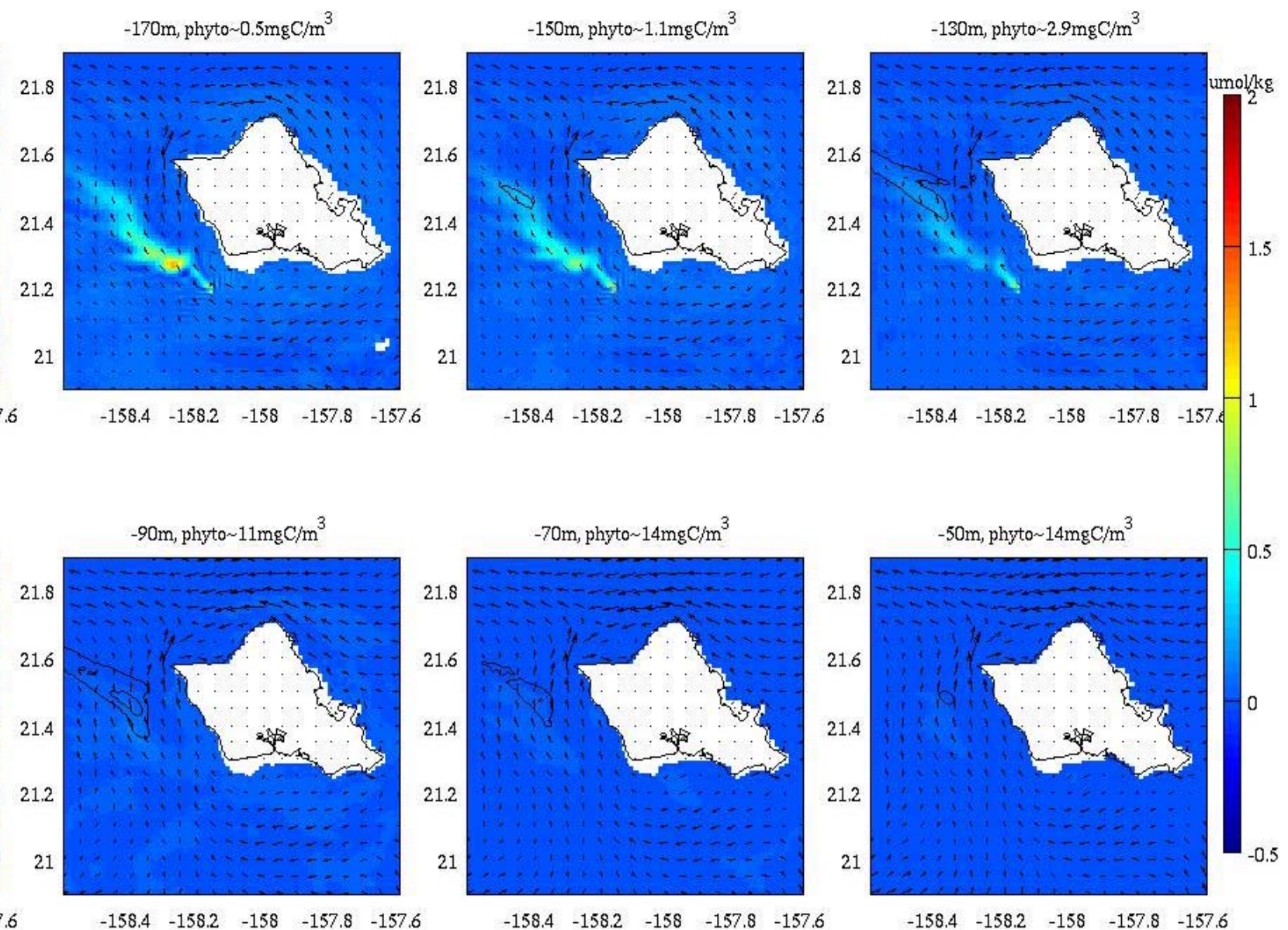

$-70 \mathrm{~m}$, phyto $14 \mathrm{mgC} / \mathrm{m}^{3}$
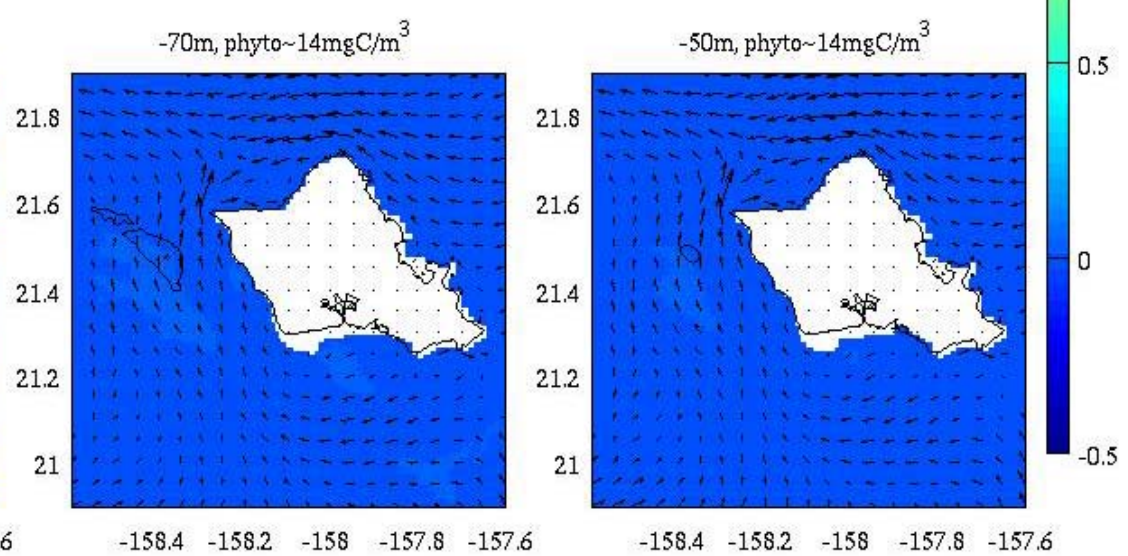

Figure 68. Nitrate perturbation (umol/kg) due to the RevX 3x100MW OTEC plant, and contour lines of the resultant diatom perturbation (black lines) drawn at intervals of $0.5 \mathrm{mgC} / \mathrm{m}^{3}$. June $3^{\text {rd }}, 2010$ at $16: 40$ Hawaii Standard Time. 


\section{0-Jun-2010 16:39:50 HST}

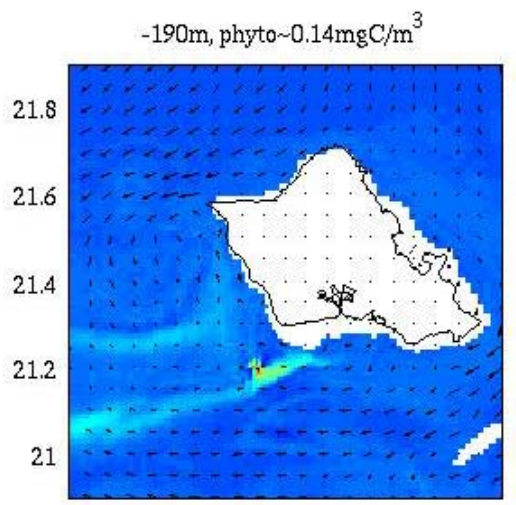

$-158.4-158.2-158 \quad-157.8-157.6$

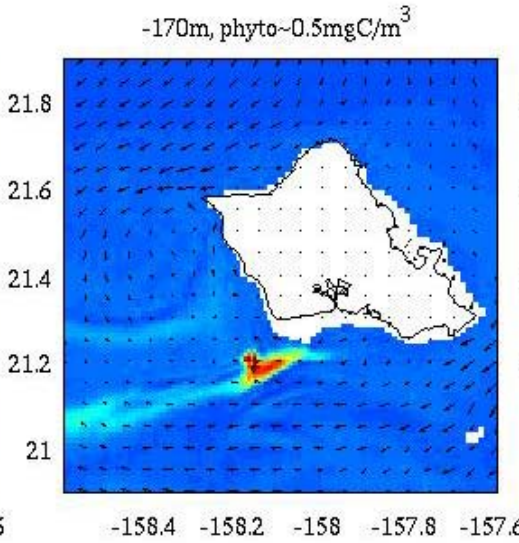

$-158.4-158.2-158 \quad-157.8-157.6$
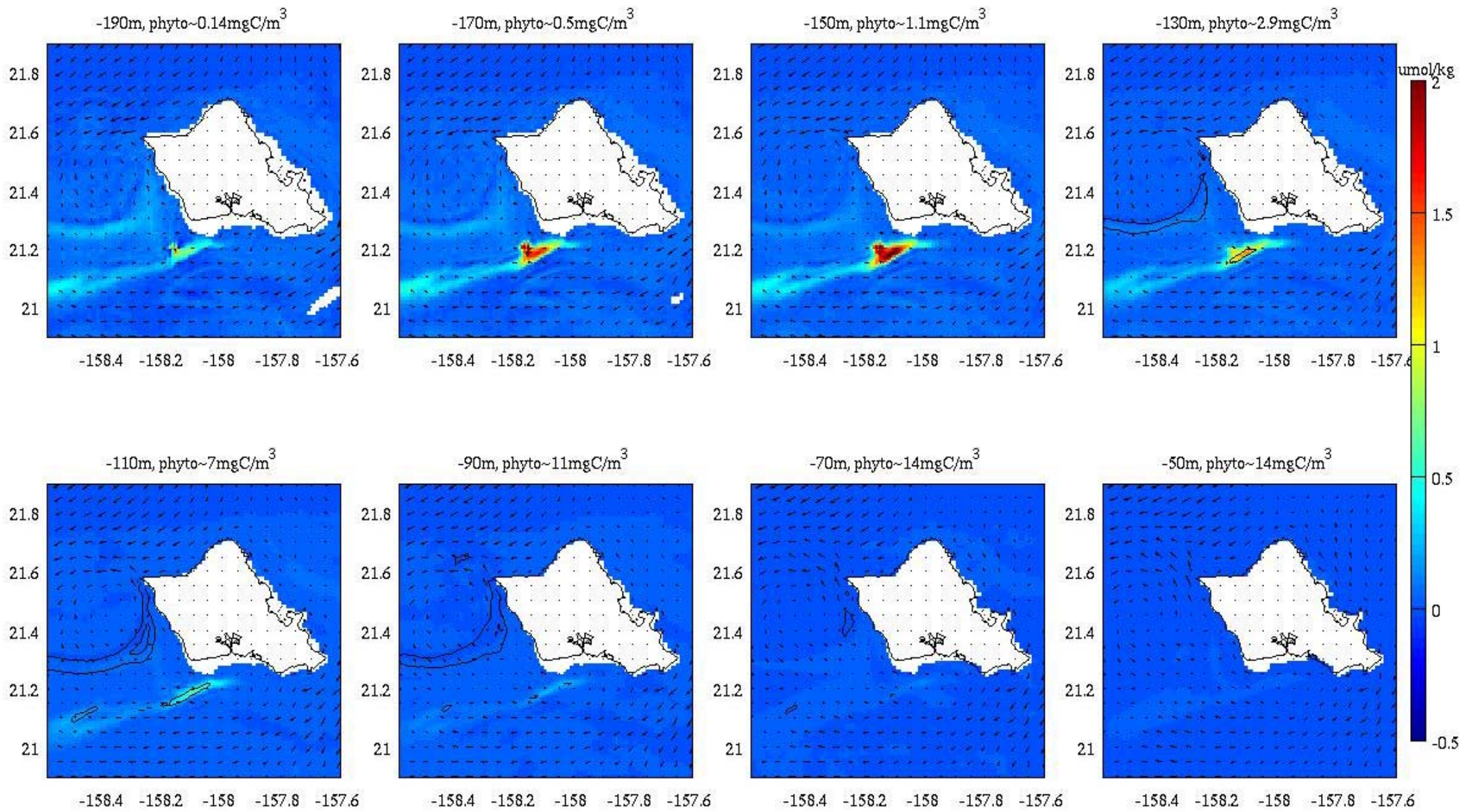

Figure 69. Nitrate perturbation (umol/kg) due to the RevX 3x100MW OTEC plant, and contour lines of the resultant diatom perturbation (black lines) drawn at intervals of $0.5 \mathrm{mgC} / \mathrm{m}^{3}$. June $10^{\text {th }}, 2010$ at 16:40 Hawaiian Standard Time. 
17-Jun-2010 16:39:50 HST
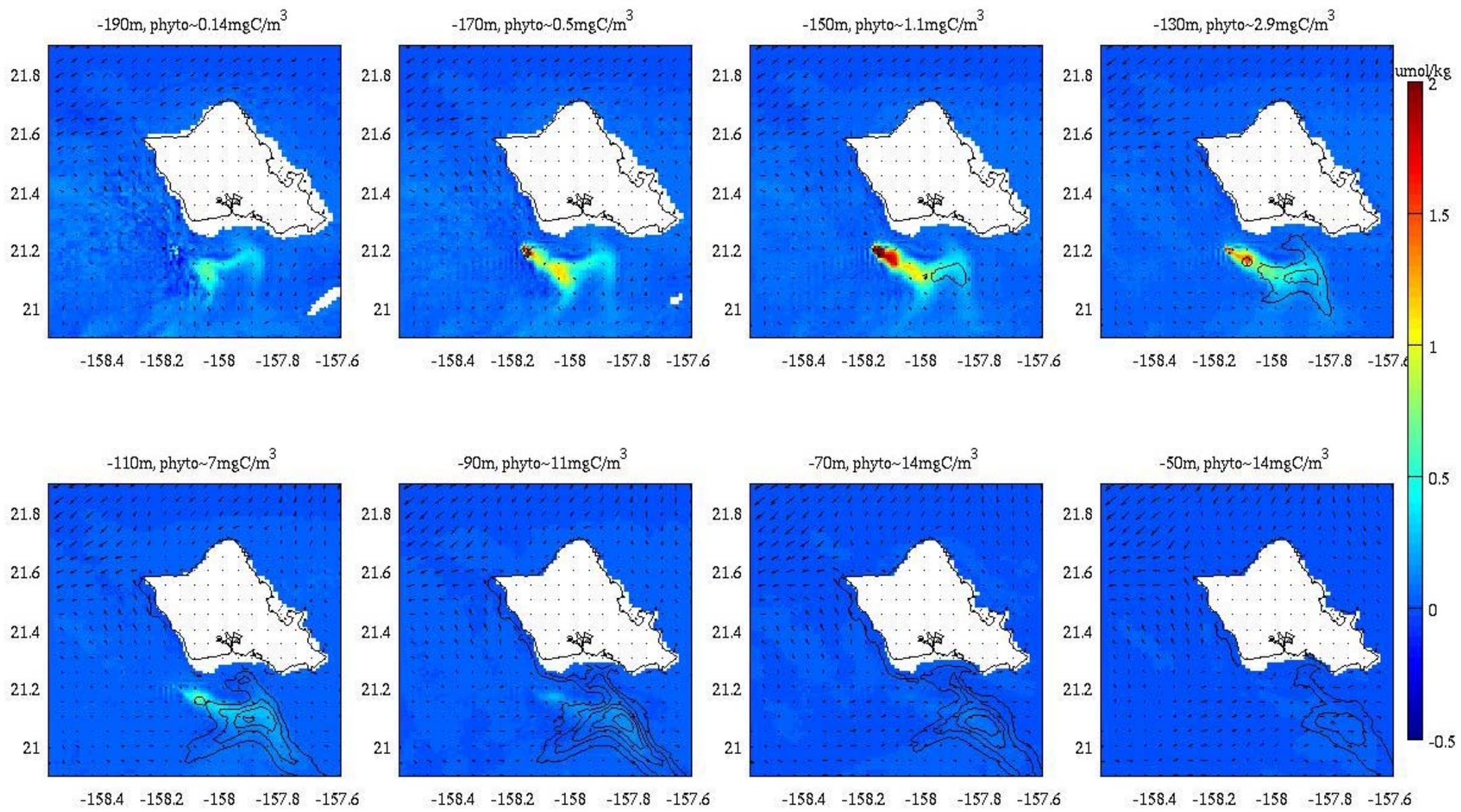

Figure 70. Nitrate perturbation (umol/kg) due to the RevX 3x100MW OTEC plant, and contour lines of the resultant diatom perturbation (black lines) drawn at intervals of $0.5 \mathrm{mgC} / \mathrm{m}^{3}$. June $17^{\text {th }}, 2010$ at $16: 40$ Hawaiian Standard Time. 
24-Jun-2010 16:39:50 HST

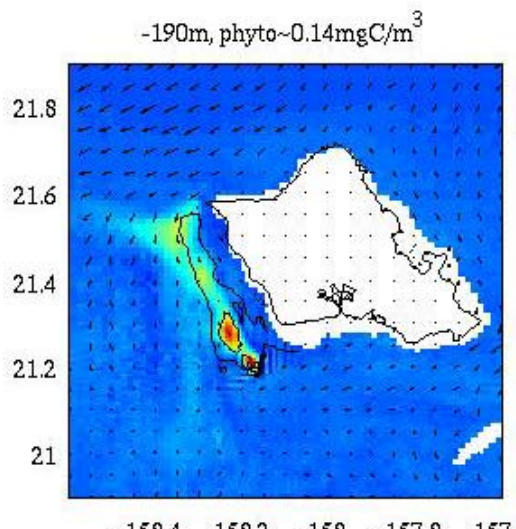

$\begin{array}{lllll}-158.4 & -158.2 & -158 & -157.8 & -157.6\end{array}$
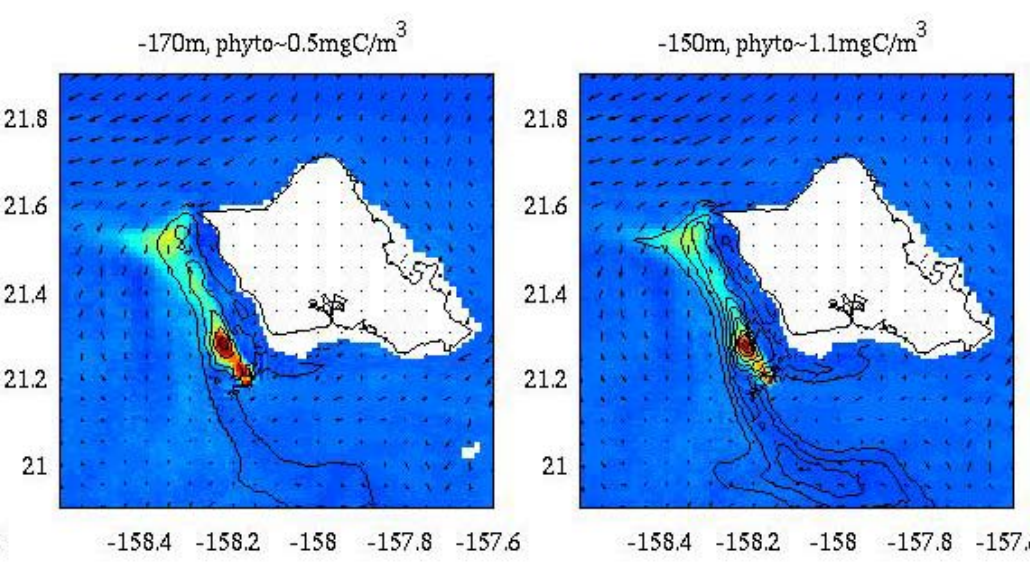

$\begin{array}{lllll}-158.4 & -158.2 & -158 & -157.8 & -157.6\end{array}$
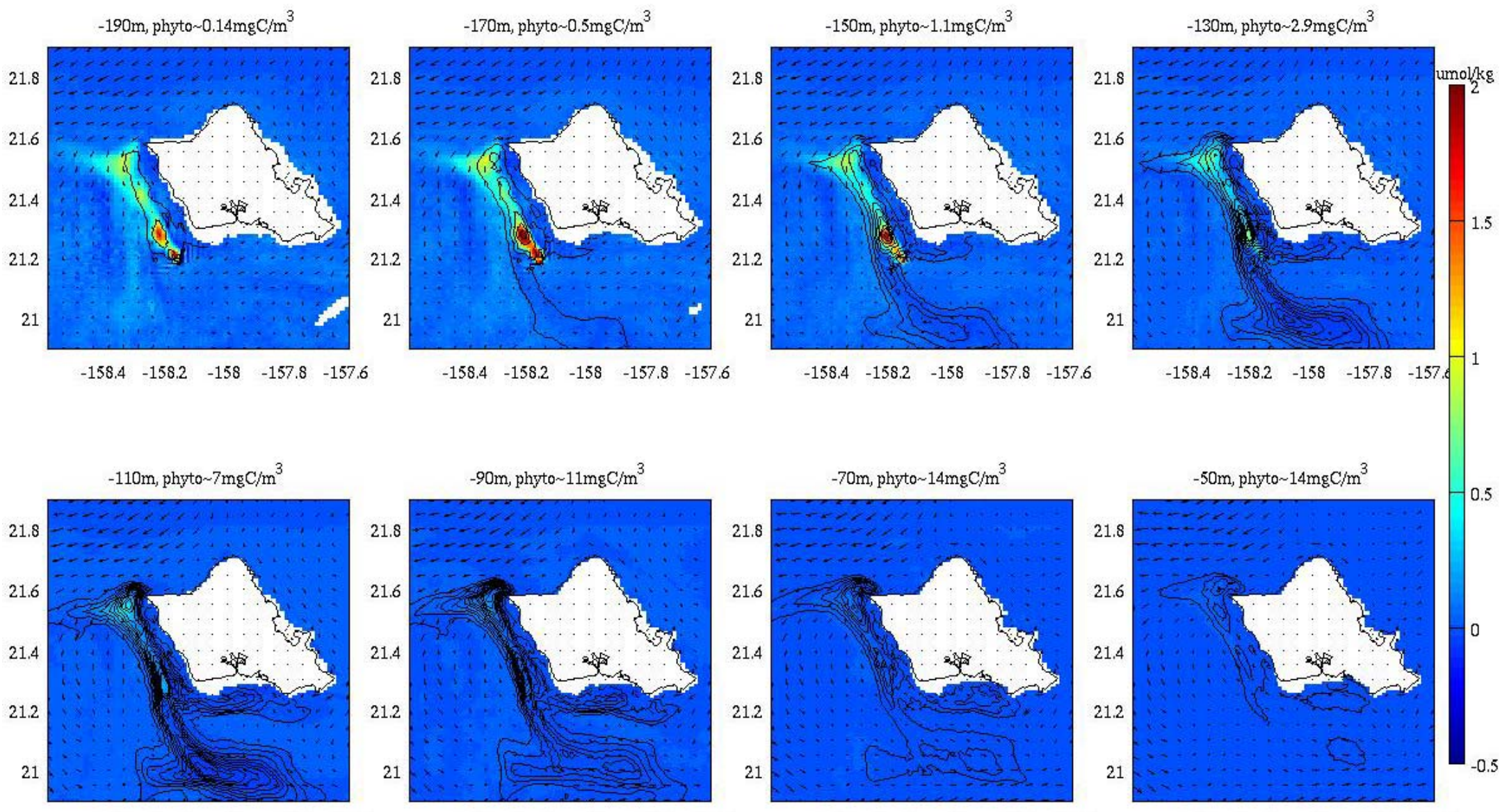

$\begin{array}{lllll}-158.4 & -158.2 & -158 & -157.8 & -157.6\end{array}$

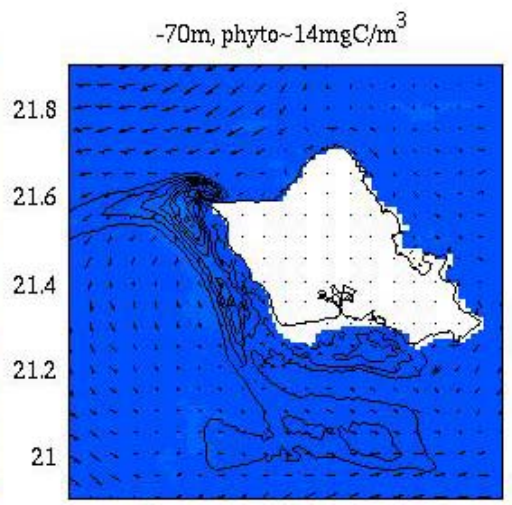

$-158.4 \quad-158.2 \quad-158 \quad-157.8 \quad-157.6$

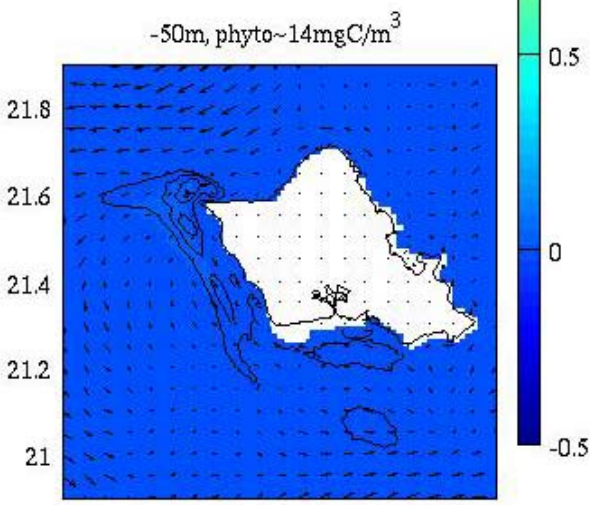

$\begin{array}{lllll}-158.4 & -158.2 & -158 & -157.8 & -157.6\end{array}$

Figure 71. Nitrate perturbation (umol $/ \mathrm{kg}$ ) due to the RevX 3x100MW OTEC plant, and contour lines of the resultant diatom perturbation (black lines) drawn at intervals of $0.5 \mathrm{mgC} / \mathrm{m}^{3}$. June $24^{\text {th }}, 2010$ at $16: 40$ Hawaiian Standard Time. 


\subsubsection{Three 100MW OTEC plants with 95 Meter Discharge, 4 Ducts each}

The model was run with three OTEC plants, each consisting of four separate ducts discharging a total combined flow rate of $420 \mathrm{~m}^{3} / \mathrm{s}$ of warm water and $320 \mathrm{~m}^{3} / \mathrm{s}$ of cold water in a mixed discharge at 95 meter depth. Each duct/port was assumed to have a diameter of $10.5 \mathrm{~m}$ producing a downward discharge velocity of about $2.18 \mathrm{~m} / \mathrm{s}$. The OTEC plants were spaced two grid cells apart, equivalent to $1.1 \mathrm{~km}$ between OTEC plants.

The results show an increase in the biological response of picoplankton and diatoms compared to the single 100MW OTEC plant with the same discharge configurations, but significantly less of a response than the same three $100 \mathrm{MW}$ plants discharged at the shallower $70 \mathrm{~m}$ depths. Figure 72 through Figure 75 shows the nitrate and pico-phytoplankton perturbations above the non-OTEC scenario. The $1 \mathrm{mgC} / \mathrm{m}^{3}$ contour of the pico-phytoplankton perturbation covers an area of 20-40 $\mathrm{km}$ by $10 \mathrm{~km}$ in size. There is a perturbation at the core of this area reaching $2.5 \mathrm{mgC} / \mathrm{m}^{3}$, about 0.5 $\mathrm{mgC} / \mathrm{m}^{3}$ greater than the perturbation from a single 100MW OTEC plant of similar discharge configurations. This perturbation is approaching $15-25 \%$ of the ambient background concentrations for pico-phytoplankton, which are on the order of 10 to $15 \mathrm{mgC} / \mathrm{m}^{3}$.

The diatom perturbations also show a slight increase relative to the single 100MW OTEC plant, and a significant reduction relative to the shallower three 100MW OTEC plants discharged at $70 \mathrm{~m}$. Figure 76 through Figure 79 shows the difference between diatom concentrations in the the OTEC and non-OTEC simulations. The perturbation covers a broad area offshore of west and south Oahu, reaching concentrations of 2 to $3 \mathrm{mgC} / \mathrm{m} 3$ above the background levels (which are simulated to be $\sim 5-10 \mathrm{mgC} / \mathrm{m} 3$ nearshore of Oahu and less offshore). The deeper discharge produces a significantly reduced growth in the natural phytoplankton populations relative to the shallower discharge. 
03-Jun-2010 16:39:50 HST
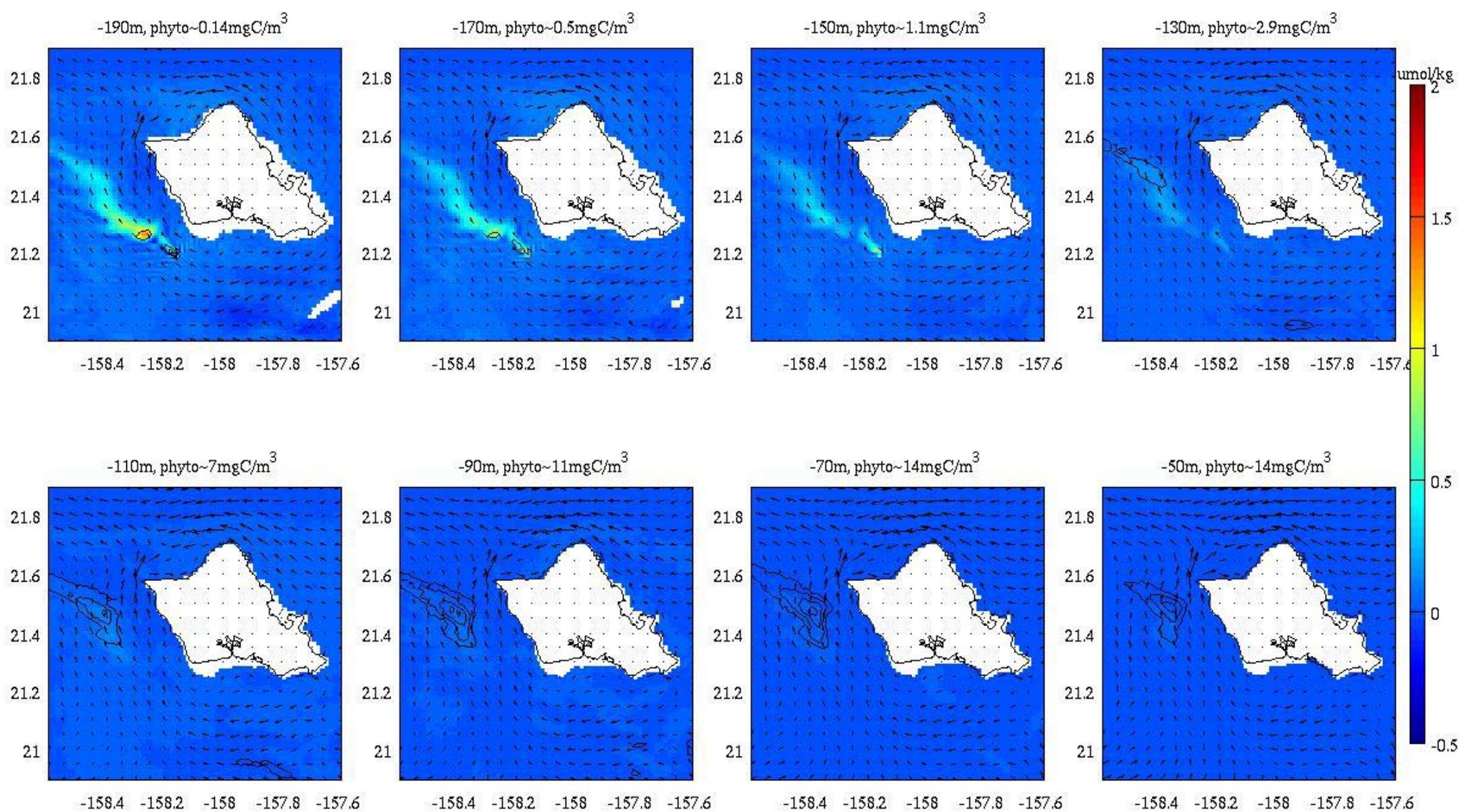

Figure 72. Nitrate perturbation (umol/kg) due to the RevX 100MW 95m OTEC plant, and contour lines of the resultant pico-phytoplankton perturbation (black lines) drawn at intervals of $0.5 \mathrm{mgC} / \mathrm{m}^{3}$. June $3^{\text {rd }}, 2010$ at $16: 40$ Hawaii Standard Time. 
10-Jun-2010 16:39:50 HST
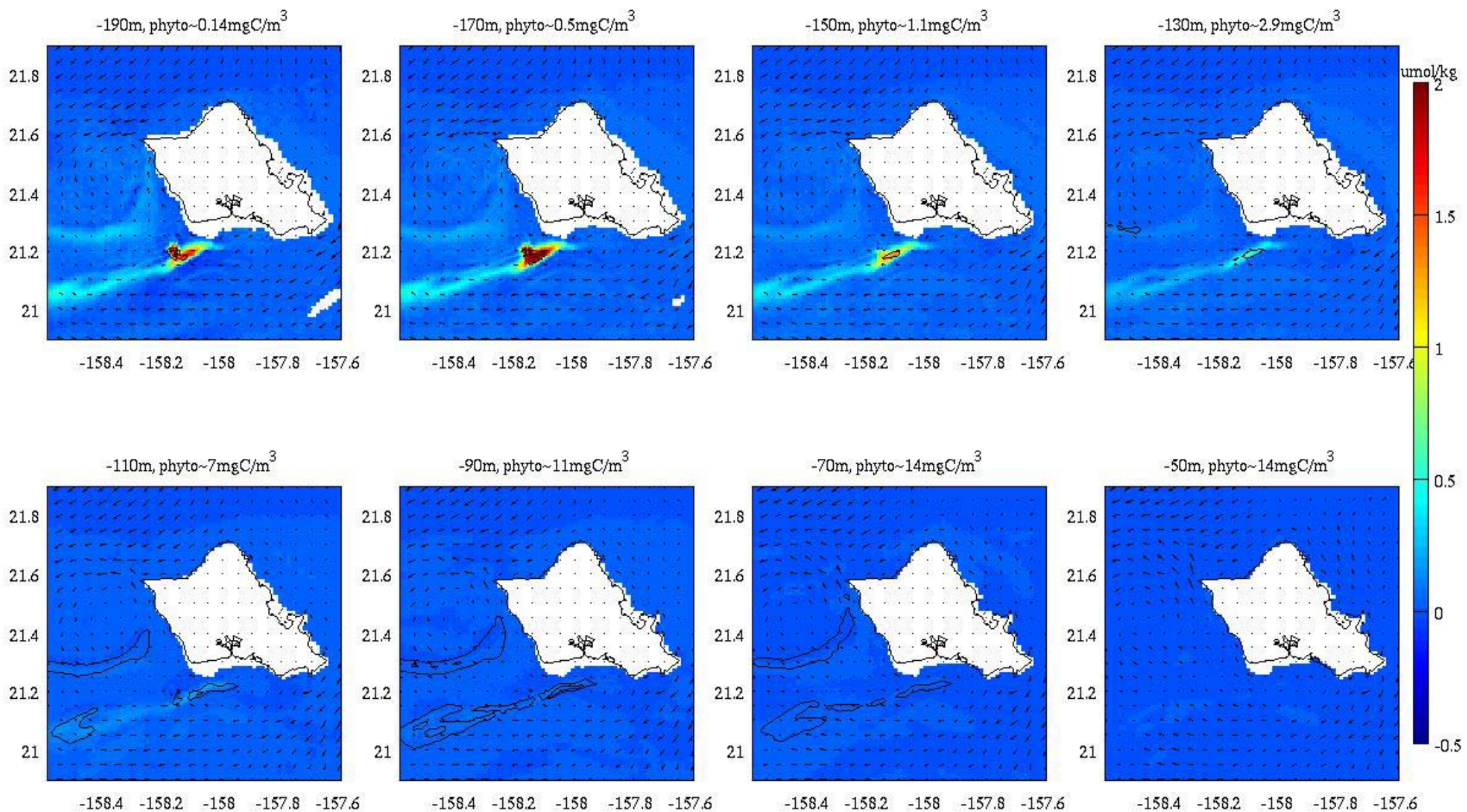

Figure 73. Nitrate perturbation (umol/kg) due to the RevX 100MW 95m OTEC plant, and contour lines of the resultant pico-phytoplankton perturbation (black lines) drawn at intervals of $0.5 \mathrm{mgC} / \mathrm{m}^{3}$. June $10^{\text {th }}, 2010$ at $16: 40$ Hawaii Standard Time. 
17-Jun-2010 16:39:50 HST
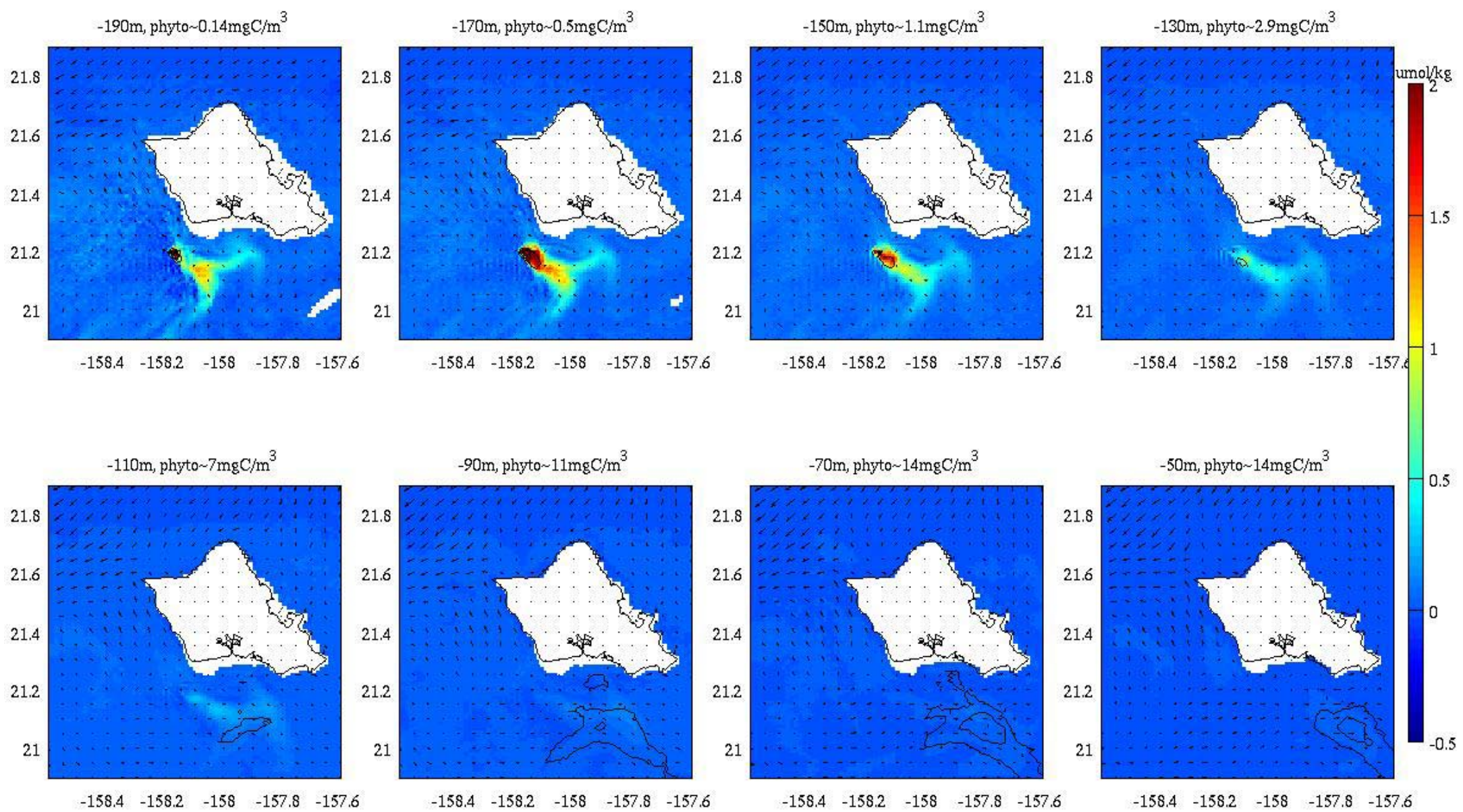

Figure 74. Nitrate perturbation (umol/kg) due to the RevX 100MW 95m OTEC plant, and contour lines of the resultant pico-phytoplankton perturbation (black lines) drawn at intervals of $0.5 \mathrm{mgC} / \mathrm{m}^{3}$. June $17^{\text {th }}, 2010$ at 16:40 Hawaii Standard Time. 
24-Jun-2010 16:39:50 HST
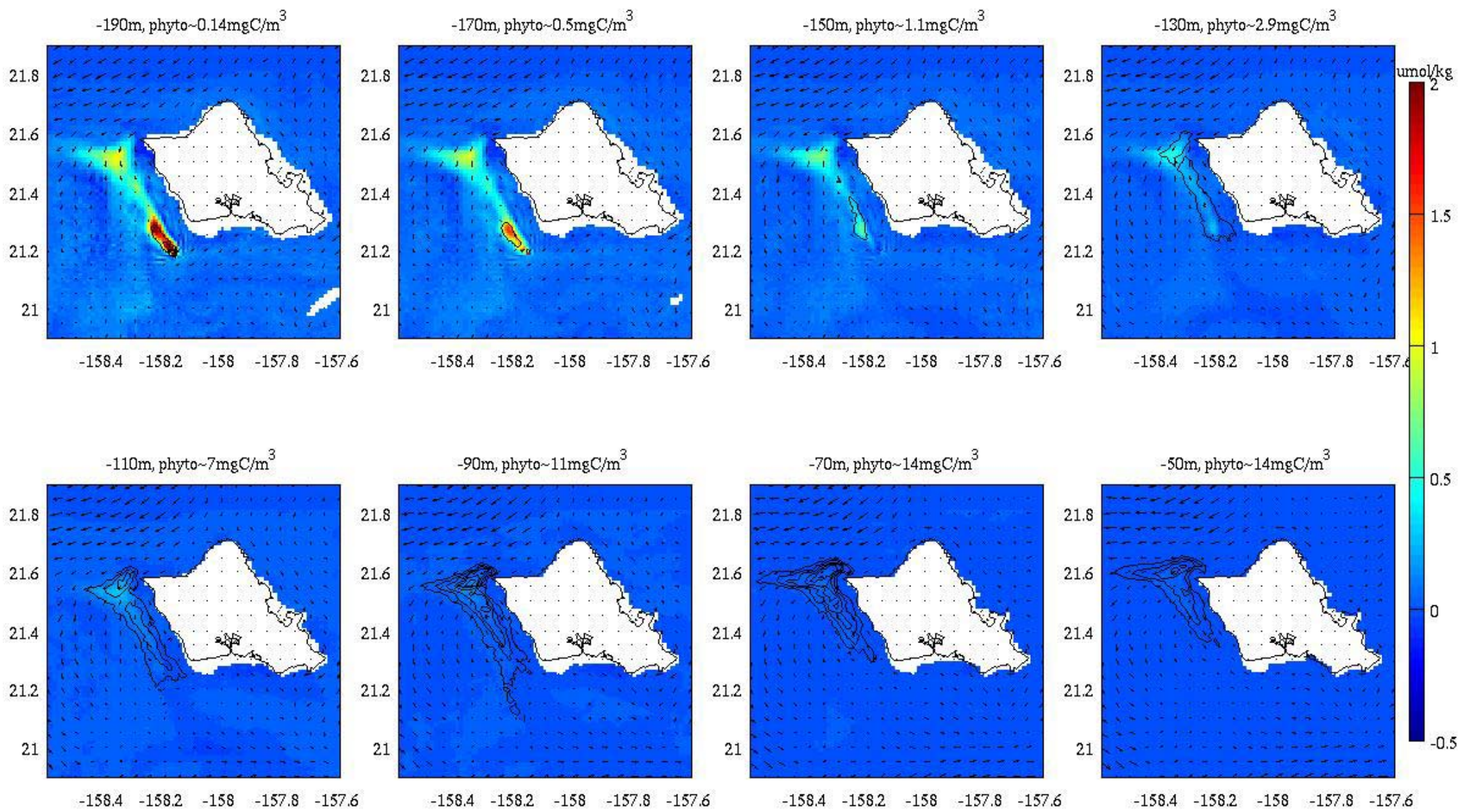

Figure 75Nitrate perturbation (umol/kg) due to the RevX 100MW 95m OTEC plant, and contour lines of the resultant pico-phytoplankton perturbation (black lines) drawn at intervals of $0.5 \mathrm{mgC} / \mathrm{m}^{3}$. June $24^{\text {th }}, 2010$ at 16:40 Hawaii Standard Time. 
03-Jun-2010 16:39:50 HST
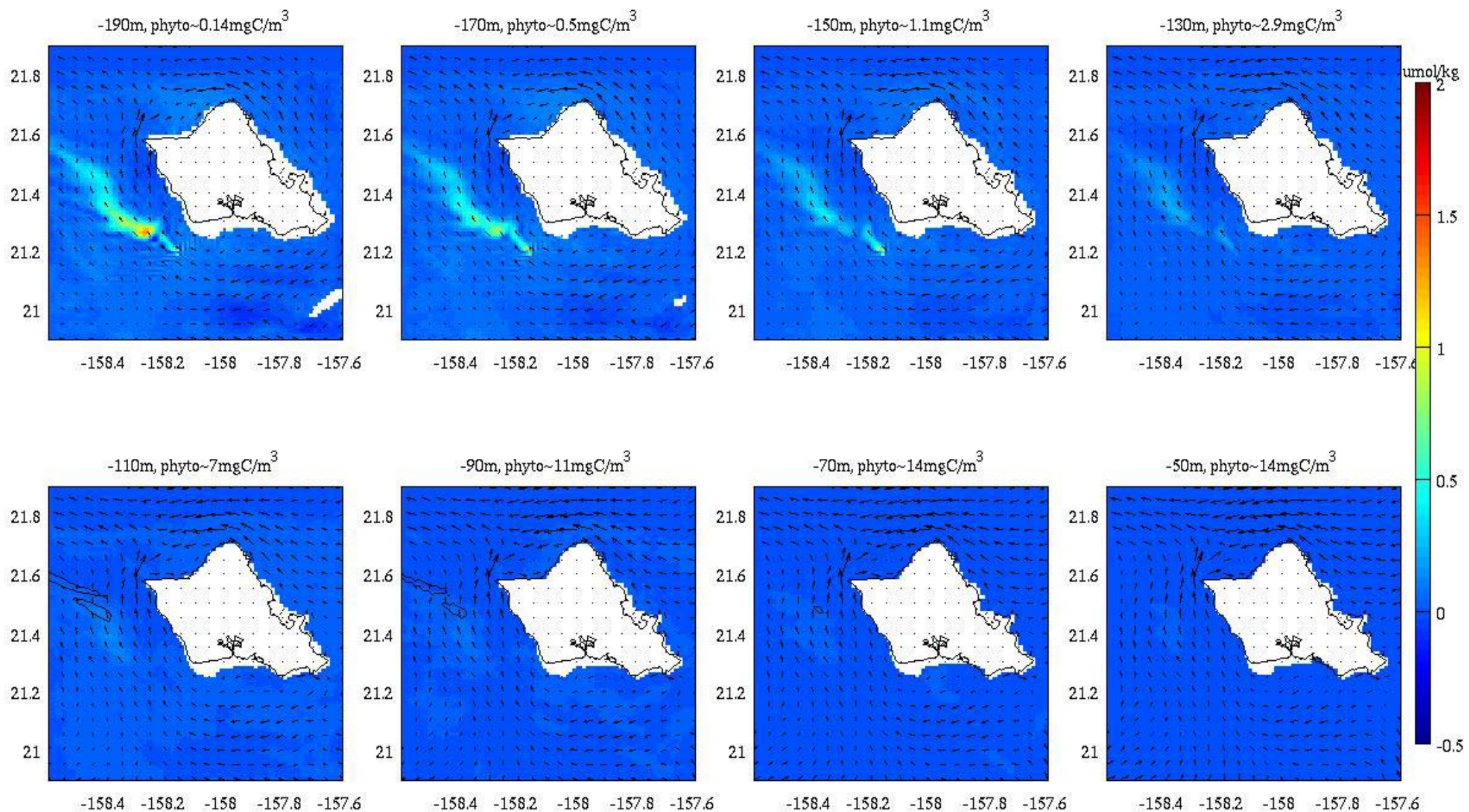

Figure 76. Nitrate perturbation (umol/kg) due to the RevX 100MW 95m OTEC plant, and contour lines of the resultant diatom perturbation (black lines) drawn at intervals of $0.5 \mathrm{mgC} / \mathrm{m}^{3}$. June $3^{\text {rd }}, 2010$ at $16: 40$ Hawaiian Standard Time. 
10-Jun-2010 16:39:50 HST
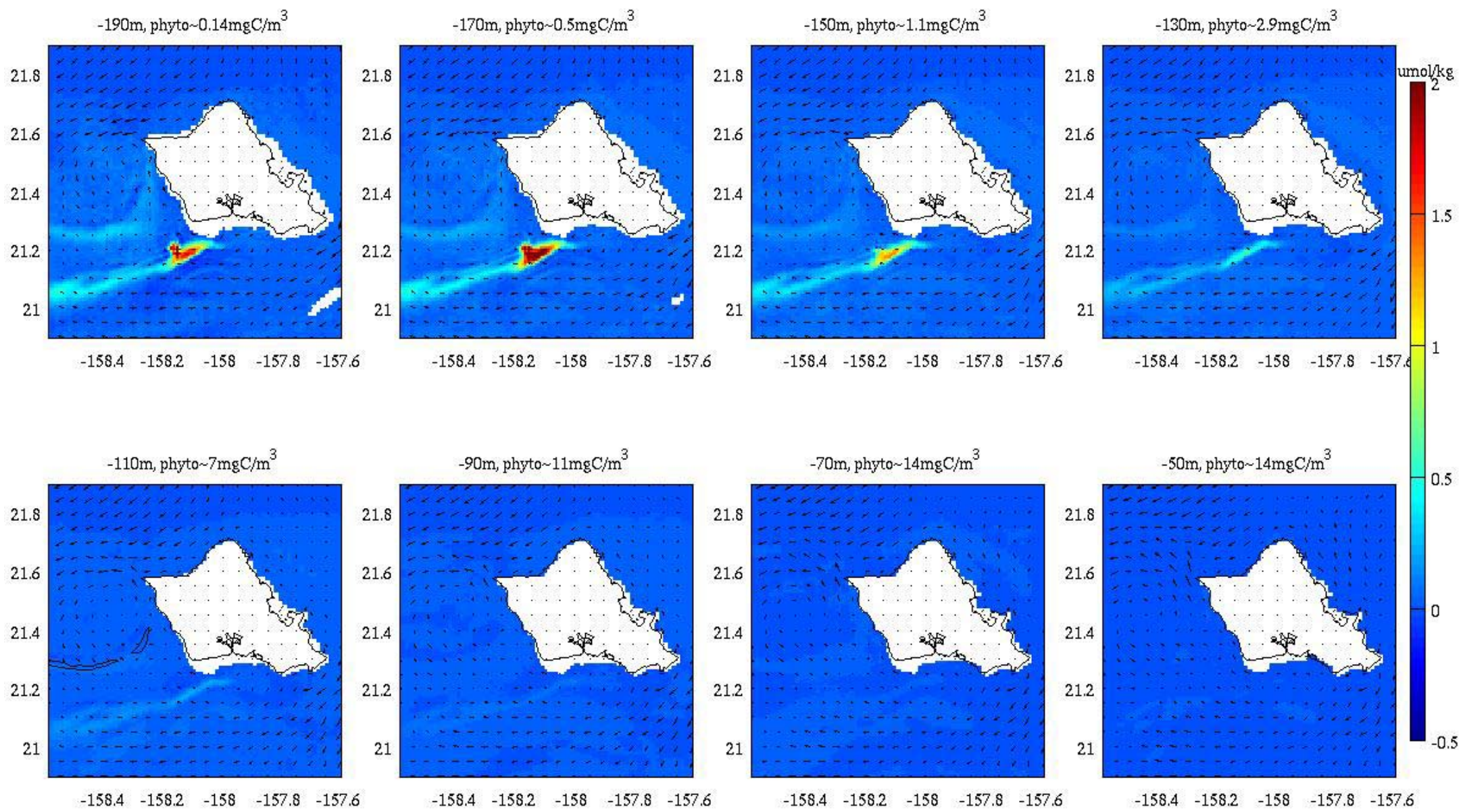

Figure 77. Nitrate perturbation (umol/kg) due to the RevX 100MW 95m OTEC plant, and contour lines of the resultant diatom perturbation (black lines) drawn at intervals of $0.5 \mathrm{mgC} / \mathrm{m}^{3}$. June $10^{\text {th }}, 2010$ at $16: 40$ Hawaiian Standard Time. 
17-Jun-2010 16:39:50 HST
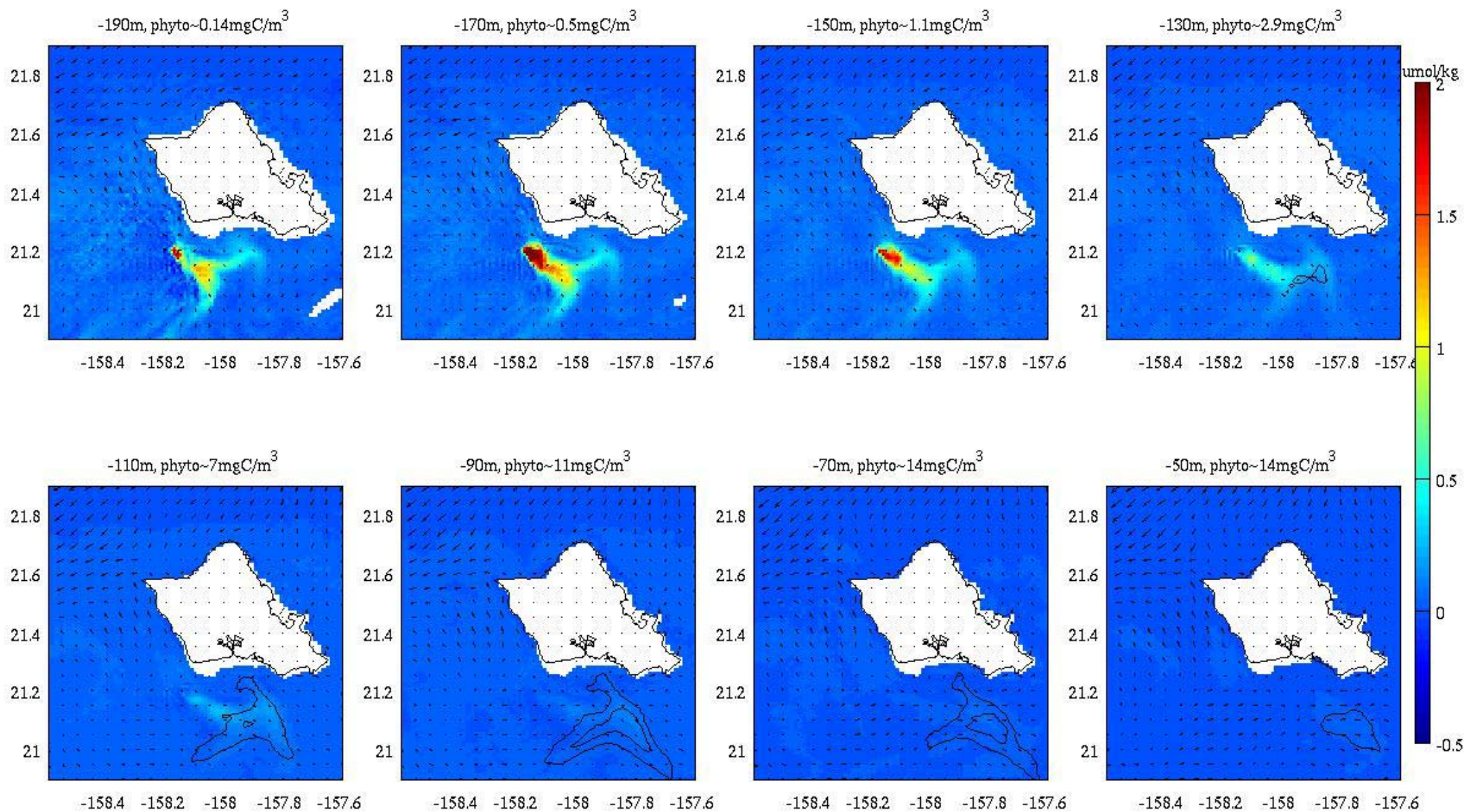

Figure 78. Nitrate perturbation (umol/kg) due to the RevX 100MW 95m OTEC plant, and contour lines of the resultant diatom perturbation (black lines) drawn at intervals of $0.5 \mathrm{mgC} / \mathrm{m}^{3}$. June $17^{\text {th }}, 2010$ at $16: 40$ Hawaiian Standard Time. 
24-Jun-2010 16:39:50 HST
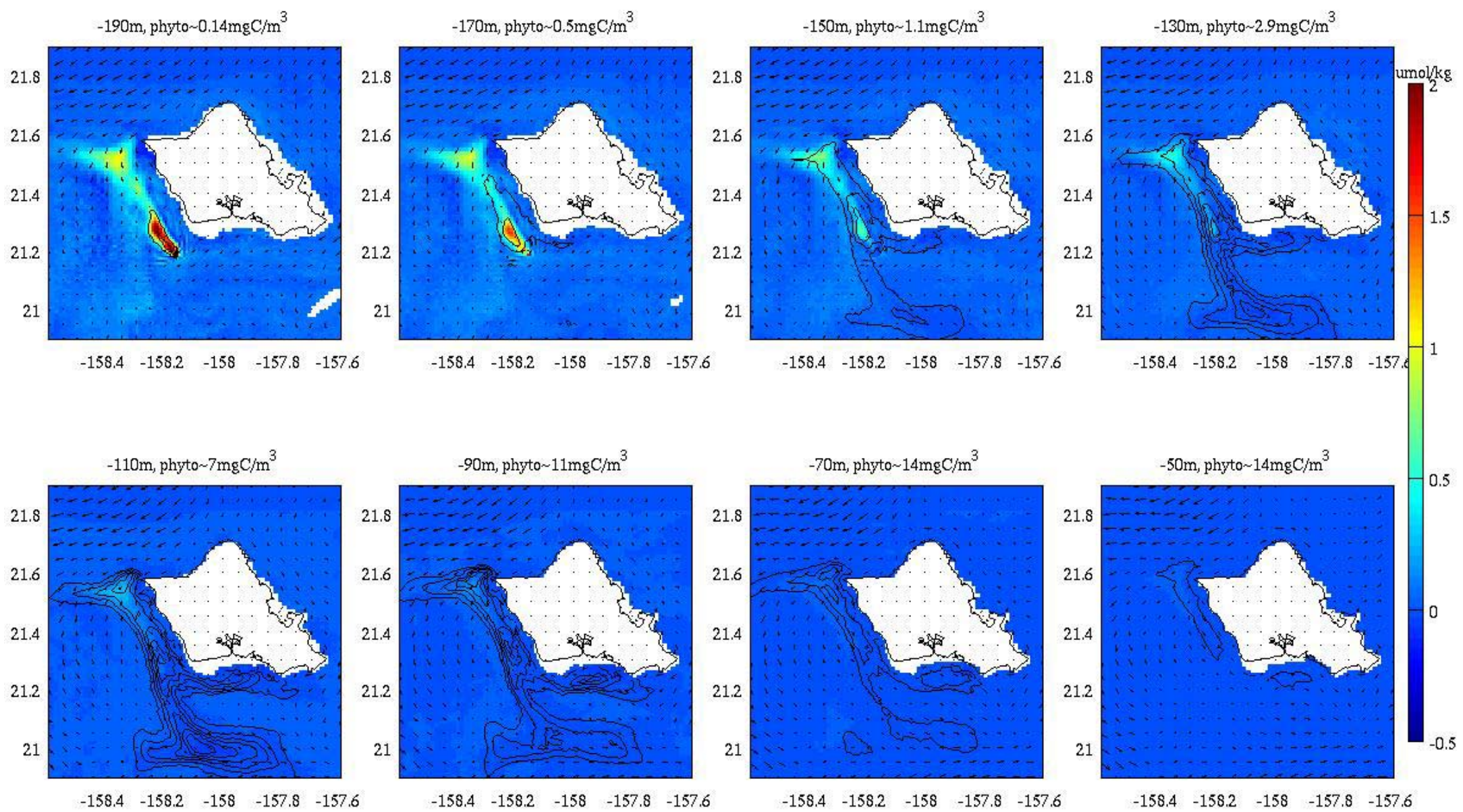

Figure 79. Nitrate perturbation (umol/kg) due to the RevX 100MW 95m OTEC plant, and contour lines of the resultant diatom perturbation (black lines) drawn at intervals of $0.5 \mathrm{mgC} / \mathrm{m}^{3}$. June $24^{\text {th }}, 2010$ at 16:40 Hawaiian Standard Time. 


\subsubsection{Single 100MW OTEC plant: 70 Meter Discharge, 8 Ducts}

The model was run with an OTEC plant consisting of eight separate ducts, discharging a total combined flow rate of $420 \mathrm{~m}^{3} / \mathrm{s}$ of warm water and $320 \mathrm{~m}^{3} / \mathrm{s}$ of cold water in a mixed discharge at $70 \mathrm{~m}$ depth. Each duct was assumed to have a discharge port diameter of $7.8 \mathrm{~m}$ producing a downward discharge velocity of about $1.94 \mathrm{~m} / \mathrm{s}$. The near field plume had an average terminal depth of 153 meters, with a volumetric dilution of $16.5: 1$. The average terminal plume temperature was $20.4^{\circ} \mathrm{C}$. This configuration results in average plumes roughly $20 \mathrm{~m}$ shallower and over half a degree warmer than the discharge from 4 ducts at $70 \mathrm{~m}$ (Section 4.1). As a result, the biological perturbation is slightly more pronounced than the single 100MW OTEC plant discharged at $70 \mathrm{~m}$ with 4 ducts.

Figure 80 through Figure 83 show the difference between the nitrate and pico-pyhtoplankton concentrations of the OTEC and non-OTEC simulations. The $1 \mathrm{mgC} / \mathrm{m}^{3}$ contour of the picophytoplankton perturbation covers an area of $20-40 \mathrm{~km}$ by $10 \mathrm{~km}$ in size, similar to the baseline single 100MW OTEC simulation ( $70 \mathrm{~m}$ discharge from 4 ducts). There is slightly greater perturbation at the core of this area, reaching 2 to $3 \mathrm{mgC} / \mathrm{m}^{3}$. This perturbation is approaching 10$20 \%$ of the ambient background concentrations for pico-phytoplankton, which are on the order of 10 to $15 \mathrm{mgC} / \mathrm{m}^{3}$.

The diatom perturbations also show a similar perturbation relative to the single 100MW OTEC plant. Figure 84 through Figure 87 shows the difference between diatom concentrations in the OTEC and non-OTEC simulations. The perturbation covers a broad area offshore of west and south Oahu, reaching concentrations of 2 to $3 \mathrm{mgC} / \mathrm{m}^{3}$ above the background levels (which are simulated to be $\sim 5-10 \mathrm{mgC} / \mathrm{m}^{3}$ nearshore of Oahu and less offshore). 
03-Jun-2010 16:39:50 HST

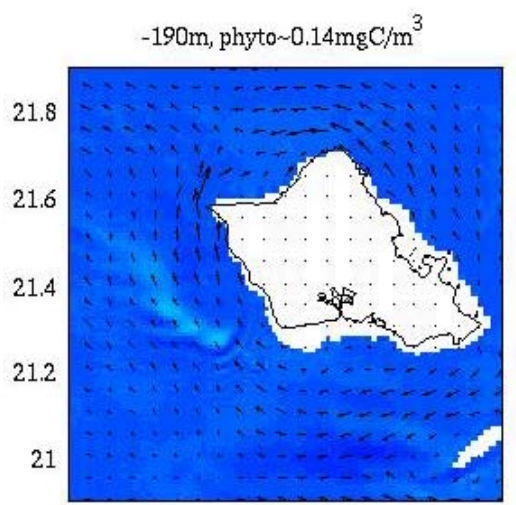

$-158.4 \quad-158.2 \quad-158 \quad-157.8 \quad-157.6$

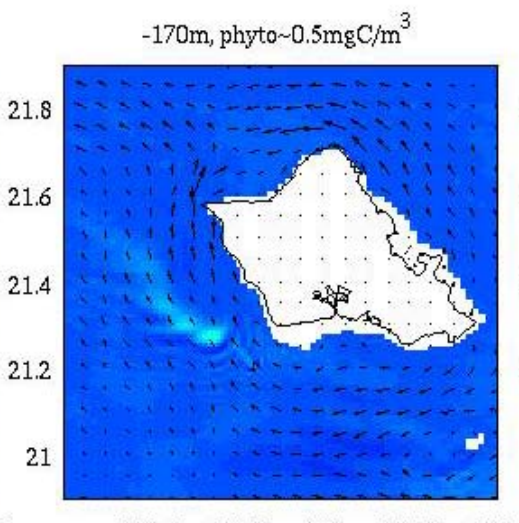

$\begin{array}{lllll}-158.4 & -158.2 & -158 & -157.8 & -157.6\end{array}$

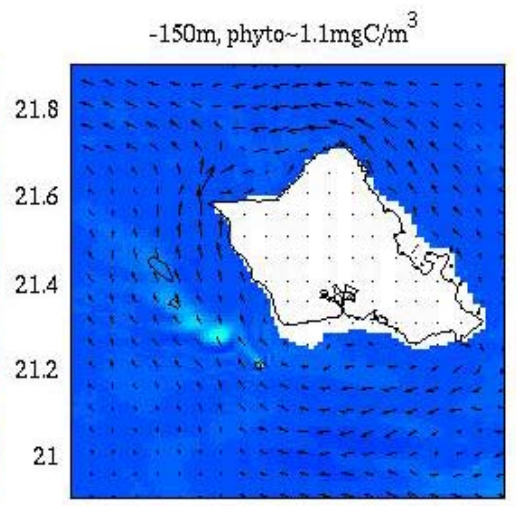

$\begin{array}{lllll}-158.4 & -158.2 & -158 & -157.8 & -157.6\end{array}$

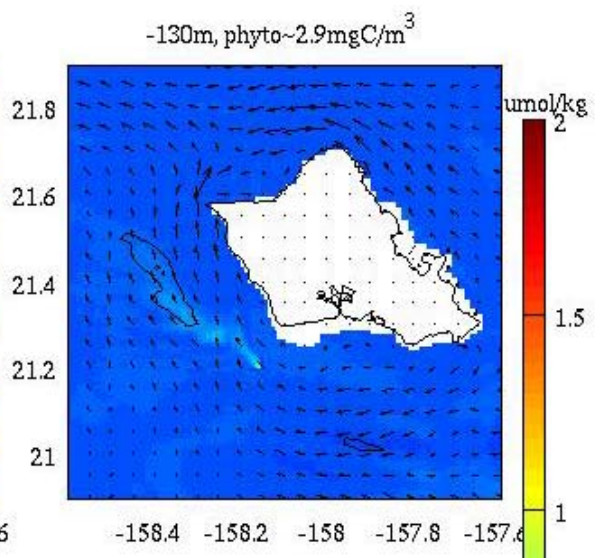

$-110 \mathrm{~m}$, phyto $7 \mathrm{mgC} / \mathrm{m}^{3}$
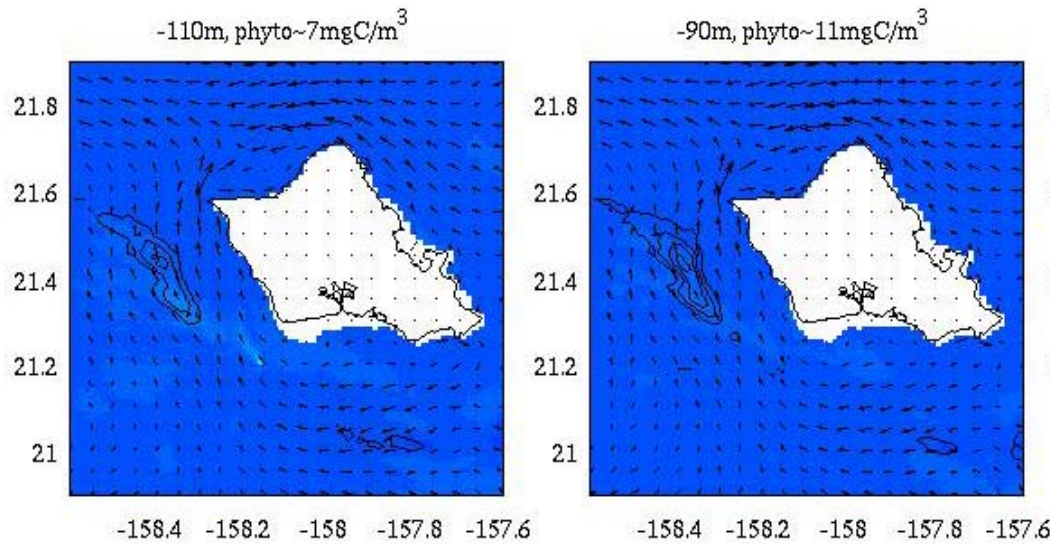

$-70 \mathrm{~m}$, phyto $14 \mathrm{mgC} / \mathrm{m}^{3}$

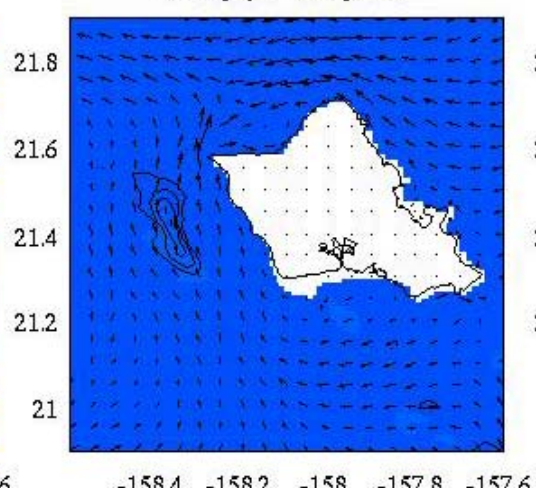

$-50 \mathrm{~m}$, phyto $14 \mathrm{mgC} / \mathrm{m}^{3}$

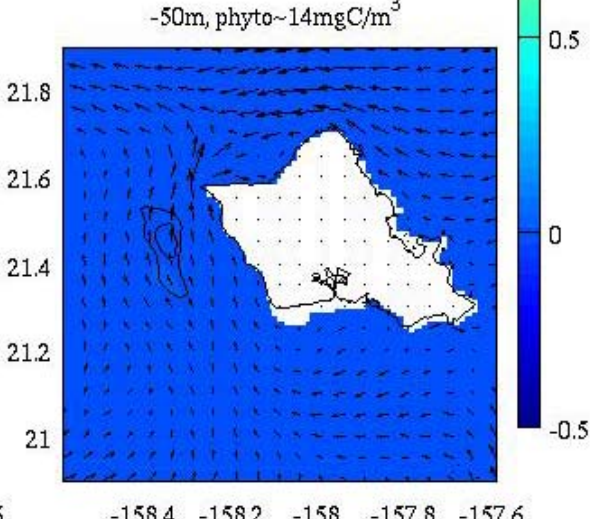

Figure 80. Nitrate perturbation (umol $/ \mathrm{kg}$ ) due to the RevX 100MW 8x70m OTEC plant, and contour lines of the resultant pico-phytoplankton perturbation (black lines) drawn at intervals of $0.5 \mathrm{mgC} / \mathrm{m} 3$. June $3^{\text {rd }}, 2010$ at 16:40 Hawaii Standard Time. 
10-Jun-2010 16:39:50 HST

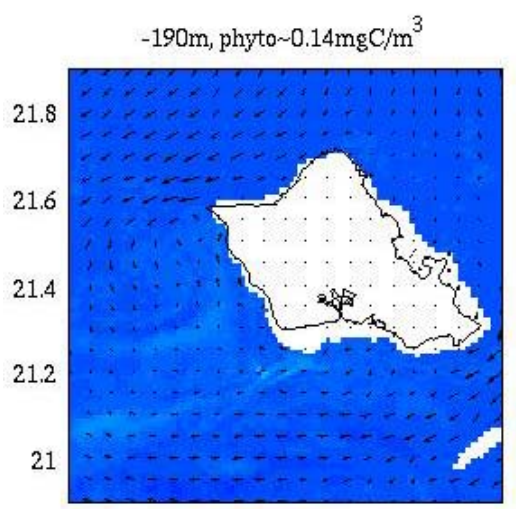

$\begin{array}{lllll}-158.4 & -158.2 & -158 & -157.8 & -157.6\end{array}$
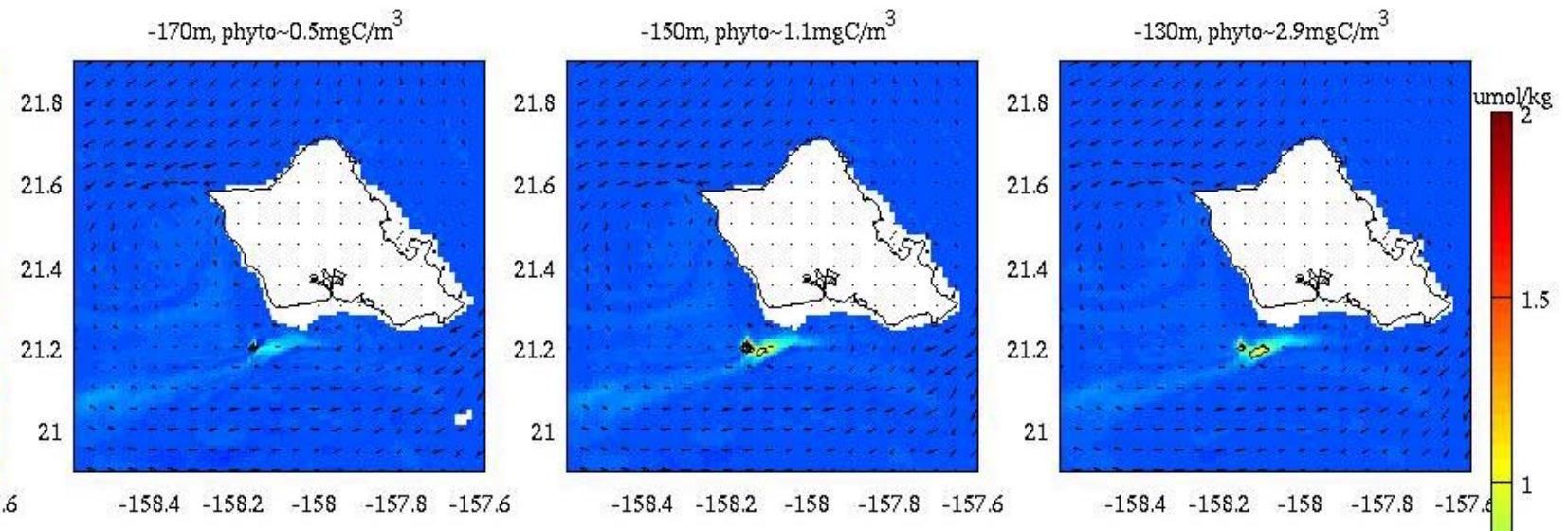

$-110 \mathrm{~m}$, phyto $7 \mathrm{mgC} / \mathrm{m}^{3}$
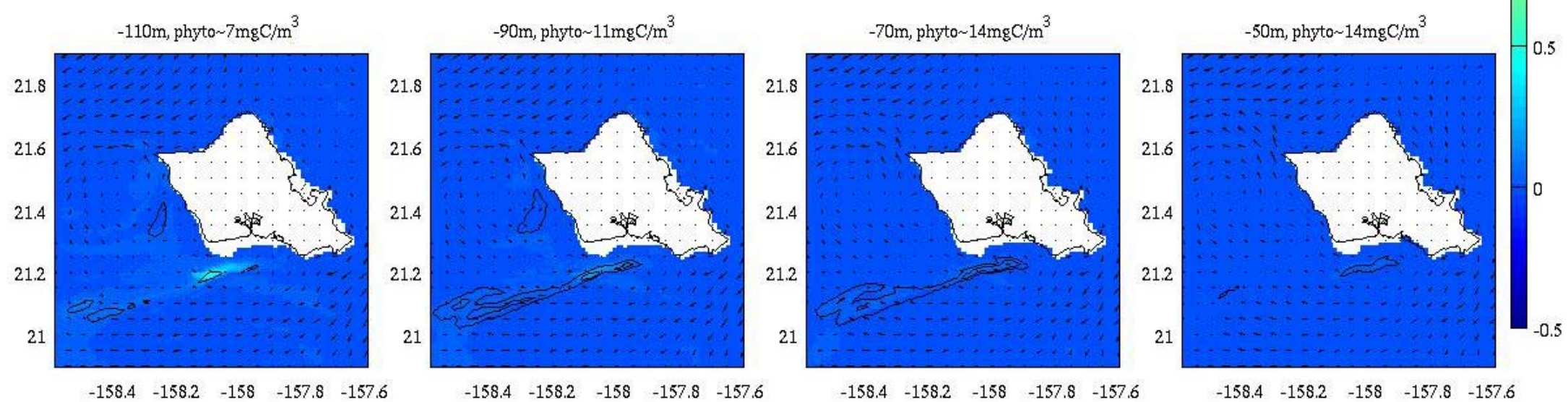

Figure 81. Nitrate perturbation (umol/kg) due to the RevX 100MW 8x70m OTEC plant, and contour lines of the resultant pico-phytoplankton perturbation (black lines) drawn at intervals of $0.5 \mathrm{mgC} / \mathrm{m} 3$. June $10^{\text {th }}, 2010$ at 16:40 Hawaii Standard Time. 
17-Jun-2010 16:39:50 HST

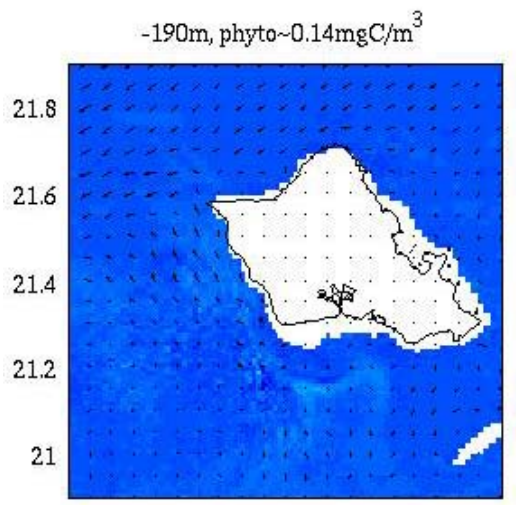

$\begin{array}{lllll}-158.4 & -158.2 & -158 & -157.8 & -157.6\end{array}$

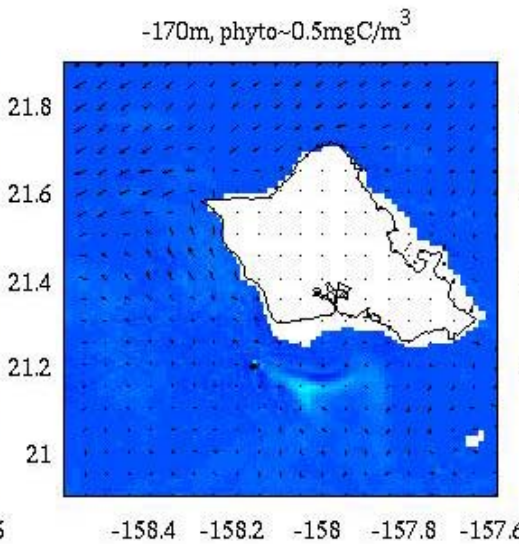

$-90 \mathrm{~m}$, phyto $11 \mathrm{mgC} / \mathrm{m}^{3}$
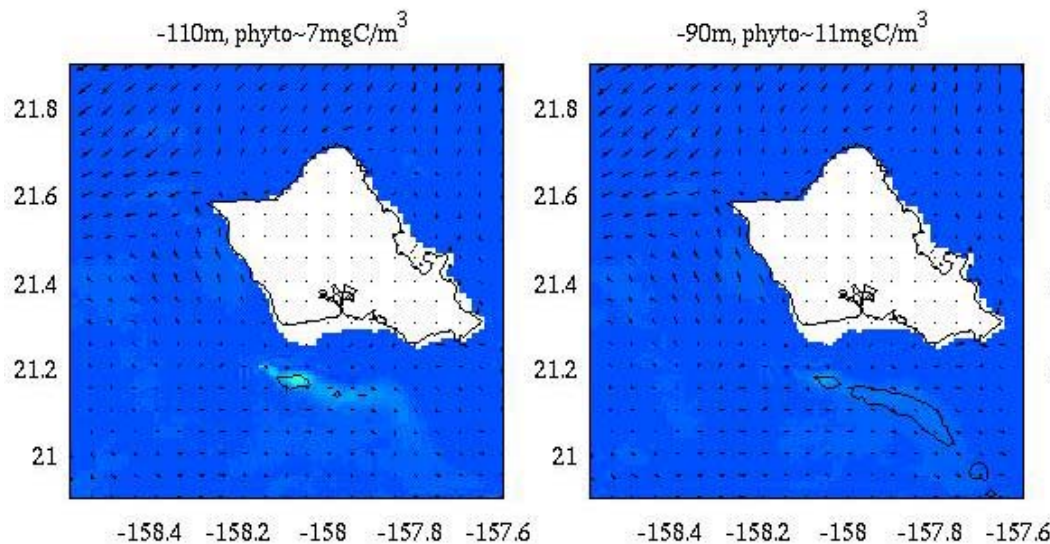

$-150 \mathrm{~m}$, phyto $1.1 \mathrm{mgC} / \mathrm{m}^{3}$

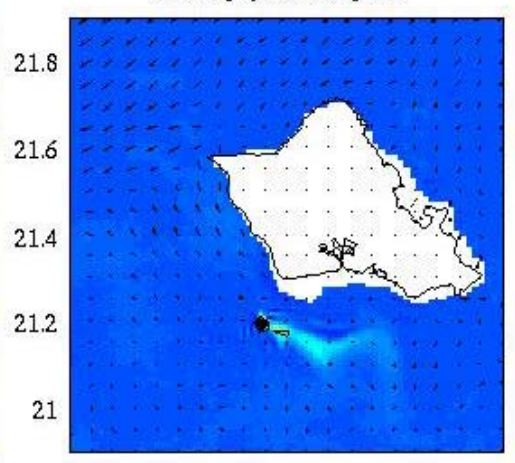

$-158.4 \quad-158.2-158 \quad-157.8-157.6$
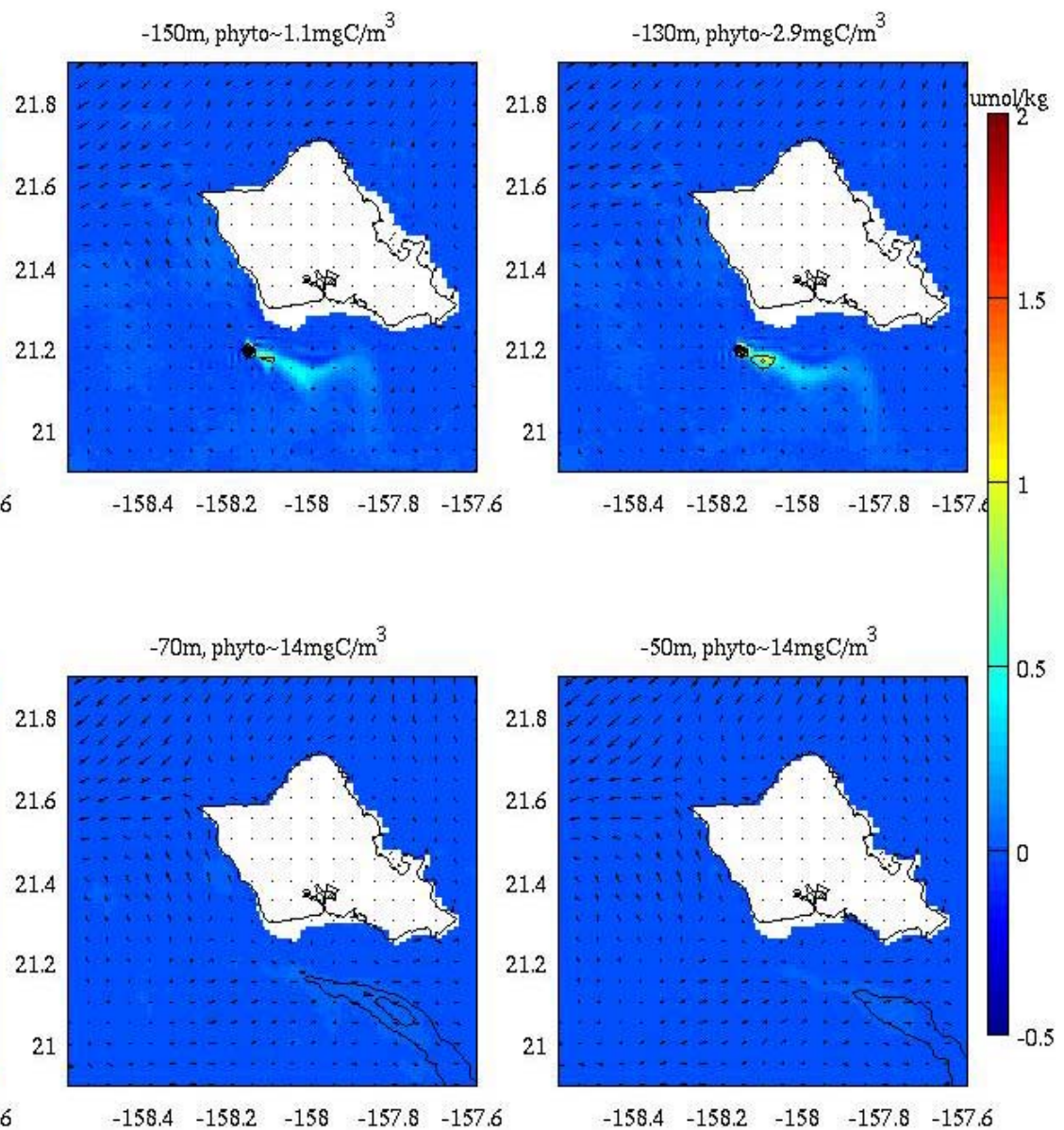

Figure 82. Nitrate perturbation (umol/kg) due to the RevX 100MW 8x70m OTEC plant, and contour lines of the resultant pico-phytoplankton perturbation (black lines) drawn at intervals of $0.5 \mathrm{mgC} / \mathrm{m} 3$. June $17^{\text {th }}, 2010$ at Hawaii Standard Time. 


\section{4-Jun-2010 16:39:50 HST}

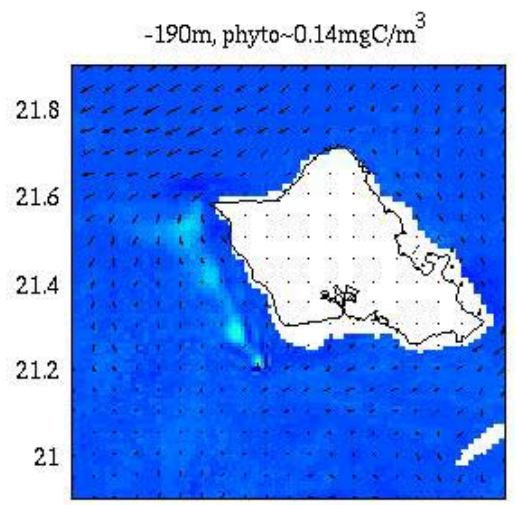

$\begin{array}{lllll}-158.4 & -158.2 & -158 & -157.8 & -157.6\end{array}$

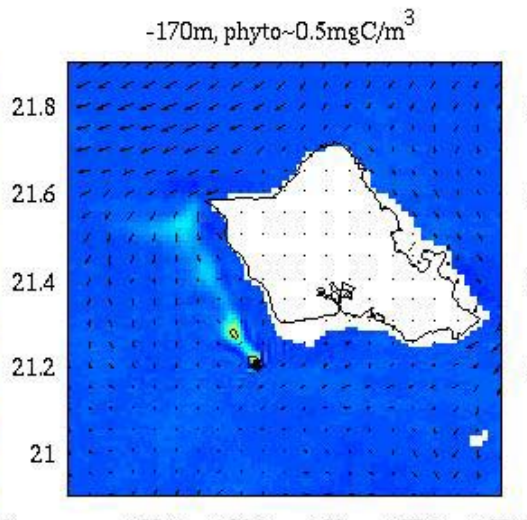

$\begin{array}{lllll}-158.4 & -158.2 & -158 & -157.8 & -157.6\end{array}$

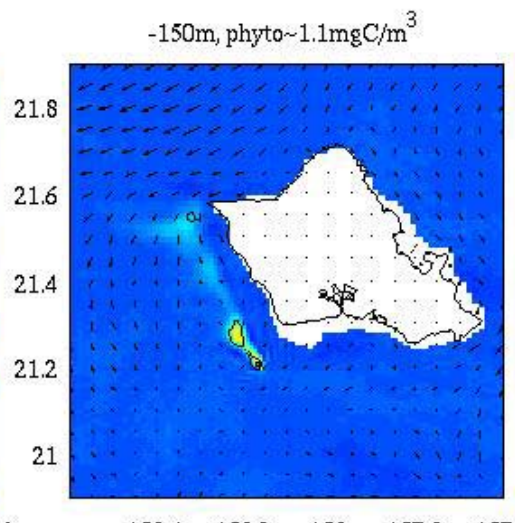

$-158.4 \quad-158.2 \quad-158 \quad-157.8 \quad-157.6$

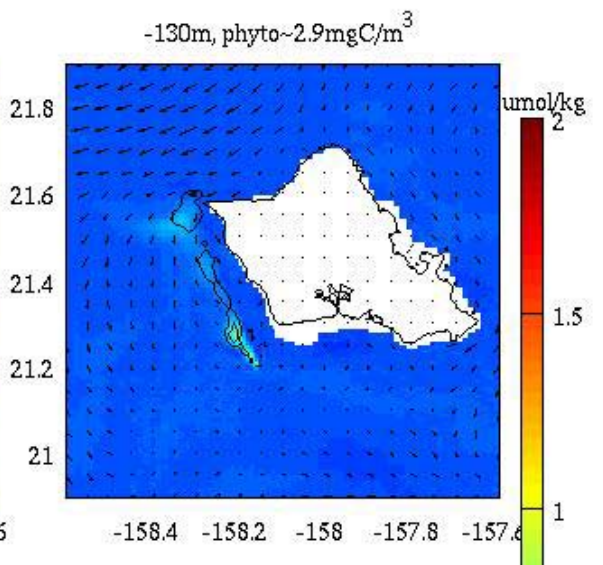

$-110 \mathrm{~m}$, phyto $7 \mathrm{mgC} / \mathrm{m}^{3}$

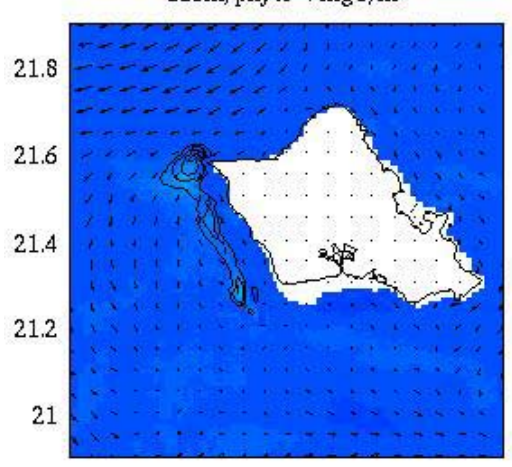

$\begin{array}{lllll}-158.4 & -158.2 & -158 & -157.8 & -157.6\end{array}$

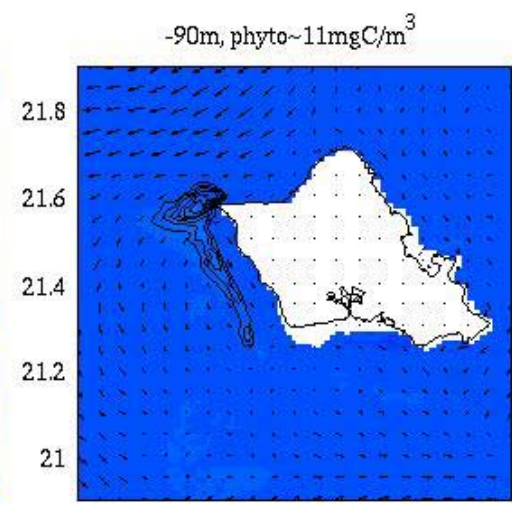

$\begin{array}{lllll}-158.4 & -158.2 & -158 & -157.8 & -157.6\end{array}$

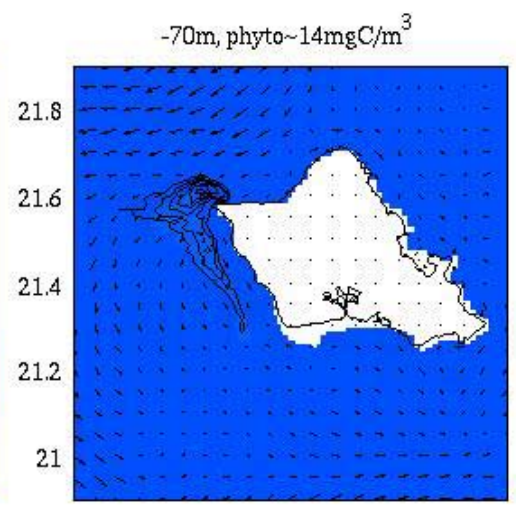

$\begin{array}{lllll}-158.4 & -158.2 & -158 & -157.8 & -157.6\end{array}$

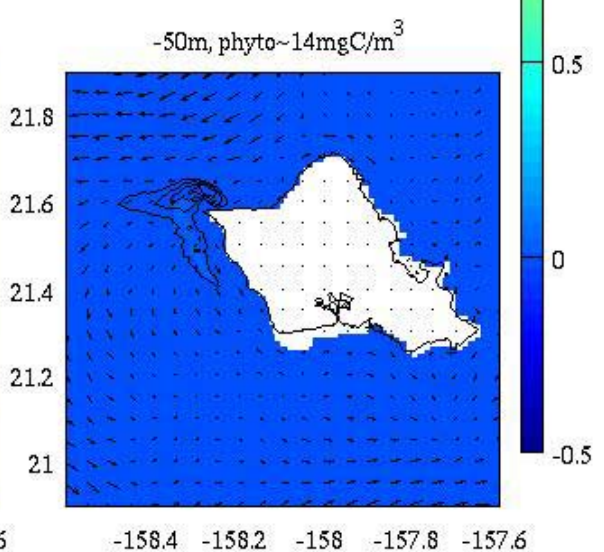

Figure 83. Nitrate perturbation (umol/kg) due to the RevX 100MW 8x70m OTEC plant, and contour lines of the resultant pico-phytoplankton perturbation (black lines) drawn at intervals of $0.5 \mathrm{mgC} / \mathrm{m} 3$. June $24^{\text {th }}, 2010$ at 16:40 Hawaii Standard Time. 
03-Jun-2010 16:39:50 HST

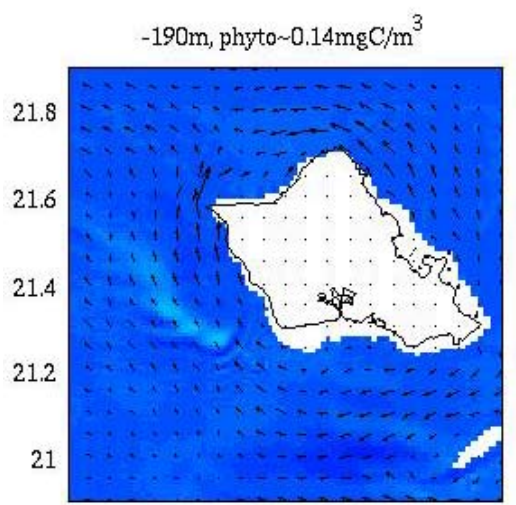

$\begin{array}{lllll}-158.4 & -158.2 & -158 & -157.8 & -157.6\end{array}$

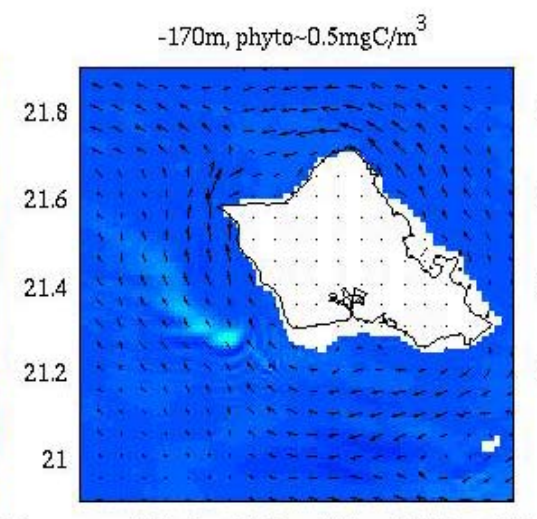

$\begin{array}{lllll}-158.4 & -158.2 & -158 & -157.8 & -157.6\end{array}$

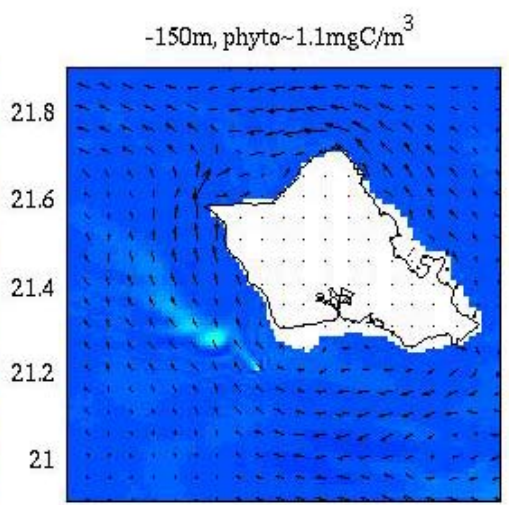

$\begin{array}{lllll}-158.4 & -158.2 & -158 & -157.8 & -157.6\end{array}$
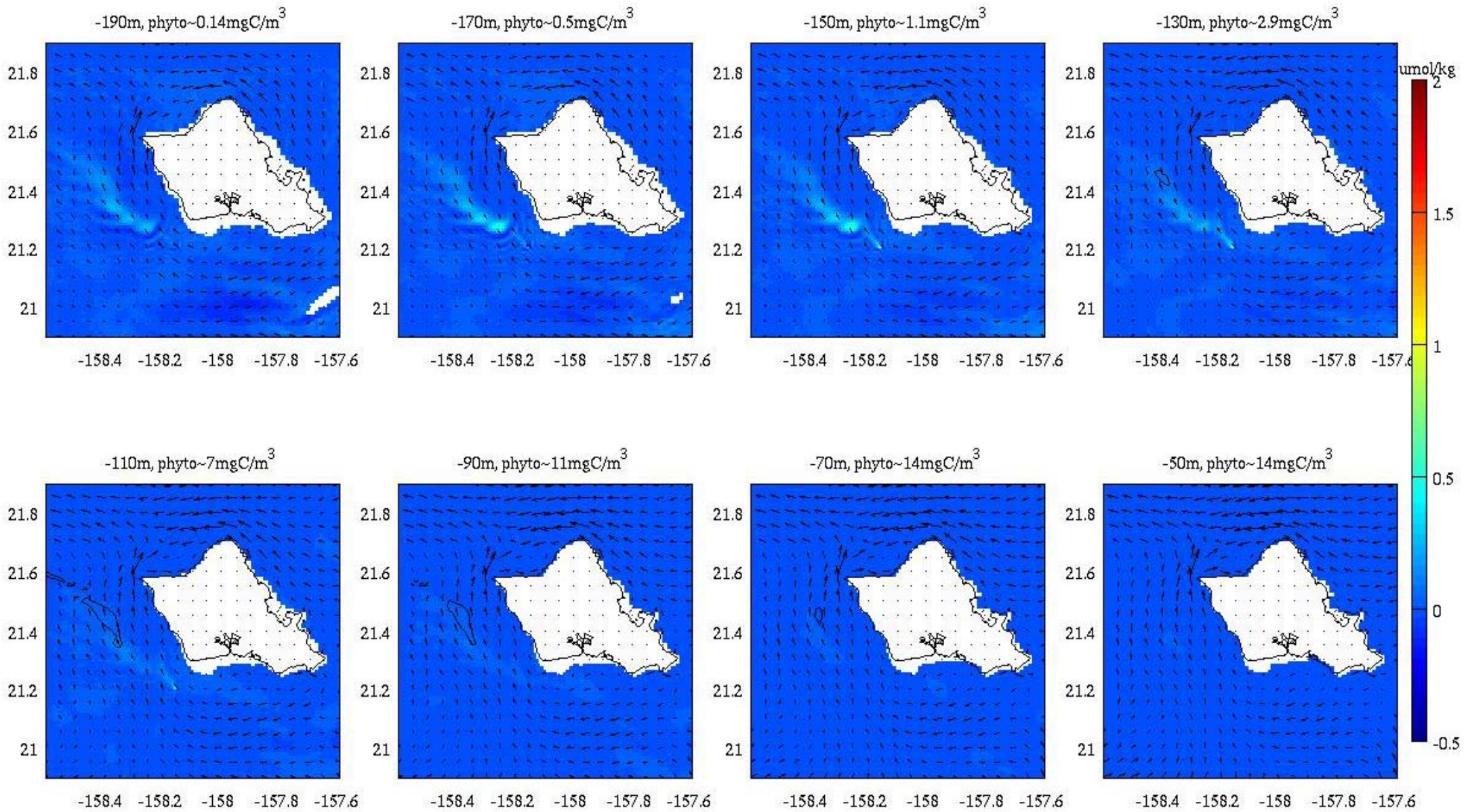

Figure 84. Nitrate perturbation (umol/kg) due to the RevX 100MW 8x70m OTEC plant, and contour lines of the resultant diatom perturbation (black lines) drawn at intervals of $0.5 \mathrm{mgC} / \mathrm{m} 3$. June $3^{\text {rd }}, 2012$ at 16:40 Hawaii Standard Time. 
10-Jun-2010 16:39:50 HST
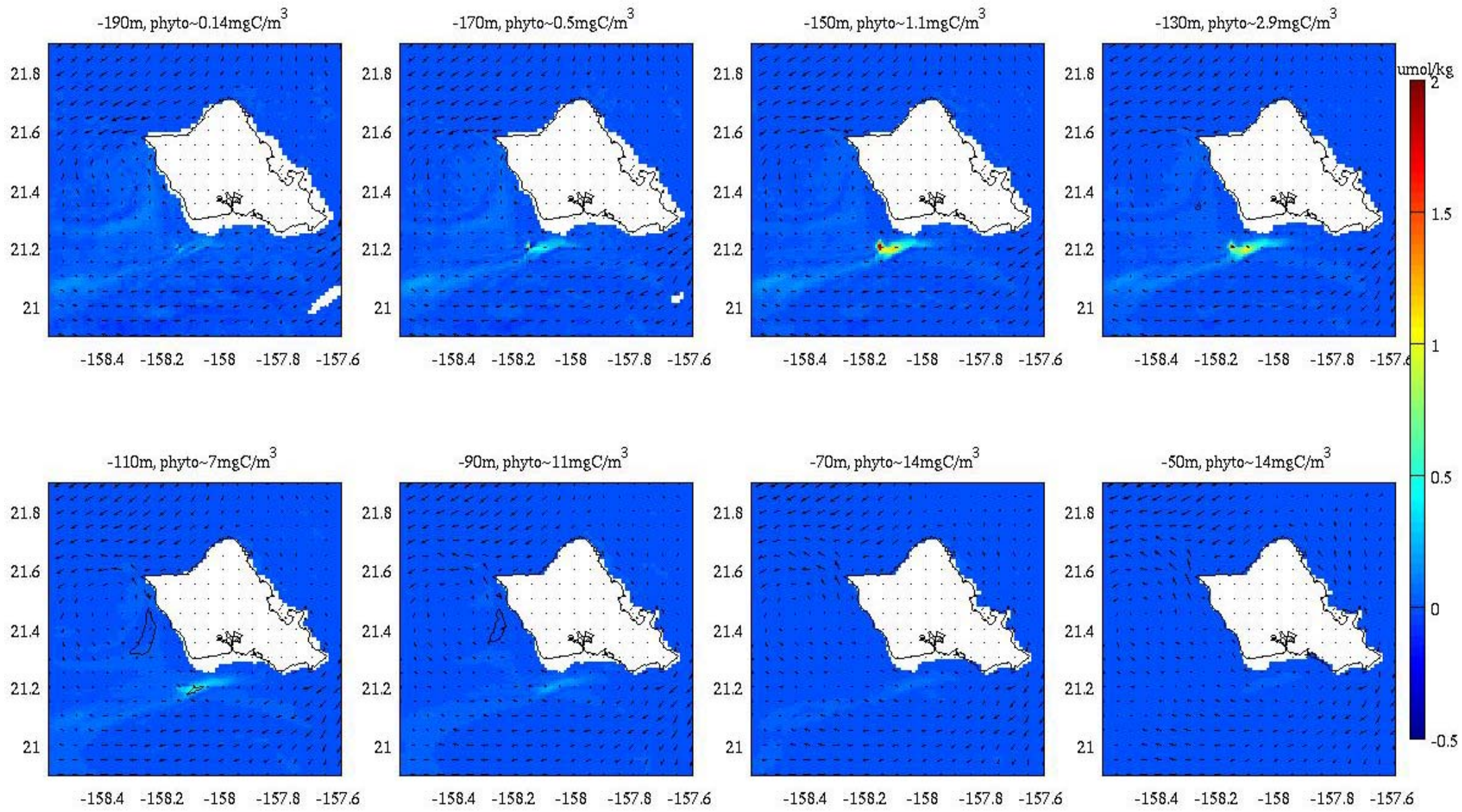

Figure 85. Nitrate perturbation (umol/kg) due to the RevX 100MW 8x70m OTEC plant, and contour lines of the resultant diatom perturbation (black lines) drawn at intervals of $0.5 \mathrm{mgC} / \mathrm{m} 3$. June $10^{\text {th }}, 2012$ at 16:40 Hawaii Standard Time. 
17-Jun-2010 16:39:50 HST

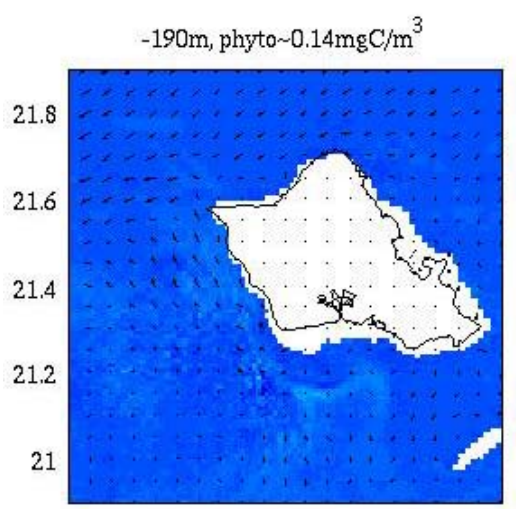

$-158.4-158.2-158 \quad-157.8-157.6$
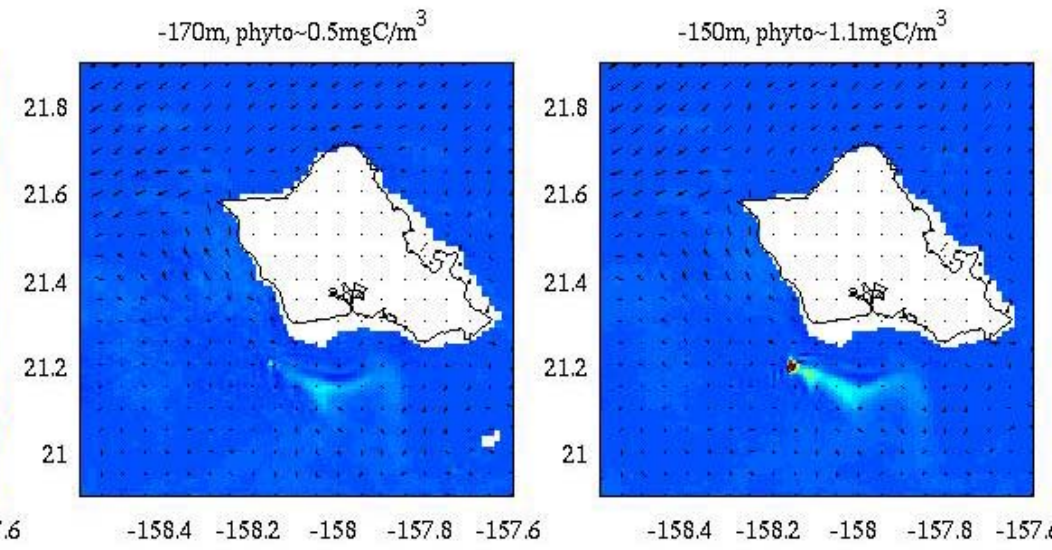

$-158.4-158.2-158 \quad-157.8-157.6$

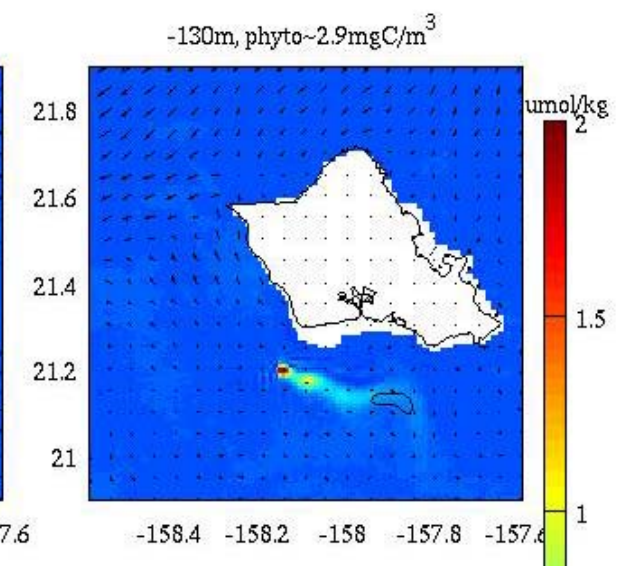

$-110 \mathrm{~m}$, phyto $7 \mathrm{mgC} / \mathrm{m}^{3}$
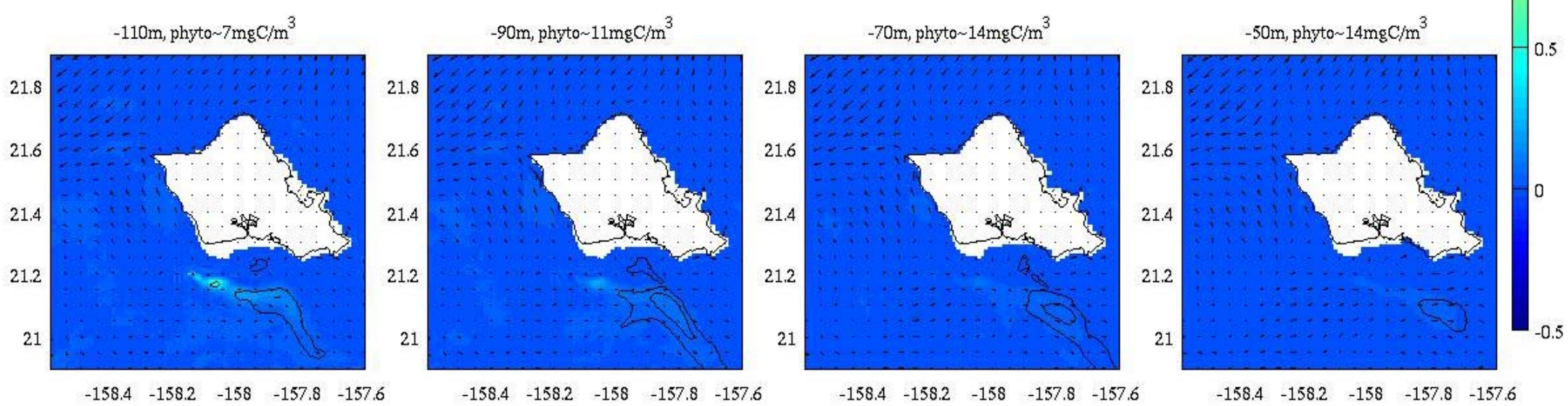

Figure 86. Nitrate perturbation (umol/kg) due to the RevX 100MW 8x70m OTEC plant, and contour lines of the resultant diatom perturbation (black lines) drawn at intervals of $0.5 \mathrm{mgC} / \mathrm{m} 3$. June $17^{\text {th }}, 2012$ at 16:40 Hawaii Standard Time. 
24-Jun-2010 16:39:50 HST
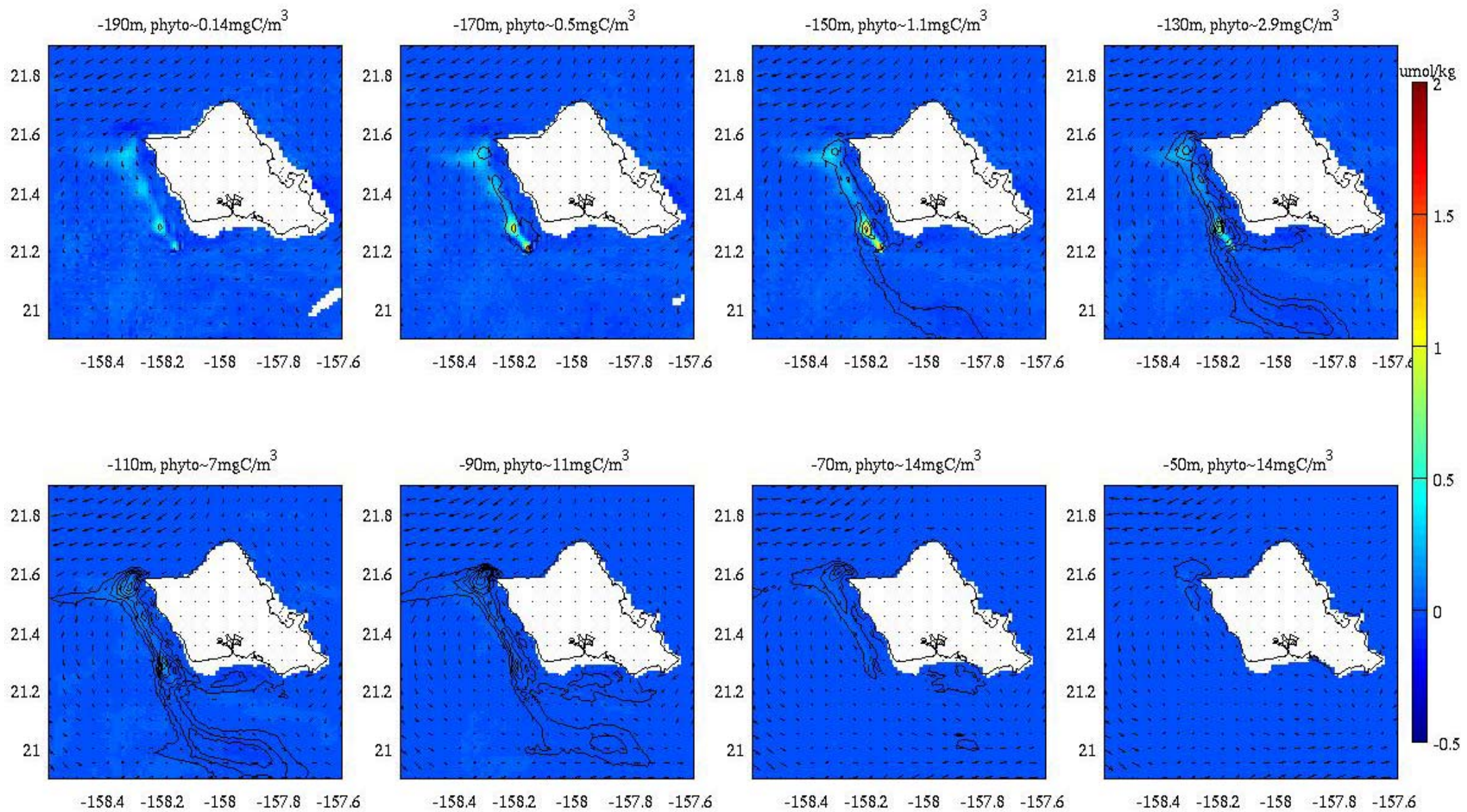

Figure 87. Nitrate perturbation (umol $/ \mathrm{kg}$ ) due to the RevX 100MW 8x70m OTEC plant, and contour lines of the resultant diatom perturbation (black lines) drawn at intervals of $0.5 \mathrm{mgC} / \mathrm{m} 3$. June $24^{\text {th }}, 2012$ at 16:40 Hawaii Standard Time. 


\subsection{5. $\quad$ Single 100MW OTEC Plant: 95 Meter Discharge, 8 Ducts}

The model was run with an OTEC plant consisting of eight separateducts, discharing a total combined flow rate of $420 \mathrm{~m}^{3} / \mathrm{s}$ of warm water and $320 \mathrm{~m}^{3} / \mathrm{s}$ of cold water in a mixed discharge at $95 \mathrm{~m}$ depth. Each duct/port was assumed to have a diameter of $7.8 \mathrm{~m}$ producing a downward discharge velocity of about $1.94 \mathrm{~m} / \mathrm{s}$. The near field plume had an average terminal depth of $175 \mathrm{~m}$ meters, with a volumetric dilution of $15.6: 1$. The average terminal plume temperature was $19.4^{\circ} \mathrm{C}$.

The deeper $95 \mathrm{~m}$ discharge appears to provide substantially reduced phytoplankton enhancement compared to the $70 \mathrm{~m}, 8$ discharge duct model.The near field terminal depths were twenty meters deeper and a full degree cooler (Celsius), increasing the tendency for the downstream plume to remain below the photic zone (i.e. elow $\sim 120 \mathrm{~m}$ ). These terminal plume dilutions and depths were more similar to the discahrges from the baseline 100MW OTEC plant, with 4 ducts at $70 \mathrm{~m}$ depth.

This 95 meter discharge with 8 ducts also shows some noticeably reduced phytoplankton perturbations compared to the baseline 70 meter 4 duct discharge configuration (discussed in section 4.1). However, the difference is slight, given that the near-field discharge from the $95 \mathrm{~m} 8$ duct plant terminates just 2 meters deeper and just $0.4^{\circ} \mathrm{C}$ cooler.

Figure 88 through Figure 91 show the difference of nitrate and pico-phytoplankton concentrations between the OTEC and non-OTEC simulations. The perturbations are roughly $0.5 \mathrm{mgC} / \mathrm{m}^{3}$ less than those observed in the $70 \mathrm{~m}$ 4-duct discharge scenario, at 1 to $1.5 \mathrm{mgC} / \mathrm{m}^{3}$.

Figure 92 through Figure 95 show the difference of nitrate and diatom concentrations between the OTEC and non-OTEC simulations. The diatom perturbations appear to reach about $1 \mathrm{mgC} / \mathrm{m}^{3}$, similar to the results for the $70 \mathrm{~m} 4$ duct OTEC simulations. The perturbations are visibly reduced compared to the $70 \mathrm{~m} 8$ discharge scenario. 
03-Jun-2010 16:39:50 HST

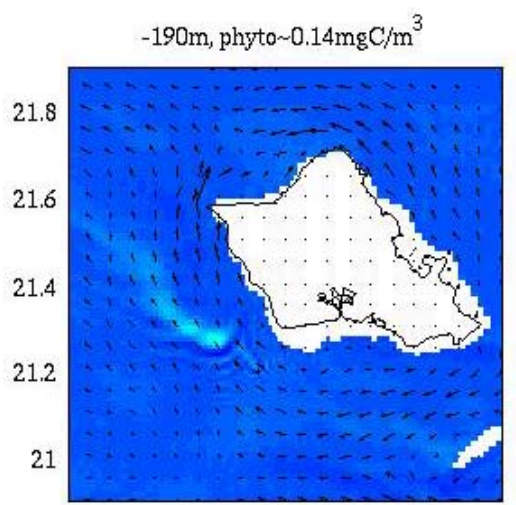

$-158.4 \quad-158.2-158 \quad-157.8-157.6$

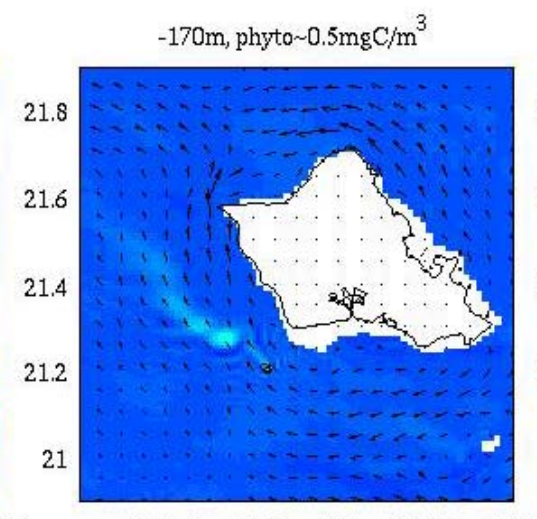

$-158.4-158.2-158 \quad-157.8-157.6$

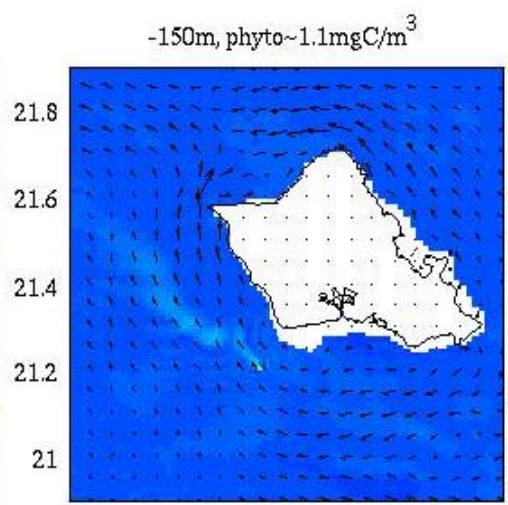

$-158.4 \quad-158.2-158 \quad-157.8-157.6$
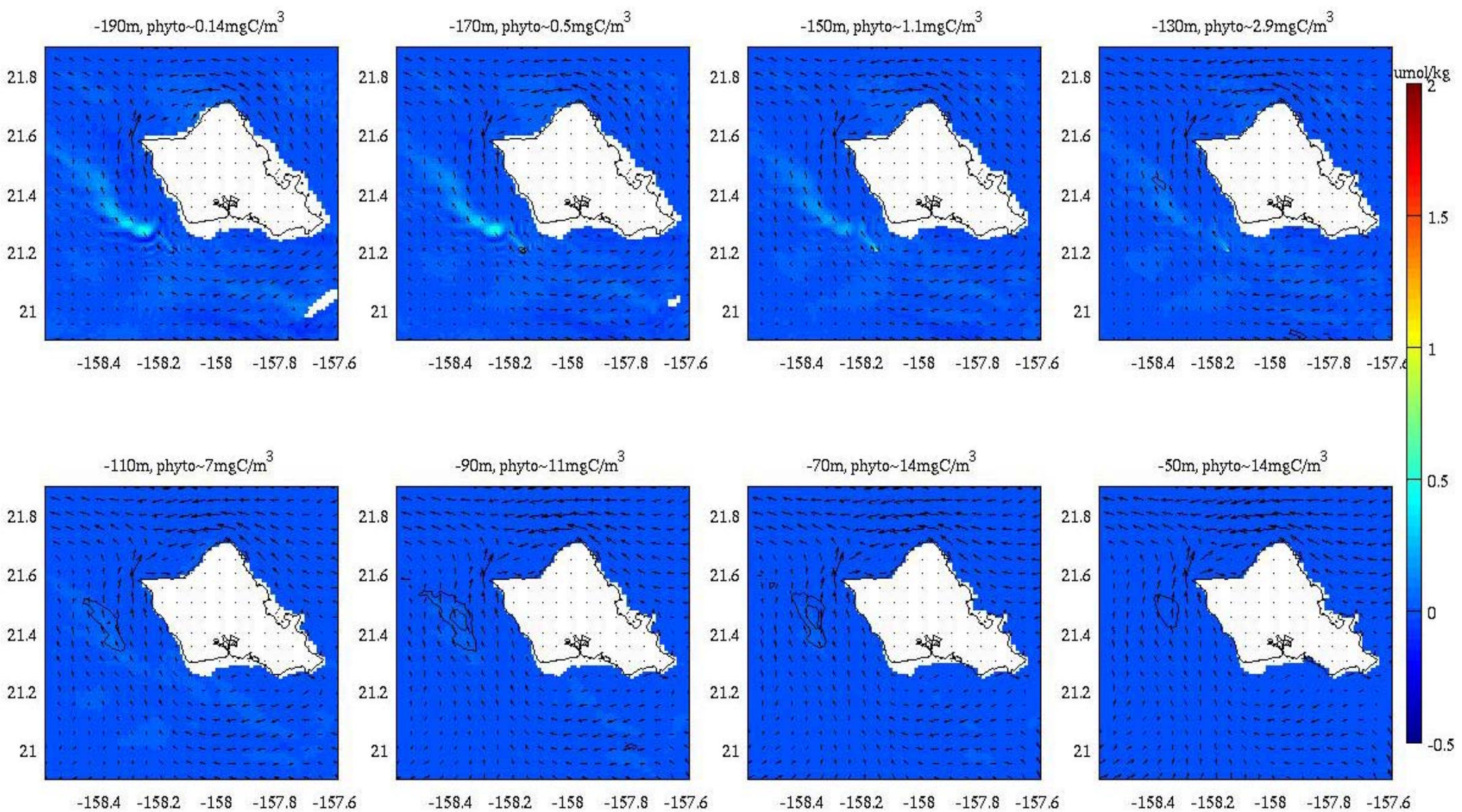

Figure 88. Nitrate perturbation (umol/kg) due to the RevX 100MW 8x95m OTEC plant, and contour lines of the resultant pico-phytoplankton perturbation (black lines) drawn at intervals of $0.5 \mathrm{mgC} / \mathrm{m}^{3}$. June $3^{\text {rd }}, 2010$ at 16:40 Hawaii Standard Time. 
10-Jun-2010 16:39:50 HST
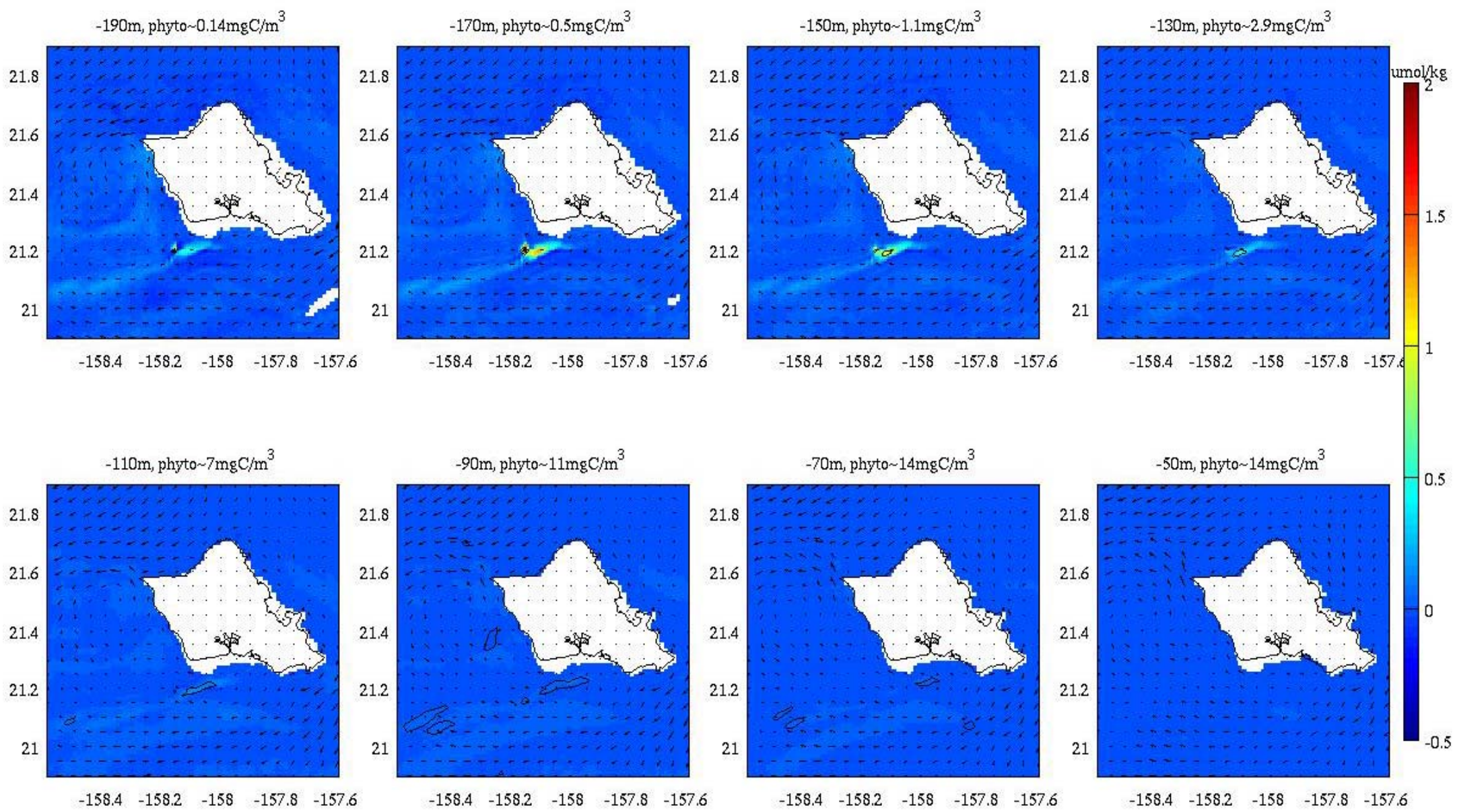

Figure 89. Nitrate perturbation (umol $/ \mathrm{kg}$ ) due to the RevX 100MW 8x95m OTEC plant, and contour lines of the resultant pico-phytoplankton perturbation (black lines) drawn at intervals of $0.5 \mathrm{mgC} / \mathrm{m}^{3}$. June $10^{\text {th }}, 2010$ at $16: 40$ Hawaii Standard Time. 
17-Jun-2010 16:39:50 HST
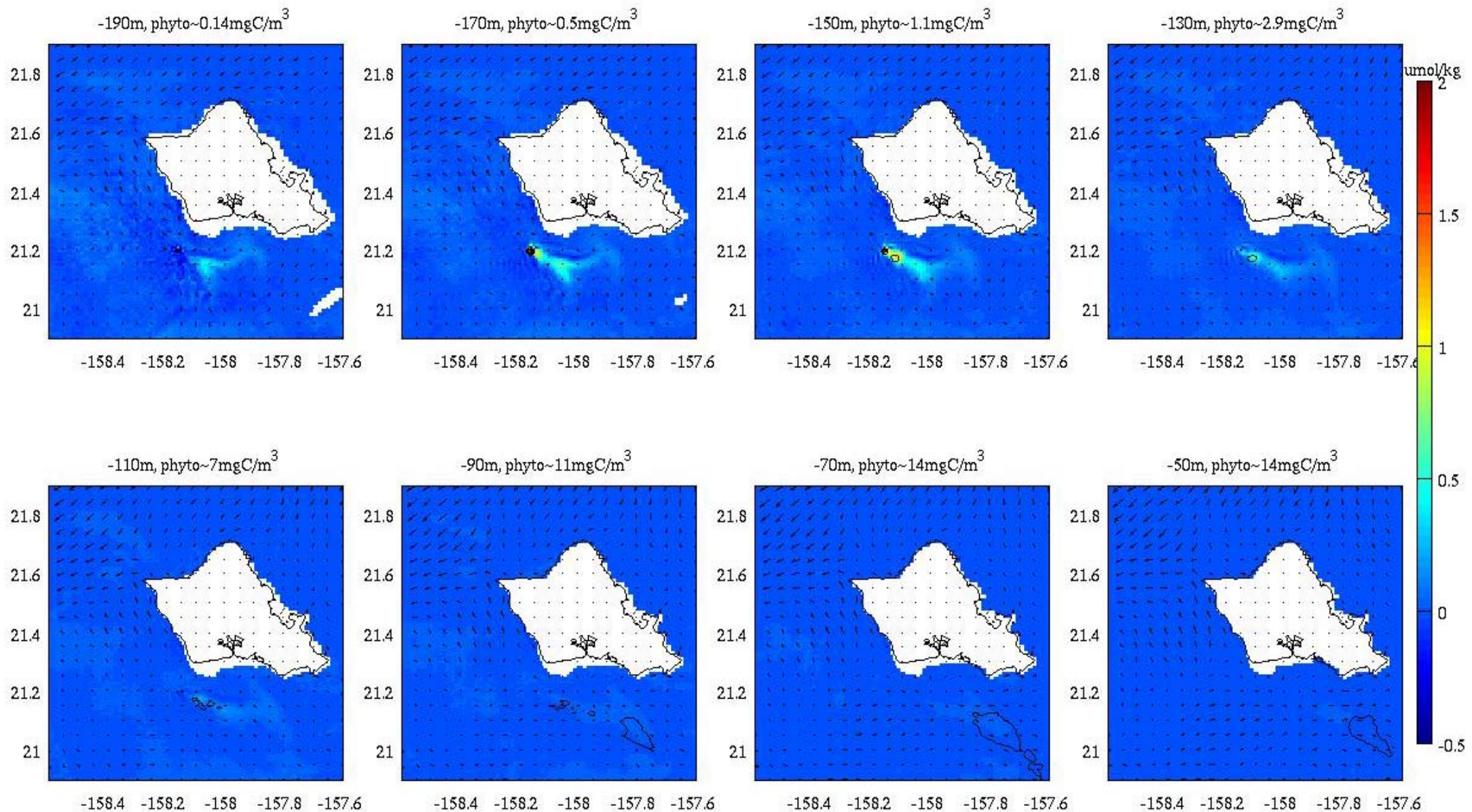

Figure 90. Nitrate perturbation (umol $/ \mathrm{kg}$ ) due to the RevX 100MW 8x95m OTEC plant, and contour lines of the resultant pico-phytoplankton perturbation (black lines) drawn at intervals of $0.5 \mathrm{mgC} / \mathrm{m}^{3}$. June $17^{\text {th }}, 2010$ at $16: 40$ Hawaii Standard Time. 
24-Jun-2010 16:39:50 HST
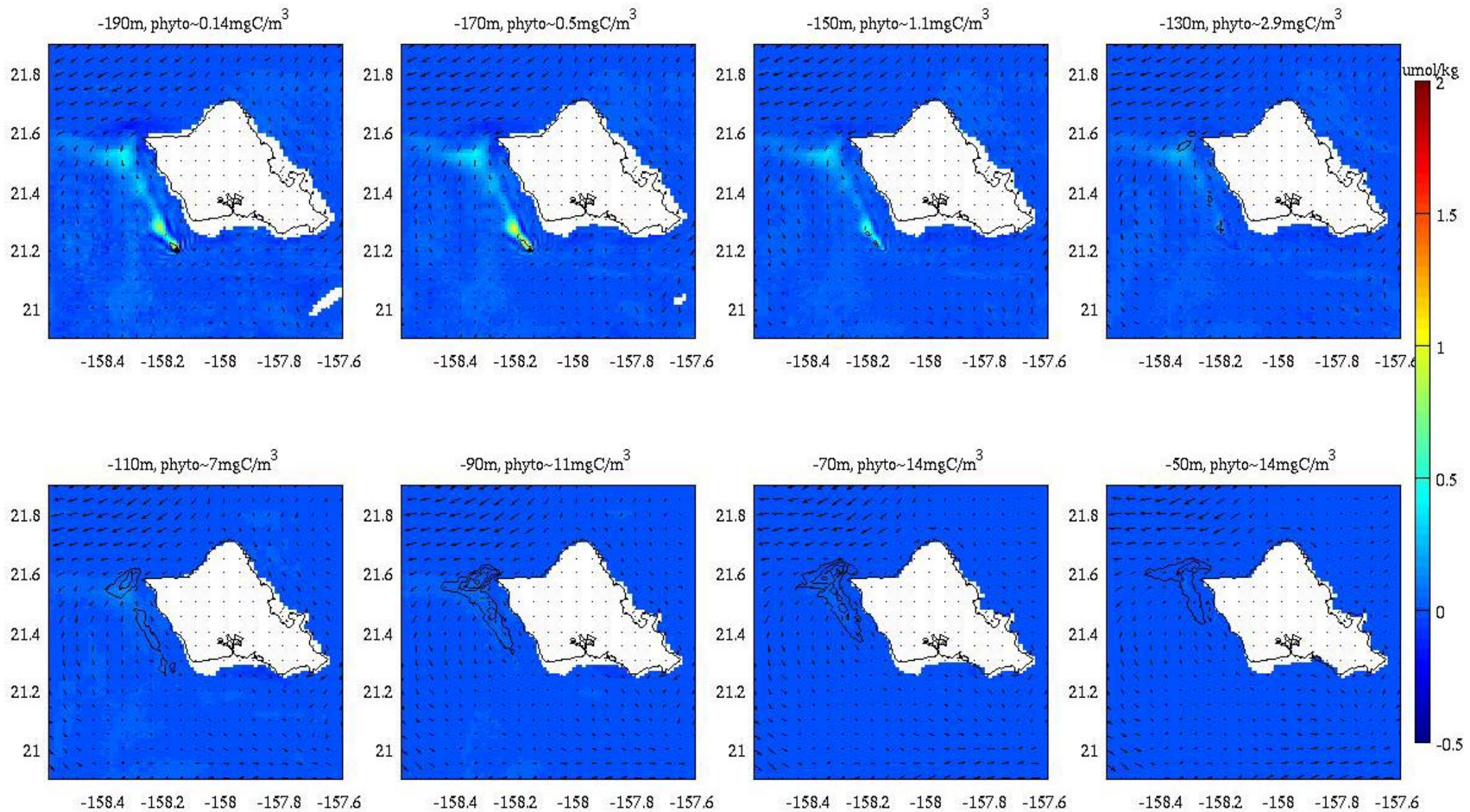

Figure 91. Nitrate perturbation (umol $/ \mathrm{kg}$ ) due to the RevX 100MW 8x95m OTEC plant, and contour lines of the resultant pico-phytoplankton perturbation (black lines) drawn at intervals of $0.5 \mathrm{mgC} / \mathrm{m}^{3}$. June $24^{\text {th }}, 2010$ at 16:40 Hawaii Standard Time. 
03-Jun-2010 16:39:50 HST
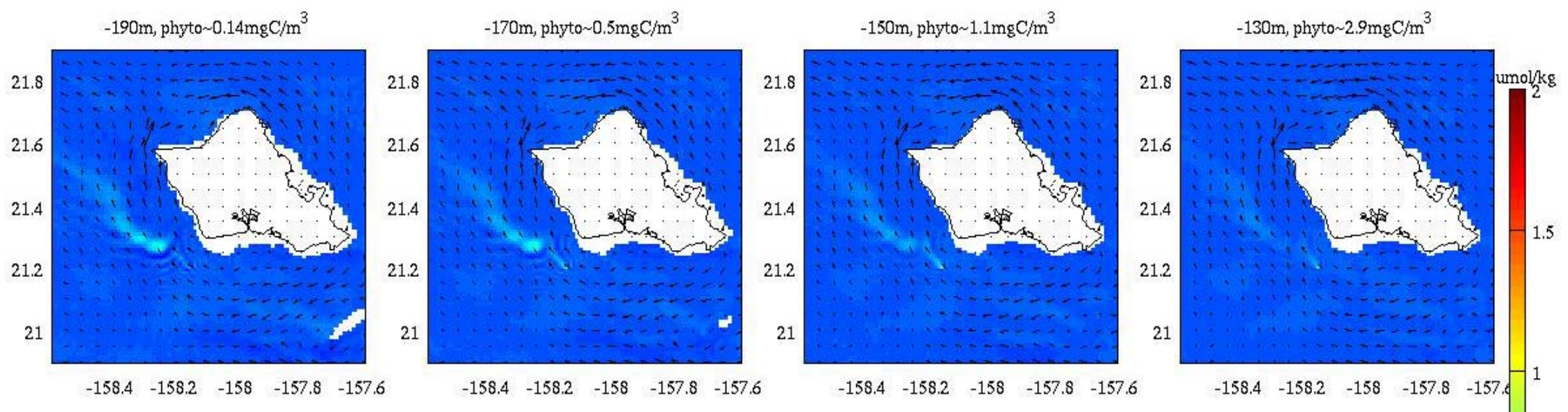

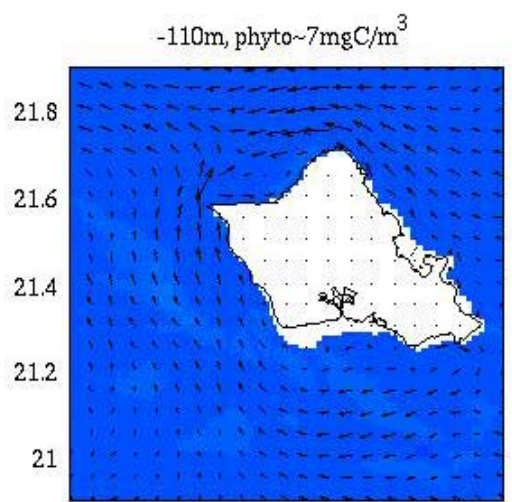

$-158.4 \quad-158.2-158 \quad-157.8-157.6$

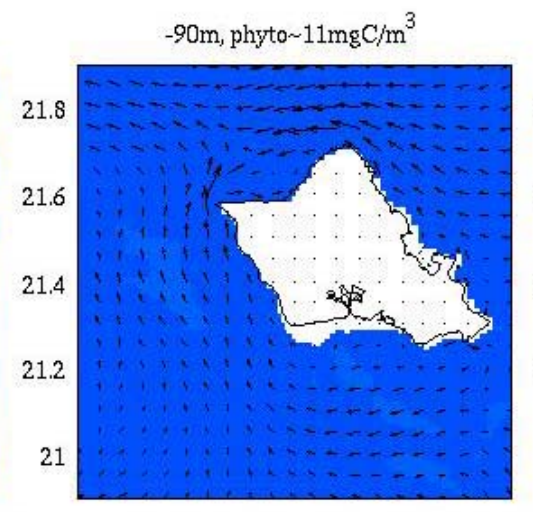

$-158.4-158.2 \quad-158 \quad-157.8 \quad-157.6$

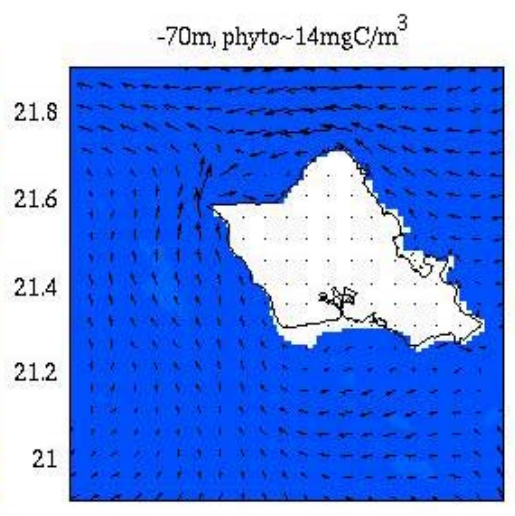

$\begin{array}{lllll}-158.4 & -158.2 & -158 & -157.8 & -157.6\end{array}$

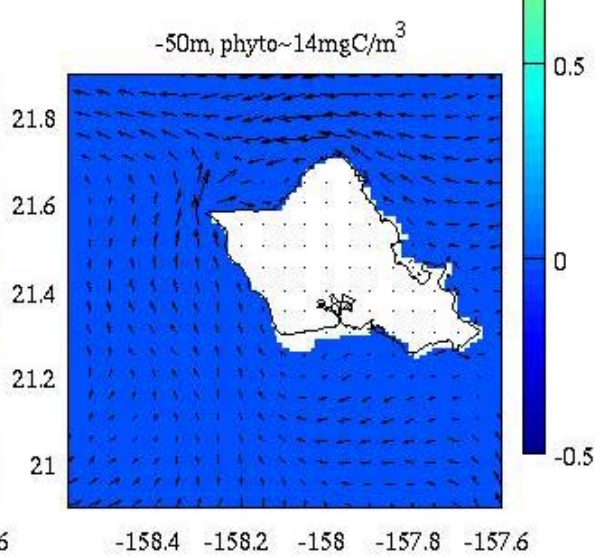

Figure 92. Nitrate perturbation (umol/kg) due to the RevX 100MW 8x95m OTEC plant, and contour lines of the resultant diatom perturbation (black lines) drawn at intervals of $0.5 \mathrm{mgC} / \mathrm{m}^{3}$. June $3^{\text {rd }}, 2010$ at 16:40 Hawaii Standard Time. 
10-Jun-2010 16:39:50 HST
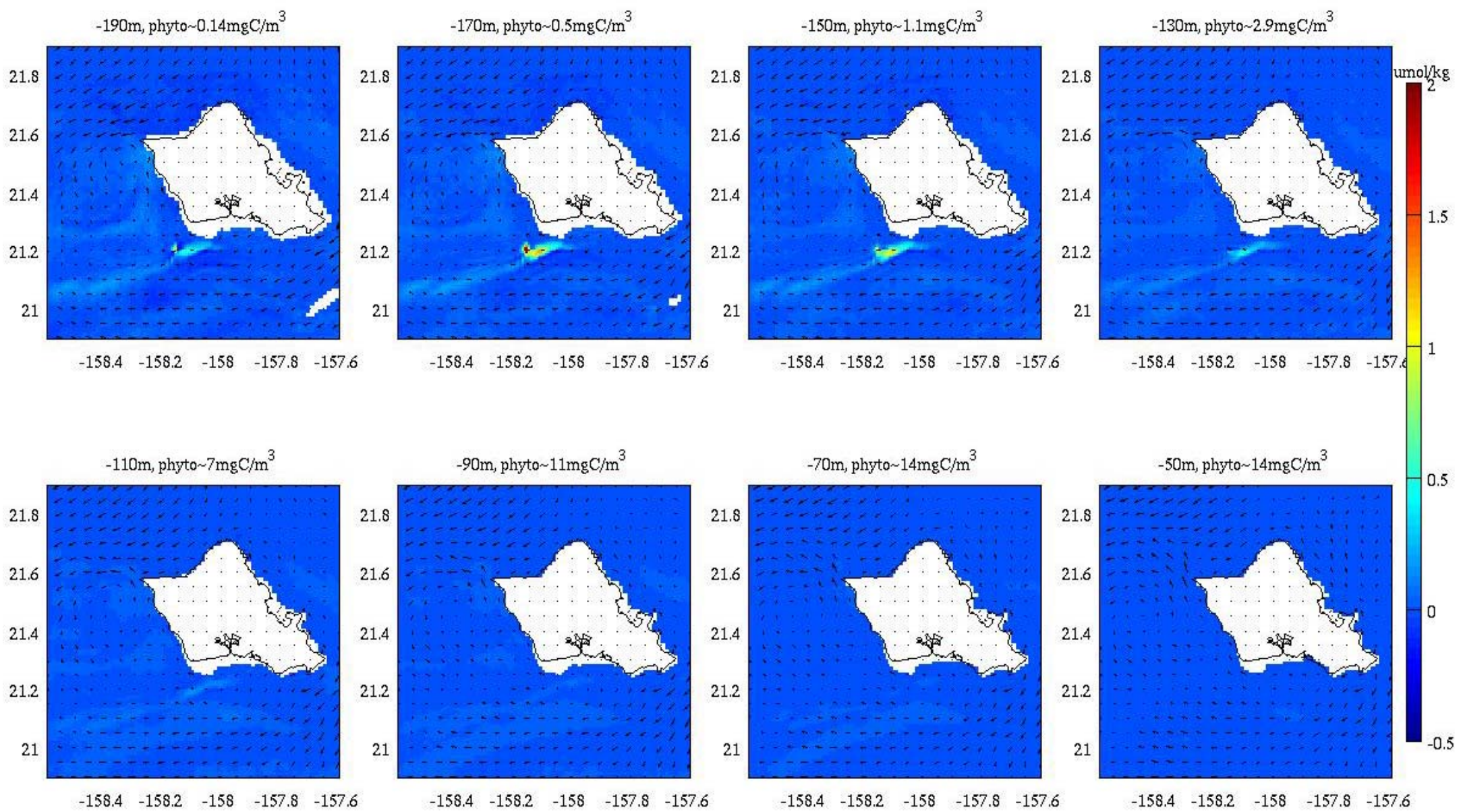

Figure 93. Nitrate perturbation (umol/kg) due to the RevX 100MW 8x95m OTEC plant, and contour lines of the resultant diatom perturbation (black lines) drawn at intervals of $0.5 \mathrm{mgC} / \mathrm{m}^{3}$. June $10^{\text {th }}, 2010$ at $16: 40$ Hawaii Standard Time. 
17-Jun-2010 16:39:50 HST
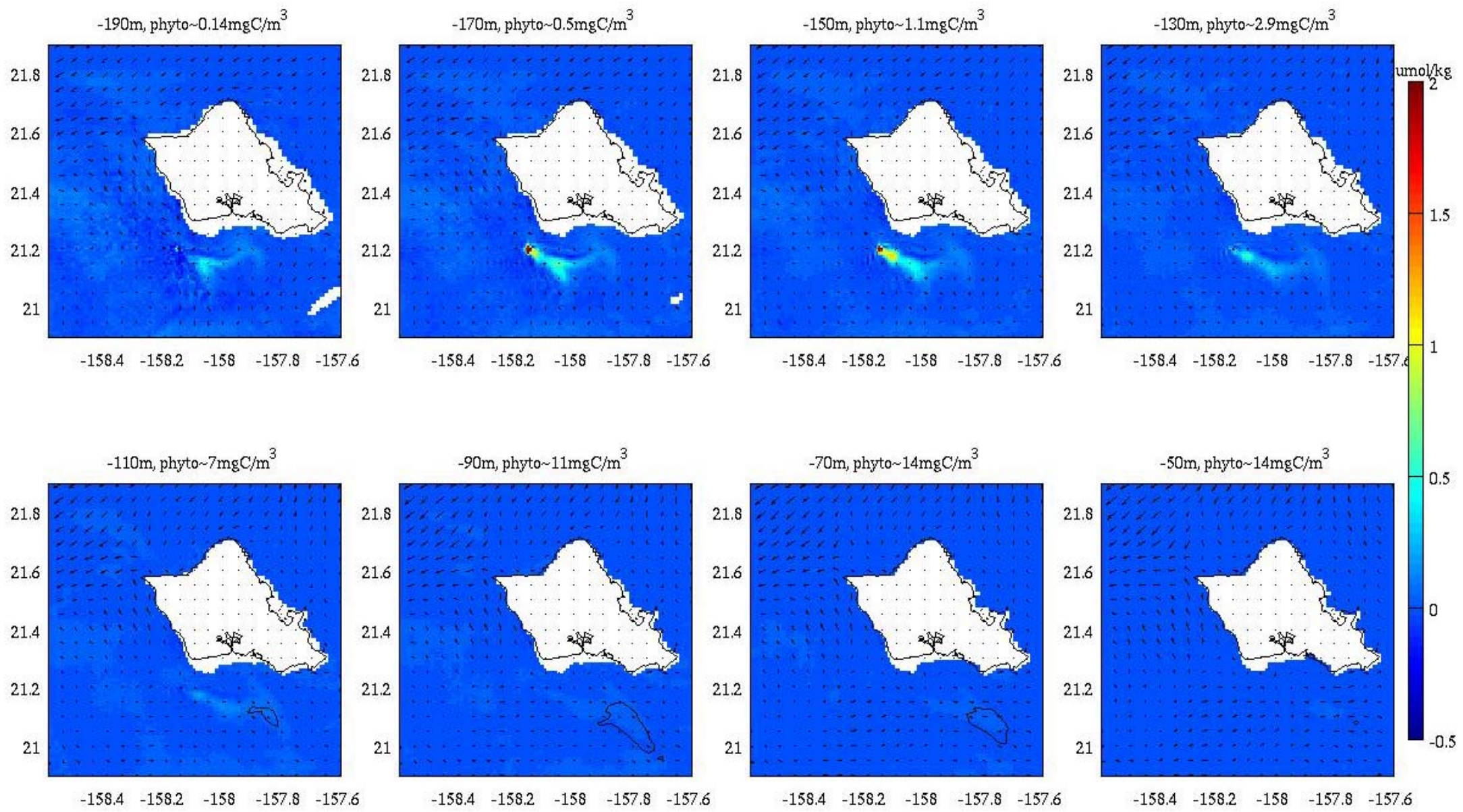

Figure 94. Nitrate perturbation (umol $/ \mathrm{kg}$ ) due to the RevX 100MW 8x95m OTEC plant, and contour lines of the resultant diatom perturbation (black lines) drawn at intervals of $0.5 \mathrm{mgC} / \mathrm{m}^{3}$. June $17^{\text {th }}, 2010$ at $16: 40$ Hawaii Standard Time. 
24-Jun-2010 16:39:50 HST

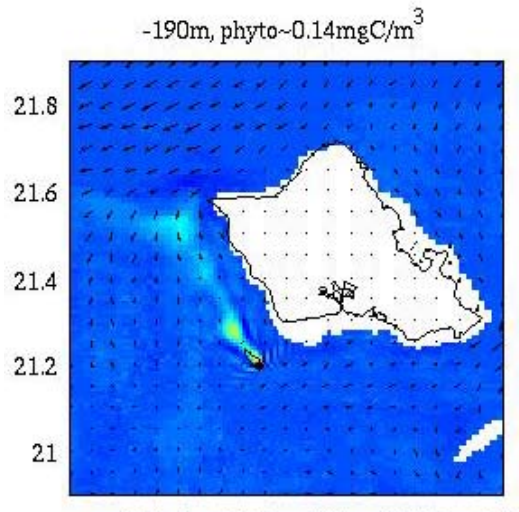

$\begin{array}{lllll}-158.4 & -158.2 & -158 & -157.8 & -157.6\end{array}$

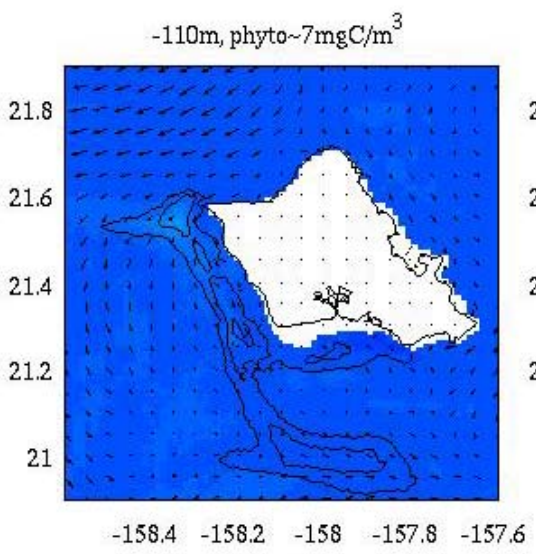

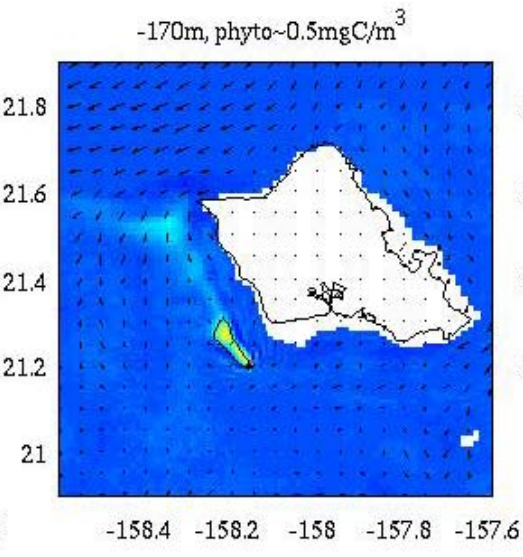

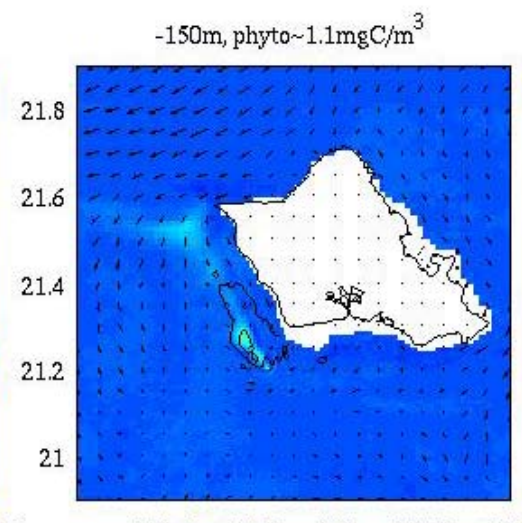

$\begin{array}{lllll}-158.4 & -158.2 & -158 & -157.8 & -157.6\end{array}$
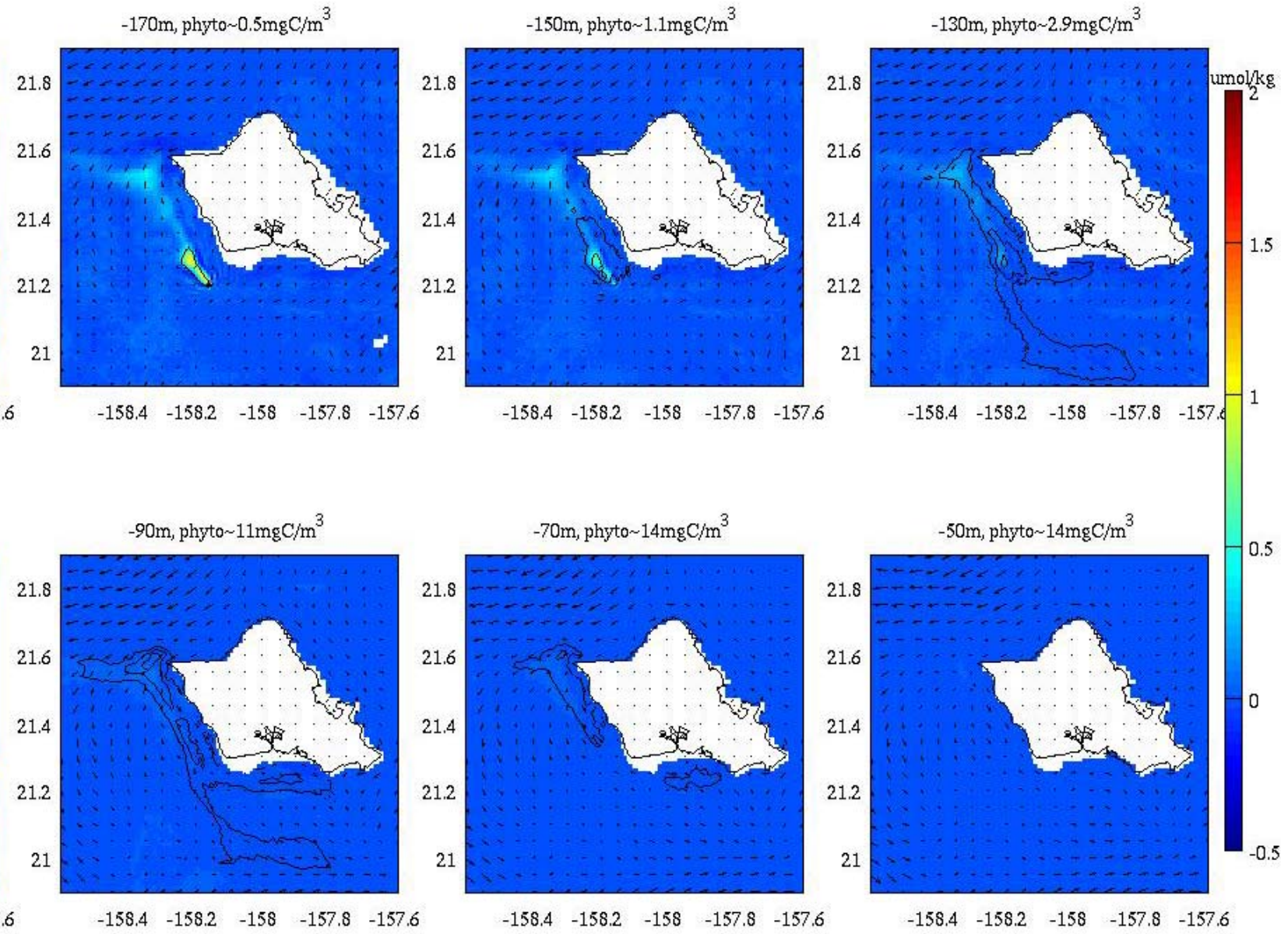

Figure 95. Nitrate perturbation (umol/kg) due to the RevX 100MW 8x95m OTEC plant, and contour lines of the resultant diatom perturbation (black lines) drawn at intervals of $0.5 \mathrm{mgC} / \mathrm{m}^{3}$. June $24^{\text {th }}, 2010$ at 16:40 Hawaii Standard Time. 


\subsection{6. $\quad$ Single 2.5MW OTEC Spar: $70 \mathrm{~m}$ discharge, 1 Duct}

The model was run with a single 2.5 megawatt OTEC plant, consisting of one discharge having a combined flow rate of $10.7 \mathrm{~m}^{3} / \mathrm{s}$ of warm water and $8.2 \mathrm{~m}^{3} / \mathrm{s}$ of cold water in a mixed discharge at 70 meter depth. The discharge was assumed to have a diameter of $1.73 \mathrm{~m}$ producing a downward discharge velocity of about $8 \mathrm{~m} / \mathrm{s}$.

The discharge produced very little perturbation to the local phytoplankton populations. The plume showed less than a $0.5 \mathrm{mgC} / \mathrm{m}^{3}$ increase at most simulations time steps, less than a $5 \%$ increase in the ambient biomass. Figures Figure 96 through Figure 99 show this very small perturbation. If a larger perturbation was desired for scientific purposes, the plume should be discharged at a more shallow depth. 
03-Jun-2010 16:39:50 HST
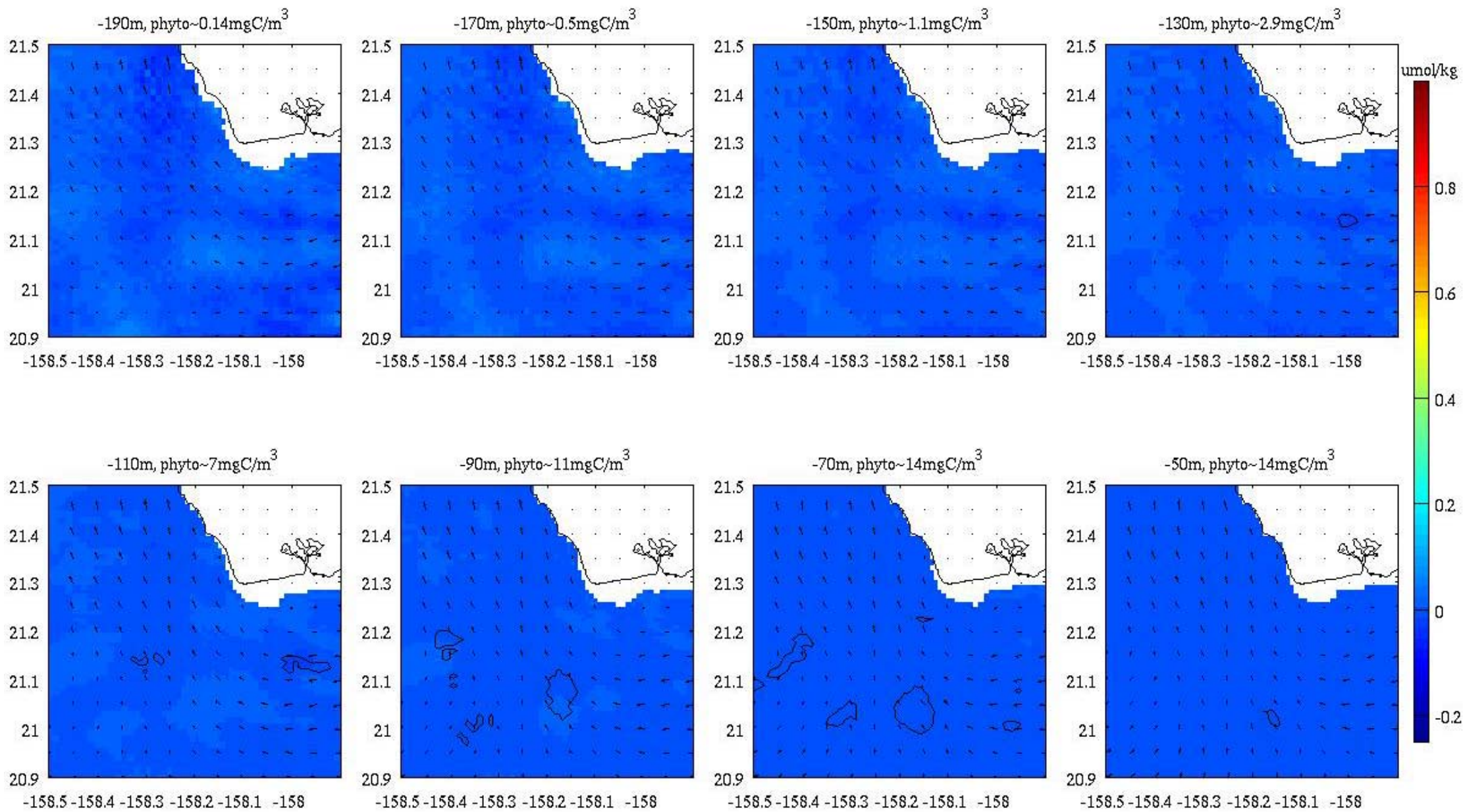

Figure 96. Nitrate perturbation (umol $/ \mathrm{kg}$ ) due to the $2.5 \mathrm{MW}$ MiniSpar at the time and date indicated. 
10-Jun-2010 16:39:50 HST
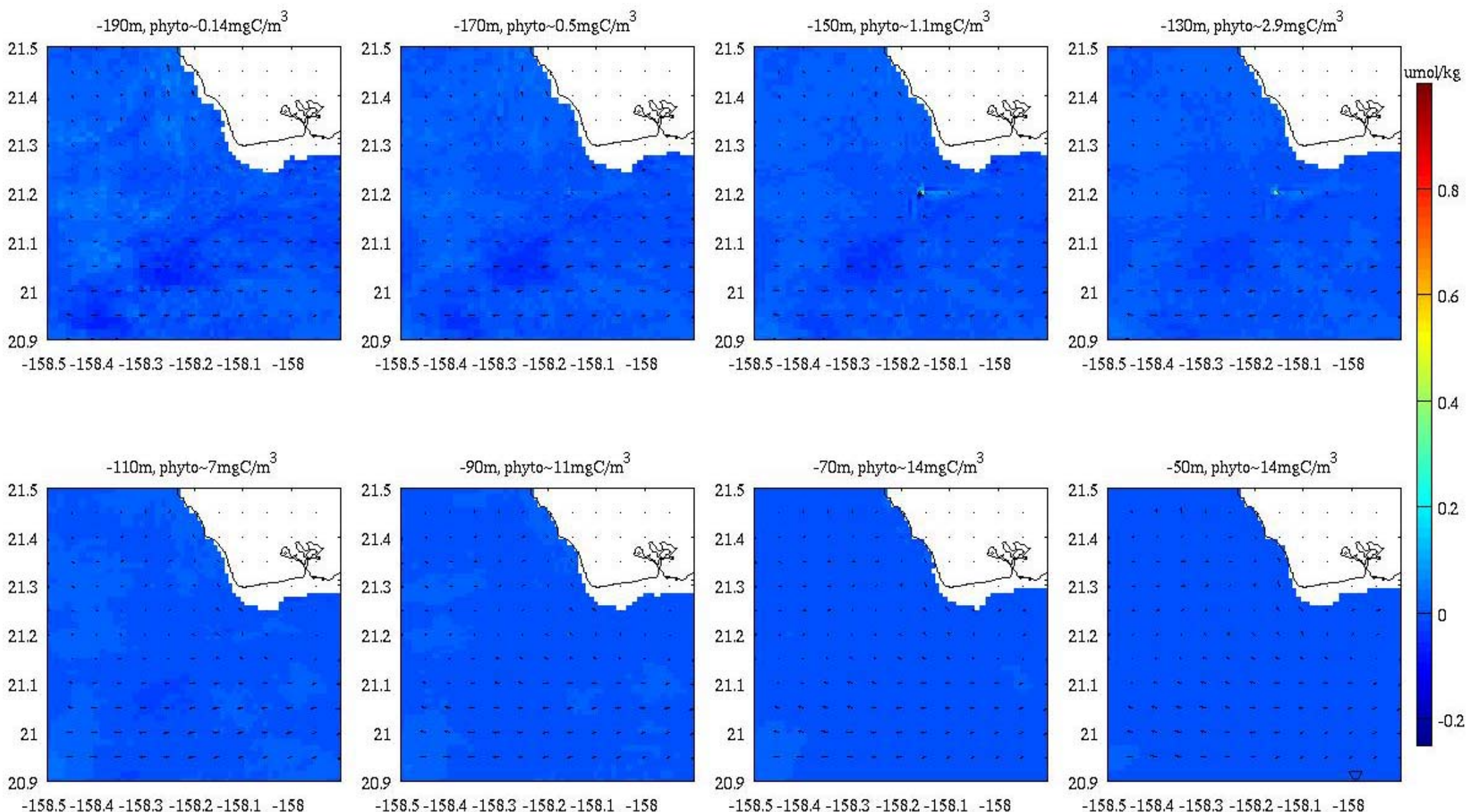

Figure 97. Nitrate perturbation (umol/kg) due to the 2.5 MW MiniSpar at the time and date indicated. 
17-Jun-2010 16:39:50 HST
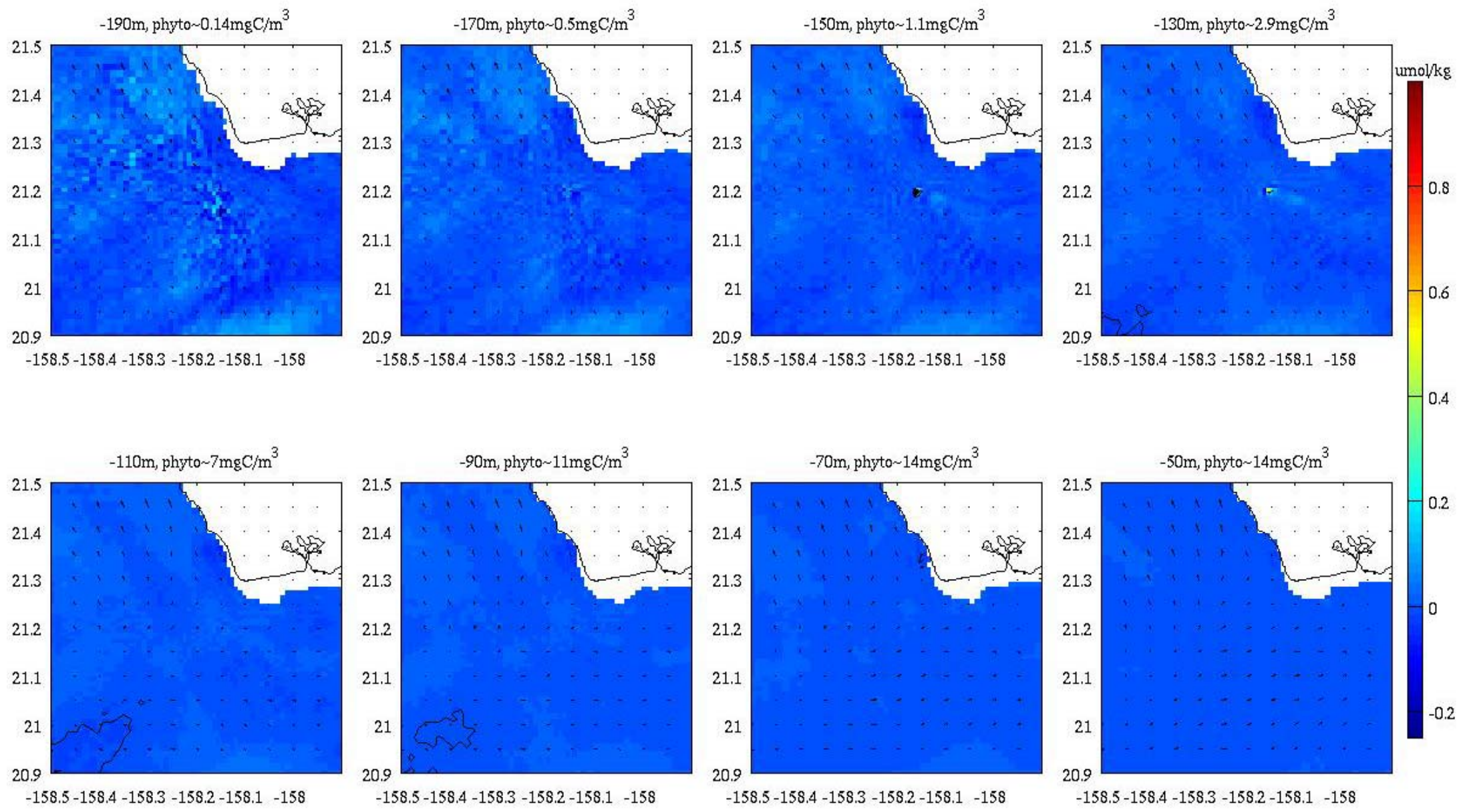

Figure 98. Nitrate perturbation (umol $/ \mathrm{kg}$ ) due to the $2.5 \mathrm{MW}$ MiniSpar at the time and date indicated. 
24-Jun-2010 16:39:50 HST
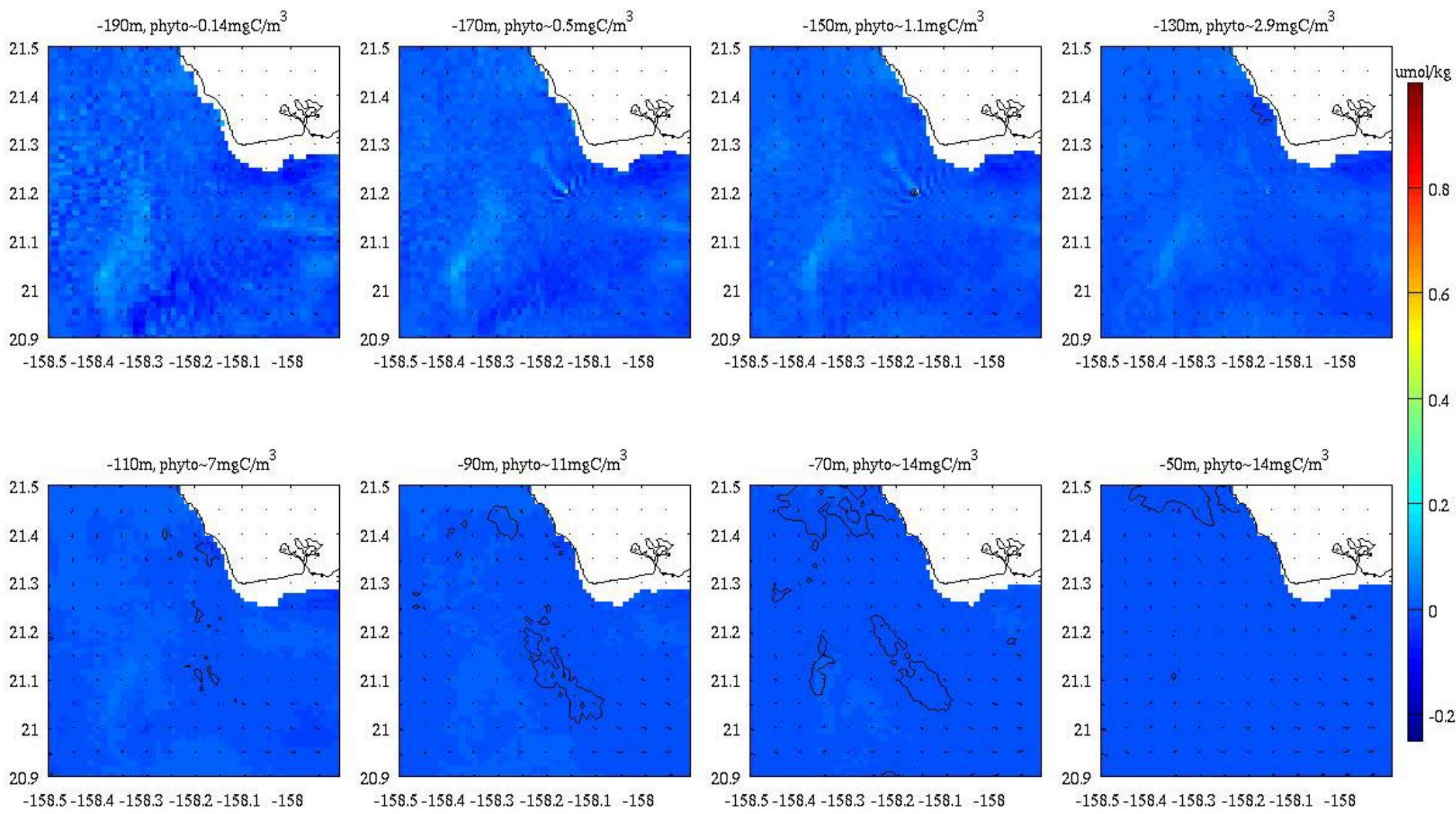

Figure 99. Nitrate perturbation (umol/ $/ \mathrm{kg}$ ) due to the $2.5 \mathrm{MW}$ MiniSpar at the time and date indicated. 


\subsection{SENSITIVITY ANALYSIS}

Phytoplankton concentrations for the non-OTEC, baseline 100MW (4 ducts at 70m depth), 8 duct $70 \mathrm{~m} \times 100 \mathrm{MW}$, and the cluster of three baseline 100MW plants were also simulated using the biological parameters of model revision ZA (shown in Table 1, Section 3.2). These parameters support a simulation with higher net growth rate by using lower predation rates and a higher nitrate remineralization rate, as discussed in section 3. As seen in the comparison with HOTS data shown in the left column of Figure 35, these parameters provide a larger estimate of the ambient biomass concentrations. Also, the combination of higher initial populations and the reduced predation provides conditions that would be more likely to cause a bloom event, providing a reasonable upper bound on the model sensitivity. For comparison, the average phytoplankton concentrations were computed off the west and south coast of $\mathrm{O}^{\prime}$ ahu in the same $5400 \mathrm{~km}^{2}$ zone that was used for analysis of average perturbations in model runs using Revision X.

Figure 100 shows the average phytoplankton concentrations from each simulation. The non-OTEC concentrations of picophytoplankton, diatoms, and the large phytoplankton classes increase by $74 \%, 39 \%$, and 69\% respectively when using RevZA versus RevX. However, the percentage increase in biomass due to OTEC relative to the non-OTEC concentrations remains similar between the RevX and RevZA scenarios. The right column of Figure 100 shows the increase in biomass for the OTEC simulations relative to the non-OTEC scenario. For the baseline 4x70m 100MW OTEC simulations, the average picophytoplankton, diatoms, and eukaryotes biomass perturbations are $0.4 \%$ vs $0.4 \%, 3.4 \%$ vs $3.3 \%$ ), and $0.3 \%$ vs $0.4 \%$ for revX and revZA, repectively.

These results indicate that the percentage increase in picophytoplankton and diatom populations are relatively insensitive to the changes in our biological model parameters. The precentage increase in phytoplankton populations relative to ambient concentrations is a robust metric for reporting the impacts of an OTEC discharge, and the changes to the total biological carbon content as a result of OTEC can be expected to be proportional to the initial phytoplankton populations. 


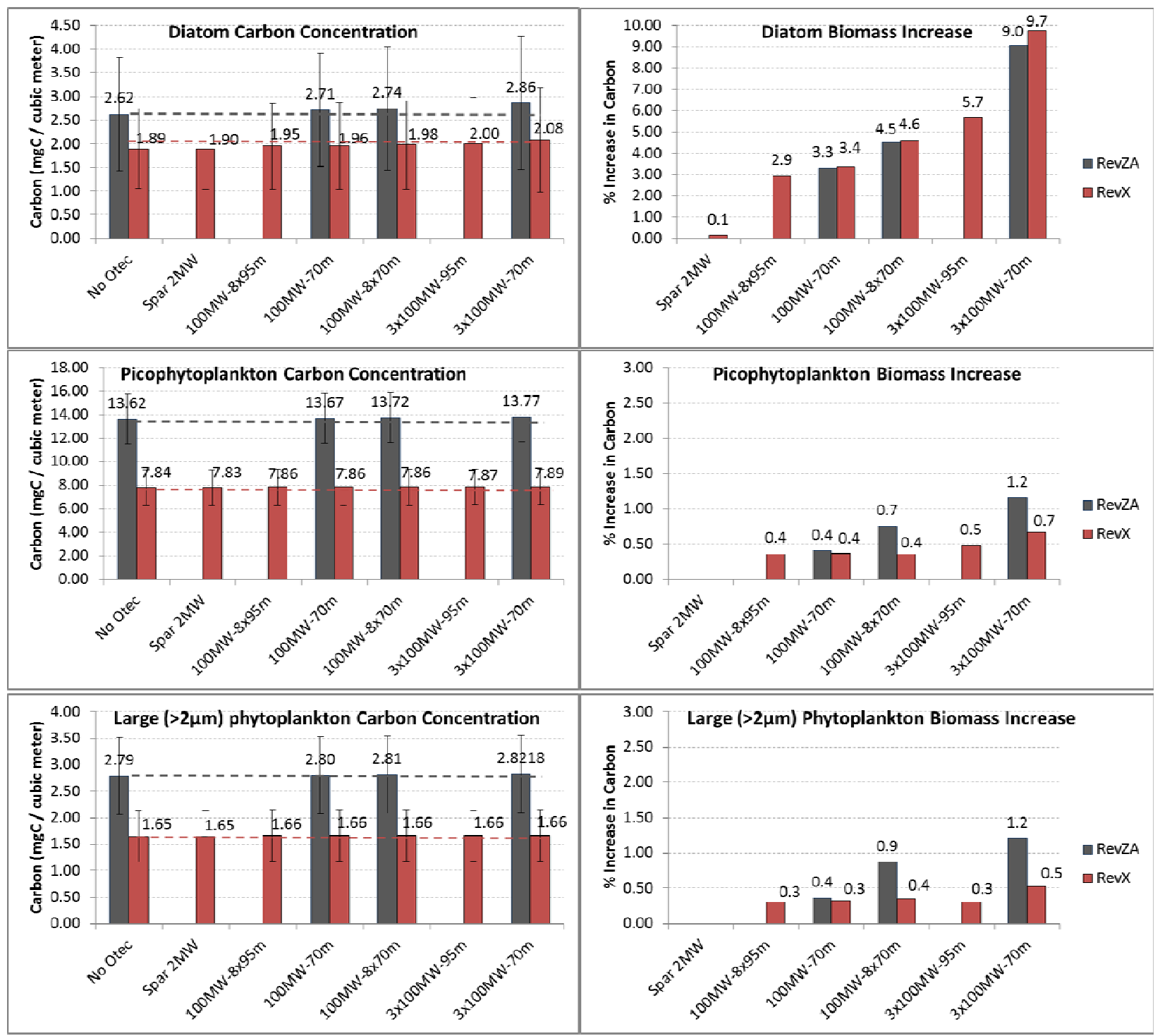

Figure 100. Left: Bar graph showing the average phytoplankton populations from each of the OTEC and non-OTEC simulations in $\mathrm{mgC} / \mathrm{m}^{3}$ in $5400 \mathrm{~km}^{2}$ area offshore of west and south O'ahu (area is shown in Figure 36). Right: Percentage increase in average carbon content above the non-OTEC scenario for RevX (red) and RevZA (grey). Although RevZA produces higher standing stocks of biomass than RevX, the increase in biomass relative to the background concentrations remains similar. 


\section{DISCUSSION \& COMPARISON}

\subsection{SUMMARY}

We have shown the successful implementation and coupling of a biological model to Makai's numerical OTEC plume model. The biological model was shown to effectively and reasonably reproduce the observed phytoplankton dynamics and biological processes that have been measured in Hawai ian waters. The numerical model was calibrated using reported values for growth kinetics, predation and mortality losses, remineralization processes, light limitation, ambient standing stocks, and and other critical phytoplankton growth factors. Several modification were made to the EFDC (Environmental Fluid Dynamics Code) to incorporate these biological parameters and formulations, many of which had been successfully implemented for other open ocean oligotrophic and tropical regions.

The model was forced with high resolution model output from the Hawaii Regional Ocean Model operated by the University of Hawai'i, providing our numerical domain with atmospheric forcing, tidal forcing, baroclinic and internal tides, basin scale circulation, and mesoscale features. The physical conditions compared favorably with the ADCP mooring data from offshore southwest of $\mathrm{O}$ 'ahu, very near the simulated OTEC locations. The inclusion of accurate tidal processes as well as larger scale circulatory features provides a uniquely accurate high resolution biological and physical model of the island of $\mathrm{O}$ 'ahu, contributing significantly to the realism on the model's predictions for the transport and fate of the OTEC plume waters. The physical accuracy of the model, in conjunction with the use of the latest biological research data and the multi-decade HOTS data for biological calibration, produced a very good agreement between the model predictions and natural biomass patterns in the middle and lower photic zone.

Several different OTEC scenarios were modeled in order to provide a quantified prediction on the perturbation to existing phytoplankton populations as a function of the different return water discharge configurations. Simulations included varying discharge depths, the number of discharge ports, and the number of OTEC plants within close proximity. The model showed reasonable sensitivity to these changes, and provides a tool for engineering design and environmental risk assessment of large scale OTEC development.

\subsection{DESIGN CONCLUSIONS}

The results indicate that a single 100MW OTEC plant discharged at 70m depth will produce a measurable but relatively limited perturbation to the existing biomass levels. Pico-phytoplankton, which are predominantly cyanobacteria prochlorococcus and synechococcus, make up nearly $80 \%$ of the ambient biomass and have concentrations of about 10 to $15 \mathrm{mgC} / \mathrm{m}^{3}$ in the lower photic zone and deep chlorophyll max (DCM). The model shows about a 10\% increase in biomass of this picoplankton class, within an area of several square kilometers downstream of the OTEC plant (on the order to $10 \times 5 \mathrm{~km}$ ). These perturbations appear to occur far downstream of the OTEC discharge, after trace levels of the plume nutrients get dispersed and diffused into the photic zone from the terminal plume water mass below. The perturbations generally occur twenty to thirty kilometers downstream of the OTEC discharge. The simulated diatom class of phytoplankton shows greater sensitivity to the initial population concentrations than the pico phytoplankton class. In early time steps of the model, the diatom show little significant increase in biomass (i.e. $<0.5 \mathrm{mgC} / \mathrm{m}^{3}$ ). As the simulation progresses, the background (non-OTEC) diatom population increases near the coast 
of Oahu, due to the continous nutrient supply from vertical mixing. These increased coastal populations $\left(\sim 5-10 \mathrm{mgC} / \mathrm{m}^{3}\right)$ start to seed the plume waters providing the initial populations needed to have a measurable and noticeable perturbation to the diatom biomass. As the nearshore populations develop to levels of 5 to $10 \mathrm{mgC} / \mathrm{m}^{3}$, the perturbations reach levels of 1 to $2 \mathrm{mgC} / \mathrm{m}^{3}$, again over an area of tens of square kilometers.

A cluster of three OTEC plants with the same $70 \mathrm{~m}$ discharge were simulated with spacing $1.1 \mathrm{~km}$ apart. The model results show increased biological perturbations compared to the single 100MW OTEC plant. The perturbations increased to 4 to $6 \mathrm{mgC} / \mathrm{m}^{3}$ for both the pico-phytoplankton and diatom classes. This increase was not intuitive from the level of nutrient perturbations. The results indicate that an increase in the number of closely spaced OTEC plants with 70m deep discharges may cause a disproportionate increase in the biological perturbation. This is likely caused by the fact that growth is proportionate to the biomass concentration. As a result, there can be a relatively sudden period of positive feedback on overall growth, with an increase in growth caused by new nutrient addition increasing the biomass, which causes further increase in growth (even without subsequent nutrient additions), until the "new nutrient" is fully utilized. However, while these multiple OTEC plants show a significantly increased level of perturbation relative to the single 100MW OTEC plant, the perturbations are still of similar magnitude to the ambient concentration and variability in these oligotrophic waters.

More configurations for single 100MW OTEC plants were modeled, including a 70m deep and $95 \mathrm{~m}$ deep discharge from eight ports rather than four. The eight port discharge from $70 \mathrm{~m}$ depth had slightly greater impact on the phytoplankton than the $70 \mathrm{~m}$ deep discharge from a lesser four port configuration (Table 2). Meanwhile, discharging from eight ports at the depth of $95 \mathrm{~m}$ resulted in a similar phytoplankton response as the $70 \mathrm{~m}$ four port discharge.

Typically, discharging from more ports is the optimal design to minimize impacts to the surrounding water quality, since more discharge ports increase the immediate dilution. Most outfalls have a series of diffuser ports for this purpose. However, due to the large volumes of flow associated with OTEC and the concern over large scale ocean fertilization, this general assumption of dilution as the key to mitigating pollution may not hold true. The eight port discharges showed increased dilution of the discharges, but all else equal (discharge depth), the impact on the phytoplankton was more noticeable. Looking back at the the terminal temperatures of these plumes (Table 2) shows that the increased dilution also causes an increase in the terminal plume temperatures, by over half a degree Celsius. The warmer temperatures of the diluted plumes can ultimately cause the trace nutrients within the downstream water mass to mix higher into the water column where they can be more effectively utilized.

While a deeper plume is clearly beneficial for reducing the aritifical fertilization of the surrounding environment, other regulatory requirements will need to be considered such as the dilution of any biofouling agents, temperatures, secondary-entrainment issues, and engineering design constraints. While acceptable thresholds for many of these factors are yet undefined by regulators and engineers, the modeling methods and resultsfrom this study indicate that an acceptable design can be achieved. Furthermore, these results indicate that this model, or one of similar complexity and sensitivity, can be used to effectively gain a better insight and predictive capability on the impact of changes to OTEC discharge designs. Also, the present implementation of Makai's OTEC plume model retains a capability to track both inert and chemically active tracers in addition to the 
biochemical and biological tracers discussed in this report. The capabilities will be important as OTEC technology continues to progress.

\subsection{FUTURE WORK, IMPLICATIONS, MODEL LIMITATIONS}

This study utilized state-of-the-art modeling methods, observational datasets, and detailed industrial knowledge of likely OTEC design to provide a comprehensive analysis of the impact on the predominant phytoplankton populations. However, as with any modeling study, there are implications and limitations of these results that should be addressed.

Based upon the dynamic and "patchy" results we have seen in this modeling, the ocean circulation dynamics near Hawai'i play an important role in OTEC plume modeling. This observation suggests that valid model results near any coastal OTEC site will likely require the inclusion of accurate bathymetry, tides, and realistic currents within the modeling effort.

There are several additional factors that have been considered when assessing OTEC impacts which were not directly addressed in this study. Some examples include the impacts on higher trophic level organisms, species-specific ecosystem shifts, long-term adaptive behaviors, and the scenarios of iron or phosphate limitation. These issues are beyond the scope of a modeling study that was designed for as broad a scope as the topic we have attempted, but the methods and results from this work can be readily used in formulating a better understanding and quantified baseline of information to ground these more complex issues. In addition, if different locations or scenarios present themselves in the future as needing investigation, such as phosphorous versus nitrate limitation, the necessary modeling inputs can be adapted while relying on the existing methodologies.

Makai expects that this model will be useful for:

- Regulators such as NOAA's Office of Ocean and Coastal Resource Management. http://www.crrc.unh.edu/publications/OTEC $\% 20$ Needs\%20Assessment $\% 20$ Revision $\% 20 \mathrm{~F}$ INAL.pdf

- OTEC development by Lockheed Martin. http://www.lockheedmartin.com/us/products/otec.html and http://www.youtube.com/watch?v=lfrWE61EeQY

- OTEC development by the French firm DCNS. http://en.densgroup.com/energy/marinerenewable-energy/ocean-thermal-energy/

- Firms growing algae as a renewable fuel, such as http://www.navy.mil/submit/display.asp?story id=69357 and http://vimeo.com/33218532 


\section{PROdUCTS DeVELOPED}

\subsection{SUMMARY}

We have shown the successful implementation and coupling of a biological model to Makai's numerical OTEC plume circulation and dilution model. The biological model was shown to effectively and reasonably reproduce the observed phytoplankton dynamics and biological processes that have been measured in Hawai ian waters. The numerical model was calibrated using reported values for growth kinetics, predation and mortality losses, remineralization processes, light limitation, ambient standing stocks, and and other critical phytoplankton growth factors. Several modifications were made to the EFDC (Environmental Fluid Dynamics Code) to incorporate these biological parameters and formulations, many of which had been successfully implemented for other open ocean oligotrophic and tropical regions.

As the decade progresses, Makai expects that this model will be of interest to OTEC regulatory agencies, OTEC developers such as Lockheed Martin, the French defense firm DCNS, and very large scale algae biofuel farms. 


\section{REFERENCES}

Abraham, E.R. (1998) The generation of plankton patchiness by turbulent stirring. Nature, Vol.391,577-580

Baines, P.G. (2002) Two-dimensional plumes in stratified environments. Journal of Fluid Mechanics. 471, 315-337

Bathen, K.H. (1975) A further evaluation of the oceanographic conditions found off Keahole Point, Hawaii, and the environmental impact of nearshore ocean thermal energy conversion plants on subtropical Hawaiian waters. A report submitted to Department of Planning and Economic Development, State of Hawaii, November 1975

Bathen, K.H. (1978) Circulation Atlas for Oahu, Hawai i. University of Hawai'I, SEAGRANT-MR-78-05, p.49

Bertilsson, S., Berglund, O., Karl, D.M., Chisholm, S.W. (2003)Elemental composition of marine Prochlorococcus and Synechococcu: Implications for the ecological stoichiometry of the sea. Limnology and Oceanography, Vol 48(5), 1721-1731

Bienfang P.K., Morales, L., Klein, K., Takahashi, M. (1984) Picoplankton Growth Rates in Subtropical Hawaiian Embayments. Pacific Science. Vol 38, No.2

Blumberg, A.F., Mellor, G.L. (1987) A description of a three-dimensional coastal ocean circulation model, Three-Dimensional Coastal Ocean Models, edited by N. Heaps, 208 pp., American Geophysical Union.

Brown, S.L., Landry, M.R., Selph, K.E., Yang, E.J., Rii, Y.M., Bidigaire, R.R. (2008) Diatoms in the desert: Plankton community response to a mesoscale eddy in the subtropical North Pacific. Deep-Sea Research II, Vol 55, 1321-1333

Carter, G.S., Merrifield, M.A. (2007) Open boundary conditions for regional tidal simulations. Ocean Modeling, 18 194-209.

Carter, G.S., Merrifield, M.A., Becker, J.M., Katsumata, K., Gregg, M.C., Luther, D.S., Levine, M.D., Boyd, T.J., Firing, Y.L. (2008). Energetics of M2 Barotropic-to Baroclinic Tidal Conversion at the Hawaiian Islands. J. Phys. Oceanog., 28 2205-2223.

Calil, Paulo Henrique. (2009) Transient upwelling hot spots in the oligotrophic ocean around Hawaii: The importance of meso and submesoscale processes. PhD Thesis University of Hawaii.

Cerco, C.F., Cole, T. (1995) User's Guide to the CE-QUAL-ICM Three-Dimensional Eutrophication Model: Release Version 1.0. USACE Technical Report EL-95-15

Choi, K.W., Lee, J.H.W. (2007). Distributed Entrainment Sink Approach for Modeling Mixing and Transport in the Intermediate Field. J. Hydraulic Eng., 133:7 804. 
Choi K.W., Mao, J.Q., Lee J.W. (2007) Real-time Hydro-environmental Modelling and Visualization System for Public Engagement: Technical Note on Validation of the 3D flow and mass transport model (EFDC/DESA). University of Hong Kong.

Cummins, P.F., Oey, L.Y. (1997) Simulations of barotropic and baroclinic tides off northern British Columbia. J. Phys. Oceanogr., 27 762-781.

Cullen, J.J., Franks, P.J.S., Karl. D.M., Longhurst, A. (2002) The Sea: Volume 12: Chapter 8: Physical Influences on Marine Ecosystem Dynamics. John Wiley \& Sons, Inc. New York.

Eppley, R.W., Rogers, J.N., McCarthy, J.J. (1969) Half-saturation constants for uptake of nitrate and ammonium by marine phytoplankton. Limol. Oceanogr., Vol.14(6), p912

Eppley, R.W., Reid, F.M., Strickland, J.D. (1970) Estimates of phytoplankton crop size, growth rate and primary production. Bull. Scripts Inst. Oceanogr 17, 33-42

Falkowski, P.G. (1975) Nitrate uptake in marine phytoplankton: Comparison of half-saturation constants from seven species. Limnol. Oceanogr. Vol.20(3), p412

Fasham, M.J.R., Ducklow, H.W., McKelvie, S.M. (1990) A nitrogen-based model of plankton dynamics in the oceanic mixed later. Journal of Marine Research, Vol 48, p591-639

Fujieki, L.A., et al. (2011) Hawaii Ocean Time Series Data Report 21: 2009. School of Ocean and Earth Sciences and Technology, University of Hawai i at Manoa, p 23 and Fig 6.5.21

Gruber, N., Frenzel, H., Doney, S.C., Marchesiello, P., McWilliams, J.C., Moisan, J.R., Oram, J.J., Plattner, G., Stolzenbach, K.D. (2006) Eddy-resolving simulation of plankton ecosystem dynamics in the California Current System. Deep-Sea Research I. Vol 53, 1483-1516

Harrison, W.G., Harris, L.R., Irwin, B.D. (1996) The kinetics of nitrogen utilization in the oceanic mixed layer: Nitrate and ammonium interactions at nanomolar concentrations. Limnol. Oceanogr., Vol.41(1), 16-32

1. Hamrick, J. (2006) The Environmental Fluid Dynamics Code Theory and Computation Volume 3: Water Quality Module. TetraTech, Inc.

Jensen, T.G. (1998) Open boundary conditions in stratified ocean models. Journal of Marine Systems, 16, 297-322

2. Karl, D.M. (2007) Microbial oceanography: paradigms, processes and promise. Nature Reviews: Microbiology. Vol 5

3. Karl, D.M., Bidigaire, R.R., Church, M.J., Dore, J.E., Letelier, R.M., Mahaffey, C., Zehr, J.P. Nitrogen in the Marine Environment: Chapter 16: The Nitrogen Cycle in the North Pacific Trades Biome: An Evolving Paradigm. Elsevier Inc. 2008. DOI 10.1016/B978-012-372522-6.00016-5

4. Landry, M.R., Brown, S.L. Rii, Y.M., Selph, K.E., Bidigaire, R.R., Yang, E.J., Simmons, M.P. (2008) Depth-stratified phytoplankton dynamics in Cyclone Opal, a subtropical mesoscale eddy. Deep-Sea Research II, Vol 55, 1348-1359 
5. Latasa, M., Landry, M.R., Schluter, L., Bidigaire, R.R. (1997) Pigment-specific growth and grazing rates of phytoplankton in the central equatorial Pacific. Limnology and Oceanograohy, Vol.42(2), p289-298

Lavelle, J.W., Thacker, W.C. (2008) A pretty good sponge: Dealing with open boundaries in limited-area ocean models. Ocean Modelling, 20, 270-292

Lavelle, J.W. (1994) A convection model for hydrothermal plumes in a crossflow. NOAA Technical Memorandum. ERL PMEL-102

Lee, J.H.W., Cheung, V. (1990) Generalized Lagrangian model for buoyant jets in current. Journal of Environmental Engineering, ASCE, 116(6), pp. 1085-1105.

Lee, J.H.W., Chu, V.H. (2003). Turbulent Jets and Plumes: A Lagrangian Approach. Kluwer Academic Publishers, Massachussets, 2003. ISBN 1-4020-7520-0

Lee, J.H., Lam, K.M. (2004) Environmental Hydraulics and Sustainable Water Management, Proceedings of the $4^{\text {th }}$ International Symposium on Environmental Hydraulics and the $14^{\text {th }}$ Congress of Asia and Pacific Division, International Association of Hydraulic Engineering and Research. Taylor and Francis Group, UK. Ch. 3.4 Pg. 450

6. Letelier, R.M., Karl, D.M., Abbott, M.R., Bidigaire, R.R. (2004) Light driven seasonal patterns of chlorophyll and nitrate in the lower euphotic zone of the North pacific Subtropical Gyre. Limnology Oceanogrraphy, 49(2), 508-519

7. Lichtman, E., Klausmeier, C.A., Schofield, O.M., Falkowski, P.G. (2007) The role of function traits and trade-offs in structuring phytoplankton communities: scaling from cellular to ecosystem level. Ecology Letters. Vol.10, p1170-1181. doi:10.111/j.14610248.2007.01117.x

8. Lima, I.D., Doney, S.C. (2004) A three-dimensional, multinutrient, and size-structures ecosystem model for the North Atlantic. Global Biogeochemical Cycles, Vol 18, GB3019; doi10.1029/2003GGB002146

9. Liu, H., Campbell, L., Landry, M.R. (1995) Growth and mortality rates of Prochlorococcus and Synechococcus measured with a selective inhibitor technique. Marine Ecology Progress Series. Vol.116, p277-287

10. List, E.J. (1982) Turbulent Jets and Plumes. Annual Review of Fluid Mechanics. 14, 189212

11. Mahadevan, A., Campbell, J.W. (2002) Biogeochemical patchiness at the sea surface. Geophysical Research Letters. Vol.29, No.19, p1926. doi:10.1029/2001GL014116

12. Marchesiello, P., McWilliams, J.C., Schepetkin, A. (2001) Open boundary conditions for long-term integration of regional oceanic models. Ocean Modelling, Vol 3, 1-20

13. McAndrew, P.M., Bjorkam, K.M., Church, M.J., Morris, P.J., Jachowski, N., Williams, P. J. le B., Karl, D.M. (2007) Metabolic response of oligotrphic plankton communities to deep water nutrient enrichment. Marine Ecology Progress Series. Vol 332, 63-75 
14. McDonald, R.N. (1990) Far field flow forced by the entrainment of a convection plane plume in a rotating stratified fluid. Journal of Physical Oceanography. 20, 1791-1798

Merrifield, M.A., Johnston, T.S., (2001) The generation of internal tides at the Hawaiian Ridge. Geophys. Res. Lett., 28 559-562.

Merrrifield, M.A., Holloway, P.E. (2002) Model estimates of M2 internal tide energetic at the Hawaiian Ridge. J. Geophys. Res. 107, 3179.

Moore, L.R., Post, A.F., Rocap, G., Chisholm, S.W. (2002) Utilization of different nitrogen sources by the marine cyanobacteria Prochlorococcus and Synechococcus. Limnol. Oceanogr., Vol.47(4), p989-996

Niwa, Y., Hibiya, T. (2001) Numerical study of the spatial distribution of the M2 internal tide in the Pacific Ocean. J. Geophys. Res., 106, 22 441-422.

Rii, Y.M., Brown, S.L., Nencioli, F., Kuwahara, V., Dickey, T. Karl, D.M., Bidigaire, R. (2008) The transient oasis: Nutrient-phytoplankton dynamics and particle export in Hawaii lee cyclones. Deep-Sea Research II, Vol 55, 1275-1290

Rocheleau, G.J., Grandelli, P. (2011) Physical and biological modeling of a 100 Megawatt Ocean Thermal Energy Conversion Discharge Plume. IEES Oceans Conference 2011, Waikoloa, HI. ISBN 978-1-4577-1427-6

Strom, S.L., Welschmeyer, N.A. (1991) Pigment-specific rates of phytoplankton growth and microzooplankton grazing in the open subartic Pacific Ocean. Limol. Oceanogr. Vol.36(1), p50-63

Turner, J.S. (1969) Buoyany Plumes and Thermals. Annual Review of Fluid Mechanics. 1:2944

Van Ryzin, J.C., Grandelli, P., et al. (2007) Integration and Optimization of Hydrogen Production with Ocean Thermal Energy Conversion Technology in Offshore Floating Platforms. Office of Naval Research SBIR Topic N04-22, Contract \# N00014-05-M-0038.

Veldhuis, M.J.W., Timmermans, K.R., Croot, P., van der Wagt, B. (2004) Picophytoplankton; a comparative study of their biochemical composition and photosynthetic properties. Journal of Sea Research, Vol.53, p7-24

15. Wang, X.J., Le Borgne, R., Murtugudde, R., Busalacchi, A.J., Behrenfeld, M. (2008) Spatial and temporal variations in dissolved and particulate organic nitrogen in the equatorial Pacific: biological and physical influences. Biogeosciences, 5, 1705-1721

Wang, X.J., Behrenfeld, M., Le Borgne, R., Murtugudde, R., Boss, E. (2009) Regulation of phytoplankton carbon to chlorophyll ratio by light, nutrients, and temperature in the Equatorial Pacific Ocean: a basin-scale model. Biogeosciences. Vol 6, 391-404 
Worden, A.Z., Nolan, J.K., Palenik, B. (2004) Assessing the dynamics and ecology of marine picophytoplankton: The importance of the eukaryotic component. Limnology and Oceanography, Vol 49(1), 168-179

Zhang, H., Baddour, R.E. (1998) Maximum penetration of vertical round dense jets at small and large Froude numbers. Journal of Hydraulic Engineering. 124,5:550-553 